\title{
OUR
}

\section{TTMPER AMENTS}

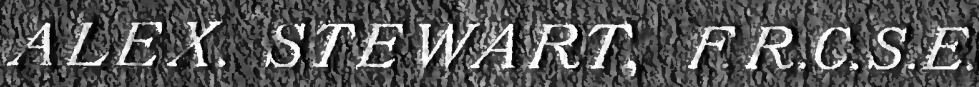
(6) 


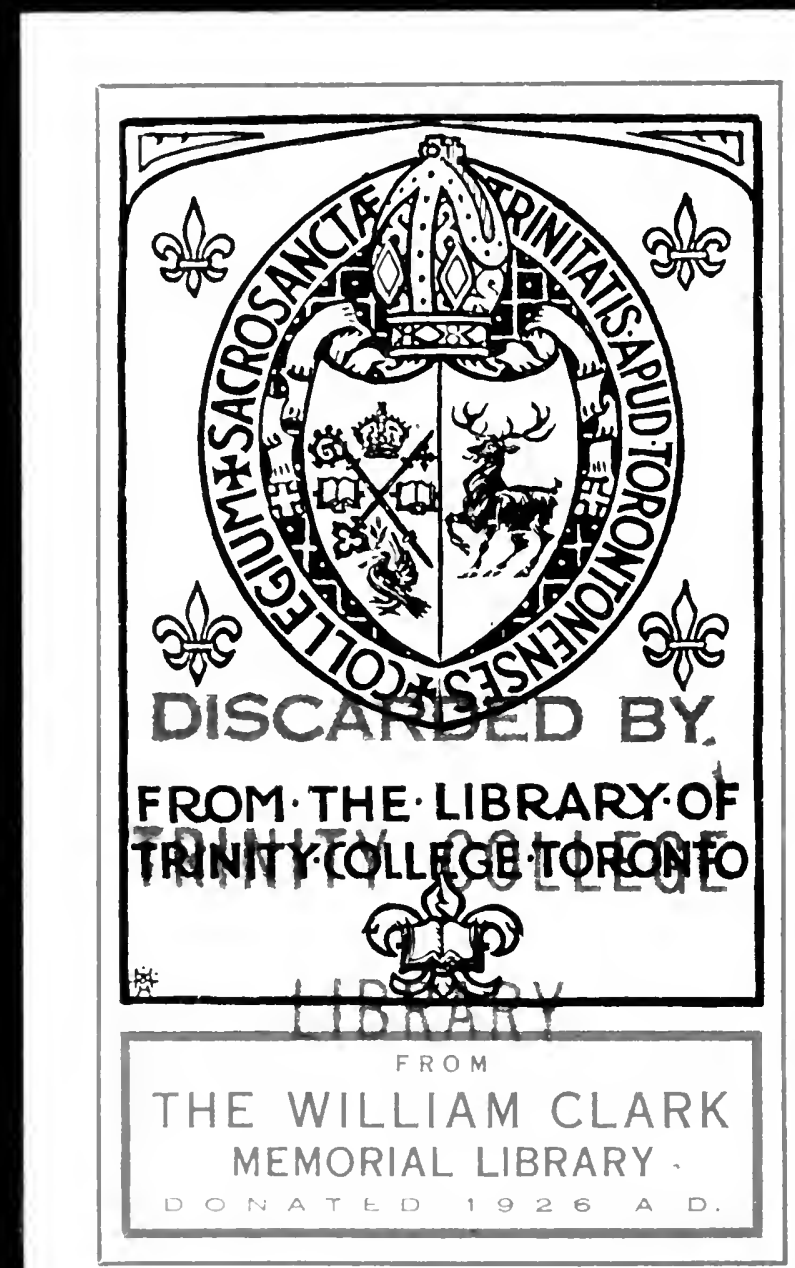


DISCAFI D D BY

TRINITY COLLEGE

LIBRARY 
OUR TEMPERAMENTS. 



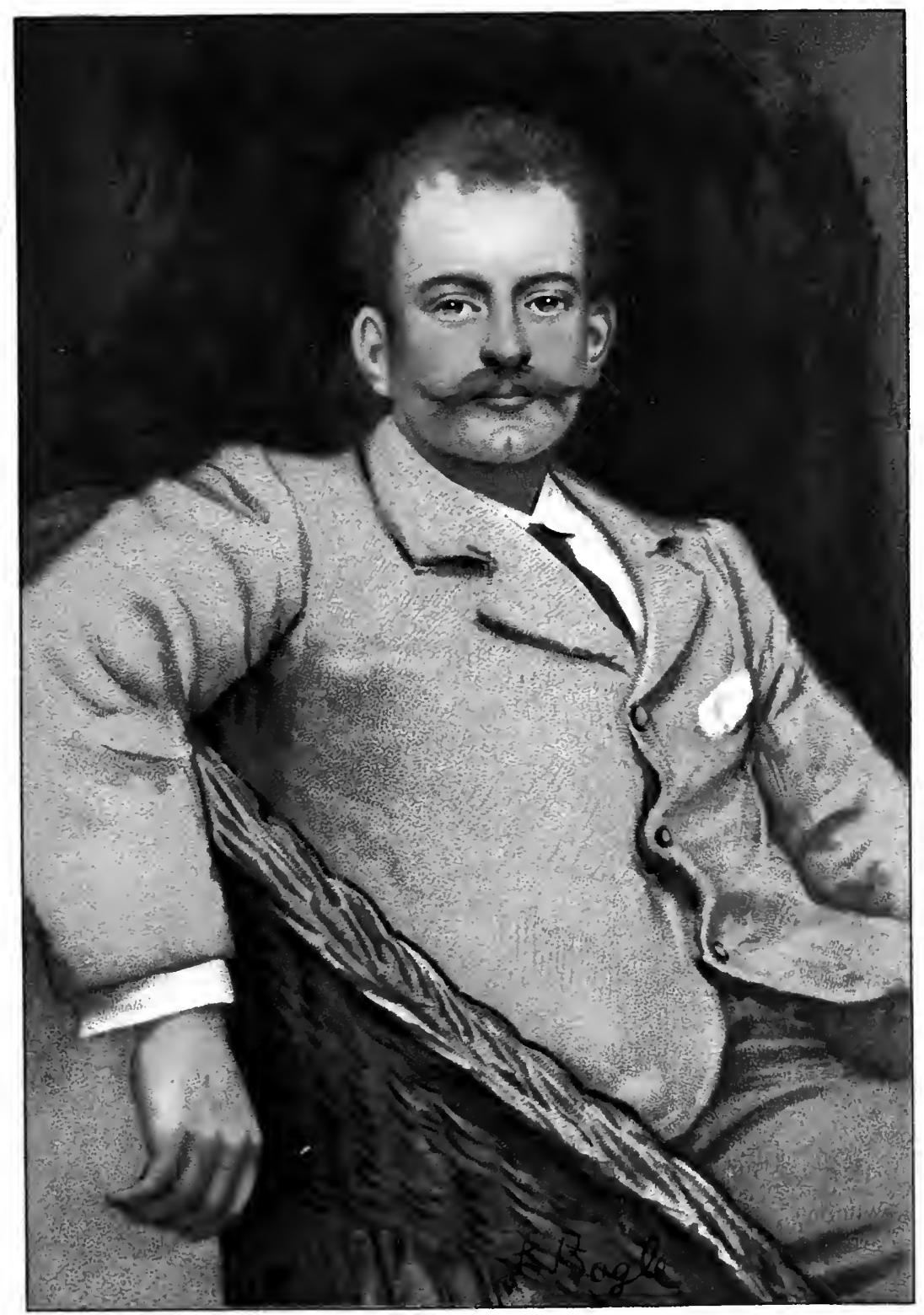

THE SANGUINE TEMPERAMENT.

see pages 76 and 79 . 
Digitized by the Internet Archive in 2007 with funding from Microsoft Corporation 


\section{OUR TEMPERAMENTS:}

THEIR STUDY AND THEIR TEACHING.

A POPULAR OUTLINE.

BY

ALEXANDER STEWART, F.R.C.S. EDIN.

SECOND EDITION,

CAREFULLY REVISED; INDEXES AND ADDITIONAL \$|Yustrations, INCLUDING

CHROMO-LITHOGRAPHS FROM DRAWINGS BY

LOCKHART BOGLE.

"We must remember that a degree of knowledge far short of actual "prediction is often of much practical value."-J. S. MILL.

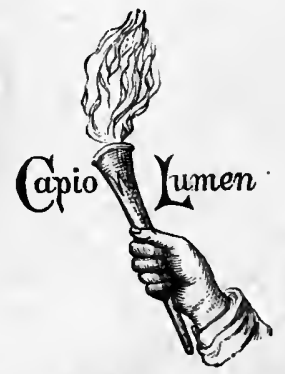

LONDON :

CROSBY LOCKWOOD AND SON, 7, STATIONERS" haLl COURT, LUdGate hILl. 1892.

[All Rights Reserved.] 
<smiles>C1#CC1</smiles> 


\title{
To \\ THE MEMORY
}

\begin{abstract}
oF
SIR ROBERT CHRISTISON, BART., M.D., D.C.L。 Oxon, LL.D. EdIN.,
\end{abstract}

Professor of Materia Medica in the University of Edinburgh,

WHOSE GREAT KINDNESS TO ITS AUTHOR WHEN A STUDENT HAS NEVER BEEN FORGOTTEN,

THIS WORK IS GRATEFULLY DEDICATED.

Queen Anne's Mansions, London, S.W.

October 1886.

The Walsingham House, Piccadilly, W.

fanuary 1892. 


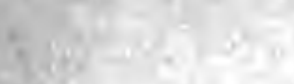

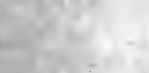

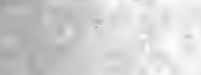

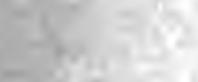

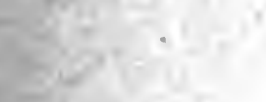

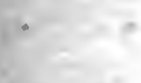

$+2 \cos 2$

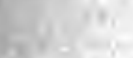

7.

8

$3 S^{2}$

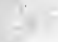

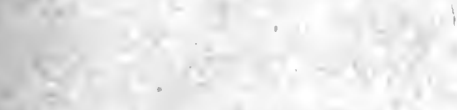

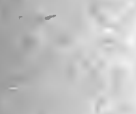

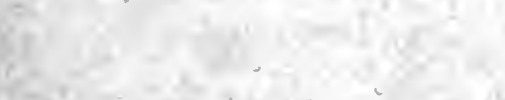

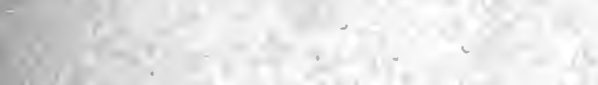

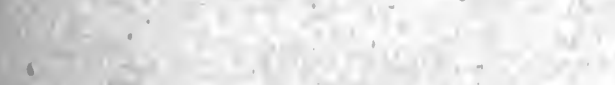

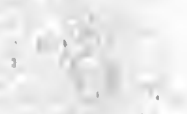

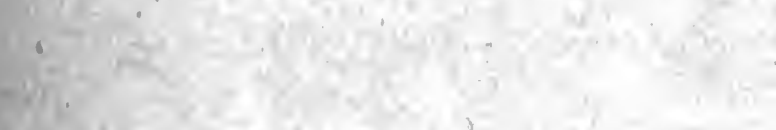

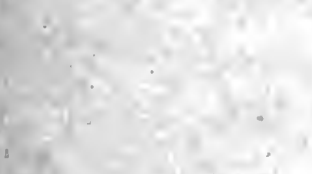

$-3,17$

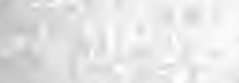

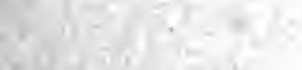

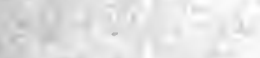

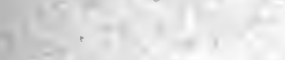

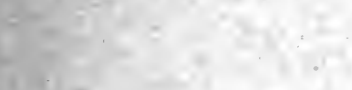

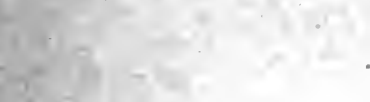

3.

,

7

$$
+y^{3},
$$

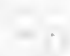

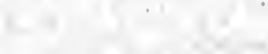

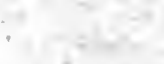

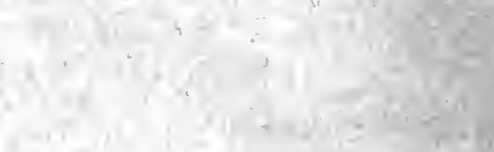

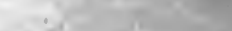

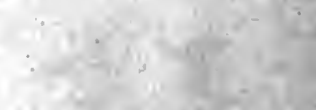

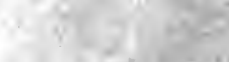

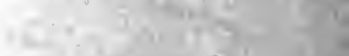

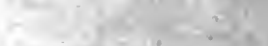
$x^{2}+2 y=1 \quad+10$

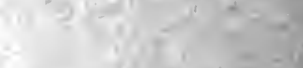

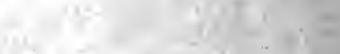

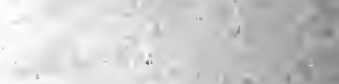
$\therefore x^{2}=x^{2}+x^{2}$

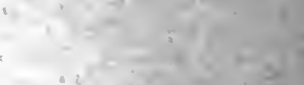

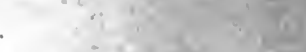

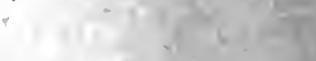
i.

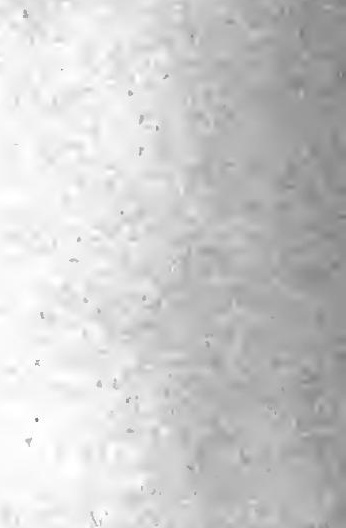

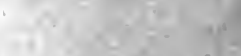
$x^{2}+2+2=0$

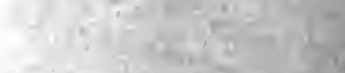

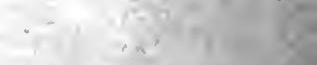

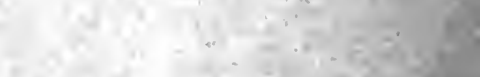

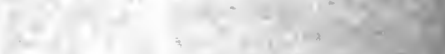

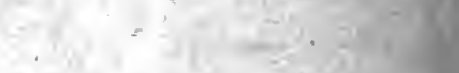

W.

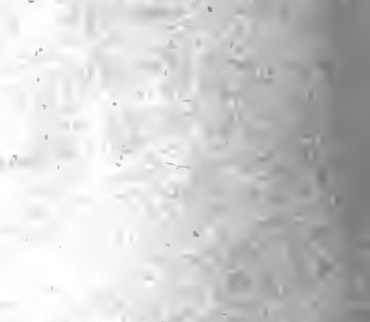

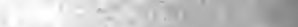

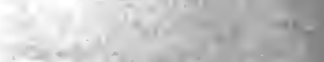

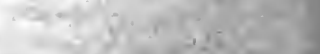

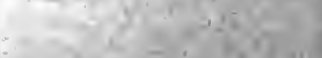




\section{P R E F A C E}

TO THE FIRST EDITION.

TMPRESSED by the frequency with 1 which the word temperament is used to account for the action that is taken, not only on the ordinary, but on the eventful occurrences of life; while so little is known of the temperaments that very few outside the medical profession can name off-hand the four principal ones,-the Sanguine, the Bilious, the Lymphatic, and the Nervous, -I have endeavoured to construct, from scattered and scanty material and my own observation, a practical guide by which observers may know the temperament of any one by looking at him, and associate 
with it certain mental qualities and traits of character.

"It is impossible to doubt that with every "temperament particular mental qualities are “associated."-Dr. Prichard, F.R.S.

"Not Sanguine and diffusive he, "But Biliary and intense."

Carlyle of Edward Irving.

Some proof of the doctrine of the temperaments - the association of certain mental qualities and traits of character with certain physical characteristics-is given in Chap. iii., founded on the experience of every one in reading faces, and on material found in the interesting and suggestive chapter "History of Twins," in "Inquiries into Human Faculty and its Development," by Francis Galton, F.R.S.

The Temperaments have occupied an important place in the science and practice of medicine since the time of Hippocrates, 
more than two thousand years ago, but have received scarcely any consideration in general literature.

Including, as it does, to some extent, the association of mental qualities with outward appearance, it seems strange that the subject has not been cultivated apart from medicine.

Even in medical works I have been unable to find precise descriptions by which the temperaments may be known with certainty, and it may be assumed that such have not been given, as in a recent publication * an eminent surgical observer says :-

"As yet, I fear we must say that the labours " of the physiognomist, and those of the student " of temperament, have been alike disappointing.

* "The Pedigree of Disease. Being six lectures on Temperament, Idiosyncrasy, and Diathesis." r884. By Jonathan Hutchinson, F.R.S., Emeritus Professor of Surgery in the London Hospital. 
"Whoever will set himself the task of attempt"ing to classify a given number of individuals " according to their temperaments, will, I think, "soon find himself baffled."

As practical acquaintance with the temperaments must be imperfect without precise descriptions by which they may be distinguished from one another, I have submitted a scheme of the four pure temperaments-the Sanguine, the Bilious, the Lymphatic, and the Nervous - in which their physical characteristics and the associated mental ones are methodically arranged; and by numerous examples I hope to have enabled observers to discern, analyze, and name the far more numerous temperaments called compound temperamentscharacteristics of two or more of the pure temperaments in one person.

"By the mixture of the physical charac"teristics of the four pure temperaments nature "bestows on man the charm of variety that 
" beautifies all her lesser works, and the study " of the temperaments will be pursued with "increasing interest when it is seen that even " one characteristic of a different temperament "from the principal one brings with it some"thing of the mental action of its own tem"perament:. That, for instance, if black eyes "replace the blue ones of the Sanguine tem"perament they bring more or less of the "caution, the persistence, the ambition of the "Bilious temperament; and, similarly, if blue " eyes replace the black ones of the Bilious "temperament they bring more or less of the "impulsiveness, the love of change, the un"warranted hopefulness of the Sanguine tem"perament" (chap. vii.)

The Temperaments having a limited range of mental association, cannot claim to supplant Expression, Physiognomy, or Phrenology; but they are more definite than Expression and Physiognomy, and more readily available than Phrenology.

Expression is read by every one in his 
own way, intuitively, and cannot be reduced to a teachable system.

The expression of the eye, for instance!

Physiognomy and Phrenology, even had they not attempted the impossible-a measured estimate of mind and moralswould have failed as generally available systems; phrenological examinations requiring time and opportunity, and physiognomical details being so numerous and minute that few, if any, are able to remember them.

The physical characteristics of the temperaments, on the contrary, are definite, few, and readily observed.

The mental characteristics here associated with the physical ones are also few, and no claim of relationship is made between the temperaments and morality, or the higher powers of the mind, except imagi- 
nation, which is assumed to be more especially associated with the physical characteristics of the Nervous temperament.

As the mental qualities and traits of character naturally associated with outward appearance may be more or less modified by the capability of adaptation and improvement that men are fortunately endowed with, attention has been drawn to the ordinary influences that may so far change the natural man.

The ability to infer mental qualities and traits of character from outward appearance, even to the limited extent in the Scheme (Chap. iv.), has a wide field of application, and I have given some consideration to the temperaments as guides in the education of youth and the choice of a profession.

Their influence on health is briefly noticed, and importance is given to the 
dependence of every pure temperament on a special internal organ of the body, and to the influence of derangement of its organ on the mental action of the temperament.

Popular ignorance of the temperaments having led to a random and unmeaning use of the word temperament in conversation and literature, "my temperament" and "his temperament" being in general use without thought of any particular temperament, a chapter is given to show the present unlimited and indefinite use of the word, and how its limited and definite use may be secured.

The concluding chapter is an endeavour to show that were the physical characteristics of the temperaments applied to word portraiture, the reader would see the subject of a biography with the mind's eye as if he had really seen and remembered him. 
I have no doubt whatever that popular knowledge of the temperaments would result in the right man being oftener found in the right place; in the more likely choice of the best advisers; and in greater harmony of life between those living or working together, from consideration of the natural impulses and tendencies of the temperaments.

I therefore hope that I may have succeeded in rendering it practicable to recognize and name the temperaments, and that familiarity with them may soon become general.

Readers may wish that I had considered more fully the association of mental with physical characteristics, but my chief intention was to make known the physical characteristics by which they may observe for themselves and form their own conclusions. 
I feel warranted in having endeavoured to build up and attract attention to the subject, by a very long acquaintance with it; commenced when a student of medicine; continued in its practice, in which I have ever found it a trustworthy guide; and cultivated, apart from medicine, by observation of the association of mental with physical characteristics.

The title "Our Temperaments" is intended to show that the temperaments described are those of the people of our own country.

To enable observers to classify faces by the form characteristics of the temperaments, a sufficient number of engravings are given from Bohn's edition of Lodge's Historical Portraits, the proprietor having readily consented to their reproduction. 


\section{P R E F A C E \\ TO THE SECOND EDITION.}

THE first edition having been favourably received by the press, and the demand for it beyond expectation, I have felt it incumbent on me to spare no pains to render the second more worthy of the subject.

Very few of the chapters remain as they were. Several are in great part re-written; that on The Temperaments in Education, wholly so.

The fundamental Scheme of the physical and mental characteristics of the four pure 
temperaments-pages $79,80,81,82$-remains as before; daily observation having farther convinced me that by its physical characteristics-three of colour and four of form-observers may soon learn to know the different temperaments; and that the mental characteristics are those naturally associated with the physical ones.

To the portraits of the first edition, those of Pope and Sterne, with quotations showing the association of mental with physical characteristics, as in the Scheme, have been added; and Chromo-lithographs from drawings by Lockhart Bogle, of temperaments very often seen, appear for the first time.

Indexes are also added.

Professional pursuits have delayed the preparation of the edition; but it has probably gained by the delay. 


\section{CONTENTS.}





\section{CONTENTS.}

\section{PART I.}

THE STUDY OF THE TEMPERAMENTS.

\section{CHAPTER I.}

PRELIMINARY.

No popular literature of the Temperaments.Origin in medicine.-Extracts from two medical authors showing the scope of the subject.-From John Stuart Mill and Mr. Buckle, acknowledging its importance, and complaining that it is undeveloped and obscure .

\section{CHAPTER II.}

GENERAL VIEW OF THE TEMPERAMENTS.

Men separated into four groups, or Temperaments: the Sanguine, the Bilious, the Lymphatic, and the Nervous.-The Tem- 
peraments are outward distinctions.-The practical value of the study wholly dependent on the natural association of mental qualities and traits of character with outward appearance . . . I

\section{CHAPTER III.}

THE TEMPERAMENTS AND MIND.

Dr. Prichard on the relation of mental peculiarities to corporeal structure.-Its extent often exaggerated. - Extracts from Dr. Maudsley, John Inglesant, and Richerand.Mind not limited by temperament.-Character and temperament.-Association of imagination with the nervous temperament. -The sculptured groups on the base of the Albert Memorial.-Their temperaments and the character of their work.-Proof of the relation between traits of character and outward appearance, from reading faces, and from the "History of Twins" . . .

\section{CHAPTER IV.}

SCHEME OF THE FOUR PURE TEMPERAMENTS.

The difficulty of distinguishing the tempera- 
ments acknowledged by authors.-Need of standard descriptions.- -Suggestion that they be undertaken by the British Medical Association.-The temperaments not sufficiently utilised in medicine.-Mr. Jonathan Hutchinson's views. - The temperaments taught in the class-room, and clinically, by Professor Laycock.-Some of the descriptions of English authors.-A scheme of the four pure temperaments, in which their physical and mental characteristics are arranged for practical guidance.-The temperaments and phrenology.-Albert Dürer and the four temperaments.-The four temperaments on an old chimney-piece in Guildford Town Hall . . . .

\section{CHAPTER V.}

OBSERVATIONS ON THE SCHEME OF THE FOUR TEMPERAMENTS.

Colour characteristics.-Colour of the hair and eyes.-Change of colour of the hair and eyes.-Colour of the complexion.-Form characteristics.-Smoking and the temperaments.-The foim characteristics of the Nervous temperament. - The Sanguine, the 
Bilious, and the Lymphatic physically powerful temperaments. - The Nervous a gentle, imaginative, and intellectual temperament.-Probably an increasing temperament.-The mental characteristics of the scheme.-Colour and form characteristics from Dr. Beddoe's Races of Britain . 101

\section{CHAPTER VI.}

THE NERVOUS TEMPERAMENT.

Its physical characteristics.-Is the key-stone of the temperaments.-Tempers or refines the three other pure temperaments. - Newly recognized as one of the four temperaments. -Confounded with nervousness.-Carlyle and Charles Lamb.-Its distinctive natural action.-Characterized by J. S. Mill.Exemplified in Nelson, Wm. Hunter, and Dickens.-Is careless of supply of energy. -Physical bankruptcy, or nervousness, the result.-Probably an increasing temperament

\section{CHAPTER VII.}

THE COMPOUND TEMPERAMENTS.

The Compound temperaments very numerous. 
- Physical and mental variety from the mixture of physical characteristics.-Descriptions of the Compound temperaments not found.--The usual mode of naming the Compound temperaments. - Examples. The analysis of Compound temperaments. Compound colour and form characteristics. -The Oval Face and Medium Build.The Balanced temperament.-Examples.The Semi-balanced temperament. - Examples.-The best temperament.-Forms of Compound temperaments to aid the student in analyzing faces . . . I 43

\section{CHAPTER VIII.}

MODIFICATION OF THE TEMPERAMENT.

Modification by business pursuits. - Mrs. Carlyle.-Mr. Froude on professional mannerisms.-Modification by surrounding circumstances other than business pursuits. By Oxford and Cambridge Universities.Lord Houghton and Cardinal Manning.Manner of speech.-Its susceptibility to modification early in life.-Change of temperament.-Dr. Wilks, Dr. Prichard, and Mr. Buckle on the causes which produce 
diversity of temperament.-National temperaments. - Change in the colour of glass eyes sold in America

Appendix : "British Calibre," from The Times, on the Reports of the Anthropometric Committee of the British Association.- "The Races of Britain," by Dr. Beddoe, F.R.S. . 205

\section{CHAPTER IX.}

THE ORGANS OF THE TEMPERAMENTS.

The four temperaments named after four internal organs of the body.-The four organs, and their influence on the mental action of the four temperaments.-Relation of the four temperaments to the causes of disease.-Food and the temperaments.Climate and the temperaments._Effects on Dickens of a month at Bonchurch, Isle of Wight.-Quotations showing the dependence of the natural mental action of the temperaments on the healthy action of the organs.-Return of natural mental action with convalescence.-The temperaments and minute structure.-Inheritance of disease limited by personal likeness.-Importance of such limitation in Life Assurance . $\quad$. 237 


\section{PART II.}

\section{THE TEACHING OF THE TEMPERA- $M E N T S$.}

\section{CHAPTER $\mathrm{X}$.}

THE TEMPERAMENTS AVAILABLE IN EDUCATION.

Gain to education by classing scholars according to the temperaments.-Dr. Carver, late of Dulwich College, on the importance of the careful study of the aptitudes of boys. - Canon Farrar on indiscriminate education.-Extracts from The Spectator, No. 307: "Thoughts on Education."-Preparation for competitive examinations often injurious to health.-Sir J. Crichton Browne's views. -Mrs. Elizabeth Garrett Anderson, M.D., on "Examinations for Girls."-How injury to health may be avoided.-How parents may advantageously modify the mental action of their children's temperaments.Temperament classes in schools, from an American work . . . . . $\quad .267$ 
xxiv CONTENTS.

\section{CHAPTER XI.}

THE TEMPERAMENTS AVAILABLE IN THE CHOICE OF A PROFESSION.

PAGE

Business openings difficult to find.-Fitness often overlooked.-Consequent continued regret.-A case in point.-Sons put into their father's business fit or unfit.-Their future often arranged before they are born. -Mr. Ruskin's by his mother. - The temperaments a guide to parents in judging the fitness of their children.-Likings sometimes found without aptitude.

\section{CHAPTER XII.}

THE TEMPERAMENTS AVAILABLE IN THE PROMOTION OF HEALTH.

The teaching of the temperaments as regards health.-Only nervousness considered.Signs of nervousness.-Some of its causes. -Predisposition relative to the number of nervous characteristics. - Effects on business men and others.-Preventive and curative means.-Addison's modes of taking exercise.-The sleeplessness of nervousness.-- 
Work and nervousness.-Work and sleep.

-Expedients to procure sleep.-The direction of the body in sleep.-The suburban homes of business men a cause of nervousness, especially in women . . . 303 Appendix: "American Nervousness" · 329

\section{CHAPTER XIII.}

THE USE OF THE WORD TEMPERAMENT.

In frequent use.-Should always indicate the physical characteristics of one of the four Temperaments, or a compound one.Extracts showing that it seldom does.Single mental or other traits wrongly called Temperaments.-List of twenty-nine socalled Temperaments.-Extracts containing some of them. - Temperament seldom used formerly.-Only once in Addison's Spectator.-Not once in Johnson's Rambler, or Idler, or Goldsmith's Vicar of Wakefield. -Probable reason.-Additional extracts showing the misuse of the word.-Standard descriptions of the four Temperaments essential to the right use of the word in literature and conversation 


\section{CHAPTER XIV.}

WORD, BIOGRAPHIC, OR TEMPERAMENT PORTRAITURE.

Word portraiture seldom effective.-Method necessary.-The form and colour characteristics of the temperaments recommended. - Sir Walter Scott on the value of portraits in biography.-Engravings only partly effective.-Descriptions of Dickens, from Mr. Forster's Life.-Of Sir Thomas More and Shelley.-Of Southey, Dickens, Tennyson, and others, by Carlyle.-Biographic portrait of $\mathrm{Mr}$. Fawcett.-Temperament portraiture valuable in conversation, cases of identity, and heredity.

Likeness of Her Majesty Queen Victoria, and Anne Clifford, Countess of Dorset, Pembroke, and Montgomery, to both their parents . . . . . . $36 \mathrm{~J}$

Conclusion.-Fields in which observation of the temperaments may yield useful results. 386

\section{INDEXES.}

1. To Authors and Quotations . . 395

2. To Personal Notices . . . . . 409 


\section{LLUSTRATIONS.}

*The Sanguine Temperament . . . Frontispiece PAGE

Nervous Characteristics and Imagination Sterne 28, 29

Nervous Characteristics - . . Pope - 30

The Melancholic Face . . . . . . $7 \mathrm{I}$

*Bilious Characteristics . . . . . . 73

Sanguine Characteristics . . . Hogarth 79

The Square Face . . . . . Steele . 113

*Nervous and Sanguine Temperament . . . . 149

*Lymphatic Characteristics . . . . . 250

A Selection from Lodge's Historical Portraits, showing the Chief Forns of Faces, precedes the Indexes.

*Chromo-lithograpis from Drawings by

LockHart Bogle. 

PART I.

\section{THE STUDY OF THE TEMPERAMENTS.}





\section{CHAPTER I.}

PRELIMINARY.

No popular literature of the Temperaments.Origin in medicine.-Extracts from two medical authors showing the scope of the subject.-From John Stuart Mill and Mr. Buckle, acknowledging its importance, and complaining that it is undeveloped and obscure.

I HAVE chosen our Temperaments for 1 this essay* because they are not generally understood, but deserve to be, including as they do the natural association of certain external characteristics that are few and easily seen, with mental qualities and traits of character of sufficient importance that to be able to indicate them from out-

* The essay now published is the enlargement of one read to a private society in January $\mathbf{r} 88 \mathrm{r}$. 
ward appearance must always be interesting and often useful.

I hope to be able to show that acquaintance with this natural association is of special value in

I. Education,

2. The choice of a profession, and

3. The promotion of health.

The frequent and almost always indiscriminate use of the word temperament also influenced me, and my choice was finally determined by the hope that my observations might be supplemented by our President who, by some striking remarks that fell from him in another place on the influence of the temperaments on religious feeling and life, showed that he has given the subject thoughtful consideration.

While recently at Cambridge I searched the catalogues of King's College and other 
PRELIMINARY.

libraries of the University for English works on the temperaments, but found none; and I became aware that I had a difficult task before me,- - to construct from scattered and probably insufficient material a concise view of the subject for practical guidance.*

Medical literature past and present is the home of the subject. Elsewhere, even in cyclopædias and works on mental and moral philosophy, it seldom finds a place,

* Continuing the inquiry, I was told of a volume of sermons: "The Four Temperaments, together with some Occasional Sermons, by William Clark, M.A., Prebendary of Wells and Vicar of Taunton. and edition. 1874."

The volume being out of print, I should have failed to procure a copy had I not applied to the author, who kindly lent me his own.

The four temperaments are taken from St. Luke: ch. ix., the Choleric (bilious), vers. $5^{\mathrm{I}-5^{6}}$; the Sanguine, vers. 57 and 58 ; the Phlegmatic (lymphatic), vers. 59 and 60 ; the Melancholic, vers. $6 \mathrm{I}$ and 62 ; and there is a fifth sermon-a general view and application of the whole subject-from St. James i. I 7 . 
and when it does is generally treated very briefly and at second-hand, medical works being the source of information.

As mental and moral action are largely attributed to temperament, one might have expected the subject to have had at least as many ardent cultivators as Physiognomy and Phrenology. That it has not may be ascribed to its having arisen out of the practice of medicine and been always looked upon as a purely medical subject.

The ancient physicians, not having the stethoscope and other modern means of bringing the internal organs of the body into view, as it were, eagerly cultivated a knowledge of external signs, and soon found that men who differ remarkably in outward appearance and conformation, as dark and fair, for instance, are predisposed to diseases of a different class or character, and that even the same diseases affect 
them differently and may require a somewhat different treatment. They therefore observed with keen professional interest the resemblances and differences among men.

Their observations having accumulated, Hippocrates, the father of medicine, founded the doctrine of temperaments four hundred years before the Christian era; and although primitive ideas of the composition and structure of the different parts " of the body have been discarded, and erroneous views of the functions of the internal organs corrected, the physical distinctions and descriptions of Hippocrates and Galen have been reproduced by nearly all modern writers on the subject.

Dr. Cullen in Materia Medica, I779, says :-

"The moderns have neither by observation "extended the ancient distinctions, nor, though 
"they have often attempted it, have they ever "given, so far as I can judge, any happy " explanation of the causes or foundation of "the distinctions they have so generally " adopted."

Professor Laycock observes :-

"Although the many attempts which have "been made to establish a complete and "practical doctrine of temperament have been " unsuccessful, the general principles first " eliminated from experience remain to this " day."

All medical writers who have gone beneath the surface of the subject, while acknowledging its great professional value, lament that it has received so little attention and is without precision.

It is indeed surprising that it is perhaps the only part of medical science that has stood still and remains not only unsatis- 
factory and behind the age, but is even in danger of being altogether neglected.

\section{Dr. Cullen says:-}

"I believe it will be generally allowed that "this part of medical doctrine is still in an "embarrassed and undetermined state."

Dr. Wilks in a valuable contribution to Guy's Hospital Reports for I869, having insisted on its great value in medicine, says :-

"And yet, singularly enough, with one or "two exceptions, our teachers of medicine "seem to have forgotten the doctrine of "temperaments, which occupied so large a "part of the old schools of education."

In the following extracts from medical works, one written only a few and the other a great many years ago, similar complaint is made, and I give them at length as they present the more important 
practical results, apart from medicine, of which the doctrine seems capable.

"The study of the temperaments has been " too much neglected in modern institutions. "Freed from the barbarous and hypothetical " jargon with which it was formerly clogged, " it forms a most interesting and important "branch of the science of man. It is not " now to be confined to the doctrine of the " humours and their various combinations. "Individual character is its object, and it "embraces the whole of the distinction by " which that character is marked. Its indica" tions are useful, not only as announcing "predisposition to particular diseases, but as "proclaiming the nature and objects of our " moral affections. But in giving due regard " to these indications, we should endeavour "to separate what depends on original confor" mation from the more variable and accidental "appearances which are produced by habits or "education."-Edinburgh Medical and Surgical Fournal, vol. iv., p. 749: 1808 . 
Dr. Maudsley, in The Pathology of Mind, I 879, says of Temperament and Idiosyncrasy :-

"Unfortunately these big words are at "present little better than cloaks of ignorance; "they are symbols representing unknown "quantities, rather than words denoting de" finite conditions; and no more useful work "could be undertaken in psychology than a "patient and systematic study of individuals, "-the scientific and accurate dissection and "classification of the minds and characters of "particular men in connection with their "features and habits of body. How vast a "service it would indeed be to have set forth " in formal exposition the steps of the quick "process by which the shrewd and experienced "man of the world intuitively judges the "characters of those he has to do with, and "refers them in a moment instinctively to " their proper classes in his mind!"

These extracts show that the study of the temperaments has a far wider scope 
than medicine, and that there is a craving among those professionally acquainted with the subject for the development and general application of what they have frequent proof-the association of certain mental qualities and traits of character with the physical characteristics of the temperaments.

J. S. Mill and Mr. Buckle complain that "a subject so intimately connected with matters of the highest importance" should have remained undeveloped.

J. S. Mill, when considering the causes that modify mental character, says :-

"That differences of bodily structure also "co-operate is the opinion of all physiologists, " confirmed by common experience. It is to "be regretted that hitherto this experience, "being accepted in the gross without due " analysis, has been made the ground-work of "empirical generalizations detrimental to the "progress of real knowledge." 
Mr. Buckle says :

"We are completely in the dark as to the "circumstances which regulate the hereditary " transmission of character, temperament, and 'other peculiarities. . . . None of the laws " of hereditary descent connected with the "formation of character have yet been "generalized, nor is our knowledge much " more advanced respecting the theory of " temperaments.

"The difficulty attending the study of " temperaments, and the obscurity in which " this important subject is shrouded, may be "estimated by whoever will compare what has " been said by the following writers."

He refers to a number of well-known medical authors-foreign and English.

The subject has remained obscure and difficult because hitherto it has been subservient to medicine. 
I am sanguine that were it a part of general literature it would be raised out of the rut in which it has lain for two thousand years, be brought within every man's comprehension, and become practically valuable. 


\section{CHAPTER II.}

GENERAL VIEW OF THE TEMPERAMENTS.

Men separated into four groups, or Temperaments : the Sanguine, the Bilious, the Lymphatic, and the Nervous.-The Temperaments are outward distinctions.-The practical value of the study wholly dependent on the natural association of mental qualities and traits of character with outward appearance.

$\int_{\text {HE Temperaments are groupings of }}$ which distinguish men from one another,dark or fair, stout or slim, a square, oval, or tapering face, a short or long neck, etc. - See Scheme, chap. iv.

The temperament is the mould in which 
men who resemble one another are said to be made :-

"Amongst these knights there were three brothers bold,

"Three bolder brethren never were ye borne, "Borne of one mother, in one happy mould." -The Faerie Queen.

Dr. Wilks says :-

"A patient enters the doctor's study, and he "will perhaps call to mind that he is only " another specimen of fifty patients, who seem " to have been taken out of the same mould;" and adds, "If this be true, a good history of "man and his varieties has yet to be written." -Guy's Hospital Reports, I 869.

Carlyle goes farther than casting in moulds :-

" A big, burly brother of hers, a clergyman "whom I have seen, struck me as kneaded out " of the same clay."

Likeness between men is not of the face 
only, or we should not on tapping the shoulder of a supposed friend overtaken in the street, find on his turning round that we had made the awkward mistake of tapping the wrong man.

Prince Bismarck writes of Prince $\mathrm{Na}$ poleon :-

"I will only say, that I was struck by the " resemblànce between him and President Ger"lach, not only in the features, but also as to "gestures, and play of countenance."

Hippocrates and his followers found it practicable, by the resemblance and difference between men, chiefly in the colour of the hair, of the eyes, and of the complexion, to sort them into four groups, into one or another of which, or one of their compounds, every person can be placed.

The four groups are the four Temperaments, named, from their dependence on 
the principal internal organs of the body,

The Sanguine.

The Bilious.
The Lymphatic.

The Nervous.

These are the pure or unmixed temperaments, seldom seen compared with combinations of two, three, or all of them, called the compound temperaments.

The Melancholic formerly held place as one of the four temperaments, but on insufficient grounds, and has therefore been excluded, and the Nervous temperament is now ranked, instead, as one of the four.

As the popular use of the term temperament refers only to the habit of mind that prompts to action, it may surprise many to learn that the temperaments are recognised distinctions in merely the outward appearance. Yet, such they were originally, having been founded on the observed relationship between the features 
GENERAL VIEW OF THE TEMPERAMENTS. I 9

of disease and the features and appearance of men, and such they still are in medicine; a patient's temperament and its influence being known by a glance at his face and figure.

Not only in medicine-

"Dürer in his 'Treatise on Proportion expressly "proposes to indicate by means of the outward "measurement and proportions of the figures, to " which of the four temperaments they belong." *

That the temperaments are external distinctions is a fundamental fact that, except professionally, seems little known: the word temperament and the common phrases "my temperament" and " his temperament" being almost invariably used without thought of external appearance or any particular temperament, and therefore without obvious meaning.

That mental qualities and traits of cha* Albert Dïrer, His Life and Times. I882. 
racter did not enter into the original idea of the temperaments, is obvious from their having been named Sanguine, Bilious, Lymphatic, and Melancholic, after the bodily organs; the heart; the liver (or rather its product the bile); and the lymphatics. Also, from the term temperament implying mixing together; the idea being that the four elements of which the body was supposed to be composed were mixed together in various proportions in the temperaments.

"The words temper and temperament are " from the Latin verb tempero, to mix, or temper, " as mortar."

"The mixing differs so that one or other " temperament predominates."-Laycock.

"It must be remembered that the ancients, " from the time of Hippocrates, held the opinion " that there existed four kinds of humours in " the human body_blood, bile, black bile, and " phlegm, -and that as one or other of such " humours was present in excess, the individual 
GENERAL VIEW OF THE TEMPERAMENTS. 2 I

"was said to be of a sanguineous, bilious, "melancholic, or phlegmatic temperament."Dr. Garrod.

As there are not two kinds of bile, black being only concentrated yellow bile, the melancholic_atrabilious-black bile-. temperament, had no sufficient claim to be classed as one of the four temperaments, and, as already stated, has given place to the nervous.

Although the temperaments were originally only physical distinctions, certain mental qualities and traits of character have been associated with them from a very early period, and they should therefore be regarded as consisting of two parts-a physical part, and a correlated mental part; -the natural association of the mental with the physical-of the mind with the body-constituting the popular value of the doctrine of the temperaments.

"To these varieties of bodily constitution 
" and external aspect, certain peculiarities of " mind, of temper or disposition, were supposed " to be superadded. The connexion of mental " or psychical qualities with those of physical "organization constitutes an essential part of " the theory of temperaments."-Dr. Prichard, "Cyclopedia of Practical Medicine."

The study of the temperaments could have no practical value, could lead to no teaching apart from medicine, but for the recognition of a physical part and a mental part of every temperament, and the dependence of the mental on the physical.

As mental qualities and traits of character have been associated with the temperaments for at least two thousand years, it is surprising that so important a part of the doctrine has remained without precision, and therefore incapable of useful application. 


\section{CHAPTER III.}

THE TEMPERAMENTS AND MIND.

Dr. Prichard on the relation of mental peculiarities to corporeal structure.-Its extent often exaggerated. - Extracts from Dr. Maudsley, John Inglesant, and Richerand.Mind not limited by temperament.-Character and temperament. - Association of imagination with the nervous temperament. -The sculptured groups on the base of the Albert Memorial.-_Their temperaments and the character of their work.--Proof of the relation between traits of character and outward appearance, from reading faces, and from the "History of Twins."

R. PRICHARD in his article "Temperament" in the "Cyclopædia of Practical Medicine," says :-

"The relation of mental peculiarities to "corporeal structure has been observed by "medical authors of every age. In the "writings of Galen there is a treatise expressly 
" composed to prove that the characters of "men depend on their temperaments. But it " is in the works of modern writers that we "find this doctrine most fully developed and " made a foundation of human characters. It " is extremely improbable that an opinion "should have held its ground for so many "ages among men of observation, especially " on a subject requiring no abstruse research, "without some foundation at least in fact. "The doctrine of the temperaments is true to " a certain extent, and has ever been confirmed "by an appeal to experience.

"States of the mind are so connected with "affections of the body that it is impossible "for any one who considers the facts which "present themselves to doubt that with every "temperament particular mental qualities must "be associated, although it is manifest that "many writers have indulged their fancy on "this subject, and have gone into more full " and minute details than experience will " establish."

With this charge of exaggeration I fully 
THE TEMPERAMENTS AND MIND. 25 agree, claiming as I do a very limited power of the temperaments over mind.

In literature and conversation every mental manifestation and every trait of character are attributed to temperament; " his temperament" having in popular use the widest possible range, including not only every mental quality, but every virtue and every vice.

Dr. Maudsley in the volume I have already quoted (The Pathology of Mind, I 879), says :-

"It is not amiss to reflect, when weighing " beliefs, that belief is very much a matter of " temperament."

In Fohn Inglesant, vol. i., page $\mathrm{I} 2 \mathrm{I}$, is the following:-

"This is the most important lesson that a "man can learn-that all creeds and opinions "are nothing but the mere result of chance " and temperament." 
Richerand, a French physiologist whose descriptions of the temperaments have been more or less reproduced by most English writers, says :-

"I have no doubt that the influence of "the physical organization on the intellectual "faculties is so decided that we may regard "as possible the solution of the following "problem, analogous to that with which "Condillac concludes his work on the origin " of human knowledge.

"The physical man being given, to determine "the character and extent of his capacity, and "to assign consequently not only the talents he "possesses but those he is capable of acquiring."

I do not believe that the mind of man is thus hampered in its operations or circumscribed by such definite bounds. Shakespeare, Newton, and others whose minds distanced all ordinary minds, differed in no other way from ordinary men. 
The writer of the article "Can there be a Science of Character?" in The National Review for March (1890) says:-

"To a science of Character there is one "contribution which dates from quite ancient "time; * the so-called doctrine of Tempera"ments. ... Ancient though this doctrine is, " and though it was doubtless connected with "absurd views, yet the theory of temperaments " has a great deal to say for itself."

Eighty years ago an author wellacquainted with the subject, said of the study of the temperaments, as quoted (page $x$ ):-

"Individual character is its object, and it "embraces the whole of the distinction by "which that character is marked."

It may be seen farther on in this chapter that I do not think that temperament characteristics reveal all that is included in character.

* See pages 23, 24 . 
Sterne, in one of his sermons, expresses very happily the different influence of the same circumstances on the temperaments:-

"The self-same happy accidents in life which "give raptures to the choleric or sanguine man "shall be received with indifference by the cold "and phlegmatic;"

and as this difference in susceptibility to surrounding circumstances necessarily includes different action, to it, chiefly, may be attributed the difference in character assigned to the sanguine, bilious, lymphatic, and nervous, in the scheme of the four pure temperaments, pages $79,80,8 \mathrm{I}, 82$; an arrangement of their physical and associated mental characteristics, for practical guidance.

Observation warrants me I think not only in limiting the mental traits associated with physical characteristics to those of the scheme, but in assuming that reason, 


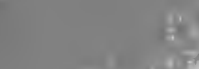

1.

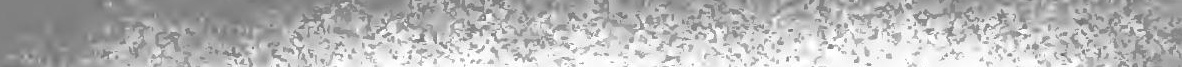

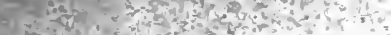

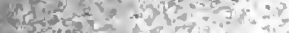

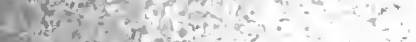

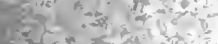

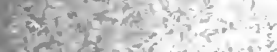

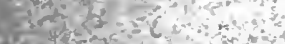

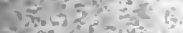

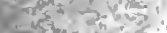

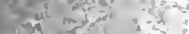

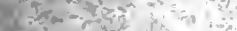

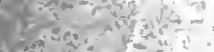

434 incotos

antion $x=5=$ in

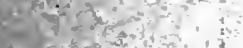

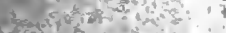

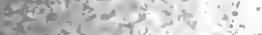

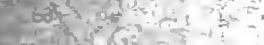

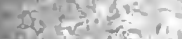

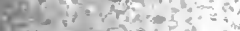

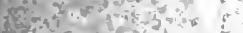

(5) is

$\rightarrow$ axi $7 x+2$

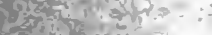

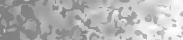

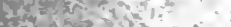

He $=7 x^{4}$

F

$-x+5=204$

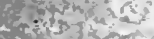

a) $7 x+2$

xis

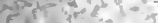

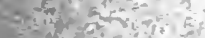

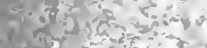

कर

$1 x^{2}=5$

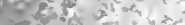

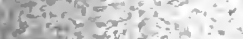

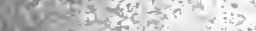

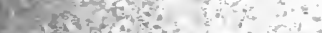

तो

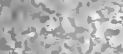

thes $5 x^{4}=$

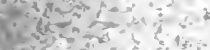

ats

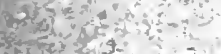

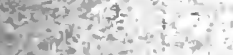

Bts

$x^{2}=3 y^{2}$ a 24

(a)

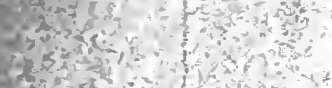

of

ations

ax is

$-7+2 y^{2}+2,1$

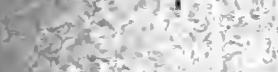

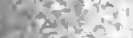

$=-3 y^{2}=$

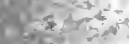

$\therefore$ intes

ind

m.

3.

$2 x+1$

$\therefore 33^{3}$

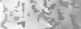

aर

$-3,34$

and 3

$1 \rightarrow-2=0$

$x=28$

$\rightarrow 0$.

$\because i n$ ine

\& $=0$ -

is

$\therefore-\cdots$

$=42$

a.

ins

$-6 e^{2}+2$

: y

$\therefore \omega^{2} / x^{2}$

$-r=\frac{c}{2}=2$

i2 $42 x=4$

int?

$37-3=$

- $45=1$

$=304$

val

3in â

$-1$

orad

tin?

sinct

Sul-

as

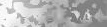

$6 y^{2} x^{2}$

$\approx+10$

$t=34$

$-7 y$

7at

tors

inde?

What

$\therefore 3 y=$

48

EN

tin

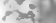

ज. 101

it $y=8$

$\because 50$

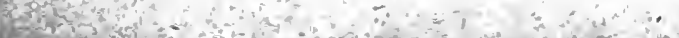

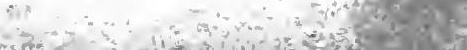




\section{STERNE.}

From Portrait hy sir J. Reynolds, and a Frontispiece.

Face tapering from a high forehead, slim build.

(Nimens Charateristics. Page 82.)
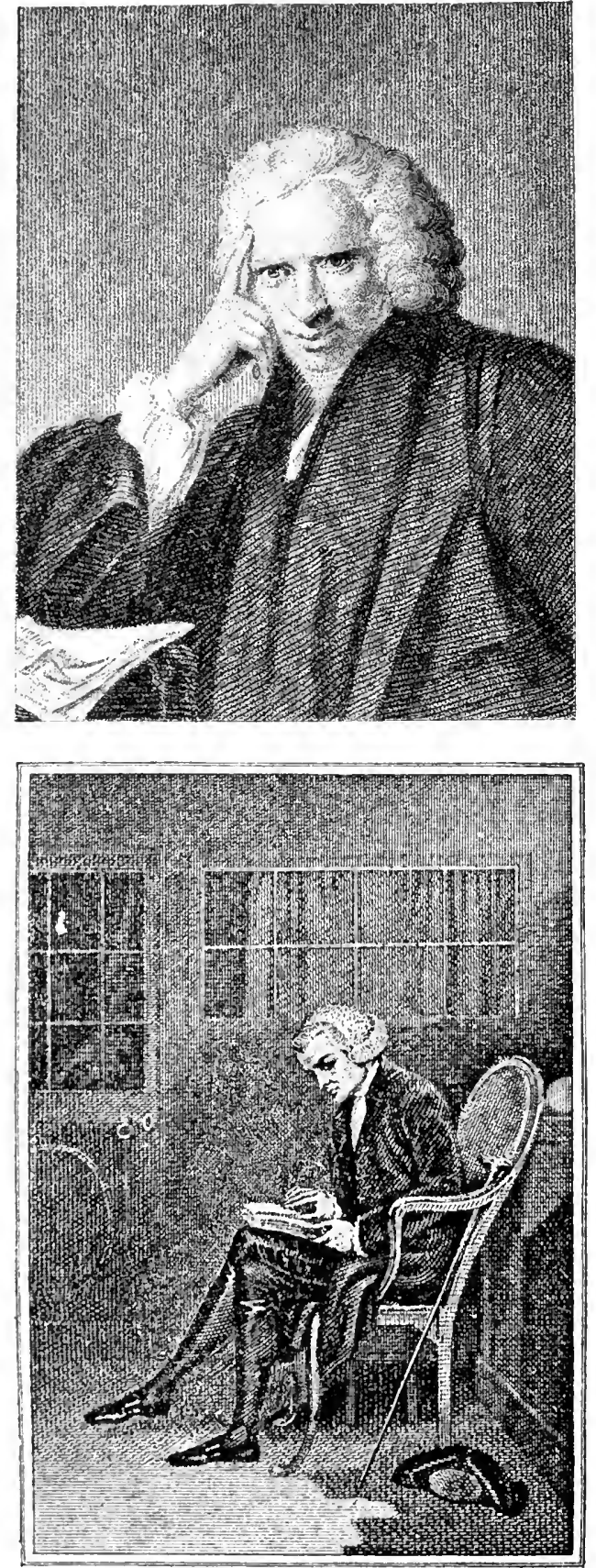

"A pale, thin person of a man."--Sent. Four. 


\section{STERNE.}

The association of Imagination in every-day life, with the Nervous temperament-Pages 28, 29.

"When my way is ton rough for my feet, or too stecp for my "strength, I get off it to some smooth relret path which fincy"

" has scattered over with rosebuds of delight, and having taken a few " turns in it, come baek strcngthened and refreshed."-Sent. Your.

"I do all that lies in my power to keep his (the reader's) inagination " as busy as my ozon." *-On. Writing.

"One of the illusions of an imagination which is etermally misleading" me."-Sent. Jour.

\section{Sterne's imagination had full play in his habit of reading faces.}

"There is not a secret so aiding to the progress of sociality as to he "quick in rendering the several turns of looks and limbs, with all their

" inflections and delineations, into plain words. For my own part, by long

" habitude, I do it so mechanically, that when I walk the streets of

"London, I go translating all the way; and have more than once stood

" behind in the circle, where not three words have been said, and have

" brought off tweity different dialogues with me which I could fairly have

"wrote down and swore to."-Sent. Four.

"I generally fall into conversation with him (The Ass), and surely" " never is my imagination so busy as in framing his responses from the

" etchings of his countenance."--Tristram Sir.indy.

\section{The regretting Nervous temperament-Page I 49.}

" My letter had not been put into the post office ten minutes before "my heart smote me; and I sent to recall it, but failcd."- - Letter to Garrick.

* The Italies in the extracts are not in the original. 

memory, and the other mental powers are, with one exception, uninfluenced by them; the exception being the association of Imagination, not only in its greatest flights, but in its every day manifestations in the ordinary affairs of life, with the physical characteristics of the Nervous or cerebral temperament.

The busts and reliable portraits of eminent men will generally be found to show a marked connection between the temperament and the character of the work that has led to fame; that the face tapering to the chin from a broad or high forehead, small features, and a long neck -the Nervous temperament (see Scheme, chap. iv.)-characterize the greater number of those whose fame rests on works in which imagination reigns; and that a square face, broad features, and a short neck, the physical characteristics of the three other pure temperaments, - the Sanguine, the 
Bilious, and the Lymphatic (see Scheme),characterize, more or less, the greater number of those whose famous works are of a more material or physical character.

Were this interesting enquiry pursuedcomparison of the features of famous men with the character of their works-not only, I think, would the relation which I have indicated between imagination and the four pure temperaments; - the Sanguine, the Bilious, the Lymphatic, and the Nervous,be found generally true; but I think it would also be found generally true, that when even one of the physical characteristics of the Nervous temperament had displaced one of the characteristics of any of the three other pure temperaments, it imported some of the imaginative power of its own temperament (ch. vii.).

Some proof of the association of the form characteristics of the Nervous or 


\section{POPE.}

From Portrait by Ifudson.

Face tapering from a high forehead, long neck, slim build.

$$
\text { (Neraous Characteristics. Pase 82.) }
$$

The association of the Nervous temperament with Intellect and Imagination. Pages 29, 30.

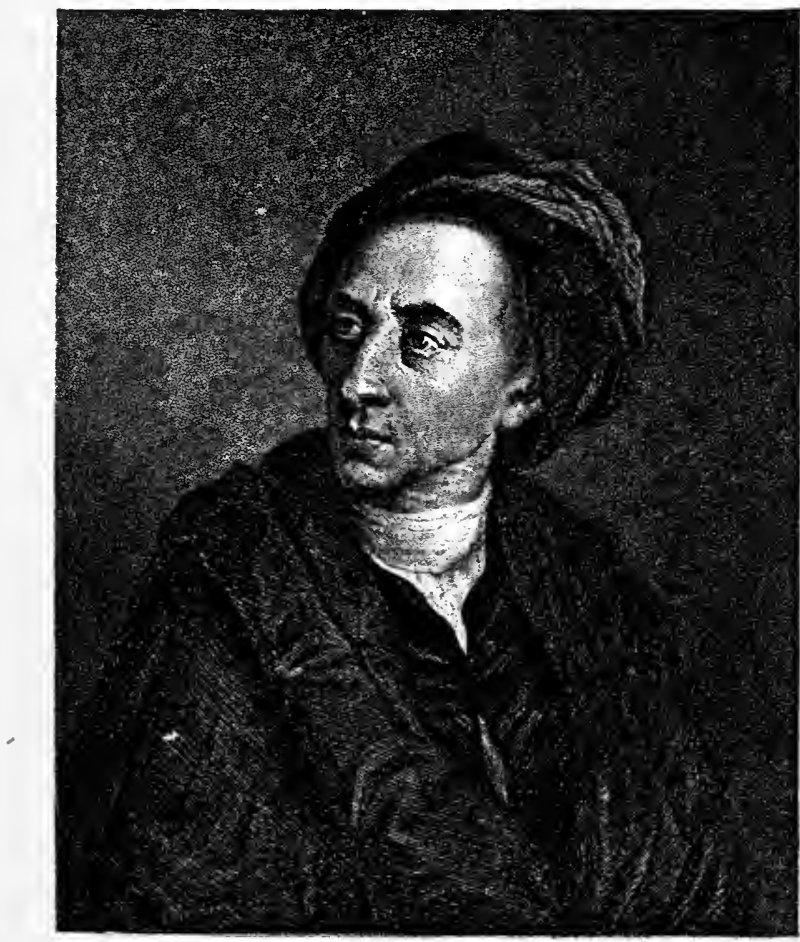

Pope had likewise genius; a mind active, ambitious and adven" turous, always investigating, always aspiring; in its widest searches "still longing to go forward, in its highest flights still wishing to be

" higher; always imagining something greater than it knows, always

" endeavouring more than it can do."-Fohnson's Lin'es. 

cerebral temperament with intellect, and probably with imagination, is afforded by the sculptured groups of famous poets, painters, musicians, sculptors, and architects round the base of the Albert Memorial in Hyde Park.

There are one hundred and sixty-nine figures, and observers may be surprised how greatly the face tapering from a high or broad forehead prevails in all the classes, and that-especially in the groups of the poets, the painters; and musicians-the exceptions are so few.

Greater variety is observed among the sculptors and architects; and it may be that imagination and originality are less essential to lasting fame in them than in poets, painters, and composers.

If the doctrine of the temperamentsthe association of certain mental with certain physical characteristics-is well founded, 
workers in the same field, whose work differs, should themselves differ in appearance. The character of Wordsworth's, Byron's, and Scott's poetry is unlike, and so are their portraits.

It may make the association of certain mental qualities with every temperament more acceptable to many, to know that it rests on a basis of proof common to the temperaments, to expression, and to physiognomy, viz., the general belief that a reliable opinion of a man's character can often be formed by looking at him; and that such belief is the result of comparison of faces and characters.

In The Spectator, No. 86, Addison says:-

"I am so apt to frame a notion of every “man's humour or circumstances by his looks, " that I have sometimes employed myself from "Charing Cross to the Royal Exchange in "drawing the characters of those who have 
THE TEMPERAMENTS AND MIND. 33 "passed by me. . . . I think we may be " better known by our looks than by our words."

At the Mansion House on Lord Mayor's Day, I 883 , Mr. Gladstone said:-

"It is true, my Lord Mayor,* that I do not " meet you on this occasion as one unknown " to me. You and I have had as good oppor" tunities as any two persons in this hall of " making accurate studies of one another-of “ one another's features and personal appearance, "from which, by an intelligent eye, it is well "known that so much is to be learnt."

It has not I think been realized that always when mental traits are inferred from the features, we are guided by those that have been found in one or more similar faces.

Relatives, companions, teachers, public characters, and others whom we have

* Sir Robert Fowler, M.P. 
seen much of in early life, supply examples of marked physical characteristics associated with equally marked mental ones, and serve as standards with which at first similar faces are compared.

Other standards of comparison are soon added, and before long we come to rely on the almost constant association of certain mental with certain physical characteristics-that when two faces and figures are strikingly alike the men will be strikingly alike in their action, manners, mode of speech, etc., unless their lives have been in very different grooves.

When belief has thus become established, our judgment of a man's character from his face and figure is so rapid that it appears intuitive, and the fact of comparison with some other face is only brought home to us when we see an unusually 
THE TEMPERAMENTS AND MIND. 35

striking likeness, or can with difficulty recall the previous face to memory.

Mr. F. Galton, F.R.S., whose work "Hereditary Genius" is so well known, has lately published a volume, "Inquiries into Human Faculty and its Development," I 883, in which there is a most interesting and suggestive chapter, "History of Twins," and although the temperaments of the twins, referred to are not given, the association of similar mental with similar physical characteristics is all but fully proved by perfectly reliable records. Mr. Galton sent

"Circulars of inquiry to persons who were " either twins themselves or near relatives of "twins, with the view of ascertaining the in"fluence of nurture on nature: whether twins " who were closely alike in boyhood and youth, " and who were educated together for many "years, subsequently grew unlike, and if so, "what the main causes were which, in the 
"opinion of the family, produced the dis" similarity.

"Also, how far the characters of twins who "were exceedingly unlike in childhood, be" came assimilated under the influence of "identical nurture, inasmuch as they had the "same home, the same teachers, the same " associates, and in every respect the same sur" roundings."

Of the numerous records received, he takes into account thirty-five sufficiently detailed cases of close similarity, and twenty of great dissimilarity, for-

"It is a fact that extreme dissimilarity, such " as existed between Esau and Jacob, is a no "less marked peculiarity in twins of the same " sex, than extreme similarity.

"When the twins are a boy and a girl, they " are never closely alike."

Mr. Galton quotes some very remark- 
THE TEMPERAMENTS AND MIND. 37

able replies concerning twins who could not be distinguished by their nearest relatives, and several amusing results of their mistaken identity.

Similar mental qualities and traits of character were observed in twins who closely resembled each other, and dissimilar ones in those between whom there was no resemblance, so far proving the doctrine of the temperaments; and had the temperaments of the thirty-five pairs of twins been named, the replies would probably have fully proved the doctrine by showing that pairs of twins whose temperaments were the same had similar mental qualities and traits of character.

The chief results of Mr. Galton's circulars may be appropriated in corroboration of the doctrine of the temperamentsthe association of similar mental action and traits with similar physical characteristics. 
In the following paragraph similarity of "manner, personal address, and voice" in twins who were similar to look at is noticed, and these and other points will, I think, be generally found more or less similar, sometimes strikingly so, not in twins only, but in all between whom there is a close resemblance.

"The manner and personal address of the " thirty-five pairs of twins are usually de"scribed as very similar, but accompanied by " a slight difference of expression familiar to " near relatives, though unperceived by "strangers. The intonation of the voice when "speaking is commonly the same, but it fre"quently happens that the twins sing in "different keys."

Similarity of organization in those of the same temperament is insisted on in chapter ix. of this essay, and is fully corroborated by the two following extracts :- 
"Both twins were apt to sicken at the same "time in no less than nine out of the thirty"five cases. Either their illnesses were non" contagious, or, if contagious, the twins "caught them simultaneously; they did not " catch them the one from the other. Thus, "the father of two twins says:-

" "Their general health is closely alike; when" "ever one of then has an illness, the other " " invariably has the same within a day or two, " "and they usually recover in the same order. " "Such has been the case with whooping-cough, " " chicken-pox, and measles; also, with slight " "bilious attacks, which they have successively. " "Latterly, they had a feverish attack at the " 'same time.'

"The next point which I shall mention in "illustration of the extremely close resemblance "between certain twins is the similarity in the "association of their ideas. No less than "eleven out of the thirty-five cases testify to "this. They make the same remarks on the "same occasion, begin singing the same song 
"at the same moment, and so on; or one "would commence a sentence, and the other "would finish it.

"An observant friend graphically described to " me the effect produced on her by two such "twins whom she had met casually. She said: " "Their teeth grew alike, they spoke alike and " " together, and said the same things, and “' 'seemed just like one person.'

"The last point to which I shall allude re"gards the tastes and dispositions of the thirty"five pairs of twins. In sixteen cases, that is, " in nearly one-half of them, these were de"scribed as closely similar; in the remaining " nineteen they were much alike, but subject to " certain named differences.

"It follows from what has been said " concerning the similar dispositions of the "twins, the similarity in the association of their " ideas, of their special ailments, and of their " illnesses generally, that their resemblances are " not superficial, but extremely intimate. 
THE TEMPERAMENTS AND MIND. 4I

"I have only two cases of a strong bodily " resemblance being accompanied by mental "diversity, and one case only of the converse “ kind."

The following are some of the replies summarised as above by Mr. Galton.

The daughter of a twin says:-

"Such was the marvellous similarity of their " features, voice, manner, etc., that I remember " as a child being very much puzzled, and I "think had my aunt lived much with us, I "should have ended by thinking I had two " mothers."

A medical man writes of twins with whom he is well acquainted:-

"Whilst I knew them, for a period of two "years, there was not the slightest tendency towards " a difference in body or mind; external influ"ences seemed powerless to produce any dis" similarity." 
A father writes:-

"At birth they were exactly alike, except " that one was born with a bad varicose affec" tion, the effect of which has been to prevent " any violent exercise, such as dancing or " running, and as she has grown older, to make " her more serious and thoughtful. Had it "not been for this infirmity, I think the two "would have been as exactly alike as it is "possible for two women to be, both mentally "and physically; even now they are constantly " mistaken for one another."

Proof of the doctrine of the temperaments from similarity of ${ }^{\prime}$ mental action and traits in twins who were alike, is complemented by dissimilarity in those who were unlike. Of the replies concerning the twenty cases of twins who were unlike, Mr. Galton gives the following :-

(I) "They have had exactly the same "nurture from their birth up to the present "time; they are both perfectly healthy and 
"strong, yet they are otherwise as dissimilar as "two boys could be, physically, mentally, and " in their emotional nature."

(2) "I can answer most decidedly that the "twins have been perfectly dissimilar in " character, habits, and likeness from the "moment of their birth to the present time, "though they were nursed by the same "woman, went to school together, and were "never separated till the age of fifteen."

(3) "They have never been separated, never " the least differently treated in food, clothing, " or education; both teethed at the same "time, both had measles, whooping-cough, and "scarlatina at the same time, and neither has " had any other serious illness. Both are "and have been exceedingly healthy, and have "good abilities; yet they differ as much from "each other in mental cast as any one of "my family differs from another."

(4) "Very dissimilar in body and mind : "the one is quiet, retiring, and slow but 
"sure; good tempered, but disposed to be "sulky when provoked; the other is quick, "vivacious, forward, acquiring easily and "forgetting soon; quick-tempered and choleric; " but quickly forgiving and forgetting. They " have been educated together and never been "separated."

(5) "They were never alike either in body "or mind, and their dissimilarity increases daily. "The external influences have been identical; "they have never been separated."

(6) "The two sisters are very different in "ability and disposition. The one is retiring "but firm and determined; she has no taste "for music or drawing. The other is of an "active, excitable temperament; she displays " an unusual amount of quickness and talent, " and is passionately fond of music and drawing. "From infancy they have been rarely separated " even at school, and as children visiting their "friends they always went together."

(7) (8) (9) These three replies are less 
THE TEMPERAMENTS AND MIND. 45

definite than the others, but also record natural dissimilarity continuing under the same influences.

(I0) "This case is, I should think, some"what remarkable for dissimilarity in physique "as well as for strong contrast in character. "They have been unlike in body and mind "throughout their lives. Both were reared in " a country house, and both were at the same "schools till æt. sixteen."

(I I) "Singularly unlike in body and mind "from babyhood; in looks, dispositions, and " tastes they are quite different. I think I "may say the dissimilarity was innate, and "developed more by time than circumstances."

(12) "We were never in the least degree "alike. I should say my sister's and my own "character are diametrically opposed, and have " been utterly different from our birth, though a "very strong affection subsists between us."

(13) "Curiously different in body and mind "from birth, my brother and I were comple- 
"mentary, so to speak, in point of ability and "disposition. He was contemplative, poetical, " and literary to a remarkable degree, showing "great power in that line. I was practical, " mathematical, and linguistic. Between us we "should have made a very decent sort of a "man."

Interesting and valuable as Mr. Galton's "History of Twins" is, whoever has given attention to this essay, even so far, cannot fail to see that the history would have gained in precision of description, and, therefore, in value and interest, had the temperaments been known and named by those who replied to Mr. Galton's circulars. 


\section{CHAPTER IV.}

SCHEME OF THE FOUR PURE TEMPERAMENTS.

The difficulty of distinguishing the temperaments acknowledged by authors.-Need of standard descriptions.- Suggestion that they be undertaken by the British Medical Association.-The temperaments not sufficiently utilised in medicine.-Mr. Jonathan Hutchinson's views.-The temperaments taught in the class-room, and clinically, by Professor Laycock.-Some of the descriptions of English authors.-A scheme of the four pure temperaments, in which their physical and mental characteristics are arranged for practical guidance.-The temperaments and phrenology.-Albert Dürer and the four temperaments.-The four temperaments on an old chimney-piece in Guildford Town Hall.

A UTHORS, past and present, acknowA ledge the necessity and difficulty of distinguishing the different temperaments. 
The celebrated Dr. Cullen writes thus in $1779:-$

"Philosophy would require that I should in "the first place distinguish temperaments by "marking the external and observable circum"stances which are found, with some steadiness, " to be commonly combined together; but this "I find a difficult task, and what my own "observation has not been so extensively applied " to as to enable me to perform in the manner "I would wish."-Materia Medica.

Mr. Starkweather, who, in a recent work (The Law of Sex, r883) gives temperament a chief place in the determination of sex, and is obviously well acquainted with the descriptions of the temperaments by authors of all countries and every period, says (page rio):-

"There is, perhaps, no point upon which " authorities differ so strangely, as what tempera" ment really is, and in determining to which "class any given individual properly belongs." 
THE FOUR PURE TEMPERAMENTS. 49

Mr. Jonathan Hutchinson, F.R.S., says:-

"As yet I fear we must say that the labours " of the physiognomist and those of the student "of temperament have been alike disappointing. "Whoever will set himself the task of attempt" ing to classify a given number of individuals " according to their temperaments will, I think, "soon find himself baffled. . . . Dr. Laycock's " is, so far as I know, the last, and certainly by "far the best of all attempts to classify the " temperaments, yet Dr. Laycock's classification "is also, in common with the older ones, open "to the criticism that it affords us but few facts " by which to recognise them." - The Pedigree of Disease, Lecture $I$.

Dr. Laycock, however, says of his classification *:-

"I think it will serve all the practical purposes "of observation and generalization, and place us "finally in a position to bring the doctrine of "temperaments to a level with modern phy" siology."

* Lectures in Medical Times and Gazette, 1862, vol. i. 
In the same lecture, page vii., Mr. Hutchinșon says :-

"I come then back to my point, and assert " that whoever will set himself to classify by " temperament a dozen healthy individuals whom "he may chance to meet on a steamboat, in a " law court, or at a dinner party, will find that " he has scarcely any data excepting those of " complexion. He will find, moreover, unless "I am much mistaken, that if he attempts to go "beyond mere complexion, there are not more "than two or three in the dozen whom he can " with any degree of confidence assign to special " temperaments."

I am hopeful that the attempt I have made to assign characteristics of form, as well as of complexion or colour, to the different temperaments, that they may be readily recognized and named, may induce competent observers to pursue this fundamental part of the subject, and that descriptions may ere long be supplied 
THE FOUR PURE TEMPERAMENTS. 5 I

which may become generally accepted as standard descriptions.

"You will find it necessary to form stan"dards for physiognomical comparison. You "should incessantly observe the healthy charac" teristics of persons of various races, ages, "sexes, rank, occupations, and the like, so " that right standards of comparison may be "formed."-Dr. Laycock.

Mr. Hutchinson was addressing the medical profession in the theatre of the Royal College of Surgeons when he said that the best classification yet given does not enable the observer to classify individuals according to their temperaments.

Even in medicine therefore-the home of the subject-there are no standard descriptions by which the temperaments may be known.

In the importanc lecture on Temperament from which the foregoing extracts 
are taken, Mr. Hutchinson examines the whole subject most carefully, and-disappointed-is obliged to conclude that not only is it impossible to distinguish the different temperaments by the features assigned - to them, but that there is very little proof of the influence of temperament on disease and its treatment. $\mathrm{He}$ is careful, however, to guard against its being thought that he does not believe in the usefulness of temperament in medicine, were it possible to discriminate it.

"I have said so much in disparagement as "well of the general as of the special signs "which have been held to indicate tempera"ment, that I fear it may be suspected that "I almost doubt the reality of temperament " in itself. If I have given that impression, "let me hasten at once to remove it. There "can be no question whatever as to the "reality of the difference between individuals, " nor any doubt as to the importance of the 
THE FOUR PURE TEMPERAMENTS. 53

" recognition of those differences by the medical " practitioner.

"Temperament is unquestionably a real force, " and one which we would most gladly re" cognise and estimate if we could. The "scepticism which I have been expressing "applies not to the reality of the thing, but "to our ability to discriminate it."

The chief aim of this essay is to make the discrimination of temperament, not only possible, but easy.

There can be no useful records of the influence of temperament on disease and its treatment unless the name given to the temperament of a patient enables the mind's eye of the reader to see his face, features, and build, as the recorder saw them; and such cannot be till precise descriptions by which the different temperaments can be recognized have been generally accepted by the profession. 
In the "Life History Album,"* issued by the Collective Investigation Committee of the British Medical Association, the first two personalities to be recorded:

I. Colour of eyes,

2. Colour of hair,

are chief temperament characteristics (see Scheme, chap. iv.), and lead me to suggest that the Committee would do essential service to medicine by promoting the investigation of the subject of temperament, first by supplying the profession with precise descriptions of the different temperaments, the want of which renders uncertain of meaning whatever is said or written concerning them, and afterwards by collecting the results of their application to practice.

It is humiliating that a doctrine which

* "Life History Album," prepared by direction of the Collective Investigation Committee of the British Medical Association. Edited by. Francis Galton, F.R.S. $\quad$ I884. 
THE FOUR PURE TEMPERAMENTS. 55

has always been an acknowledged part of medicine, and is capable of useful application to every case of illness, should still be so practically useless that an observer so experienced as $\mathrm{Mr}$. Hutchinson should be obliged to say:-

"I have been speaking thus far on the "subject of temperament considered as the " aggregate of a man's physical personality, " and have felt obliged to return the verdict " that its study in this form is but little " useful for our purposes as surgeons."

In a quotation already given-page 53and throughout his lecture, Mr. Hutchinson ascribes the blame, not to temperament itself, but to our inability to discriminate it.

$\mathrm{He}$ thus acknowledges the necessity for such discrimination in practice :-

"By far the commonest error of the pre- 
"scriber, and one which most interferes with " his success, is the easy-going habit of " regarding all persons as alike, and recognis" ing differences only in their diseases. . . .

"The farmer who would succeed in his "pursuits must not content himself with " making sure that he has sown good seed, " and according to the most approved methods: " he must go farther back, to take knowledge " of the nature of the soil with which he "has to deal, of the crops which it has "previously borne, and of the manures which "have been used. It is much the same with "us in the diagnosis and treatment of disease."

No one can doubt that were the temperaments carefully discriminated, treatment would become more certain, because more individual.

It may be hoped that in an age when the science of medicine has been so greatly advanced by minute physical 
THE FOUR PURE TEMPERAMENTS. 57

examination of the different, organs, Mr. Hutchinson's accusation that temperament, " unquestionably a real force, and one that we would most gladly recognize and estimate if we could," remains useless because it cannot be discriminated, may stimulate professional observers to study temperament as they have studied the heart or any other of the organs, that physical characteristics may be established by which the different temperaments may be readily recognized.

Dr. Wilks (page 9) may well consider it singular that

"with one or two exceptions our teachers of "medicine seem to have forgotten the doctrine " of temperaments which occupied so large " a part of the old schools of education."

Professor Laycock was no doubt one of the exceptions. He taught the doctrine 
enthusiastically, not only in the classroom, but clinically, and no part of his professorial teaching made a deeper or more lasitng impression on those who studied under him, or has had a greater influence on their practice.

"Chief among those to whom I allude stands " one to whom I have myself been greatly in" debted-my first teacher of medicine, the late "Professor Laycock.

"With a power of insight which amounted "almost to genius, Dr. Laycock had applied " his mind to the study of the physiognomical " diagnosis of disease, and by long practice in "observations in this direction, he was enabled "sometimes to give opinions which astonished "those who were accustomed to more plodding " methods of investigation.

"In a series of lectures delivered in I $86 \mathrm{I}$, and "published in the following year in The Medical "Times and Gazette, he embodied the results "of his experience. 
THE FOUR PURE TEMPERAMENTS. 59

"He believed that his rules of diagnosis were " to a large extent based upon peculiarities of "temperament, and he naturally gave great "attention to the correct classification of these "so-called fundamental states."-Mr. Hutchinson.

Our teachers of medicine, in avoiding, as they do, the apparently complex study of the temperaments, would do well to consider their responsibility to students and the science they teach.

In a recent important work on medicine, the article "Temperament" is contributed by a teacher of medicine in one of our schools, but he omits the bilious temperament, and scarcely notices the influence of the temperaments in disease and its treatment.

Were distinctive descriptions of the temperaments authorised by the Collective Investigation Committee of the British 
Medical Association, as suggested (page 54), they would no doubt be immediately accepted by the profession, and with the best results. The patient's temperament would come to be named in every case, reliable observations would accumulate, and Temperament would occupy the important place in the science of medicine to which it is entitled; a place which physical examination, however minute, cannot occupy.

Such examination only makes known to what extent any of the organs has become invaded by disease. Temperament takes cognizance of the whole of the organization, and of the greater liability of nearly. every person to disease of one of the four organs. It indicates individual, and therefore the most effectual treatment, influenced by the organic differences between men; and it renders more definite the important influence of the mind in disease, 
THE FOUR PURE TEMPERAMENTS. 6I

by teaching the natural association of certain . mental with certain physical characteristics.

It is probably by the unwritten law of temperament that experienced physicians and surgeons have acquired the rapidity of judgment which they possess of the probable course of disease, and their power over it by treatment.

Professor Gairdner has well said :-

"An experienced observer has an instinct of "divination, so to speak, by which the true " character and the history of the organism may "be read in the external features and physical "characteristics, and this not only as to health " and disease, but as to all the leading elements " of character."

This being "a popular outline," I have gone out of my way to call the attention of medical men to the fundamental need of standard descriptions of the temperaments, in the sanguine hope 
that among so many observers who are more or less familiar with the subject, some may be induced to revise those I have given, or supply others which would be accepted by the profession, and thereby secure uniformity of meaning to the name given in clinical records to any of the temperaments, and make it a photograph, as it were, of the patient's form and colour characteristics.

To enable observers to become practically familiar with the temperaments; to know the temperament of any one, and the mental qualities and traits of character naturally associated with it; I have arranged, from scattered and scanty material, a scheme (pages 79, 80, 8I, 82) of the four pure temperaments, - the sanguine, the bilious, the lymphatic, and the nervous, - that their physical and associated mental characteristics may be easily compared and readily remembered. 
THE FOUR PURE TEMPERAMENTS. 63

As definite mental characteristics have probably not been assigned to the four temperaments till now, the scheme should be regarded as only a wellconsidered endeavour to give precision to the subject, and more or less provisional till confirmed or corrected by other observers. I am hopeful, however, that it may prove a generally reliable guide.

The compound or mixed temperaments -physical characteristics of two or more of the pure temperaments in the same person-are described in Chapter VIII.

They are far oftener seen than the pure temperaments; but the student of temperament must become practically familiar with the physical characteristics of the pure or. standard temperaments, that he may be able to analyze and name the compound ones.

To show that the scheme includes the 
generally accepted characteristics, I precede it by the best descriptions of the four temperaments I have yet found in the works of the few English authors who appear to have observed for themselves; and the very complete descriptions of an American author - Mr. Hecker - whose work is referred to at page 286 .

\section{The Sanguine Temperament:}

"The sanguine temperament is strongly " marked by a florid complexion, fair skin, blue "eyes, light hair, generally, and oftentimes red, " an animated countenance, bright red lips, an "active and easily excited circulation, muscular "fibres firm without rigidity, and elastic with"out feebleness."-The Reciprocal Influence of Body and Mind, by Neronham, 1842.

"The sanguine man displays a pretty well "developed figure, has a capacious cranium, " biggish nose, broad chin and cheeks, massy, " well set teeth, ruddy complexion, his limbs "capacious, and as he advances in life he 
THE FOUR PURE TEMPERAMENTS. 65 "becomes fat."-Professor Laycock in Medical Times and Gazette.

"In this (the sanguine temperament), the "external appearances are the following: the "hair, soft and never much curled, is of a "pale colour, or from thence passing through "different shades to red; the skin is smooth " and white; the complexion ruddy; the eyes "commonly blue; the habit of body soft and "plump; after the period of manhood, dis"posed to obesity, and at all times readily "sweating upon exercise; the strength of the "whole body is moderate, and the mind sen"sible, irritable, cheerful, and unsteady."-Dr. Cullen, I779.

Of Sir John Forbes, whose temperament was chiefly sanguine, Professor Laycock says :-

"He had an ample brain, and in youth had "blue eyes, a bright florid complexion, and was "full of spirits, frank and joyous, with a certain 
"impetuosity of temper."-Medical Times and Gazette, I 862.

"A bright, blue-eyed, rosy-cheeked, curlyheaded youth" (sanguine temperament).Mr. Galton, F.R.S.

"In persons of this temperament, the hair is "red, the eyes are blue, the complexion is ruddy, " and the skin throughout is fair, and suffused " with a reddish tinge, which shows the aerated "blood to be actively and abundantly diffused.... "The cheek flushes quickly and readily with " exercise, or with the varying emotional changes "of the mind. The face inclines to roundness. "The countenance is animated. The chest is "full, high, and expanded. The limbs are plump, "but tapering and delicate, with hands and feet "relatively small."-Mr. Hecker.

\section{The Bilious Temperament.}

"The choleric (bilious) temperament is " marked by black curling hair, dark eyes, a "swarthy and at the same time ruddy com- 
THE-FOUR PURE TEMPERAMENTS. 67

"plexion, a thick rough hairy skin, and a "strong full pulse."-Dr. Prichard, F.R.S., Article "Temperament," in Cyclopedia of Practical Medicine.

"In persons of this temperament the hair is "black or dark, strong and abundant. The "complexion is sallow, and the skin dry and of "an olive colour. This temperament gives also "blackness to the pupils of the eyes, and the "general expression harmonizes with their hue." - Mr. Hecker.

\section{The Lymphatic Temperament.}

"The phlegmatic (lymphatic) temperament " is distinguished by light, sandy, or white " hair, light grey eyes, a pallid, unhealthy white" ness of skin, which is almost bereft of hair, "small bloodvessels, a weak, slow pulse, cold "surface, general defect of energy in the func"tions both of animal and physical life."-Dr. Prichard.

"As usually seen in this country, it (the 
"lymphatic temperament) is characterised by a "large person, flaccid muscles, and more or less "pallor of countenance-in short, a degenerate "John Bull."

"These are the slow-moving, pale, flaccid "men of the lymphatic temperament."

-Laycock.

Mr. Starkweather quotes a graphic description by Mr. Fred. Douglas, of the manner of his reception by President Lincoln, probably "lymphatic," certainly "slow-moving" :-

"I was politely ushered into his reception "room, and as he saw me approaching he began "to draw up his feet preparatory to rising; " ere long commenced to rise, and as I ad"vanced, he continued to rise."

Mr. Starkweather adds :-

"This affords a striking contrast to the "movements of an active, nervous man, who 
THE FOUR PURE TEMPERAMENTS. 69

"would have risen on to his feet the moment " he made up his mind to do so."- "The Law of Sex," page 216.

"Where there is an excess of this temperament, " the hair is light or pale in colour. In childhood " it is of a dull white colour, but lifeless in its "expression. The eyes are tranquil and expres"sionless. The skin has a dull leady tinge of "white, and there is an expression of lassitude in "all the tissues. The countenance is listless "when at rest. The features are rounded, but "elongated, pendent, and heavy, and the lips " thick. The figure is rather shapeless and the "flesh soft. The body is full and rather thick "in proportion to the height, yet there is a "general appearance of weakness and apathy." Mr. Hecker.

\section{The Nervous Temperament.}

"When the characters of the nervous "temperament predominate, as a slight figure, "small features and limbs, thin, elegantly "formed nostrils, thin lips, and pointed chin." 
"In the nervous temperament the eye is "almost always vif and restless, the forehead "lofty, and the whole head disproportionately "large compared with the face."-British and Foreign Medical Review.

"Figure small and wiry, face mobile, fea"tures small and delicate, great activity of mind " and body, dyspeptic, and with highly strung " nervous system. Individuals of this tempera"ment are specially liable to nervous diseases. "of all kinds."-Medical Diagnosis, by $\mathcal{F}$. Graham Brown, M.D., I883.

"The nervous or mental temperament may "be known by the sharp, quick, intelligent "eye, well-formed brain, and $\mathbf{V}$-shaped pale "face, with small bones and neatly-formed "body. This is the most active, finely strung, " and delicate of all the temperaments." -

Anonymous Medical Work.

"Whilst the flow of ideas is rapid, and the " expression of them prompt, the muscular "movements are remarkable for their energy 
$\because$

c. 


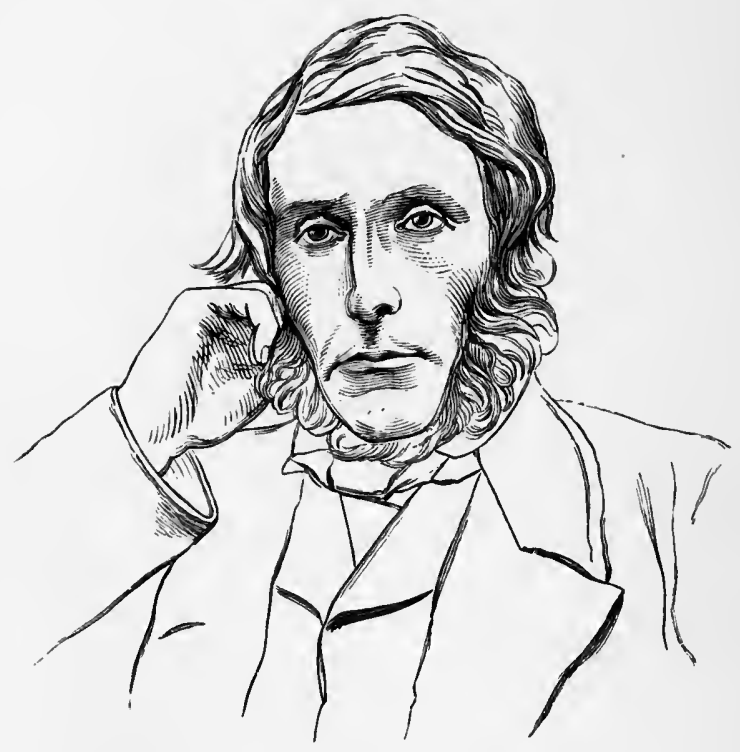

THE MELANCHOLIC FACE. 
THE FOUR PURE TEMPERAMENTS. 7 I

"and rapidity, so that the limbs and body "move quickly and impulsively."-Laycock.

"In the Nervous temperament the eyes are "bright, vivid, and expressive; quick in their " movements, and brilliant and deep in colour, " usually tending towards gray.

"There is a general fineness of quality cha"racterising the whole physical structure. The "figure is delicate, and there is a tendency "towards slenderness. . . . The features about "the head, particularly the chin and nose, are " sharp, well-marked, yet delicate, and the brain "development is clearly defined. The muscles " are small but well-formed, and indicate an "active condition, and their movements are "marked by rapidity and promptness."- $M r$. Hecker.

The Melancholic Temperament.

The melancholic, or, as its name implies, the black bile temperament, formerly held place as one of the four pure tem- 
peraments, but is a long-faced, hollowcheeked compound of the bilious and nervous temperaments, and is characterized by black hair, dark and generally large eyes, a dull, dark complexion, darker in some, under the lower eyelids, the face tapering somewhat to the chin, and the neck long.

"The well-known Puritan features, black, "straight hair, hollowed cheeks, and sallow “complexion."-Mr. Galton, F.R.S.

Whatever the colour of the hair, eyes, or complexion, the long tapering face, with depressed cheeks, large eyes, and long neck, give, more or less, the same air of melancholy.

The few extracts that follow are the most striking references to the mental characteristics of the temperaments that I have met with. 
THE FOUR PURE TEMPERAMENTS. 73

\section{The Sanguine and Bilious Tempera-} MENTS.

"Not sanguine and diffusive he, "But biliary and intense."

-Carlyle.

"The sanguine are easily moved emotionally, "i.e., the circulation is readily influenced by "mental changes, and they readily blush, laugh, "weep, sigh, sympathise. But the emotion, " though prompt and violent, soon ceases. $\mathrm{He}$ "tells you that his temper is soon up and soon "over."

"In all these respects the differences between "the excitable (sanguine) and the choleric "(bilious) temperament are clearly marked. In "the choleric man the circulation is compara" tively little disturbed by emotion, and the "resentment or other emotion is more " abiding." - Laycock.

"As Micheline and 'feanne, Mesdames Ange " and Lina Munte reproduce that eternal con- 
" trast of the femme blonde and the femme brune "the one simple and confiding, the other "passionate, jealous, revengeful, unscrupulous." - Notice of a French Play.

"If anything can be confidently predicated as "to the two principal complexions, it is that "the fair goes more usually with active courage " and a roving adventurous disposition, the dark " with patient industry and attachment to local " and family ties."-Dr. Beddoe.

"The sanguine by a happier temperament " are rendered cheerful and free from care."

\section{The Lymphatic Temperament.}

Of those of the lymphatic temperament, Dr. Southey says :-

"Their memories are good, their reasoning " powers are considerable, and their judgment " sound and logical. Common sense and "straightforward conduct characterise them in 
THE FOUR PURE TEMPERAMENTS. 75

"their dealings with their fellow creatures. "Socially, they are seldom the best company, "but their sterling qualities make them the " best friends."

\section{The Nervous Temperament.}

Of the nervous temperament Professor Laycock says :-

"There is greater susceptibility to all impres"sions, finer susceptibilities, greater rapidity of " action, of ideas, and of speech; in the ex"pression of the feelings and ideas greater "vividness of the imagination."

\section{The Melancholic Temperament.}

"The melancholic temperament is characterised "by inexcitability, or, at least, inactivity, and "by gloomy, disparaging ideas as to self, "children, country, which take the place of "the confidence and sanguine anticipations of " the nervous and sanguine temperaments." 
“The Puritan's character is joyless and " morose; he is most happy, or, to speak "less paradoxically, most at peace with himself " when sad. It is a mental condition cor" related with the well-known Puritan features, "black straight hair, hollowed cheeks and " sallow complexion (melancholic characteris" tics). A bright, blue-eyed, rosy-cheeked, "curly-headed youth (sanguine characteristics) "would seem an anomaly in a Puritanical "assembly."-Mr. Galton, F.R.S.

The following sketch shows the natural action of the sanguine man in daily life.

\section{The Sanguine Man.}

The man of a purely sanguine temperament, the hair more or less red, the eyes blue, and the complexion florid, is warm-blooded, warm-hearted; his blood soon boils, soon cools; his heart rules his head; action precedes thought. In youth it is a word and a blow, then sorrow. 
THE FOUR PURE TEMPERAMENTS. 77

$\mathrm{He}$ has often to apologize for words spoken in haste.

I know two partners in business, one sanguine, the other bilious. The bilious has often to throw cold water on the projects of the sanguine, who almost invariably fires up and says too much, which makes him for a short while miserable, downcast, and meekly ready to yield anything.

$\mathrm{He}$ is useful however. His sanguine temperament helps to dispel the dark views of events from temporary troubles which his bilious partner would indulge in.

The sanguine man has great expectations. His disappointments are short-lived; his forecasts always sunny. His views are large and liberal. The law is not half summary enough for him. He would often dispense with both judge and jury. 
$\mathrm{He}$ is loved by the young; enters heartily into their sports and games, and laughs more merrily than the merriest. This therefore might well be called the jolly temperament. 


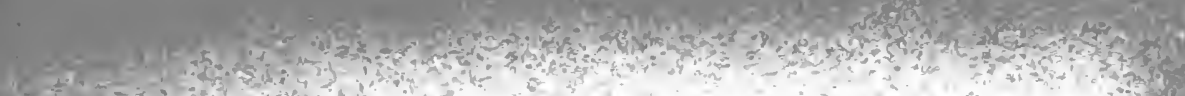

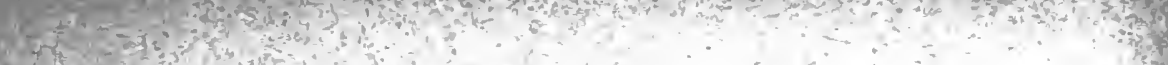

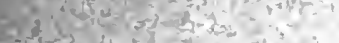

- की

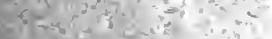

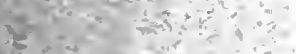

Fi $20-312=0$

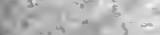

$x_{30}+3=2, n$

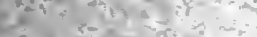

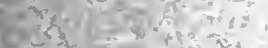

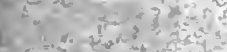

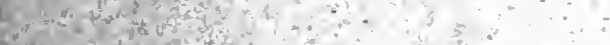

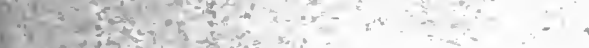

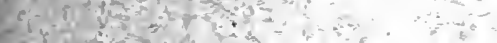

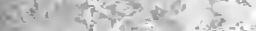

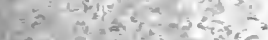

(4), for

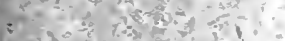

Sto

mats

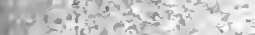

7-che

$6 x+x^{2}=20$

$(x+1)=0$

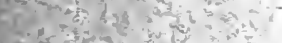

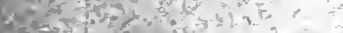

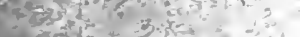

$=\frac{1}{4}=y^{2}+x^{2}$

aton $2=0$

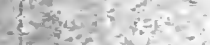

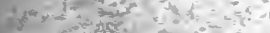

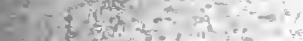

(1. $a^{2}=-1$

atity

Ex a

4 rexts $3=$

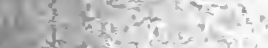

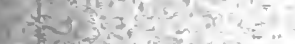

की

$5+50=-13$

tive 30 :

of

(x)

दिय,

(A) of

की $x+b^{\circ}=$

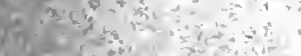

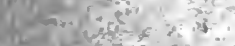

- nathentas

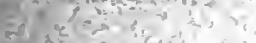

$x^{2}=0, y+x^{-1}$

$y_{1}=2 ; 0$

1s

(1)

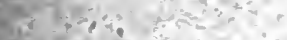

2.

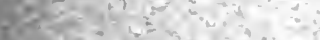

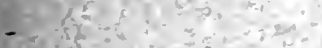

a dy a

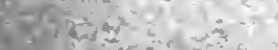

(2)

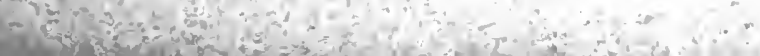

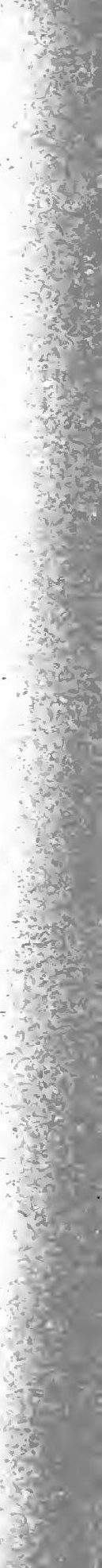


HOGARTH.

From lortait in the National Galtery.

Square Face, Outspread Nose, Short Neck.

See sicleme, Chap, is:

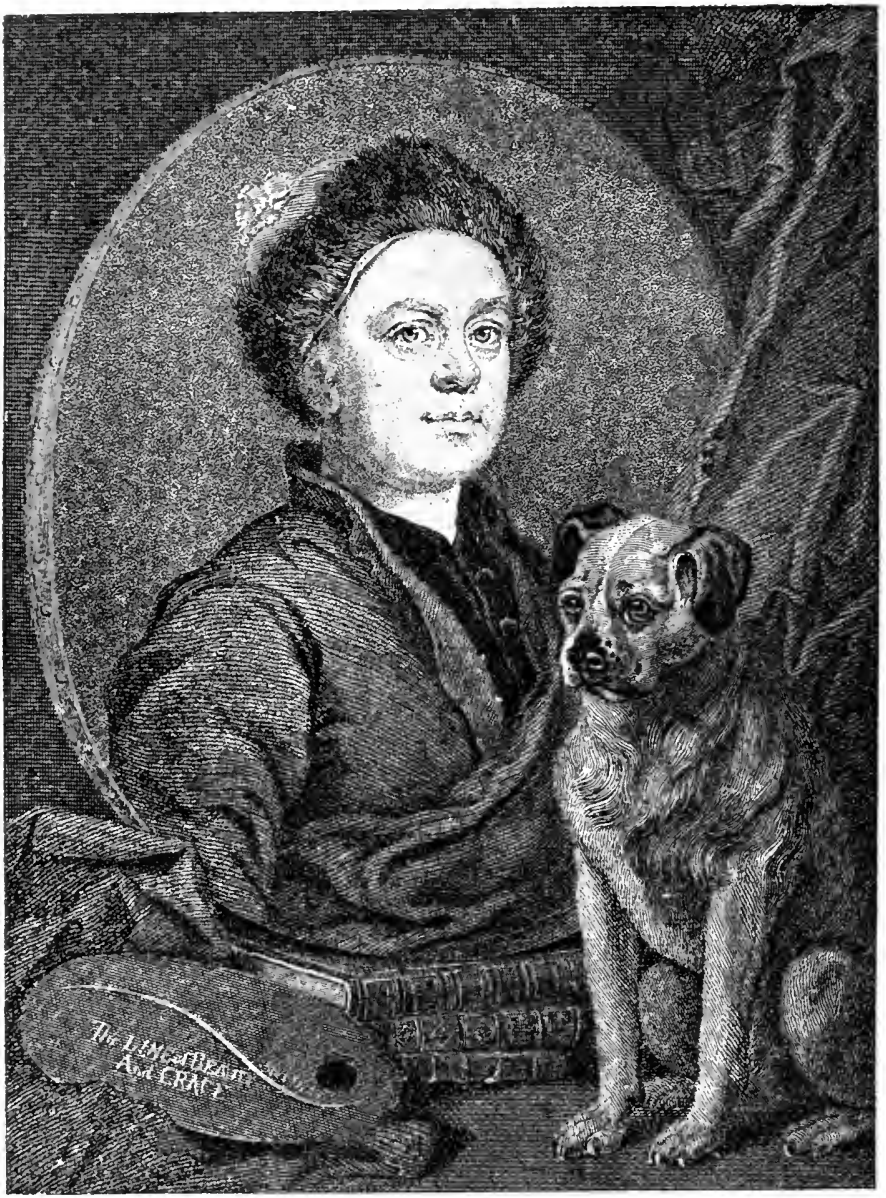

OTHER SANGUine CharaCteristics,

" W'u. Ilogarth out of his appenticeship is, I take it, a sturly, ruddy "complexioned, clear-eyed (blue eyed-Austin Dolson) rather round"shouldered young fellow.

"A healthful, sanguine constitution.

"IIe was an outspoken man, and his pencil and graver were as "unbridted as his tongue,"-G. A. SALA. 
SCHEME OF THE FOUR TEMPERAMENTS. 79

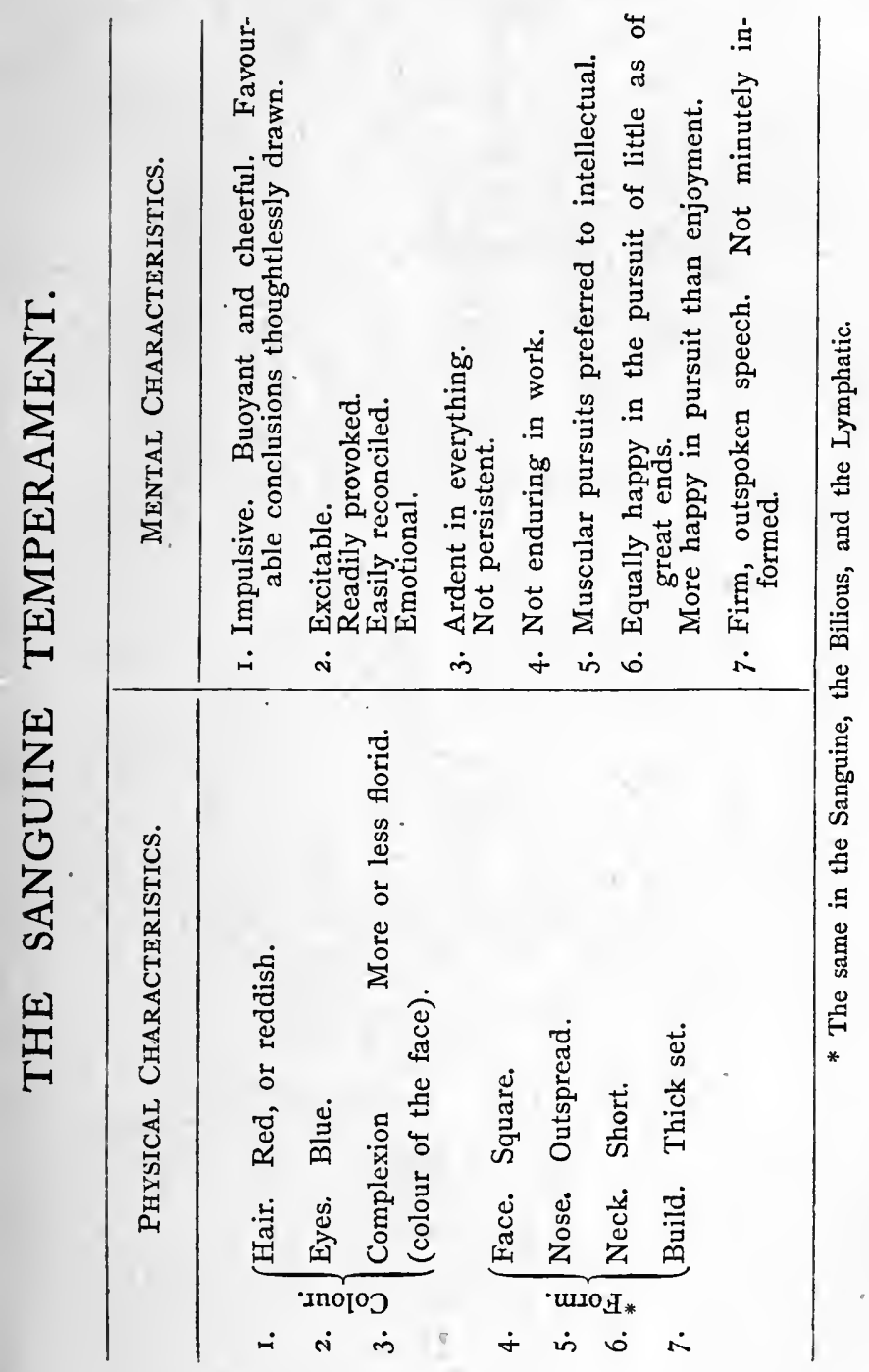


80

OUR TEMPERAMENTS.

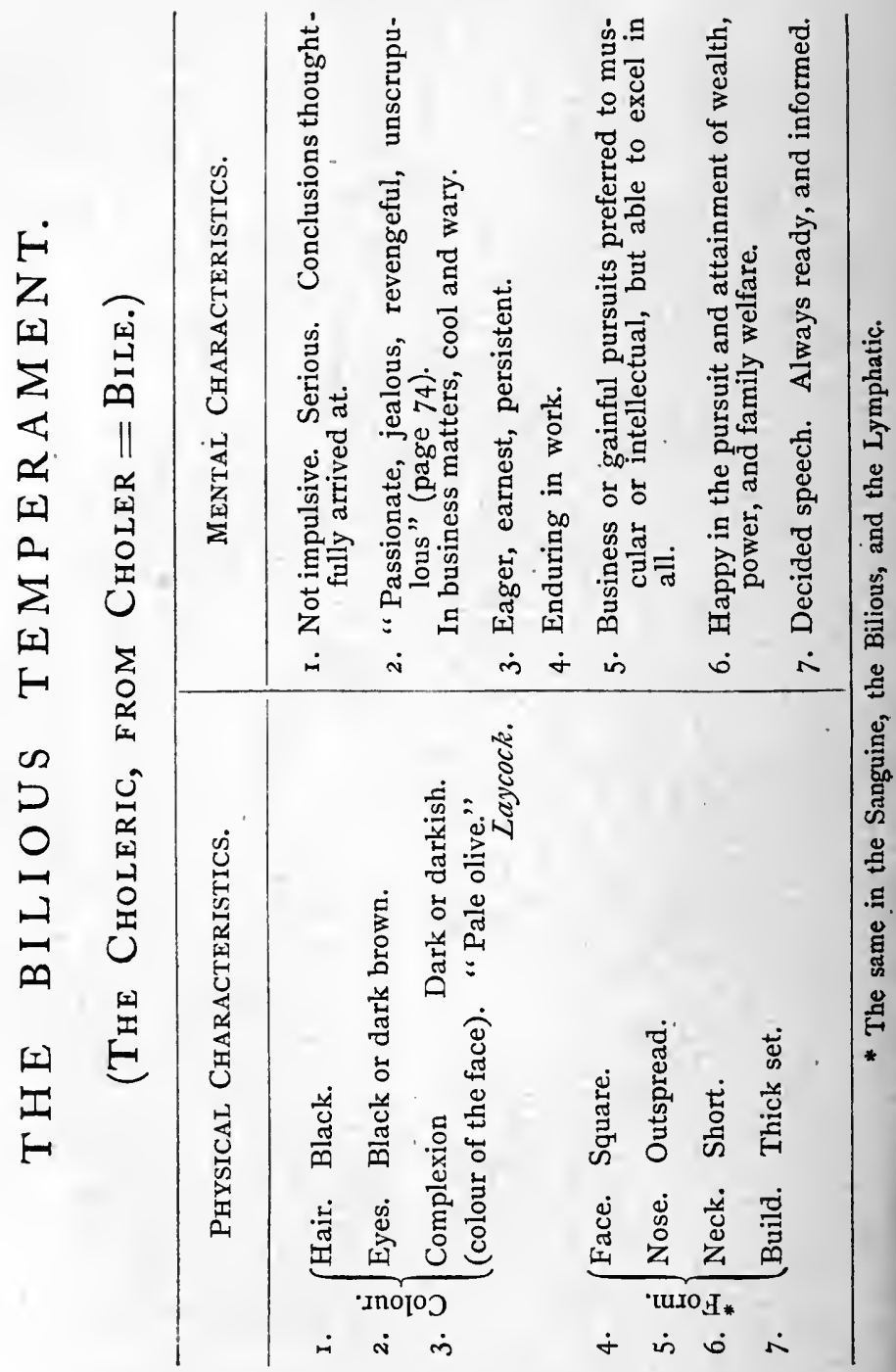


SCHEME OF THE FOUR TEMPERAMENTS. 8 I

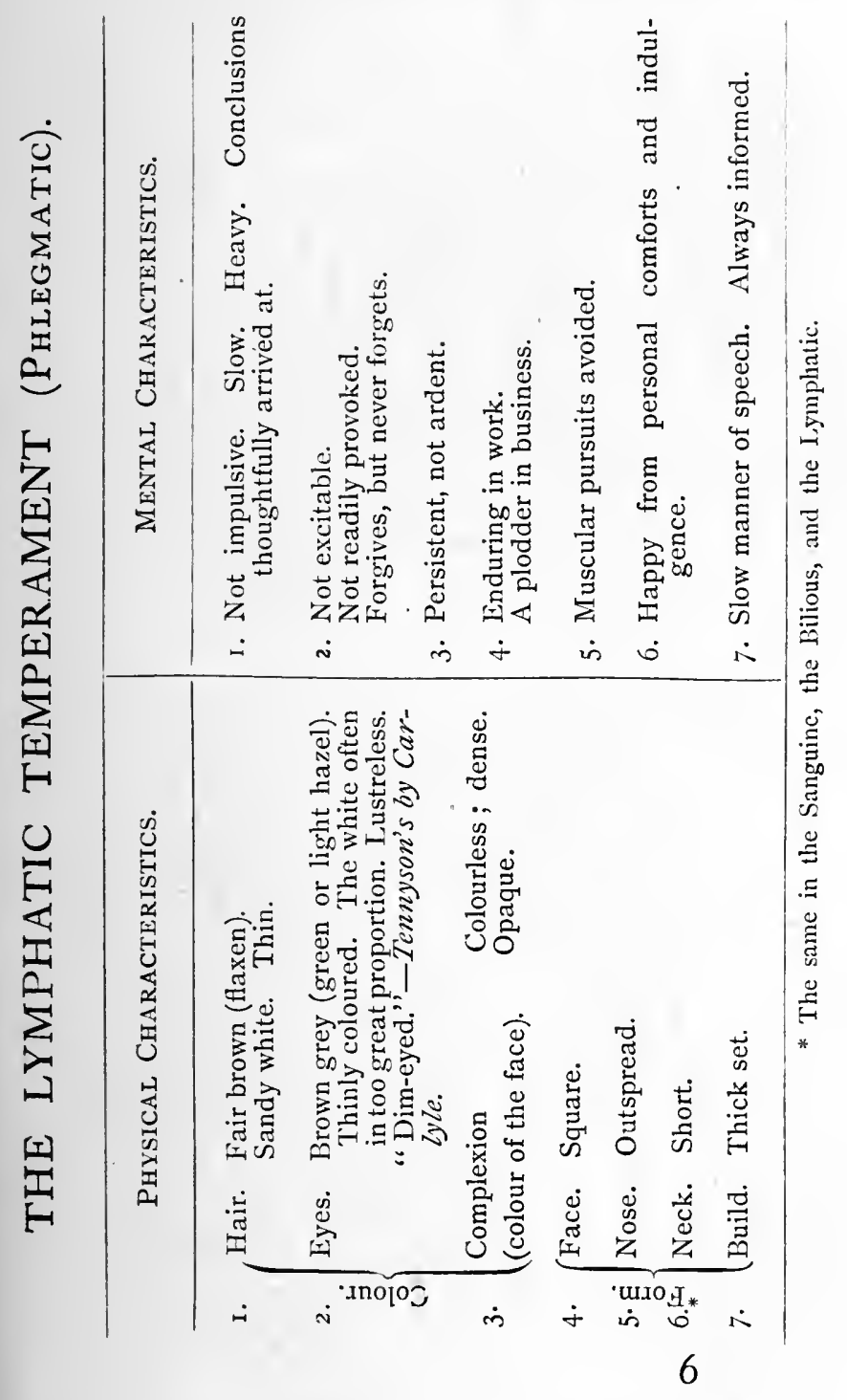




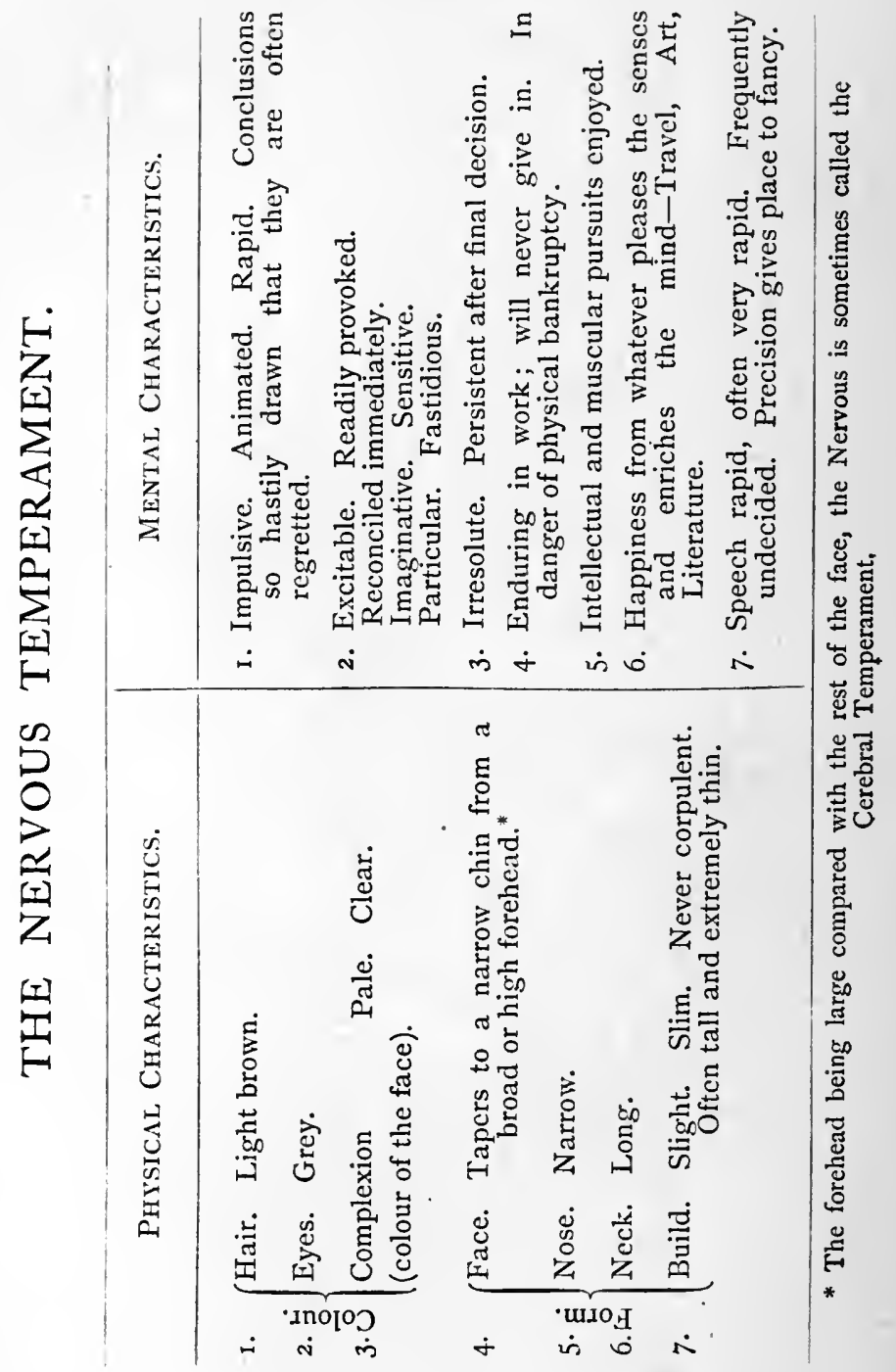


THE FOUR PURE TEMPERAMENTS. 83

I should state that the characteristics which I have assigned to the temperaments are taken from the people of our own country, and therefore may not apply to those of other countries, the physical characteristics and the influences that modify the mental ones being more or less different.

The descriptions of the temperaments in English works were, till fifty years ago, nearly all taken from Hippocrates and his followers, and therefore no doubt refer to the temperaments of the Greeks; and since then they have, with scarcely an exception, been taken from a French source; Richerand's Physiology, ${ }^{*}$ and therefore, no doubt, refer to the temperaments of the French.

* Elements of Physiology, by A. Richerand, Professor of the Faculty of Medicine, of Paris, etc., translated from the French. Revised, with notes and a copious Appendix, by James Copland, M.D., etc. Second Edition. 1829. 
Dr. Wilks says :-

"It is remarkable how few have studied " the different temperaments of Englishmen, " most medical writers having been content " to take the different varieties as described "by Hippocrates as existing among the "Greeks."-Sanitary Record, 1876.

"Not only may the inhabitants of ancient "Greece and Rome be different from those "of England, but in our own country these "may have altered in the lapse of centuries." -Guy's Hospital Reports, I869.

Richerand's descriptions of the temperaments show that he had not realized the fundamental necessity of assigning physical characteristics with sufficient fulness and precision, or of the kind to enable observers to distinguish the different temperaments.

He omits the colour of the eyes from his descriptions, assigns only one physical characteristic to the nervous temperament, 
THE FOUR PURE TEMPERAMENTS. 85

not even one to the melancholic temperament, and loosely describes characteristics as "good," " moderate," "tolerable."

In his description of the Sanguine temperament, for example, eight physical characteristics are given, but only two of them:

"The complexion ruddy."

"Hair fair and inclining to chestnut,"

help observers to recognise the temperament at sight. Of the others:

"The pulse sharp, frequent, regular."

"The countenance animated."

"The shape good."

"The form softened, though distinct."

"The flesh of tolerable consistence and moderate "plumpness."

"The nervous susceptibility lively, and attended "with rapid susceptibility,"

some are not sufficiently precise and others seem for professional observers only. 
$\mathrm{He}$ has not attempted descriptions of the Compound temperaments.

As Richerand's descriptions are the source of most of those that have been given by English authors since their publication in this country, the now prevalent assignment of mental characteristics to temperament, without specifying, often, probably, without thought of, any particular temperament, has no doubt been greatly owing to his descriptions being insufficient guides to the physical characteristics of the four temperaments and the ordinary compound ones.

He has given interesting details of the lives of many eminent men, to show the influence of the temperaments on character, but as the physical characteristics of his examples are not given, there is no proof that their temperaments are correctly named. 
THE FOUR PURE TEMPERAMENTS. 87

Descriptions of the Four Temperaments by Mr. Combe.*

The distinctive feature of the scheme of the physical and mental characteristics of the four pure temperaments, just given, is the assignment of the three form characteristics :-

Form of the face.

Width of the nose.

Length of the neck,

to the several temperaments (see pages I 12 , I 3 ); and to show that these have not generally been included in the characteristics given by well-known authors, I give the descriptions of the four temperaments by the celebrated phrenologist, Mr. George Combe :-

* "Lectures on Phrenology." By George Combe, Esq. New York: 1839 . 
"The temperaments are indicated by external " signs.

I. "The lymphatic is indicated by roundness " of form, softness of muscle, fair hair, pale "skin, sleepy eyes, and inexpressive face. In "this temperament the brain, and all other "parts of the system, are feeble in action, slow " and languid.

2. "The sanguine is indicated by a well-defined "form, moderate plumpness, firm flesh, chestnut " hair, blue eyes, and ruddy, fair complexion. "There is great fondness for exercise, and in"tolerance of muscular quiescence. The brain "partakes of the general activity.

3. "The bilious is indicated by black hair, "dark skin, moderate stoutness, firm flesh, and " harsh features. It gives great power of en"durance, or bottom, as the jockeys call it.

4. "The nervous is indicated by fine thin hair, "small muscles, thin skin, paleness of counte" nance, and brightness of eye. The temperament "gives great vivacity of mental action." 
THE FOUR PURE TEMPERAMENTS. 89

The Temperaments and Phrenology.

Not only in Mr. Combe's Lectures, but in nearly every systematic work on Phrenology, the temperaments have a prominent place; Phrenologists having found it necessary to adopt them to account for the occurrence of prominence of phrenological organs without manifestation of faculty, and manifestation without prominence.

\section{Mr. Combe says :-}

"Let us now inquire into the circumstances "which modify the effect of size. The most "important of these is the constitution of the "brain; and the question naturally arises-do we " possess any means of ascertaining this constitu"tion? We do, in the observation of what are "called the temperaments, which are four in " number-the lymphatic, the sanguine, the " bilious, and the nervous-each of which is 
"accompanied by a different degree of activity " of the brain....

"It is to be remembered, then, that a large "brain may, in fact, be less active than a "smaller one if its temperament be inferior."

In a paper-“ "Old and Modern Phrenology"-read in the Anthropological Section of the British Association Meeting this year ( 1890 ) by an advocate of Phrenology, it is said :-

"All that Phrenology asserts is that with the "assistance of certain known elements, such as " physical temperament, education, and surround"ings, positive conclusions as to character can "be drawn from the configuration of the skull."

Probably better drawn from physical temperament, education, and surroundings (Chaps. iv. and viii. of this essay) without reference to the skull, there being no certainty of correspondence between it and the brain. 
THE FOUR PURE TEMPERAMENTS. 9I

There had been many departures from the ancient division of temperaments into the Sanguine, Bilious, Lymphatic, and Melancholic, but, founded more or less on theory, they have been impracticable and short-lived, and the old division, modified by the pure Nervous having taken the place of the Melancholic or bilious-nervous (page 72), still keeps its ground. Yet another departure however, not likely to grow old, has been made by recent American phrenologists.

The following account of it is from "The Temperaments," etc., "By D. H. Jacques, M.D., with an Introduction by the Editor of The Phrenological Fournal. New York: I 884.

"As has been shown in Chapter I., the human "body is made up of three grand classes or "systems of organs, each of which, as a system, 
" has its special function in the general economy. "We have denominated them-

"I. The Motive or Mechanical System;

" 2. The Vital or Nutritive System;

"3. The Mental or Nervous System.

"On this natural anatomical basis rests the "most simple and satisfactory doctrine of the "Temperaments; of which there are primarily "three, corresponding with the three systems of " organs just named. They are called-

"I. The Motive Temperament;

"2. The Vital Temperament;

"3. The Mental Temperament.

"Each of these Temperaments is determined " by the predominance of the class of organs "from which it takes its name, the constitution " being tempered by the admixture of the other " elements in a less proportion, all being ne" cessarily present in every human being.

"The first is marked by a superior develop"ment of the osseous and muscular systems 
THE FOUR PURE TEMPERAMENTS. 93

"forming the locomotive apparatus; in the "second, the vital organs, the principal seat of "which is the trunk, give the tone to the "organisation; while in the third the brain "and nervous system exert the controlling "power."

It need only be said of this classification that it was quite uncalled-for, and that very few of the characteristics are available in recognising the temperaments at sight. In proof, I give the chief characteristics of the 'Motive Temperament ':-

"Bones proportionally large, and long rather " than broad; strong, hard muscles and promi" nent articulations. The figure is commonly "tall and striking, if not elegant; the chest "moderate in size and fulness; the shoulders " broad and definite; the abdomen proportional ; "the limbs long and only moderately tapering. "The face is oblong; the cheek bones rather " high; the front teeth large, and the features "generally prominent and sharply defined." 


\section{Albert Dürer and the Four TEMPERAMENTS.}

In “Thausing's Life and Works of Dürer," two vols., I882, it is shown that several of Dürer's chief works were inspired by the then well-known doctrine of the temperaments :-

"That men were to be classed according to " the four categories under which the humanistic "wisdom of the age thought all humanity could " be included, viz., according to the four tempera" ments or complexions.

"It is well known what a great part this "theory has played in medicine and in all "other sciences since the days of Hippocrates " and Galen. Dürer naturally adhered to it " unreservedly. He explained the difference in "the outward appearance of men simply by "a reference to the four complexions, and he "considered it indispensable that, before choosing " art as a profession for children, their tem"peraments should be well considered. $\mathrm{He}$ " consequently made the four temperaments the 
THE FOUR PURE TEMPERAMENTS. 95

" object of his closest study, and it is to his "interest in this question that we owe those "engravings which show him at the height "alike of his creative power and his technical "skill.

"These engravings are the 'Melancholia', the " 'St. Jerome in his Chamber,' both of 1514 , " and the 'Knight,' commonly called 'The " ' Knight, Death, and the Devil,' of 15 I 3. Of all "Dürer's engraved works these have ever been, " and still are, the most valued and admired, "though their meaning has always remained "doubtful and obscure."-Vol. II., page $22 \mathrm{I}$.

Of his last great work, "The Four Apostles," or "The Four Temperaments," it is said :-

" $\mathrm{He}$ cherished the ambitious desire of giving " in one last great picture, evidence of the "progress of his taste, and of leaving this picture "to his native city as a monument of his. "patriotic and religious sentiments.

"The result of this wish was the picture 
“called 'The Four Apostles,' or 'The Four " ' Temperaments,' finished in the year 1526 , " and now in the Pinakotheck at Munich.

"The two panels at Munich may be con"sidered as placing before us types of the "four complexions; the one panel representing "the passive, the other the active natures. "Thus St. John represents the melancholic "temperament and St. Peter the phlegmatic; "St. Paul the choleric temperament and St. "Mark the sanguine. . . Upon the right "panel appears the master's own particular "hero, St. Paul, the Apostle of the Gentiles, "one of the grandest figures ever imagined.

"It would be difficult, indeed, to find another "work of art so simple and so grand, and at "the same time so full of thought, so rich in "the deepest spiritual associations, as Dürer's “" Four Apostles,' or 'Four Temperaments.'”Vol. II., pages $26_{3}-274$.

The ten pages referred to are full of interesting matter concerning this picture, and its two panels are represented by admirable wood engravings. 
THE FOUR PURE TEMPERAMENTS. 97

The Four Temperaments on an old Chimney-Piece in the Guildford Town Hall.

Màny artists besides Dürer were no doubt inspired by the latitude which the doctrine of the temperaments gives of drawing on fancy for the influence of physical characteristics on character and action.

A poetical rendering of the tendencies of the four temperaments is thus described in "Guildford: A Hand-Book to the "County Town of Surrey and Environs, "I 862."

\section{"The Town Hall.}

"The Guild or Town Hall stands in the centre " of the High Street, on the north side; it was " erected by public subscription in 1683 .

"Immediately over the entrance and southern "part of the building is a large oak-wainscoted "room, denominated the Council Chamber. This 
"apartment contains a very curious chimney-piece, "which was brought from Stoughton House, in " the parish of Stoke, about I720. It is formed " of STONE, and is carved with figures repre"senting the four human temperaments, viz., "the Sanguine, the Bilious or Choleric, the "Phlegmatic, and the Melancholy; which words "are inscribed (in Latin) in the several com"partments. The Sanguine temperament is "represented by a lover and his mistress (in "another account_- vowing eternal fidelity to " 'his mistress'); the Choleric (bilious) by a "warrior. surrounded by arms and military im"plements; the Phlegmatic, by an idle-looking " individual sitting in a boat, and taking in a "lading of fish; and the Melancholy by a "solitary figure, which presents an extremely "woe-begone aspect. Above are the arms of "Edward the Confessor, the arms of Arch"bishop Abbot, and those of the Corporation."

The following is from a correspondent at Guildford:-

"The material is chalk, and the carving is 
THE FOUR PURE TEMPERAMENTS. 99

" considered by some to be Flemish work. A "few years ago, when the Council Chamber "was cleaned and renovated, the chimney-piece "was painted as you saw it on Saturday last, " much to the disgust of many of the towns"people and antiquarians alike."

I hoped to give a photograph of this interesting old chimney-piece, but for some reason or other, probably insufficient light, the operator I employed failed to get the figures sufficiently distinct.

Sterne, who contrasts the Sanguine and Choleric with the Cold and Phlegmatic (page 28), substitutes temperature for temperament in the following extract:-

"Any one may do a casual act of good nature, "but a continuation of them shows it is a part "of the temperature."

$\mathrm{He}$ had authority for such use of the word, hot and cold being two of the four 
qualities, of which, according to the old physiologists, every temperament consists.

" These principles of living bodies (blood, bile, " black bile, and phlegm) are compounded of the " simple elements or qualities of nature thus: " hot and moist produce blood (sanguine); cold " and moist, phlegm or pituita (lymphatic); hot "and dry, yellow bile; and cold and dry, black " bile."-Dr. Prichard.

As the blood is more watery in the lymphatic than the other temperaments (page 245 ), it is very likely that the thermometer used in medical practice would show some difference in the temperature of the four pure temperaments, in health; at any rate, in the ruddy, and impetuous Sanguine, and the colourless, and slow Lymphatic. 


\section{CHAPTER V.}

OBSERVATIONS ON THE SCHEME OF THE FOUR TEMPERAMENTS.

Colour characteristics.-Colour of the hair and eyes.-Change of colour of the hair and eyes.-Colour of the complexion.-Form characteristics.-Smoking and the temperaments.-The form characteristics of the Nervous temperament.- - The Sanguine, the Bilious, and the Lymphatic physically powerful temperaments.-The Nervous a gentle, imaginative, and intellectual temperament.-Probably an increasing temperament.-The mental characteristics of the scheme.-Colour and form characteristics from Dr. Beddoes' Races of Britain.

THE physical and the associated mental characteristics of the four pure temperaments being the very foundation 
of the doctrine, their mere enumeration and arrangement, as in the scheme, seemed insufficient, and I have therefore in this chapter considered them as fully as appeared necessary.

The Physical Characteristics of The Scheme are :-

I. Colour of the hair.

2. Colour of the eyes.

Colour

3. Colour of the com-
plexion.

4. Form of the face.

5. Form of the nose.

Form

6. Length of the neck. characteristics.

7. Build of the body. 
OBSERVATIONS ON THE SCHEME. IO3

Colour Characteristics.

I. Colour of the Hair.

In the "Life History Album" of the British Medical Association, recorders are asked to state whether the hair is-

I. Fair brown (flaxen).

2. Light brown.

3. Brown.

4. Dark brown.

5. Fair red (golden, sandy).

6. Red.

7. Dark red (chestnut, auburn).

8. Jet black ;

and regarding these as temperament colours, I have assigned four as characteristics of the pure temperaments, and four as compound characteristics (chap. vii.) 
Pure Colour Characteristics.

$$
\text { (The Hair.) }
$$

I. Red. . . Sanguine characteristic.

2. Jet Black . Bilious characteristic.

3. Fair brown . Lymphatic characteristic. (flaxen)

4. Light brown . Nervous characteristic.

Compound Colour Characteristics.

$$
\text { (The Hair.) }
$$

5. Dark red . Sanguine and Bilious characteristic.

6. Fair red . Sanguine and Lymphatic characteristic.

7. Brown.. . Sanguine and Nervous characteristic.

8. Dark brown. Bilious and Lymphatic characteristic. 
OBSERVATIONS ON THE SCHEME. IO5

Mr. Galton in "Inquiries into Human Faculty and its Development," page 6, says :-

"Englishmen are now a fair and reddish "race; - as may be seen from the diagram, " taken from the Report of the Anthropometric "Committee to the British Association in I 880, " and which gives the proportion in which the "various colours of hair are found among our "professional classes.

"I take the professional classes because they "correspond with the class of English worthies " better than any of the others from which " returns have been collected. The diagram, "however, gives a fair representation of other "classes of the community. For instance, I "have analysed the official records of the very "carefully selected crews of H.M.S. Alert " and Discovery, in the Arctic Expedition of " $1875-6$, and find the proportion of various "shades of hair to be the same among them "as is shown in the diagram. Seven-tenths " of the crews had complexions described 
" as light, fair, fresh, ruddy or freckled, " and the same proportion had blue or grey " eyes."

2. Colour of the Eyes.

The colours given in "The Life History Album" are

I. Dark blue.

2. Blue.

3. Grey:

4. Dark grey.

5. Brown grey (green, light hazel).

6. Brown.

7. Dark brown (black);

and of these I have assigned four as characteristics of the four pure temperaments and three as compound characteristics. 
OBSERVATIONS ON THE SCHEME. IO7

Pure Colour Characteristics.

$$
\text { (The Eyes.) }
$$

1. Blue . . Sanguine characteristic.

2. Dark Brown . Bilious characteristic. (black)

3. Brown grey . Lymphatic characteristic. (green, light hazel)

4. Grey . . Nervous characteristic.

Compound Colour Characteristics.

$$
\text { (The Eyes.) }
$$

5. Dark blue . Sanguine and Bilious characteristic.

6. Brown. . Bilious and Lymphatic characteristic.

7. Dark grey . Bilious and Nervous characteristic. 
Change in the Colour of the Hair and Eyes.

Mr. Galton, in the "Record of Family Faculties," says :-

"The hair of children darkens considerably " as they grow older,"

and Dr. Beddoe found that the darkening process had not quite ceased even at thirtyfive (The Races of Britain).

Mr. Froude, however, says of Carlyle's eyes that "they became lighter late in life."

In the "Life History Album" it is said :-

"The eyes of infants at birth are always " dark blue, but it should be observed at what "period after birth their colour begins to " change. This generally occurs within a few "days." 
OBSERVATIONS ON THE SCHEME. IOQ

Professor Laycock says :-

"Fair hair, blue eyes, and florid complexion "usually go together; but I have met with "persons having these characteristics in early "life whose hair turned dark in later years."

As there is no great change, when any, in the colour of the hair and the eyes after the age when the character has become formed, conclusions as to the association of mental characteristics and traits of character with their colour in manhood, are not likely to be wrong.

3. Colour of the Complexion.

Neither in the "Life History Album," nor Mr. Galton's “ Record of Family Faculties," is inquiry made as to the natural complexion, and although it has always been considered a leading character- 
istic of temperament, and is important in medicine, being altered in many diseases, I have not succeeded in finding any complete account of the complexions.

Mr. Hutchinson enumerates several :-

"It is easy to apply with tolerable accuracy "such words as blonde, fair, dark, brunette, "sallow, pale, florid, clear, muddy, and the like, "and these and many others are epithets "applicable to the complexion." - T The Pedigree of Disease, page 6.

The complexion-colours assigned in the scheme to the sanguine, the bilious, and the lymphatic temperaments, have been generally accepted; and the colour'pale and clear'-assigned to the nervous temperament is I think more characteristic than any of those I have met with in descriptions.

I have limited complexion to the 
colour of the face, but it is not always used in the same limited sense; dark and fair complexion often including the colour of the eyes and hair.

Albert Dürer names the four temperaments "The Four Complexions," and Mr. Hutchinson says :-

"In complexion we include the colour of "the hair and eyes, the state of the skin as "regards thickness, thinness, or transparency, and "the various degrees of freedom of distribu"tion of blood in the capillaries of the face.

"Temperament, however, although to a large " extent confessedly indicated by complexion, is "generally held to include something more. "If it did not, I fear we should find it " but a sorry basis upon which to build a "knowledge of the vital peculiarities of the " individual."

"Something more" will be found in its form characteristics. 
Form Characteristics.

$$
\text { 4. Form of the Face. }
$$

Hitherto, the forms of the face have not occupied the important place in descriptions of the temperaments that they do in the scheme, but they are as different and as striking (see portraits, end of volume), and more permanent, than the colours of the hair, eyes, and complexion; and I have therefore endeavoured to classify them for practical guidance, and to assign their associated mental characteristics.

A square face is assigned in the scheme to the sanguine, the bilious, and the lymphatic temperaments, and a tapering one to the nervous temperament.

By a square face is meant one Henry the Eighth like-the sides parallel. 
i

.

?
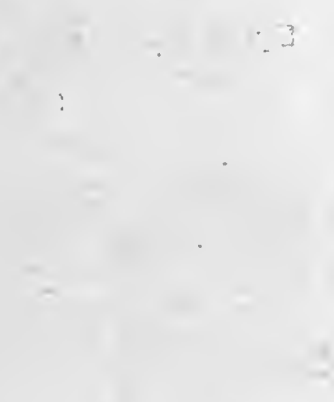

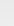




\section{STEELE.}

Square Face, Nose Outspread, Short Neck, Thick-set.

Sce Scheme, Chap. iv.

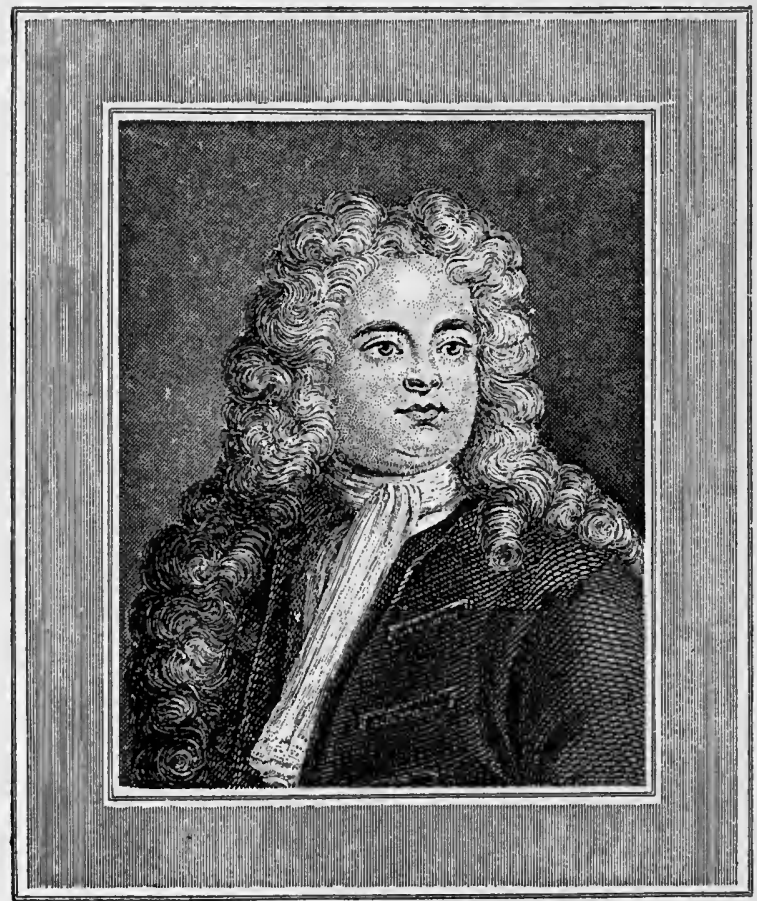

"I ant a little unhappy in the mould of my face, which is not quite so long as it is broad."-The Spectator, No. I7. 
OBSERVATIONS ON THE SCHEME. II 3

"That thick-set, square-faced, black-eyed, "little Irish boy."-Of Steele, by Thackeray, in "English Humorists."

"The jowl is strong and square, and the "chin is heavy. The weak, "vanishing", (tapering and nervous) "form being very "uncommon."-Burton's "Summer in Iceland."

5. Form of the Nose.

An outspread nose is assigned to the sanguine, the bilious, and the lymphatic temperaments, and a narrow one to the nervous.

\section{Length of the Neck.}

In the scheme, a short neck characterises the sanguine, the bilious, and the lymphatic temperaments, and a long neck the nervous temperament.

Length of neck as a temperament cha- 
racteristic is rarely noticed by authors, but observation has convinced me that its place in the scheme as a chief characteristic of the nervous temperament is fully warranted.

Unusual length of neck is not uncommon, but adds nothing, I think, to the ordinary manifestation of the nervous temperament.

\section{The Build of the Body.}

Heavy, or thick-set, in the sanguine, the bilious, and the lymphatic, and slim in the nervous.

Not many of the faces of the square type are so strikingly square as Steele's is seen to have been, and the tapering face may taper only slightly, but it must do so from a high or broad forehead; not, as sometimes seen, from high cheekbones-the forehead small. 
OBSERVATIONS ON THE SCHEME. I I 5

As with the square and tapering faces of the four pure temperaments, so it is with the other characteristics. The nose may be more or less outspread; the neck more or less long; the colour of the hair, eyes, and complexion, only a near approach to that of the standards.

Beard or dress will often be in the way, and prevent even a practised observer from seeing whether the neck is short or long. $\mathrm{He}$ will have found, however, that it is always short when the face and features are wide.

Soon after the publication of the former edition of this Essay, a small work * which I had not seen, containing a table of temperament characteristics, was sent me by a

* "Smoking: When Injurious, When Innocuous, When Beneficial. With Compendium of the Temperaments, shewing how they are influenced by Tobacco. By John C. Murray, M.D., Newcastle-upon-Tyne. London: Simpkin, Marshall, \& Co. 1871." 
friend who thought it would interest me: and it did; for among the characteristics are the form of the neck, and others which I was surprised to see given so fully. There are twelve characteristics:-

"Head; Hair, Beard and Whiskers; Face ; "Eyes; Teeth; Neck; Shoulders; Hands ; "Stature ; Voice ; Mind ; Health."

The table is given to enable a smoker to know his temperament; experience, the author says, having unquestionably proved that the temperaments are not equally susceptible to the effects of the stimulant alcohol and the sedative tobacco.

In Chap. V., and under Health in the table, the influence of smoking on the temperaments is given, but too loosely I think to be practically useful. 
Assignment of Form Characteristics.

In the scheme, the same form characteristics-

$$
\begin{aligned}
& \text { Square face, } \\
& \text { Outspread nose, } \\
& \text { Short neck, } \\
& \text { Heavy build, }
\end{aligned}
$$

are assigned to the sanguine, the bilious, and the lymphatic temperaments; and four others, as opposite as possible-

$$
\begin{aligned}
& \text { Tapering face, } \\
& \text { Narrow nose, } \\
& \text { Long neck, } \\
& \text { Slim build, }
\end{aligned}
$$

to the nervous temperament.

By this important generalization, which may, I hope, gain the concurrence of other observers, observation of the physical characteristics of the four temperaments 
acquires both method and simplicity; the sanguine, the bilious, and the lymphatic temperaments being made to differ only in their three colour characteristics.

There is more however to commend the generalization than its facilitating, by method and simplicity, the recognition of the different temperaments.

It suggests a relation between the form characteristics of the temperaments and use.

It is obvious that the form characteristics-

$$
\begin{aligned}
& \text { Square face, } \\
& \text { Outspread nose, } \\
& \text { Short neck, } \\
& \text { Heavy build, }
\end{aligned}
$$

mark the pure sanguine, bilious, and lymphatic temperaments as physically powerful temperaments, and therefore more 
OBSERVATIONS ON THE SCHEME. II 9

fit for mechanical pursuits than the nervous temperament, the form characteristics of which-
Tapering face,
Narrow nose,
Long neck,
Slim build,

mark it as a gentle temperament.

Lavater has given very similar signs-
" A thick neck,
"A broad face,
"A strong prominent chin,"

as those of physical strength, and
"A long, cylindrical neck,
"Smallness of nose, and
"Small chin,"

as those of weakness.

It will be seen (chap. vi.) that the three physically powerful temperaments - the 
sanguine, the bilious, and the lymphatic -are also matter-of-fact temperaments, and that the nervous is intellectual as well as gentle, and tempers and refines them.

The relation just referred to between form and use suggests that "the survival of the fittest" may apply to the temperaments.

Labour-saving appliances and inventions having rendered physical strength less generally necessary in the daily pursuits of an increasing proportion of the population, it may be that the square face, outspread nose, short neck, and heavy. build of the three physically powerful and matter-of-fact temperaments-the sanguine, the bilious, and the lymphaticare giving place to the tapering face, small features, long neck, and slight frame of the gentle, imaginative, and intellectual temperament-the nervous. 
OBSERVATIONS ON THE SCHEME, $12 \mathrm{I}$

The Mental Characteristics of

THE Scheme.

As the mental characteristics of the temperaments have received even less consideration from authors than the physical ones, I have not been able to give special authority for those in the scheme, except in the few extracts that precede it, but none were admitted without careful consideration. The sixth and seventhsources of happiness, and manner of speech -being unusual, require notice.

\section{Sources of Happiness.}

That the ordinary sources of happiness merited a place as one of the mental characteristics is shown in the belief expressed by Mr. Galton, in the Record of Family Faculties, 1884 .

"Favourite pursuits and interests and artistic "capabilities are facts useful to record, as being "definite expressions of character and tempera"ment." . 


\section{Manner of Speech.}

Manner of speech, one of the mental characteristics of the scheme, has been only cursorily noticed by authors. I am sanguine, however, that observation will warrant my having given it a place as one of the fundamental characteristics of the temperaments; but as modes of speech are greatly subject in early life to the influence of imitation, exceptions may frequently be found to their natural association with the different temperaments, as in the scheme.

The following observations on the physical superiority of blonds, and the colour of the eyes and complexion in different districts, are from Dr. Beddoe's Races of Britain, referred to at page $231:-$

"It may be said that with a few notable 
OBSERVATIONS ON THE SCHEME. I 23

" exceptions, conquering and ruling races have "always, been fair, while the vanquished and "submissive races have been dark."

"There is a general concensus of opinion, "as to the superiority as marksmen in shoot"ing, of men with light blue and light gray " eyes."

"In most parts of Great Britain I have "found that the higher stature goes with the "fair complexion; but there are important " exceptions to the rule in particular districts."

"Strangely enough blonds are said to stand "the climate of West Africa better than " brunets."

"I publish a list, compiled by the Rev. J. H. "Rowlatt, of the complexional colours of 123 " natives of the British Isles who have been " distinguished for physical superiority, which " in many cases has been conjoined with con"spicuous courage and intrepidity. His way of "using terms is evidently not identical with 
"mine, but there can hardly be a doubt that "the list includes many more fair than dark "men, and that red hair particularly abounds "among these athletes and champions."

"If anything can be confidently predicated as " to the two principal complexions, it is that " the fair goes more usually with active courage " and a roving adventurous disposition, the dark "with patient industry and attachuent to local " and family ties,-the one with the sanguine "the other with the melancholic temperament." (With the bilious, instead, in ch. ivi. of this volume, puge 80).

A table is given by Dr. Beddoe which shows,

"That among the working classes of Bristol, "women with red and women with black hair "do not marry in quite so large proportion as " those with hair of other colours. . . . It is "obvious that if in several successive genera"tions the same relations of complexion to " matrimony were to continue, red and black 
OBSERVATIONS ON THE SCHEME. I 25

" hair would probably become somewhat less " prevalent."

There are tables which show the proportion of light to dark eyes in districts, countries, and cities, throughout the three kingdoms and the Continent, and in many cases the causes of the different proportions are stated. Some striking local peculiarities are given in the following extract :-

"Blue is comparatively uncommon in South "Wales, and common in the south and east of "England; hazel, as distinguished from brown, " is rather common in England and South Wales, " and uncommon among the Gaels. But special "varieties of eye-colour, too minutely dis"criminated to be brought to the test of "numbers, do occur in special districts and "attract the attention of travellers. Thus, a "kind of muddy brownish-gray is common in "Wiltshire (the Wiltshire eye) and the West "Riding; clear china-blue in some of the "Saxon counties; violet in Munster; both gray. " and blue, with a surrounding dark ring, in 
"most parts of Ireland; * a large blue iris, " reticulated with gray or yellowish fibres, in "North Devon. Greenish-gray is thought to "prevail where Scandinavian blood is potent."

"Ancient Irish poetry indicates that blue "eyes and yellow hair were most characteristic " of the higher ranks, or ruling caste. Some "heroes, however, are described as having "blue eyes and black hair, with a clear skin " and ruddy cheeks, a combination very rare " out of Ireland."

"The following is a numerical expression of "the complexions or colour of skin prevalent in " several parts of Britain :-

Fair. Intermediate. Dark.

" E. and N. of England . (100) $74 \quad \begin{array}{lllll}74 & \ldots & \text { I4 } & \ldots & \text { I } 2\end{array}$

"Wiltshire • • • • " " $5 \begin{array}{llllll}54 & \ldots & 30 & \ldots & 16\end{array}$

$\begin{array}{llllllll} & \text { "Bristol . . . " } & 54 & \ldots & 24 & \ldots & 22\end{array}$

$\begin{array}{lllllllll} & \text { "Highlands } & . & \text { " } & 48 & \ldots & 30 & \ldots & 22\end{array}$

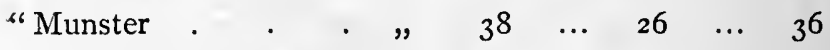

$\begin{array}{lllllllll} & \text { "Devon .. . . . " } & 36 & \ldots & 22 & \ldots & 4^{2}\end{array}$

$\begin{array}{lllllllll}\text { “South Wales } & \text {. } & \text {. } & & 24 & \ldots & 28 & \ldots & 48 ”\end{array}$

* "The 'Irish eye,' blue with dark lashes."-Sir Richard Burton's Ultima Thule, vol. i., p. I32. 
"The colour of the skin seems to be corre"lated with that of the hair more nearly than "with that of the eyes."

"The natives of Geneva are in process of "being swamped by dark-complexioned immi"grants from France and Savoy; but their com"parative fairness is still noticeable."

"There is a prevalent idea that the English " are gradually changing from a fair to a dark "race, while the sanguine is giving place to the " nervous or nervo-bilious temperament. I con"fess to holding this opinion myself, but rather " as a matter of speculation and conjecture than " as a well-grounded belief."

Dr. Beddoe tried to test this idea "by the inspection of portraits, mostly of distinguished men," but says: "On the whole, the results of this part of the investigation are unsatisfactory."

They could not well have been otherwise when he found that portraits of the 
eighteenth century are not available "owing to the practice then in vogue of wearing wigs and powder," and that Holbein. "in the case of women gives hardly any but reddish and golden tints."

From portraits by Holbein and others of the same period, Mr. Galton "traced "what appear to be indisputable signs of one "predominant type of face supplanting another" (see page 203 of this volume). 


\section{CHAPTER VI.}

THE NERVOUS TEMPERAMENT.

Its physical characteristics. - Is the key-stone of the temperaments.-Tempers or refines the three other pure temperaments.-Newly recognized as one of the four temperaments.-Confounded with nervousness.Carlyle and Charles Lamb.-Its distinctive natural action. - Characterized by J. S. Mill.-Exemplified in Nelson, Wm. Hunter, and Dickens. - Is careless of supply of energy.- Physical bankruptcy, or nervousness, the result.-Probably an increasing temperament.

A LTHOUGH the four temperaments are probably sufficiently characterized in the scheme that I have arranged (chap. iv.), 
I have thought it necessary to give an extended description of the nervous temperament, that the common error may be avoided of confounding it with nervousness, which is altogether a departure from the natural or healthy manifestations of the temperament.

The nervous has now taken its place as one of the four pure temperaments, but not without opposition from many who, familiar with the Hippocratic four, would have retained the melancholic.

Dr. Prichard, in the Cyclopadia of Practical Medicine (1835), says :-

"It is not distinguished, as the other tempera" ments are, by marked diversity of external " character, and, therefore, cannot be accepted " as one."

I have no doubt, however, that the face tapering to the chin from a high or broad 
forehead, a narrow nose, a long neck, and a slight frame-the physical characteristics assigned to it in the scheme of the four pure or standard temperaments-mark it well, and establish its claim.

I regard it as the key-stone of the temperaments, binding them together, and rendering their study systematic and practical.

The other pure temperaments are rough and matter-of-fact; the nervous tempers, softens, and refines them.

In the sanguine, the bilious, and the lymphatic, the face and features-John Bull like-are broad, and the neck short; and variety would be wanting in nature's chief work were it not that the nervous temperament, like the wand of the magician, works wondrous change.

Replace the outspread nose of any of the 
other pure temperaments by the narrow one of the nervous, and the face, although still broad, becomes refined.

Replace also the short by a long neck,another characteristic of the nervous temperament,-and the refinement is strikingly. increased.

What literature would be without the grace, the tenderness, the sublimity of poetry, the other temperaments would be without the nervous.

Like the other temperaments the Nervous was discriminated by physicians; but no longer ago than the beginning of the present century, when nervousness first claimed their attention.

A recent writer observes :-

"Our fathers in medicine of the last century, "if they could be brought from their graves, 
THE NERVOUS TEMPERAMENT. I 33

"would have to be told what we mean by "nervousness." (See appendix to chap. xii.)

Unfortunately, the signs of the disease nervousness have come to be popularly accepted as the natural action of the nervous temperament; hence the belief that it is a wretched temperament, which makes life almost intolerable to its possessor and all who live with him; whereas, on the contrary, it is a refined temperament that eagerly pursues and keenly enjoys pure pleasures of every kind; that delights and charms by a vivid imagination; with wit that does not injure, and sympathy that always soothes.

It is however a delicate temperament, feeling pain more acutely than the other. temperaments, and liable, on the slightest constitutional disturbance, to be invaded by its enemy nervousness, always waiting an opportunity. 
Whenever any one begins to make himself and those around him miserable about trifles that others would overlook, or be indifferent to, nervousness has supervened.

Of Carlyle it is said in the review of Mrs. Carlyle's letters in The Times (March 3ist, I883):-

" $\mathrm{He}$ was morbidly nervous, irritable, and "thin-skinned. The slightest noise prevented " his sleeping; the slightest disturbance pre"vented his working. $\mathrm{He}$ could tolerate no "derangement of his habits; and the trifles "that seriously annoyed him threw him off " his balance for days."

Charles Lamb says of himself:-

"Business which I once used to enter upon " with some degree of alacrity, now wearies, "affrights, and perplexes me. I fancy all sorts "of discouragements, and am ready to give up " an occupation which gives me bread, from "a harassing conceit of incapacity. 
THE NERVOUS TEMPERAMENT. I 35

"The slightest commission given me by a "friend, or any small duty which I have to "perform for myself, as giving orders to a "tradesman, haunts me as a labour impossible " to get through."

The distinctive natural action of the nervous temperament is greater sensibility and more rapid movement.

The organs of sense, and the nerves throughout the body, receive messages and carry them more quickly to their centres, which respond with equal celerity.

"The rate at which a nervous impulse travels " along a nerve to a muscle can be accurately " measured, and this has been found to vary " much in different animals. In a frog such "an impulse travels at the rate of twenty-eight " mètres per second, and in a man at the rate " of thirty-three mètres per second, and in " individual men the rate of nerve conduction "varies slightly. 
"M. Hirsh has shown that there are differ" ences in the rapidity with which impressions " are transmitted through the nerves of sight, " hearing, and touch.

"Common observation affords abundant " illustration of different rates of rapidity of "mental processes in different persons, and thus "guides to a rough estimate of the quality " of brain-matter; one man is spoken of as " quick-witted, another as slow of thought; " one is said to be vivacious, another lethargic; " and for scientific purposes, differences of this " kind are summed up in temperaments, in "which rapidity of mental action, and quality " of brain-substance, are indicated by certain " outward characteristics.

"From the nervous to the lymphatic tem"perament, through the sanguine and bilious " and intermediate temperaments, compounded " of these, there is a gradual diminution in "the rate of nerve action, and in the fineness " of quality" of nerve-substance."-Sir J. Crichton Browne, in "The Book of Health," pp. 285-6. 
THE NERVOUS TEMPERAMENT. I 37

Rapidity of mental action is one of the most striking characteristics of the nervous temperament.

You are speaking to one of this temperament; he sees the conclusion of your sentence before it is finished; probably helps you to finish it; and has begun his reply while you are still speaking. $\mathrm{He}$ asks you to do some little thing for him, but before you can do it, he does it himself.

Rapidity of muscular movement is . equally characteristic.

Professor Laycock says, as already quoted :-

"Whilst the flow of ideas is rapid and "the expression of them prompt, the muscular " movements are remarkable for their energy " and rapidity, so that the limbs and body "move quickly and impulsively." 
I 38 OUR TEMPERAMENTS.

J. S. Mill in one of his works says :-

"It is the character of the nervous tempera"ment to be capable of sustained excitement, "holding out through long-continued effort. "It is what is meant by spirit. It is what " makes the high-bred race-horse run without "slackening speed till he drops down dead. "People of this temperament are the material " of great orators, great preachers, impressive " diffusers of moral influences."

That is quite in harmony with what Nelson writes of himself in letters quoted by Southey :-

"While I serve I will do it actively and " to the best of my abilities. I require nursing "like a child: my mind carries me beyond " my strength, and will do me up; but it is " my nature."

Professor Laycock says of the celebrated William, brother of the still more celebrated John Hunter:- 
"William Hunter was a well-marked example "of the nervous temperament. His small dapper "person, small limbs, small mobile features, "thin ale nasi (sides of the nose) and lips, "are very characteristic, as well as his active " habits and power of continuous labour."

The busts of Dickens show the tapering face of the Nervous Temperament; and Mr. Forster gives numerous proofs of "his untiring energy in work and play."

"Bar-leaping, bowling, and quoits were "among the games carried on with the "greatest ardour, and in sustained energy, "what is called keeping it up, Dickens "certainly distanced every competitor."

The following probably shows a departure from the healthy action of the temperament :-

"Little Mary and her sister Kate had taken " much pains to teach their father the polka 
"that he might dance it with them at their " brother's birthday festivities (held this year " on the 7 th, as the 6th was a Sunday), and " in the middle of the previous night, as he "lay in bed, the fear had fallen on him "suddenly that the step was forgotten, and "there and then, in the dark, cold wintry " night, he got out of bed to practise it.

"Anything more characteristic could cer"tainly not be told, unless I could have "shown him dancing it afterwards, and far " excelling the youngest performer in untiring "vigour and vivacity."

Unfortunately, it is characteristic of the nervous temperament to ignore the necessity for fresh supplies of energy to meet the expenditure, and nervousnessthe inevitable "physical bankruptcy" of the scheme-ensues; often, alas! while life should be in its prime.

Some of the safeguards to the 
THE NERVOUS TEMPERAMENT. I 4 I

maintenance of a healthy nervous system are given in Chapter XII., and should be systematically followed by all of the nervous temperament; probably an increasing number (see page $\mathrm{I} 2 \mathrm{O}$ ), and likely to continue to increase; for it may I think be accepted that

"The invariable tendency of education is "towards the nervous temperament."-Sir J. Crichton Browne, in "The Book of Health," p. 285 .

\section{Mr. Galton says :-}

"One fine Sunday afternoon I sat with a "friend by the walk in Kensington Gardens "that leads to the bridge, and which on such " occasions is thronged by promenaders. It "was agreed between us that whichever caught "sight of a typical John Bull should call the " attention of the other. We sat and watched "keenly for many minutes, but neither of us "found occasion to utter a word."

Probably every third or fourth person 
who passed Mr. Galton and his friend was a foreigner; and the English passers-by being chiefly of the educated class, typical John Bulls could scarcely be expected. They still exist. At the Agricultural Hall, on a Smithfield Show-day, Mr. Galton and his. friend would not have sat long silent; nor would they in Kensington Gardens had they been looking out for the tapering face and slim build of the nervous temperament. 


\section{CHAPTER VII.}

THE COMPOUND TEMPERAMENTS.

The Compound temperaments very numerous.Their study somewhat complex.-Physical and mental variety from the mixture of physical characteristics.-Descriptions of the Compound temperaments not found.-The usual mode of naming the Compound temperaments.-Examples.-Proposed addition to their names that they may indicate personal appearance.-The analysis of Compound temperaments.-Compound colour and form characteristics.-The Oval Face and Medium Build.-The Balanced temperament.-Examples.-The Semi-balanced temperament.-Examples.-The best temperament.-Forms of Compound temperaments to aid the student in analyzing faces.

THE student of temperament who has become familiar with the physical 
characteristics of the four pure or standard temperaments, as in the scheme (chap. iv.), is prepared to enter on the somewhat complex study of the mixed or compound temperaments, which are very numerous; the physical characteristics of the pure temperaments being interwoven with one another in the most varied manner.

Any of the four temperaments free from invasion by at least one of the physical characteristics of another is not often seen; and it will now be realized by the student that the precise assignment of physical characteristics to the pure temperaments which are seldom seen, renders possible the analysis of the compound temperaments which are so often seen.

By the mixture of the physical characteristics of different temperaments seen in 
THE COMPOUND TEMPERAMENTS. I 45

nearly every face, nature bestows on man the charm of variety that beautifies all her lesser works, and the study of the temperaments is pursued with increasing interest when it is seen that even one colour or form characteristic of a different temperament from the prevailing one, brings with it something of the mental action of its own temperament. That, for instance, if black eyes replace blue ones, they bring more or less of the caution, the persistence, the ambition, of the bilious temperament; and similarly, if blue eyes replace black ones, they bring more or less of the impulsiveness, the love of change, the unwarranted hopefulness of the sanguine.

By reference to the physical characteristics of the scheme, and the few compound characteristics given farther on in this chapter, the student will soon be able to recognize those compound temperaments 
which are most frequently seen, and sooner or later, as he is more or less gifted with observation and memory, to analyze any temperament, however uncommon or however compounded.

But he must pursue the study as Professor Laycock advised his medical classes to pursue it:-

"By habitual, constant, and careful obser"vation, which is easy, because you can "always practise the art wherever there are "faces and forms to be seen. If you look "about you, whether in the clinical wards or " in the streets, you will observe the like "variety of temperaments."

Although the compound temperaments are those most frequently seen, I have failed to find any attempt to describe them with precision, $*$ and have therefore

* Mr. Starkweather, in "The Law of Sex," 1883 , p. 118 , says : "Dr. Powell, in his 'Human Temperaments,' 
had but little guidance in the endeavour to give method to this important part of the subject.

A classification intended to include every form of face and the various colours of the hair, eyes, and complexion must be somewhat complex, but I am sanguine that the one I present will, after a time, be found by others as it is by myself, easily remembered and as inclusive as need be.

If not, it will at least serve as a basis on which other observers may construct one that may be found simpler and more generally applicable.

"points out with considerable precision the colour of "the hair and eyes, and the complexion, by which "the temperaments in all their numerous combinations "may be known. He makes black or dark hair, eyes, "and skin spring from the bilious element, and the "light from the sanguine."

Mr. Hecker, in the volume the title of which is given at page 286, refers to Appleton's "New American Cyclopædia" : article, "Temperaments," for a good account of Dr. Powell's work. 
The compound temperaments should take the names of the temperaments that compose them, the temperament being named first which contributes the greater number of characteristics.

The following are examples:-

Sanguine and Bilious Temperament.

Hair . . . Red or reddish.

Complexion . More or less florid.

Face . . Square.

Nose . . Outspread.

Neck . . Short.

Build . . Heavy (thickset).

(Six Sanguine characteristics, see scheme.)

Eyes . . Black or dark brown.

(One Bilious characteristic, see scheme.)

An example this of the invasion of a pure temperament by one characteristic of another. 


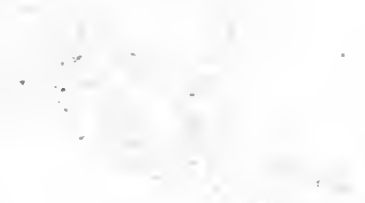

;

? 


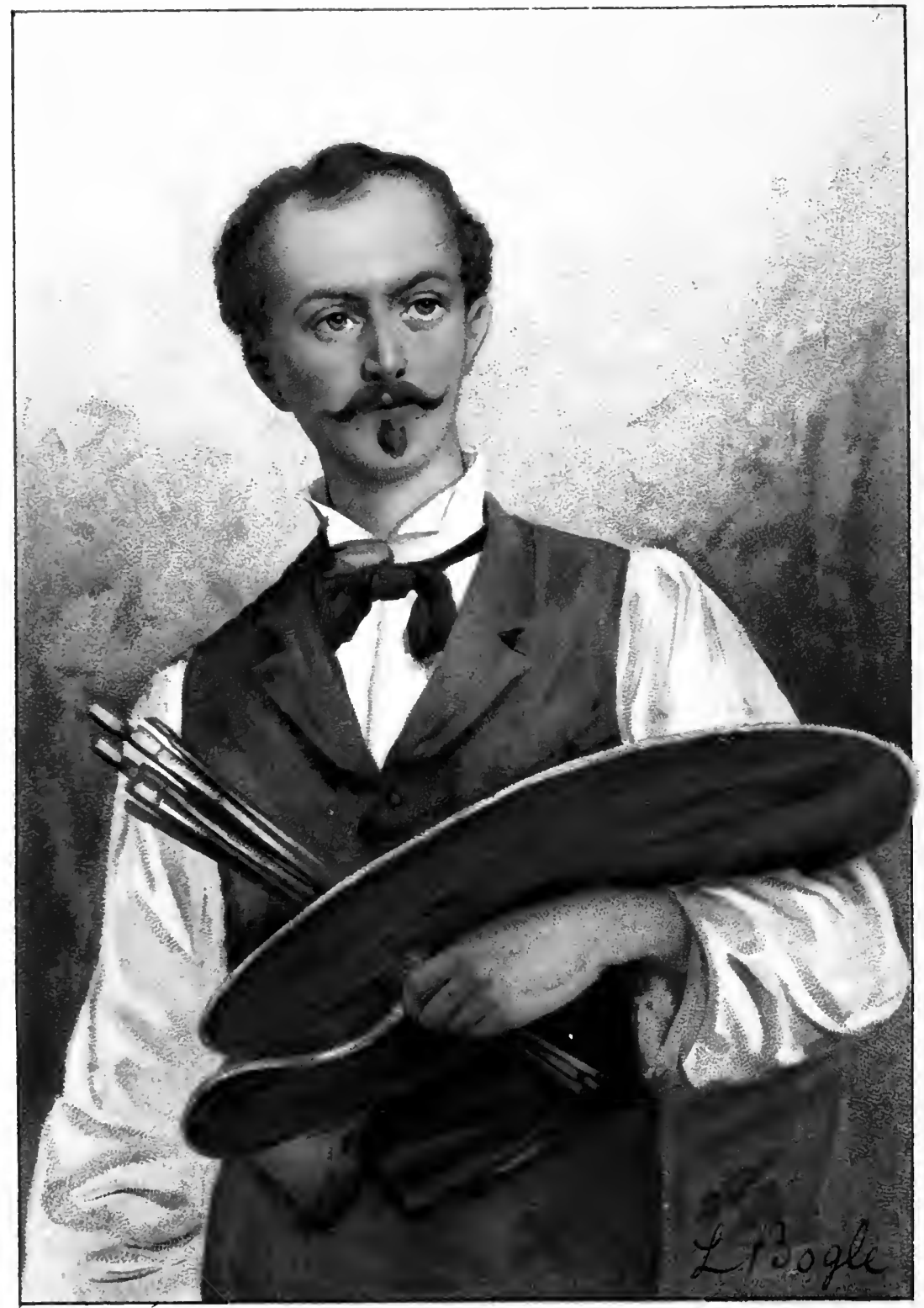

NERVOUS AND SANGUINE TEMPERAMENT.

See page 149 
THE COMPOUND TEMPERAMENTS. 149

Nervous and Sanguine

Temperament:

Face . . Tapering from a high or broad forehead to a narrow chin.

Nose . . Narrow.

Neck . . . Long.

Build . . Slim.

(Four Nervous characteristics, see scheme.)

Hair . . . Red or reddish.

Eyes . . Blue.

Complexion . More or less florid.

(Three Sanguine characteristics, see scheme.)

A happy tempering this of the irresolute, imaginative, and regretting Nervous, by the impulsive, matter-of-fact, and selfsatisfied Sanguine temperament. 
Sanguine, Bilious, and Nervous

Temperament.

Hair . . . Red or reddish.

Complexion . More or less florid.

Face . . Square.

Neck . . Short.

Build . . . Heavy (thickset).

(Five Sanguine characteristics, see scheme.)

Eyes . . Black.

(One Bilious characteristic.)

Nose . . Narrow.

(One Nervous characteristic.) 
The names of the four pure temperaments-Sanguine, Bilious, Lymphatic, and Nervous--represent physical characteristics which make a life-like portrait. To be told that any one is of a sanguine temperament should bring before the mind's eye a man with red or reddish hair, blue eyes, a more or less florid complexion, and the other physical characteristics of his temperament. And so of the other pure temperaments.

The names of compound temperaments do not indicate personal appearance with the same certainty. Sanguine and Bilious temperament, for example, does not inform us which of the bilious characteristics has replaced a sanguine one; whether black hair, black eyes, or a darkish complexion. I therefore suggest that in conversation and literature the characteristics which replace those of the chief temperament be always named; as in the following forms of the three preceding examples:- 
Sanguine and Bilious Temperament.

SAnguine; with Bilious eyes.* One sanguine characteristic replaced by a biliousblack or dark-brown eyes.

Nervous and Sanguine Temperament.

Nervous; with Sanguine hair, eyes, and complexion. Three nervous characteristics replaced by three sanguine- reddish hair, blue eyes, a florid complexion.

Sanguine, Bilious, and Nervous Temperament.

Sanguine; with Bilious eyes and Nervous nose. Two sanguine characteristics replaced by one bilious and one nervous-black or dark-brown eyes; a narrow nose.

Several compound temperaments are named in Ultima Thule; or, $A$ Summer in Iceland, by Sir Richard Burton, who shows unusual familiarity with the

* This mode of description is recommended at page 377 . 
THE COMPOUND TEMPERAMENTS. I 53

temperaments; but the names would have made readers still better acquainted with the Icelander's appearance had they been followed by the replacing characteristics of the lymphatic and sanguineous, and the bilious temperaments :-

"The Icelander's temperament is Nervoso "lymphatic, and, at best, Nervoso-sanguineous. "The Nervoso-bilious, so common in the South "of Europe, is found but rarely; and the "author never saw an instance of the pure "Nervous often met with in the United States "and the Brazil."

Mr. Starkweather, in The Law of Sex, says :-

"The musical temperament is a combination "of the lymphatic and nervous" (page I69);

and in reference to one of the illustrations-

"The woman is of the nervous-lymphatic " order; and the perfection of the musical "temperament" (page 140, with illustration). 
In one of three essays on Physiognomy in The Cornhill Magazine, vol. iv., the same compound temperament-nervous and lymphatic - is assigned to musicians:-

"We put together the heads of the chief " musicians, and no one can help observing in all " the greatest-Bach, Handel, Mozart, Beethoven " - the presence of a nervous in remarkable " combination with a lymphatic temperament. We "look at the three peoples who are the most "famous for musical skill-Italians, Germans, " and Jews-it is to note in them generally a " temperament half nervous, half lymphatic, in " which the nervous volatility is rendered suffi"ciently precise by abundance of phlegm."

Naming the replacing lymphatic characteristics, as I have suggested, was necessary to make known to readers which of the nervous and lymphatic characteristics $\mathrm{Mr}$. Starkweather and the Cornhill writer call the musical temperament; for in one nervous and lymphatic compound, there may be the 
THE COMPOUND TEMPERAMENTS. I 55

lymphatic eye; in another the lymphatic complexion; in a third the lymphatic hair; two of these characteristics in a fourth; and in a fifth, all three.

As lymphatic characteristics are chiefly those of colour, Mr. Starkweather's colourless illustration of the nervous-lymphatic woman does not help us to her lymphatic characteristics, nor do the heads of Bach, Handel, Mozart, and Beethoven, seen near one another on the Albert Memorial.

Germans being so different in appearance from Italians and most Jews, the statement of the Cornhill writer that all three are generally nervous and lymphatic, required to be supported by the names of the nervous and lymphatic characteristics which he saw in the three peoples.

It would be interesting were any one who has become familiar with the tem- 
peraments and sees much of our musical celebrities, to note the physical characteristics of as many of them as possible and make known the result. It would surprise me were it to come out that lymphatic characteristics are more general in them than are sanguine and bilious.

The analysis of the compound temperaments would be comparatively easy were it limited to the physical characteristics of the four pure temperaments; but it is not; for other colours of the hair and eyes than those in the scheme; one other form of face-the oval-and a medium build of body, between thickset and slim, are often seen, and must be included in a classification which aims at enabling the observer to recognize and name the temperament of whoever he may meet.

I assume that the other colours of the hair and eyes than those in the scheme, 
THE COMPOUND TEMPERAMENTS. I57

and the other form of the face-the oval-are the outcome of the blending; the former, of two of the colour characteristics of the four pure temperaments, and the latter, of the two forms of the face-the . square and the tapering-and I have named them, and also the build of the body between thickset and slim, Compound Characteristics.

I have no authority for introducing Compound Characteristics into the study of the temperaments, but the material was at hand, and they seemed to me the missing link in analyzing the compound temperaments which have baffled observers who endeavoured to recognize and name every temperament.

The Compound Characteristics are,

Four colours of the hair.

Three colours of the eyes.

One form of the face (oval).

One form of the figure (medium build). 
Compound Colour Characteristics. See chaps v.

$$
\text { (The Hair.) }
$$

I. Dark red . . Sanguine and Bilious (red and black) characteristic.

2. Fair red . . Sanguine and Lym(red and sandy) phatic characteristic.

3. Brown . . . Sanguine, and nervous (red and grey) characteristic.

4. Dark brown . Bilious and Lymphatic (black and sandy) characteristic.

\section{(The Eyes.)}

I. Dark blue . Sanguine and Bilious (blue and black) characteristic.

2. Brown . . Bilious and Lymphatic (black and brown grey) characteristic.

3. Dark Grey . Bilious and Nervous (black and grey) characteristic. 
THE COMPOUND TEMPERAMENTS. I 59

Compound Form Characteristics.

\section{The Oval Face \\ and \\ Medium Build}

characterize two compound temperaments which are very frequently seen. One has received the name of the balanced temperament, and I have ventured to name the other the semi-balanced.

When I have described these, I hope to have provided the student with all the information necessary to a practical knowledge of the temperaments.

Guided by the details and examples in this chapter, he will not find it difficult, I think, if practically familiar with the four pure temperaments, to become equally familiar with the compound ones, and so be able to recognize and name any temperament. 
The Balanced Temperament.

The compound temperament, in which the four pure temperaments are so equally represented by their physical characteristics that no one temperament is more prominent than another, was called by the ancients the balanced temporament; probably the most appropriate name that has been given to it.

It is very frequently seen, perhaps more frequently than any other of the temperaments, but it has hitherto remained a mere idea, for, although both ancients and moderns have inferred and named it, it has been characterized by neither.

The face is always oval, and the build medium-between thickset and slim-and the compound colour characteristics (page I 58) are frequent components of the ternperament.

The following are examples:- 
THE COMPOUND TEMPERAMENTS. I6 I

\section{A Balanced Temperament.}

Face . Oval . The blended square and tapering faces of the four temperaments.

Build . Medium. The blended stout and slim builds of the four temperaments.

Nose - Outspread . Sanguine, Bilious, and Lymphatic.

Neck . Long . . Nervous.

Hair . Black . Bilious.

Eyes . Blue. . Sanguine.

Complexion. . .

Colourless . Lymphatic. 
A Balanced Temperament.

Face . Oval . The blended square and tapering faces of the four temperaments.

Build . Medium . The blended stout and slim builds of the four temperaments.

Nose . . Outspread - Sanguine, Bilious, and Lymphatic.

Neck . . Long . . Nervous.

Hair . Fair-brown . Lymphatic. (Flaxen)

Eyes . Blue . . Sanguine.

Complexion. . .

Dark . . Bilious. 
The COMPOUND TEMPERAMENTS. I6 3

A Balanced Temperament.

Face . Oval . . The blended square and tapering faies of the four temperaments.

Build . Medium . The blended stout and slim builds of the four temperaments.

Nose . Narrow . Nervous.

Neck . . Long . . Nervous.

Hair . . * Dark-red . Sanguine and

\section{Bilious.}

Eyes . . Dark-blue . Sanguine ana

\section{Bilious.}

Complexion. .

Colourless . Lymphatic.

* Compound Characteristics (page i 58). 
I64 OUR TEMPERAMENTS.

The Semi-balanced Temperament.

I have named the temperament semibalanced in which the physical characteristics associated with the oval face and medium build are not balanced, but chiefly Sanguine, Bilious, or Lymphatic, or wholly Nervous.

There are, therefore, four forms of this compound temperament :-

The Semi-balanced Sanguine temperament (Oval and Sanguine).

The Semi-balanced Bilious temperament

(Oval and Bilious).

The Semi-balanced Lymphatic temperament

(Oval and Lymphatic).

The Semi-balanced Nervous temperament (Oval and Nervous).

In analyzing faces I mentally express the long names of these four temperaments by the short ones given in italics. 
THE COMPOUND TEMPERAMENTS. I 65

The Semi-balanced Sanguine Temperament.

\section{(Oval and Sanguine.)}

Face . Oval . The blended square and tapering faces of the four temperaments.

Build . Medium. The blended stout and slim builds of the four temperaments.

Hair . . Reddish . Sanguine.

Eyes . Blue . . Sanguine. Complex- Florid . Sanguine. Nose . Narrow ' Nervous. Neck . . Long . . Nervous. 


\section{The Semi-balanced Bilious} Temperament.

\section{(Oval and Bilious.)}

Face . Oval . . The blended square and tapering faces of the four temperaments.

Build . Medium . The blended stout and slim builds of the four temperaments.

Hair . Black . Bilious.

Eyes . Black . . Bilious.

Complex- Dark . . Bilious. ion.

Nose . Narrow . Nervous.

Neck . . Long . . Nervous. 
THE COMPOUND TEMPERAMENTS. I 67

The Semi-balanced Lymphatic Temperament.

(Oval and Lymphatic.)

Face . Oval . The blended square and tapering faces of the four temperaments.

Build . Medium . The blended stout and slim builds of the four temperaments.

Hair . . Sandy . Lymphatic.

Eyes . Light-hazel Lymphatic.

Complexion

Colourless . Lymphatic.

Nose . Narrow . Nervous.

Neck . . Long . . Nervous. 


\section{The Semi-balanced Nervous} Temperament.

(Oval and Nervous.)

Face. . Oval . The blended square and tapering faces of the four temperaments.

Build. Medium. The blended stout and slim builds of the four temperaments.

Hair . . Light brown Nervous.

Eyes . . Grey. . . Nervous.

Complex-
ion. . . Pale and clear Nervous. ion . .

Nose . Narrow . Nervous.

Neck . . Long . . Nervous. 
THE COMPOUND TEMPERAMENTS. I69

The Best Temperament.

It may be asked, Which is the best temperament? The reply is not doubtful. The compound in equal proportions of the four pure temperaments, - the balanced temperament, - is certainly the best for its possessor, for in it the four temper one another, and the troublesome special tendencies or impulses that characterize every pure temperament are toned down to comfortable smoothness of action.

The impulsiveness of the Sanguine is tempered by the inaction of the Lymphatic. The eye-to-business, position, and power, of the Bilious, by the imaginativeness of the Nervous. The love of ease, and contentment with personal comforts, of the Lymphatic, by the ambition of the Bilious. The perplexity and indecision of the Nervous from seeing too 
many ways open, by the impulsiveness of the Sanguine.

That surely is the best temperament whose action avoids extremes; has sufficient of the natural force of all the pure temperaments to acquire any kind of knowledge; is well-fitted for success in any profession or business; retains through life the natural figure, and has equal health, free from the tendency or predisposition that every pure temperament has to disease or derangement of its special organ.

Such is the Balanced temperament. 
THE COMPOUND TEMPERAMENTS. I 7 I

Forms of Compound Temperaments.

To familiarize the student with the formation and the analysis of the Compound temperaments, I give the forms of three of the many classes into which they may be divided-

I. Sanguine and Bilious.

2. Sanguine and Lymphatic.

3. Sanguine and Nervous.

As the Sanguine, the Bilious, and the Lymphatic temperaments have the same form characteristics-

Square face,

Outspread nose,

Short neck,

Heavy build-

the compound temperaments they can 
form with one another are very few, being limited to the replacement of their colour characteristics-

The colour of the hair,

The colour of the eyes,

The colour of the complexion-

the chief temperament having two colour characteristics, and the replacing temperament one.

All the physical characteristics-colour and form-of the Nervous temperament being different from those of the Sanguine, the Bilious, and the Lymphatic temperaments (see scheme), it has a wide range of replacement, which it exercises freely, and the compound temperaments in which it is represented by one or more of its characteristics are, therefore, extremely numerous. 
THE COMPOUND TEMPERAMENTS. I 73

I. Forms of Compound Temperaments, in Which a Sanguine CharacTERISTIC IS REPLACED BY A Bilious.

Sanguine And Bilious Compound.

$$
\text { (The Hair Black.) }
$$

Face . . Square.

Nose . . Outspread.

Neck . . Short.

Build . . Thickset.

Eyes . . Blue.

Complexion. More or less florid.

(Six Sanguine characteristics.)

Hair . . Black.

(One Bilious characteristic.) 
Sanguine And Bilious Compound.

$$
\text { (The Eyes Black.) }
$$

Face . . Square.

Nose . . Outspread.

Neck . . Short.

Build . . Thickset.

Hair . . Red or reddish.

Complexion. More or less florid.

(Six Sanguine characteristics.)

Eyes . . Black.

(One Bilious characteristic.)

Sanguine and Bilious Compound.

(The Complexion Dark.)

Face . . Square.

Nose . . Outspread.

Neck . . . Short.

Build . . Thickset.

Hair . . Red or reddish.

Eyes . . Blue.

(Six Sanguine characteristics.)

Complexion . Dark or darkish.

(One Bilious characteristic.) 
THE COMPOUND TEMPERAMENTS. I 75

II. Forms of Compound Temperaments, in Which a Sanguine Characteristic is Replaced by a Lymphatic.

Sanguine and Lymphatic Compound.

\section{(The Hair Flaxen, Sandy.)}

Face . . Square.

Nose . . Outspread.

Neck . . Short.

Build . . Thickset.

Eyes . . Blue.

Complexion . More or less florid.

(Six Sanguine characteristics.)

Hair . . Flaxen, sandy.

(One Lymphatic characteristic.) 
Sanguine and Lymphatic Compound.

(The Eyes Light Hazel, Dim.)

Face . . Square.

Nose . . Outspread.

Neck . . Short.

Build . . Thickset.

Hair . . . Red or reddish.

Complexion. More or less florid.

(Six Sanguine characteristics.)

Eyes . . . Light hazel, dim.

(One Lymphatic characteristic.)

Sanguine and Lymphatic Compound.

(The Complexion Colourless.)

Face . . Square.

Nose . . Outspread.

Neck . . Short.

Build . . Thickset.

Hair . . Red or reddish.

Eyes . . Blue.

(Six Sanguine characteristics.)

Complexion . Colourless.

(One Lymphatic characteristic.) 
THE COMPOUND TEMPERAMENTS. I 77

It has been stated (page I48) that the pure temperament which contributes the greatest number of physical characteristics to a compound one should be named first, and in the foregoing forms the Sanguine is named first, because-the form characteristics of the three temperaments being the same-it contributes two of the three colour characteristics. Similarly, when the Bilious or Lymphatic temperament contributes two, it should be named first.

But the Sanguine, the Bilious, and the Lymphatic temperaments may contribute equally to the colour characteristics-one each - in which case the temperament which contributes the colour of the complexion should, I think, be named first.

III. Forms of Compound Temperaments in which Sanguine ChaRACTERISTICS ARE REPLACED BY Nervous. 
Sanguine and Nervous Compound.

$$
\text { (The Hair Light Brown.) }
$$

Face . . . Square.

Nose . . . Outsiretched.

Neck . . . Short.

Build . . . Thickset.

Eyes . : . Blue.

Complexion . . More or less florid.

(Six Sanguine characteristics.)

Hair . . . Light brown.

(One Nervous characteristic.)

Sanguine And Nervous Compound. The Eyes Grey.

Face . . . Square.

Nose . . . Outstretched.

Neck . . . Short.

Build . . . Thickset.

Hair . . . Red or reddish.

Complexion . . More or less florid.

(Six Sanguine characteristics.

Eyes . . . Grey.

(One Nervous characteristic.) 
THE COMPOUND TEMPERAMENTS. 179

Sanguine and Nervous Compound.

(The Complexion Pale, Clear.)

Face . . . Square.

Nose . . . . Outstretched.

Neck . . . Short.

Build . . . Thickset.

Hair . . . Red or reddish.

Eyes . . . Blue.

(Six Sanguine characteristics.)

Complexion . Pale, clear.

(One Nervous characteristic.)

Sanguine and Nervous Compound.

(The Nose Narrow.)

Hair . . . Red or reddish.

Eyes . . . Blue.

Complexion . More or less florid.

Face . . . Square.

Neck . . . Short.

Build . . . Thickset.

(Six Sanguine characteristics.)

Nose . . . Narrow.

(One Nervous characteristic.) 
Sanguine and Nervous Compound.

$$
\text { (The Neck Long.) }
$$

Hair . . . Red or reddish. Eyes . . . Blue.

Complexion . More or less florid.

Face . . . Square.

Nose . . . Outspread.

Build . . . Thickset.

(Six Sanguine characteristics.)

Neck . . . Long.

One Nervous characteristic.)

Sanguine and Nervous Compound.

$$
\text { (Hair Light Brown, Nose Narrow.) }
$$

Eyes . . . Blue.

Complexion . More or less florid.

Face . . . Square.

Neck . . . Short.

Build . . . Thickset.

(Five Sanguine characteristics.)

Hair . . . Light brown.

Nose . . . Narrow.

(Two Nervous characteristics.) 
THE COMPOUND TEMPERAMENTS. I 8 I

Sanguine and Nervous Compound.

(Eyes Grey, Nose Narrow.)

Hair . . . Red or reddish.

Complexion . . More or less florid.

Face . . . Square.

Neck . . . Short.

Build . . . Thickset.

(Five Sanguine characteristics.)

Eyes . . . Grey.

Nose . . . Narrow.

(Two Nervous characteristics.)

Sanguine and Nervous Compound.

(Complexion Pale, Clear, Nose Narrow.)

Hair . . . Red or reddish.

Eyes . . . Blue.

Face . . . Square.

Neck . . . Short.

Build . . . Thickset.

(Five Sanguine characteristics.)

Complexion . Pale, clear.

Nose. . . Narrow.

(Two Nervous characteristics.) 
Sanguine and Nervous Compound.

$$
\text { (Hair Light Brown, Neck Long.) }
$$

Eyes . . . Blue.

Complexion . More or less florid.

Face . . . Square.

Nose . . . Outspread.

Build . . . Thickset.

(Five Sanguine characteristics.)

Hair . . . Light brown.

Neck . . . Long.

(Two Nervous characteristics.)

Sanguine and Nervous Compound.

(Eyes Grey and the Neck Long.)

Hair . . . Red or reddish.

Complexion - More or less florid.

Face . . . Square.

Nose . . . Outspread.

Build . . . Thickset.

(Five Sanguine characteristics.)

Eyes . . . . Grey.

Neck . . . Long.

(Two Nervous characteristics.) 
THE COMPOUND TEMPERAMENTS. I 83

Sanguine and Nervous Compound.

(Complexion, Pale, Clear, and Neck Long.)

Hair . . . Red or reddish.

Eyes . . . Blue.

Face . . . Square.

Nose . . . Outspread.

Build . . . Thickset.

(Five Sanguine characteristics.)

Complexion . Pale, clear.

Neck . . . Long.

(Two Nervous characteristics.)

Sanguine and Nervous Compound.

(Face Tapering, Neck Long, Build Slim.)

Hair . . . Red or reddish.

Eyes . . . Blue.

Complexion . . More or less florid.

Nose . . . Outspread.

(Four Sanguine characteristics.)

Face . . . Tapering from a high or broad forehead.

Neck . . . Long.

Build . . . Slim.

(Three Nervous characteristics.) 
There are other Sanguine compounds:-

Sanguine, with Bilious and Nervous characteristics.

Sanguine, with Lymphatic and Nervous; and others.

Compounds of the Bilious, and also of the Lymphatic with the three other temperaments, are equally numerous as those of the Sanguine; and the possible compounds of the Nervous temperament with the Sanguine, the Bilious, and the Lymphatic are almost innumerable.

It is hoped, however, that the forms of Sanguine compounds just given may enable observers who persevere in the study, to recognize, analyze, and name, almost at a glance, the compound temperaments most frequently seen. 


\section{CHAPTER VIII.}

MODIFICATION OF THE TEMPERAMENT.

Modification by business pursuits.-Mrs. Carlyle.-Mr. Froude on professional mannerisms.-Modification by surrounding circumstances other than business pursuits.By Oxford and Cambridge Universities. Lord Houghton and Cardinal ManningManner of speech.-Its susceptibility to modification early in life.-Change of temperament.-Dr. Wilks, Dr. Prichard, and Mr. Buckle on the causes which produce diversity of temperament.-National temperaments.-Change in the colour of glass eyes sold in America.

Appendix: "British Calibre," from The Times, on the Reports of the Anthropometric Committee of the British Association._-"The Races of Britain," by Dr. Beddoe, F.R.S.

"What strange shapeable creatures we are!" -Carlyle.

THE observer of temperament soon finds that the traits of character naturally 
associated with physical characteristics as in the scheme (chap. iv.), are often more or less modified by various causes; every system that seeks to infer mental qualities from outward appearance having frequently to give way to the capability of adaptation and improvement that men are fortunately endowed with.

In business pursuits the sanguine man finds that he must curb his impetuosity and pursue business much as the coolheaded bilious man does. The lymphatic man has to bestir himself; and telegrams and messengers waiting reply on business of importance, compel the man of nervous temperament to put aside his doubts and act promptly.

The action of the temperaments is levelled up or down to business uniformity.

Carlyle could have had no better 
MODIFICATION OF THE TEMPERAMENT. I 87

example of how strangely shapeable human creatures are than his. own wife.

In the review of Mrs. Carlyle's letters in The Times it is said:-

"Mrs. Carlyle had two distinct sides to her "character: on the one hand, she was what " circumstances had made her; she was a " bustling, frugal, notable housewife, who seemed "to regard everything from the practical point "of view. At the same time, she was intensely "emotional, and almost morbidly susceptible. "That she had schooled herself to go on "phlegmatically and conscientiously about her "daily tasks is all the more to her credit."

Certain mannerisms of external action result from business and professional pursuits.

Dr. Wilks quotes Mr. Froude as having well remarked in one of his essays :-

"Every one of the many professions has "a peculiar character of its own, which, with 
" rare exceptions, it inflicts on those who follow "it. There is the shopkeeper type, the manu"facturing type, the medical type, the lawyer "type, the soldiers', the sailors" :

"The nature of man is,

" "Like the dyer's hand, " "Subdued to what it works in,'

" and we can distinguish with ease on the "slightest intercourse to what class a grown "person belongs: it is seen in his look; in " his words; in his tone of thought; his voice, "gesture, and everything he does."

Pope, in the Epistle "Of the Knowledge " and Characters of Men," says :-

"Boastful and rough, your first Son is a Squire; “The next a Tradesman, meek, and much a liar ; " Tom struts a Soldier, open, bold, and brave; “Will sneaks a Scriv'ner, an exceeding Knave ; "Is he a Churchman? then he's fond of power ; 
MODIFICATION OF THE TEMPERAMENT. 189

"A Quaker? sly; A Presbyterian? sour;

"A smart Free-thinker? all things in an hour."

The surrounding circumstances other than business pursuits that modify mental action, mode of speech, the natural impulses and tendencies, and the manner of men, are chiefly those of association with others; of children with their parents, their sisters and brothers, their schoolfellows, and the companions they are fond of.

The only sanguine carroty-haired girl of "The Irving Family" could not fail to become in many ways like her bilious black-haired sisters (page 372).

Old bachelors and family men, old maids and grandmothers, are contrasts; and all who live an isolated, hermit-like life differ conspicuously both in mind and manner from those who enjoy and cultivate society. 
On nothing has association more influence than the mode of speech.

As talking habitually to a deaf person begets the habit of loud speaking, so undertoned speech may arise from being obliged to talk in a low tone, and children, however loud and impulsive by nature, may have their speech and manner permanently subdued by having to move about the house afraid of being heard by a nervous father or mother.

An interesting account of the life and works of the late Lord Houghton appeared in The Times a day or two after his death, and I extract from it a reminiscence of his Cambridge days, supplemented by particulars from Cardinal Manning which apply to the subject of this chapter.

"It was in company with Mr. Sunderland " and Mr. Arthur Hallam that I formed part " of a deputation sent from the Union of Cam- 
"bridge to the Union of Oxford. And what "do you think we went about? Why, we "went to assert the claims of Mr. Shelley to "be regarded as a greater poet than Lord "Byron. We had a very interesting debate, "one of the principal speakers at which "reminded me of the circumstance the other "day."

The principal speaker referred to is now Cardinal Manning, and his account of the debate shows very, strikingly the effect of surrounding circumstances on manner.

Eton boys at Cambridge, and others at Oxford, became after a few years Oxford and Cambridge men differing widely in their oratory, as described. Probably, as some say, the influence of the Universities on ordinary address also is such that the stamp of the University can be recognized through life.

"It was, $l$ think, a passage-of-arms got up 'by the Eton men of the two Unions. My 
"share, if any, was only as a member of the " august committee of the green-baize table. "I can, however, well remember the irruption " of the three Cambridge orators. The Oxford "men were precise, orderly, and morbidly "afraid of excess in word or manner. The "Cambridge oratory came in like a flood "into a mill-pond. Both Monckton Milnes "(Lord Houghton), and Hallam took us "aback by the boldness and freedom of their " manner. I remember the effects of Sunder"land's declamation to this day. We were "utterly routed."

\section{Change of Temperament.}

The phrase "change of temperament" is in common use, but probably modification of mental characteristics and traits of character is meant; not a change from one temperament to another, as the phrase implies.

Yet an eminent physician and author of 
fifty years ago (J. Mason Good, M.D., F.R.S.), concludes with the following paragraph, descriptions of the temperaments, which, like those of most authors, are not from personal observation, but Richerand, and ancient Greek sources (see page 83).

"Each of these temperaments, how widely "soever they differ from each other, is capable " of being transmuted into any of the rest. "The temperament of boys may be born with " them, but they are capable of alteration, " nay, of a total reversion both in mind and "body."-The Book of Nature.

This is a thoughtless exaggeration, for certainly "transmutation" and "total reversion" cannot apply to any change that may take place in the physical or the mental characteristics of any of the temperaments.

A moment's consideration will suffice 
to convince any one who is familiar with the physical and mental characteristics of the four temperaments, as in the scheme, that no one of the four can change into another; the sanguine into the bilious; the bilious into the lymphatic, or the lymphatic into the nervous.

In the chief physical characteristics of a temperament there can be no fundamental change by time. The boy may at first sight appear lost in the man, but the features are soon seen to be unchanged. The face remains broad, oval, or tapering; the nose outspread or narrow; the chin full or pointed; the neck short or long.

No boy, sanguine, fair, and impulsive, has ever become in manhood, bilious, dark, and calculating; or lymphatic, heavy, and slow, if in boyhood he was nervous, slim, and rapid. 
In some few there may have been change in the colour of the hair or of the eyes; or the complexion may have become darkened by exposure to the weather and the sun; but as the form characteristics remain the same, such change of one of the colour characteristics is very far from a change of temperament as regards the body, which Dr. Mason Good asserts is as liable as the mind, not only to "alteration," but to "a total reversion" of its temperament characteristics.

The phrase "change of temperament" is no doubt almost always used in reference to change in the mode of mental action, and when it includes only partial change, it expresses what I have fully acknowledged as modification of the mental characteristics of the temperaments.

Modification of the natural mental 
action of the temperaments may be only superficial and conventional.

The sanguine man may no longer show his natural warmth in daily life, but let some extraordinary circumstance rouse him to anger, and in a moment speech and action are as rapid as in his youth, his rage is violent, he takes the law into his own hands; the veneer has come off, and the natural man is revealed.

It is shown in the next chapter-" The Organs of the Temperaments,"-that the natural mental action of the temperaments is more or less modified while there is derangement of the organs, and that there is a return of the natural action with the return of health.

The following, from Dr. Pereira, shows that the natural action of the temperaments may be modified by the kind of 
food that is habitually taken, and it may be inferred that vegetarianism or any special diet may suit those of one temperament, and not those of another (see page 284).

"The temper of the lcopard changes for the "worse by being fed with two meals instead " of one a day, and the temper of a gentle" man of sanguine temperament, who for some "months lived on vegetables, became much "less excitable, and an individual of an " opposite (lymphatic) temperament was observed "during the time that he lived on a reduced " diet to be more irritable."

If irritability, excitability, and faults of temper may be cured by a method of treatment so rational as diet that modifies the temperament, it would be well were it generally adopted. Precision of treatment, however, obviously necessitates an intimate acquaintance with the tempera- 
ments and the effects of different kinds. and quantities of diet.

\section{National Temperaments.}

Although in most countries there has been more or less intermixture of races, there is in all a prevailing temperament, characterized by colour, form, build, or manner, which marks the nationality of its people.

In our country, variety in the colour of the hair, eyes, and skin; in height, weight, etc., from the intermixture of races and some local causes, has lately been reported on by the Anthropometric Committee of the British Association, and is a subject of so much interest in relation to the temperaments, and otherwise, that I give, as an Appendix to this chapter, an admirable account of the work done by the Committee, from The Times of September 24th, 1883 . 
Dr. Prichard devotes a section of his valuable article "Temperament" in The Cyclopadia of Practical Medicine to the "Origin of Temperaments. Causes which give rise to these Diversities," full of research and interest; and in the following extract, Dr. Wilks (Lecture in the Sanitary Record, I 876) attributes diversity of temperament to climate and food :-

"Probably the more highly civilised a country " is, the greater the diversity of form, of "temperament, and of character : different, "however, as these are, there must be national "peculiarities. An hotel-keeper abroad, for "example, knows his Englishman at once. "Whatever opinion we may hold as to the " origin of man, we must regard his surround"ing of climate and food as having been " mainly instrumental in producing his modi" fications. In the orthodox view, as originating "from a single pair, no other conclusion can "be framed thar that climate was instrumental " in producing the different races. Now these 
" races when of the lowest kind, as in " uncivilised nations, show no peculiarities " amongst individuals; these seem as much "alike as the sheep in a flock; they are " all employed in the same manner, they eat "the same simple food, and their mode of "life is remarkably uniform. There seem to "be no especial temperaments amongst the "African tribes, who live on vegetables, or " in some savage islands where the inhabitants " subsist on fish. If it be true that a perfect " uniformity of character exists where the food " is of one kind, we may gain a clue to the "diversity of temperament from the variety " of food used in civilised life. The nature of "the soil implying different occupations will "also have its effects, also the influence of "light and the density of the atmosphere. "Thus it has been thought that bilious "temperaments prevail in hot, and phlegmatic " in cold climates. The soil and the occu"pations of its inhabitants, necessarily de"pendent on it, produce in our own small "island different types, as the agriculturists "along the eastern border, the manufacturers 
" in the centre, and the miners amongst the "western hills."

The same influences are very fully considered by Mr. Buckle in his second chapter,-

“Influence Exercised by Physical Laws "over the Organization of Society and “over the Character of Individuals,"-

which begins thus:-

"If we inquire what those physical agents " are by which the human race is most power"fully influenced, we shall find that they may "be classed under four heads : namely, Climate, "Food, Soil, and the General Aspects of Nature ; "by which last I mean those appearances which, "though presented chiefly to the sight, have, "through the medium of that or other senses, " directed the association of ideas, and hence in " different countries have given rise to different "habits of national thought. To one of these "four classes may be referred all the external 
"phenomena by which Man has been per" manently affected."

In Guy's Hospital Reports, I 869, Dr. Wilks, as previously quoted, says:-

"Not only may the inhabitants of ancient "Greece and Rome be different from those "of England,' but in our own country "these may have altered in the lapse of "centuries."

The following extract shows that such alteration as regards the eyes is now going on with great rapidity in some parts of America :-

\section{Glass Eyes.}

"It appears that there are as many as " $I, 000$ wearers of these eyes in Chicago, and "that from 600 to 800 eyes are sold there " every year.

"Twenty years ago there were sold very "many more dark eyes than light, but from 
" that period on, the sale of dark eyes has "been perceptibly dying out. About twenty "light eyes are now sold to one dark. In "Boston the percentage is even larger-about " thirty-five blue or light eyes to one brown; "while on the other hand, in New Orleans, "fifty brown or dark eyes are sold to one " light.

"The change in Chicago is supposed merely " to show that the influx of population has "been from the East principally, and from " Northern Europe."

\section{Mr. Galton says :-}

"The prevalent type of English face has "greatly changed at different periods, for after "making large allowance for the fashion in "portrait-painting of the day, there remains a "great difference between the proportion in " which certain casts of features are to be met "with at certain dates. I have spent some "time in studying the photographs of the "various portraits of English worthies that " have been exhibited at successive loan col- 
"lections, or which are now in the National "Portrait Gallery, and have traced what "appear to be indisputable signs of one pre"dominant type of face supplanting another. "For instance, the features of the men painted "by and about the time of Holbein, have " usually high cheek-bones, long upper lips, thin "eyebrows, and lank hair. It would be im"possible, I think, for the majority of modern "Englishmen so to dress themselves and clip "and arrange their hair as to look like the "majority of these portraits." - Inquiries into Human Faculty, p. 6.

Dr. Beddoe did not find the inspection of portraits a satisfactory mode of determining whether change in the colour-type of our upper classes had taken place during the last three or four centuries (see page $\mathrm{I} 27$ of this volume). 


\section{A P P E N D I X}

\section{To Chap. VIII.}

See page I 98.

\section{“BRITISH CALIBRE.”}

From The Times of Sept. 24 th, I 885.

"The record we print to-day of the pro"ceedings shows that the final report of the "Anthropometric Committee (of the British "Association) was read on Saturday. This "report is one that will appeal to every one, "and is a fine illustration of the real work "which is being carried on by the Association, "the results of which are only briefly told at "the annual meetings. In itself it is a strik"ing illustration of the application of rigidly "scientific method to the most ordinary and "commonplace operations, and of the vast "amount of research into apparently trivial "points which the real scientific worker must 
"institute before he is able to discover a few "apparently simple facts.

"The Anthropometric Committee have been "at work for some years, and have produced "annual reports. The report of the present "year is their final one, though they admit "that they are only on the threshold of their "research, and have merely provided a solid "point d'appui for further operations. As the "title of the Committee shows, the object of "its appointment was for the measurement of "men-the people, in fact, of these islands. "“The Committee was appointed for the pur" "pose of collecting observations in the syste" "matic examination of the height, weight, and " " other physical characteristics of the inhabit" "ants of the British Isles.' The fact is that "all sorts of measurements were taken of "people of all classes, of all ages, of both "sexes, living in all parts of Great Britain, "but only to a small extent in Ireland. Not "only have the Committee been taking our "heights and weights, but the dimensions of "chests and heads and of all our limbs, our "heights sitting and standing, the stretch of 
"our arms, the colour of our hair and eyes "and their various combinations (complexion, "in short), our strength as measured by power " to pull an ingenious spring apparatus, rate "of growth of children, and many other "points.

"Probably the first and main object in view " in the appointment of this committee was "ethnological; to discover whether the vari"ous elements that have contributed to the "formation of this nation have left any " marked racial characteristics upon the present "population. We know pretty well what have "been the leading racial elements that have "contributed to the population of these islands. "We know that before a Celt sighted the "cliffs of Dover Britain was occupied by a "people quite unlike either Celt or Saxon"a short, long-headed, dark, curly-haired race, "whose remains have been , abundantly found " in the long barrows. And even they, in all "probability, were not the first occupants of "our islands, for the caves and river-drifts "have revealed the remains of a people of "quite different type and more civilization, 
"though to what extent they have contributed " to the population may probably never be dis"covered. When the Celts appeared it is "likely enough that they treated the curly"haired race pretty much as the Saxons " treated themselves, and drove them back "into the remote and inaccessible parts of "the islands; though, to judge from the "mixed features almost everywhere found, "there must have been considerable mixture "of the two races. But that the Celts, in "their two types, Gael and Cymri, in the "end. spread themselves over nearly the whole " of the islands, there is little reason to "doubt. And so the Romans found them "on their arrival. The latter appear to have "made but little impression on the racial "features of the population, and it remained "for the Saxons to introduce a new element "which told powerfully on the ethnological "characteristics of the islands. We know the "directions in which they spread. We know "that the Celts were driven westwards and "northwards, towards the same regions in which "their predecessors had in the main collected. 
"Not sanguine and diffusime he,

"But biliary and intense."

Carlyle.

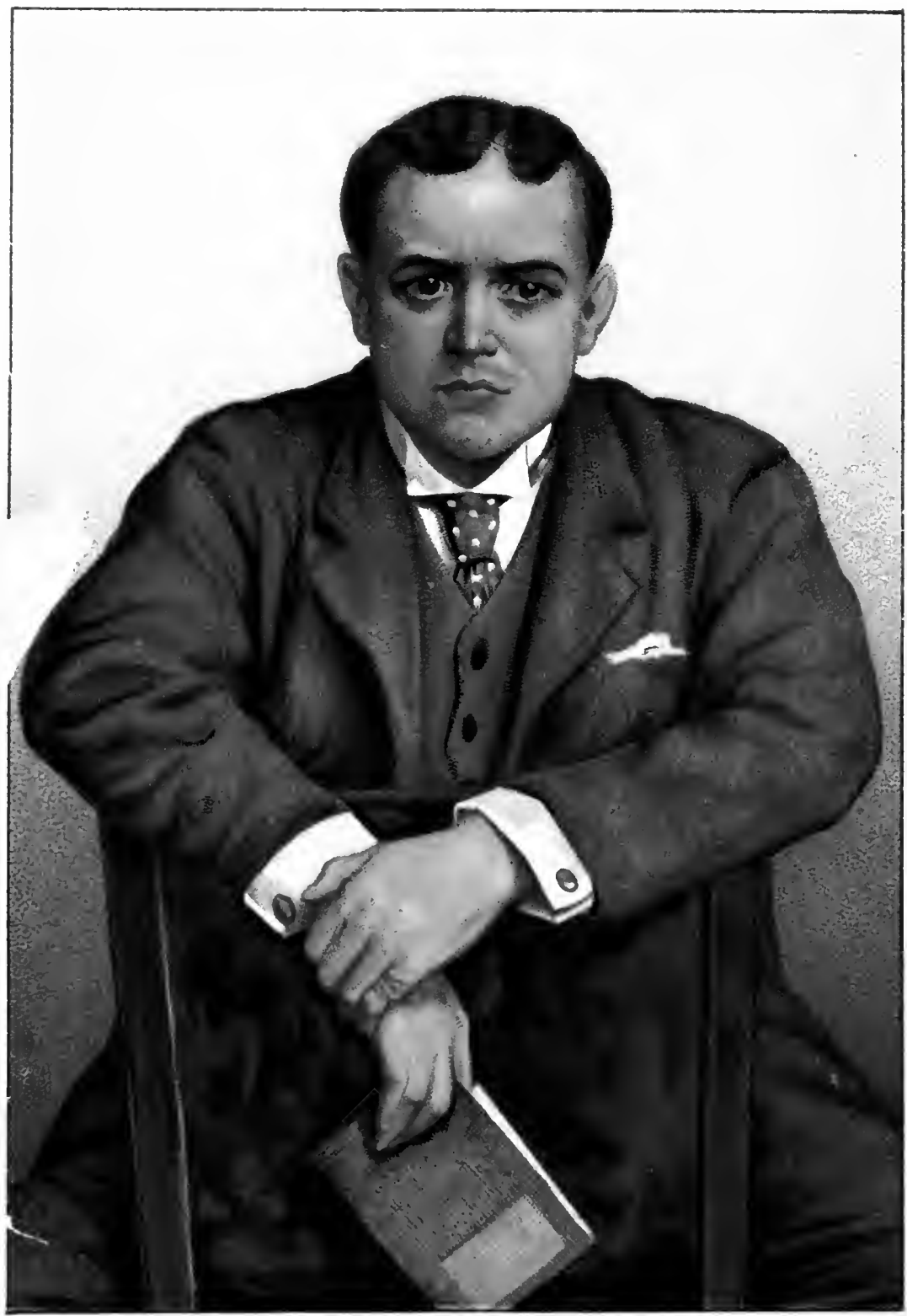

THE BILIOUS TEMPERAMENT (COLOUR CHARACTERISTICS OF). See page 80. 
"Wales and Strathclyde-i.e., North-West Eng"land and South-West Scotland-formed a "refuge for the Cymri; while Northern Scot"land remained the home of the Picts, to "whichever branch of the Celts they belonged. "Ireland remained largely Gaelic: and sent its "hordes into Western Scotland to establish " there, after four centuries, a Gaelic king"dom. All over Southern, Eastern, and "Central England, and Southern and North"Eastern Scotland, we should expect to find " the fair-haired, blue-eyed, large-limbed Teu"tonic element, only slightly modified subse"quently in some of the east-coast regions " and the extreme North and North-West of "Scotland by the Scandinavian intrusions. The "Norman invasion did not materially change "the ethnological position; it only, to a very "small extent, ousted the existing population, " contenting itself with giving us a dynasty " and an aristocracy. How, then, are we to "discover whether the characteristics which we "know marked these various elements still "survive in the districts which were finally "peopled by them? The Anthropometric 
"Committee have sought to solve the pro"blem by taking a large series of minute "measurements and observations of the leading "features that go to make up the physical " character of men, and comparing them with "what we know were the racial charac"teristics of the various swarms that formed " the original elements of the population. The " results are of the greatest interest. Another "Committee are collecting photographs from "the various districts of the kingdom, and "when their labours are complete, the com" parison of the results obtained by the two "Committees must be very curious.

"The following, then, are the twelve points " to which the Anthropometric Committee have "mainly directed their attention :- Stature, "weight, girth of chest, colour of eyes and " hair (complexion), breathing capacity, strength " of arm, sight, span of arms, size and shape " of head, length of lower limbs as shown "by the difference between the sitting and "standing positions, girth, length and breadth " of other parts of the body. As might be "expected, the Committee found some diffi- 
"çulty in obtaining complete answers to all "their inquiries; but quite enough has been " obtained to justify them in coming to pro"visional conclusions. With their own obser"vations they have combined those previously "obtained by Dr. Beddoe* and Mr. Roberts, "so that for the leading points of their in"quiry they have had observations on about " 53,000 individuals of both sexes and all " ages. We need scarcely say the Committee " have taken the greatest precautions in col"lecting their information, and have tabulated " and compared the results with complete in"difference as to what might be the final con"clusions. Into their carefully devised methods "we cannot enter, but must content ourselves " with a brief résumé of the results. As the "observations made on Irishmen were mainly "on those living in England, the conclusions " as to that country cannot be regarded so "satisfactory as those with reference to Eng"land and Scotland.

"The first observations discussed are those 
" relating to the stature, weight, chest-girth, " and strength of 8,585 adult males (ages "from 23 to 50) of the population of the "United Kingdom, arranged according to place " of birth. The general results of these ob"servations are summarized as follows :- In "height the Scotch stand first (68.6I inches), " the Irish second $(67.90$ inches), the English " third $(67.36$ inches), and the Welsh last (66.66 " inches), the average of the whole being 67.66 " inches. In weight the Scotch take the "first place $(165.3$ lb.), the Welsh second "( $158.3 \mathrm{lb}$.), the English the third (I $55 \mathrm{lb}$.), " and the Irish the fourth ( $\left.154^{\circ} \mathrm{I} l \mathrm{lb}.\right)$, the " average weight of the whole being $158.2 \mathrm{lb}$. "Thus the Scotch are the tallest and the " heaviest, the English take the third place in " both tables, while the position of the Welsh " and Irish is reversed; the Irish, occupying "the second place in stature, come last in "weight, and the Welsh, though lowest in "stature, stand second in weight. For each " inch of stature a Scotchman weighs $2.406 \mathrm{lb}$., “a Welshman $2.375 \mathrm{lb}$., an Englishman " $2.30 \mathrm{I} \mathrm{lb.,} \mathrm{and} \mathrm{an} \mathrm{Irishman} 2.270 \mathrm{lb}$. Thus, 
"then, so far as height and weight are " concerned, the Scotchman bears the palm; " but we look upon the discovery of the "British Association Committee as simply "giving the hall-mark of science to his own " instinctive conviction that he is a much "better man in all respects than the 'dause "southron.' The Committee make the im"portant practical remark on the above results " that, if each country is to furnish its quota " of soldiers, it is obvious that the minimum "standard for Welsh recruits should be two " inches lower, and for English and Irish "recruits one inch lower, than for Scotch " recruits. Unfortunately, the chest measure"ments taken in the above-mentioned group " are almost entirely those of Englishmen, " as also the figures for strength. These "measurements show that an adult English"man of typical proportions has a stature of " 5 ft. $7 \frac{1}{2}$ in., a chest girth of $36 \frac{1}{2}$ in., a weight " of rost. rolb., and is able to draw, as in "drawing a bow, a weight of $77 \frac{1}{2} \mathrm{lb}$. On " the diagram in which all these observations " have been embodied, the curve of the 
"English very nearly corresponds with that of " the average of the whole kingdom, so "that, in these respects at least, the English"man is the typical Briton.

" Another series of observations refer to " the relative stature, weight, and strength of "adult males and females in England. The "average stature of adult males is $67.36 \mathrm{in}$. "and of females $6_{2} \cdot 6_{5}$ in., showing a difference " of $4.7 \mathrm{I}$ in. The average weight of males " is $155 \mathrm{lb}$., and that of females $122.8 \mathrm{lb}$., "showing an excess of $32.2 \mathrm{lb}$, , or about " $2 \mathrm{I}-3$ stone, on the side of males. Although " the observations as, to strength were not so "comprehensive as they might have been, "still they may be regarded as an approxi" mation to the average. The difference of "strength, then, was found to be $35 \mathrm{lb}$., the "females being little more than half as "strong as the males. Thus the weaker sex " have a very long leeway to make up before " they can consider themselves on such a "footing of equality with the stronger sex " as the advocates of their 'rights' maintain " they ought to have. 
"One of the most interesting features of "the report is a series of shaded maps, "which present at once to the eye the rela"tive distribution of the stature, weight, and "complexion of the adult male population in "the several counties of Great Britain and " in each province of Ireland. The results, " the Committee candidly point out, must "be accepted with a certain amount of "reservation, though they tally wonderfully "with what might be expected as the result " of the original distribution of the racial "elements of our nation. We all know how "persistent through generations are family "features, and no less persistent are the "leading characteristics of a tribe or race " often in spite of extensive intermixture. "It is only since the very recent introduction " of railways that the free intermixture of the "various sections of the population has begun " to take place; and in spite of that the "great bulk of the people probably still. "continue to occupy the localiries, within " narrow limits, in which their remote an"cestors found themselves after the invasions 
" and the disturbances consequent thereon " ceased. 'From these maps, then, we find, " in the first place, that the very tallest "men (average stature $5 \mathrm{ft}$. $9 \frac{1}{2}$ in. and up"wards) are found in the Scotch counties " of Kirkcudbright, Ayr, and Wigton on the " one side, and the three Lothians and "Berwickshire on the other. The next stage " in height, 69 in. to $69 \frac{1}{2}$ in., is found to " prevail also in Scotch counties-Sutherland, "Ross and Cromarty, Skye, Perth, Stirling, "Dumbarton, Fife, Kinross, and Clackmannan, " to which, however, must be added the "North and East Ridings of . Yorkshire. " All the other Scotch counties are embraced " in the heights between $67 \frac{1}{2}$ in. and 69 in., " only Shetland and the Western Hebrides " coming so low as $67 \frac{1}{2}$ in. to $68 \mathrm{in}$. "Northumberland and the Irish Provinces of "Connaught and Munster have for their " average heights $68 \frac{1}{2} \mathrm{in}$. to 69 in. Ulster " and Leinster have for their average $68 \mathrm{in.}$ " to $68 \frac{1}{2}$ in., in which category also are " embraced the English counties of Cumber"land, Westmoreland, Lincoln, and Norfolk. 
"The average of $67 \frac{1}{2}$ in. to $68 \mathrm{in}$. is dis"tributed over the counties of Durham, "Lancashire, Derby, Stafford, Suffolk, Essex, "Kent, Berks, and Cornwall; 67 in. to " $67 \frac{1}{2}$ in. is found in Nottingham, Leicester, "Rutland, Northampton, Bedford, Warwick, "Worcester, Flint, Denbigh, Sussex, Hants, "Dorset, and Devon. The London average " is given separately-66.92 in. In the West " Riding, Chester, Carnarvon, Anglesea, "Merioneth, Montgomery, Cardigan, Brecon, "Radnor, Cambridge, Huntingdon, Bucks, " and Oxford, the average is found to be " $66 \frac{1}{2}$ in. to 67 in.; and the lowest average, " 66 in. to $66 \frac{1}{2}$ in., belongs to Herts, Middle"sex (ex-metropolitan), Surrey (ex-metro"politan), Shropshire, Hereford, Monmouth, "Gloucester, Wilts, Somerset, Glamorgan, "Carmarthen, and Pembroke.

"The second map, on which the distri"bution of weight is marked, shows that "weight and height do not invariably go " together. In respect of weight the Lothians " and Argyllshire bear the palm, the average " in these districts being from I75 lb. to 
" I $80 \mathrm{lb}$. South-West Scotland and Perthshire "come in the second line with an average "of from 170 lb. to $175 \mathrm{lb}$., while the whole " of Northern Scotland comes into the third " rank, with weights from $165 \mathrm{lb}$. to $\mathrm{I} 70 \mathrm{lb}$. "With the exception of the coal and iron " districts along the middle and lower course " of the Clyde, no other parts of Scotland " come below the fourth standard, 160 lb. to " $165 \mathrm{lb}$. ; ; in these districts, however, the "standard of weight is the second lowest, " I $55 \mathrm{lb}$. to I60 lb. The highest standard "found in England is No. 4, from $160 \mathrm{lb}$. " to $165 \mathrm{lb}$., in Northumberland, Central and "East Yorkshire, Lincoln, Norfolk and "Suffolk, Cornwall, Stafford, and North "Wales. The bulk of England-the north"west counties, a great part of the centre " and east-Derby, Leicester, Northampton, "Worcester, Beds, Cambridge and Hunts, "Essex, with Worcester, South Wales, the "South Thames counties (except Surrey), "Kent, and the South Coast counties, with "South Wales, Ulster in Ireland, the West " Riding of York, Lancashire, Cheshire, Notts, 
"Durham, Oxford and Bucks, Hereford and "Monmouth, Herts and Middlesex, with "Connaught and Munster, all come within "Standard 6-150 lb. to I5 lb. London has "for its standard weight $152.9 \mathrm{lb}$. Surrey, "Warwick, Shropshire, Gloucester, and Somer" set, with Ulster, fall to the lowest standard, "I 45 lb. to r $50 \mathrm{lb}$.

"Other three maps are devoted to the "distribution of the leading complexions-(I) "fair-i.e., light eyes and light hair ; "dark-dark eyes and dark hair ; (3) fair " eyes and dark hair. From a purely ethno"logical point of view these three maps are "perhaps the most interesting. Over all, there "seems no doubt, the lighter complexions "prevail, though there is a large percentage " of dark complexions, stretching in a band " across the centre of England and Wales, "running south-east into Essex, and in Kent, "Sussex, and Hants.

"The ethnological results of the inquiry are "well stated by Dr. Beddoe, the Committee "expressing the opinion that the variations " in the various features appear to be chiefly 
"due to difference of racial origin, the influ" ence predominating over a!l the others. Dr. "Beddoe says :-

"'We have reason to believe, from historical and " " antiquarian researches, that the ancient Caledonii, the " "Belga and Cimbri, and the Saxons and Frisians, as " "well as the Danes and Normans, were all people of " "great stature. On the other hand, the prehistoric " "(neolithic) race or races in Britain appear to have " "been of low or moderate stature. Accordingly the " "higher statures are found in the Pictish or Cimbro" "British districts of Galloway; in the Anglo-Danish " "ones of North and East Yorkshire, Westmoreland and " "Lincolnshire, and in Cumberland, whose people are " " ethnologically intermediate between the two. Lothian " "and Berwickshire are mainly Anglian, while the Perth" "shire Highlanders are the most clearly identified as " " the descendants of the Caledonii. The high position " "of Norfolk in the list is due to a large admixture of " "Danish blood on the coast. There is a fringe of " ' moderately high stature all round the coast from Nor" " folk to Cornwall, while the inland people, retaining " " more of the ancient British blood, yield lower averages. "“ Middlesex and Hertfordshire, which stand very low, " "were later and less perfectly colonized by the Anglo" "Saxon than the surrounding counties, and nearly the " "same may be said of the counties around the Severn " " estuary and the Welsh border. Cornwall stands higher " " than the surrounding counties, and this is probably due to " "its having become the refuge of the military class of " "Southern Britain, in the main of Belgic origin. Flint 
" "and Denbigh owe their superiority to the other Welsh " "counties to the immigration of the Cumbrian and "' 'Strathclyde Britons.'

\section{"Again the Committee say :-}

" "The racial elements of the British population are " "best demonstrated by separating a few of the counties " "where there has been the least admixture of foreign " "blood, and comparing these together, thus :-

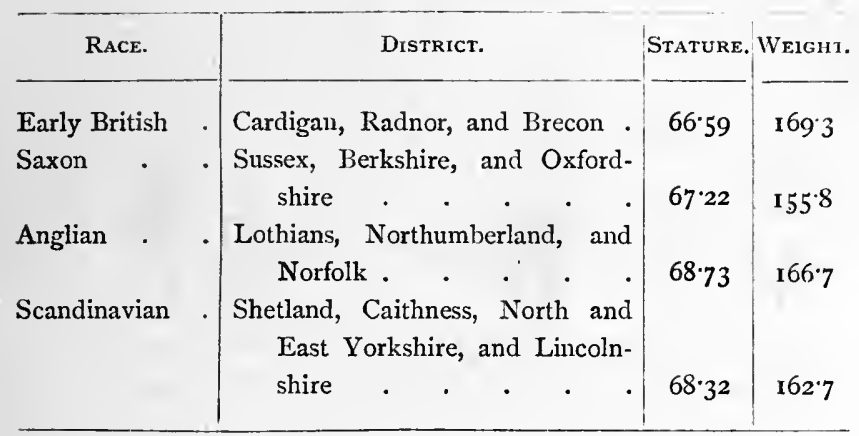

"These, then, are the leading ethnological "results of the Committee's labours, and they " are solid and interesting enough to justify " its appointment. But there are other issues " which render this report of many-sided im"portance, and of immense practical value "from a hygienic and sanitary point of view. "We can only and very briefly allude to a 
" few of these side results. With regard to "geographical distribution, for example, it has " been found that the inhabitants of the "more elevated districts possess a greater "stature than those of the alluvial plains, " and the inhabitants of the northern and " colder districts than those of the southern " and warmer parts of the island; those of " the north-eastern and drier regions are taller " than those of the south-western and damper " climates. A special table is devoted to a " comparison of the average stature of adult " males in the United Kingdom with that of " adult males of American and European " origin who were examined for admission " to the United States Army in 1863-4, the "result being to show, not that the Anglo"Saxon race in America reaches a higher "stature than in England, as has been main" tained by some American writers, but that " there is a close correspondence between the " two groups. A still more interesting table " compares British stature with that of all " other nationalities, from Polynesians to "Bushmen. The result is that, with the 
" exception of a few imperfectly observed "South Sea Islanders, the English professional "class head the long list, and that the "Anglo-Saxon race takes the chief place in " it among the civilized communities, although " it is possible it might stand second to the "Scandinavian countries if a fair sample of "their population were obtained. The Poly" nesians lead the way with an average "stature of $5 \mathrm{ft} .9 .33 \mathrm{in}$., closely followed by " the English professional class with $5 \mathrm{ft}$. " $9.1_{4}$ in. of average stature. Next come the "Patagonians, $5 \mathrm{ft} .9$ in. ; the Angamis of the "Naga Hills, $5 \mathrm{ft}$. 9 in.; negroes of the "Congo, $5 \mathrm{ft} .8 .95$ in.; and after these the "Scotch of all classes, $5 \mathrm{ft}$. $8 \cdot 7 \mathrm{I}$ in. At the " bottom of the list stand the Bushmen, with an " average height of $4 \mathrm{ft} .4 \cdot 78$ in. The difference "between the tallest and shortest races is " I ft. 4.55 in., and the average height of man, " according to this table, is $5 \mathrm{ft} .5 \frac{1}{4}$ in.

"Among other special subjects of inquiry "by the Committee were the physical differ" ence of (a) persons engaged in different "occupations, (b) persons bred or living in 
"towns and country, $(c)$ natives of parts of " the British Isles differing ethnologically, "geologically, or in climate, (d) boys and " men whose intellect and industry are above " or below the average, $(e)$ the general cha" racteristics of men noted for their athletic " powers, $(f)$ the rate of growth in persons " of both sexes in town and country, and " engaged in different occupations. It comes " out very clearly that an open-air country "life is much more favourable to height and " weight than a sedentary town life, and that "favourable hygienic and sanitary conditions " have a marked influence on growth and "weight. At the top in this respect are the "Scotch agricultural population of Galloway, " with average height $5 \mathrm{ft}$. $10 \frac{1}{2}$ in. and weight " $173^{.} 6 \mathrm{lb}$., closely followed by the Metro"politan Police, a carefully-selected body of "men, with average height $5 \mathrm{ft} .10^{\circ} \mathrm{I}$ in. and "weight $185.7 \mathrm{lb}$. In Galloway the influence " of race may prevail, as we find the lead " miners of Wanlockhead, in the same dis" trict, notwithstanding their unhealthy occupa"tion for generations, reaching an average 
" height of $5 \mathrm{ft} .8 .43$ in. and weight $163.9 \mathrm{lb}$., "while the Welsh lead miners have an "average height less by $2^{\circ} \mathrm{I} 3$ in. and weight "less by $8.7 \mathrm{lb}$.

"If the results of the Committee's inquiries " as to criminals and lunatics can be altogether " accepted, they may prove suggestive to those "practically interested in the improvement of " both classes. When compared with the "general population, lunatics show a deficiency " of stature of $1 \cdot 96$ in. and of weight. $10.3 \mathrm{lb}$. ; " and criminals of $2.06 \mathrm{in}$. and $17.8 \mathrm{lb}$., indicat" ing, according to the Committee, a deficiency " of physical as well as mental stamina in " both these unfortunate classes of society. "The average stature of athletes exceeds that " of the general population by 0.68 in., while "their average weight falls short of that "standard by $14.5 \mathrm{lb}$. Thus, a trained athlete "whose stature is $5 \mathrm{ft} .7$ in. should weigh ro st., "while an untrained man of the same height "should weigh IIst. The result of the in"quiry into the influence of age, sex, nurture, "occupation, and sanitary surroundings on the " physical development of the British popula- 
"tion deserves the serious attention of all " interested in the improvement of our race. "The most obvious facts which the figures "disclose are the check which growth receives " as we descend lower and lower in the social "scale, and that a difference of 5 in. exists " between the average statures of the best and "worst nurtured classes of children of corre"sponding ages, and of $3 \frac{1}{2}$ in. in adults. One "very curious remark is suggested with regard " to the observations on the size and weight " of new-born infants. It would appear, accord"ing to the Committee, that the physical (and " most probably the mental) proportions of " a race, and their uniformity within certain " limits, are largely dependent on the size of "the female pelvis, which acts as a gauge, as " it were, of the race, and eliminates the " largest infants, especially those with large "heads (and presumably more brains), by "preventing their survival at birth. This, "however, must be regarded as simply a con"jecture, but the point is worthy of precise " investigation. A long series of tables and "curves is summed up as follows:-(I) 
"Growth is most rapid during the first five "years of life; the observations, however, at " those ages are not sufficient in number or "variety to give a trustworthy average. "From birth to the age of five years the "rate of growth is the same in both sexes, "girls being a little shorter in stature and "lighter in weight than boys. (3) From five "to ten years boys grow a little more rapidly " than girls, the difference being apparently "due to a check in the growth of girls at " these ages. (4) From Io to I 5 years girls "grow more rapidly than boys, and at the " ages of II $\frac{1}{2}$ to $I 4 \frac{1}{2}$ are actually taller, and "from $12 \frac{1}{2}$ to $I 5 \frac{1}{2}$ years actually heavier than " boys. This difference appears to be due to " a check in the growth of boys as well as to " an acceleration in the growth of girls inci"dent on the accession of puberty. (5) From " 15 to 20 years boys again take the lead, " and grow at first rapidly, and gradually "slower, and complete their growth at about " 23 years. After I5, girls grow very slowly, " and attain their full stature about the 2oth "year. (6) The tracings' and tables show a 
" slow but steady increase in stature up to the " 5oth year, and a more rapid increase in "weight up to the 6oth year in males, but " the statistics of females are too few after the "age of 23 to determine the stature and "weight of that sex at the more advanced " periods of life. (7) The curve of the chest"girth in males shows an increase at a rate " similar to that of the weight up to the age " of 50 years, but it appears to have no " definite relation to the curve of stature.

"The strength of males increases rapidly from " I 2 to I9 years, and at a rate similar to that "of the weight; more slowly and regularly " up to 30 years, after which it declines at an " increasing rate to the age of 60 years. The " strength of females increases at a more uni"form rate from 9 to 19 years, more slowly " to 30 , after which it falls off in a manner "similar to that of males. The curves of "strength for the two sexes are not parallel; " at I I years females are weaker than males "by $22 \mathrm{lb}$,, at 20 years of age by $36 \mathrm{lb}$. The "fact that man continues to grow in stature " up to his 5oth year goes right in the face 
" of all popular notions on the subject, accord"ing to which he has ceased to grow before " he reaches half that age.

"Only one other point can we refer to. "The supposed degeneracy of the population "of our manufacturing towns is frequently "lamented; but the Committee, by comparing "their own with previous observations, have "come to the conclusion that in spite of their " unfavourable surroundings, these classes are " not degenerating, but that, on the contrary, "a slight but uniform increase in stature and "a very large increase in weight is observable. "Such then are the leading points or con"clusions of this most suggestive inquiry. We "have been weighed and measured and have " not been found wanting; in spite of many "drawbacks in the surroundings of large sec" tions of our population we, on the whole, "keep the lead of all civilized nations in " height and weight, lung capacity, and strength "of arm. The exact influence in inches and "pounds of the special surroundings which "affect different classes have been tabulated "by the Committee; the results are at least 
"worthy of the study of all interested in "sanitary science and practice. The whole in"vestigation is creditable in the highest degree " to the Committee, and especially to Mr. C. "Roberts and Sir Rawson Rawson, who have "drawn up the report. So long as the British "Association spends its money in endowing " committees to carry on investigations of this "kind it will have a sufficient raison d'être. "To quote one of the concluding sentences " of the report:-

" 'The Committee believes that it has laid a substantial " "foundation for a further and more exhaustive study of " "the physical condition of a people by anthropometric " "methods, and that its action will prove it has been " "useful as an example to other scientific societies and " " to individuals in stimulating them, as well as directing " "them, in the methods of making statistical inquiries " 'relative to social questions." " 
DR. BEDDOE'S “RACES OF BRITAIN." 23I

A most important work ${ }^{*}$ has lately been published, which will be found of the greatest value to the student of temperament. It is full of maps and tables, which give Dr. Beddoe's personal observation of the colours of the hair and eyes, the forms of the features, the head-forms of the different races, and the prevailing colours and forms in many districts and counties of the three kingdoms, and parts of the Continent.

There are three pages of faces, all admirably characteristic of the type of face which prevails in districts at home where one or other of the races is still met with comparatively pure; and as the colour, form, and other physical characteristics are given in the text, students who have become familiar with the

* The Races of Briain; A Contribution to the Anthropology of Western Europe. By John Beddoe, M.D., F.R.S., etc., 1885 . 
scheme of the four temperaments (chap. iv.) may at once see the people of these districts with the mind's eye, assign their temperaments, and infer their mental from their physical characteristics.

Dr. Beddoe's first work-Contributions to Scottish Ethnology, I 853-may be said to have originated precise observation of physical characteristics; a field now occupied by eminent workers at home and abroad, in which, however, he has always been one of the most eager and careful.

Although the results of his observations "have been extensively utilized" by the Anthropometric Report of the British Association, the more complete record given in the volume now published renders it indispensable to students of history, character, and temperament, and it will be invaluable as a work of reference through future ages. 
DR. BEDDOE'S “RACES OF BRITAIN." 233

Dr. Beddoe's own estimate of its value in that respect is fully warranted:-

"The ever-increasing rapidity of local migra"tion and intermixture, due to the extension "of railways and the altered conditions of society, "will in the next generation almost inextricably "confuse the limits and proportions of the "British races; and it is a source of satis"faction to me that I have laboured to seize "on fleeting opportunities, and to observe and " record phenomena, which, however trivial they " may appear from some points of view, may "for generations to come retain some biological "and historical value."

Much of Dr. Beddoe's method of observing racial colour characteristics may well be followed by the observer of temperament :-

"When engaged in this work I set down " in his proper place on my card of observa"tion every person (with the exceptions to be " mentioned presently) whom I meet or who 
"passes me within a short distance, say from "one to three yards. . . . I neglect those "whom I suppose to be under age-fixing the " point roughly at eighteen or twenty for men, "seventeen or eighteen for women,-as well as "all those whose hair has begun to grizzle. " Thus I get a fairly uniform material to work "upon, though doubtless the hair of most "people does darken considerably between " twenty and forty or fifty. In order to "preserve perfect fairness, I always examine "first, out of any group of persons, the one "who is nearest, rather than the one to "whom my attention is most drawn. Certain "colours of the hair, such as red; certain "shades of the eye, such as light grey, can be " discerned at a very considerable distance; but "I take no note of any one who does not " approach me so nearly that I can recognise "the more obscure colours. Much allowance "needs to be made for the varying effects of " light. Direct sunlight is better avoided when "possible; I always choose the shady side of " a street on a sunny day.

"Considerable difficulties are created by the 
DR. BEDDOE'S “RACES OF BRITAIN.” 235

"freaks of fashion. I once visited Friesland, " in order to study the physical type of that "region. Conceive my disappointment when I "found myself surrounded by comely damsels " and buxom matrons, not one of whom suffered " a single yellow hair to stray beyond her lace " cap or silver-gilt head plate. When I began " to work in England dark hair was in fashion " among the women; and light and reddish "hues were dulled with greasy unguents. In "later years fair hair has been more in vogue; " and golden shades, sometimes unknown to " nature, are produced by art."

In the foregoing extract Dr. Beddoe refers to the colour characteristics only of passers-by; the chief form characteristics of race requiring careful measurement, and therefore consent, to obtain which he had frequently to put his hand in his pocket.

"Sometimes other means have proved suc"cessful. I cannot resist detailing those by " which I succeeded in obtaining a valuable series 
" of head measurements in Kerry. Our travel" ling party consisted of Dr. Barnard Davis, “Dr. T. Wise, Mr. Windele, and myself. "Whenever a likely little squad of natives was " encountered, the two archæologists got up a "dispute about the relative size and shape of " their own heads, which I was called in to settle "with the callipers. The unsuspecting Irish"men usually entered keenly into the debate, " and before the little drama had been finished "were eagerly betting on the sizes of their "own heads, and begging to have their wagers " determined in the same manner."

The observer of temperament is able, fortunately, to assign the temperament of nearly every one without consent; form as well as colour characteristics being generally seen at a glance. 


\section{CHAPTER IX.}

THE ORGANS OF THE TEMPERAMENTS.

The four temperaments named after four internal organs of the body.-The four organs, and their influence on the mental action of the four temperaments.-Relation of the four temperaments to the causes of disease.-Food and the temperaments.-Climate and the temperaments. -Effects on Dickens of a month at Bonchurch, Isle of Wight._Quotations showing the dependence of the natural mental action of the temperaments on the healthy action of the organs.-Return of natural mental action with convalescence. - The temperaments and minute structure. - Inheritance of disease limited by personal likeness. - Importance of such limitation in Life Assurance.

$7 \mathrm{HE}$ four pure or standard tempera1 ments are named after the four chief organs of the body, and it is an 
essential part of the doctrine of the temperaments that every temperament is specially influenced by the organ after which it is named.

The four organs of the temperaments are :-

The Heart or Blood. The Sanguine Temperament.

The Liver or Bile. . The Bilious Temperament.

The Lymphatic system . The Lymphatic

Temperament.

The Nervous system. The Nervous Temperament.

The following quotation expresses the general influence of the organs on physical and mental characteristics:-

"The predominance of any particular system "of organs modifies the whole economy, " impresses striking differences in the results 
THE ORGANS OF THE TEMPERAMENTS. 239

" of the organization, and has perhaps almost " as great an influence on the moral and " intellectual as on the physical faculties. "This prominence establishes the tempera" ment; it is the cause of it, and constitutes "its essence."-Art. "Temperament" in Penny Cyclopadia.

Organization is sometimes used instead of temperament, and as it has an obvious and a definite meaning and is often the better term, it would be well were it more frequently used; but, as with temperament, precision of meaning requires the kind of organization to be added:-

A sanguine organization.

A bilious

A lymphatic

,

A nervous

,

,

I noted its use in place of temperament by $\operatorname{Sir}$ F. Leighton, in one of his annual 
addresses to the students of the Royal Academy of Arts.

"I wish," he said, " to seek with you the "solution of certain perplexities and doubts "which will often, in these days of restless "self-questioning, arise in the minds and weigh " on the hearts of students who think as well " as work. These perplexities, which few " are fortunate enough wholly to escape, arise "sooner in some and later in other organiza" tions."

I give a brief account of the four organs, and of their influence on the characteristics of the temperaments, but the student of temperament would do well to gain fuller information on this important part of the subject.

The Blood and the Sanguine Temperament.

The blood consists chiefly of small red corpuscles floating in a clear, colourless 
THE ORGANS OF THE TEMPERAMENTS. 24I

fluid-serum; and the florid complexion, the more impulsive mental action and energetic manner of those of the sanguine temperament, and the greater activity of all their bodily functions, are no doubt chiefly owing to the skin, the brain, and the other internal organs being more freely supplied with blood, in which probably the red corpuscles are in excess.

In a contribution, "The Analysis of the Human Blood," by Dr. George Martin, in Medical Essays and Observations, vol. ii., 1771 , is a section entitled

"Of The Temperaments Denomi"NATED FROM The Constituent "Parts of the Blood,"

in which it is said :-

"If the blood be plentiful, and abound "with red globules, such a state will plainly " enough constitute what the antients called 
" 'temperamentum sanguineum'; the symptoms "whereof are easily explained from these "circumstances."

\section{The Bile and the Bilious}

\section{TEMPERAMENT.}

The organ of the bilious temperament is the liver, but the temperament takes its name from its product-the bilewhich has important uses in digestion, and, as is well known, is a dark-yellow, bitter, and acrid fluid.

As the florid complexion and the mental characteristics of the sanguine temperament depend on the red corpuscles of the blood, so the dark complexion and the mental characteristics of the bilious temperament may depend on the presence, at all times, of more or less bile in the blood. Its natural flow or course being arrested, it often finds its way into the 
THE ORGANS OF THE TEMPERAMENTS. 243

blood too largely, darkens the complexion unnaturally, and makes things seen with "a jaundiced eye."

"All seems infected that th' infected spy, As all seems yellow to the jaundic'd eye."

Pope.

Carlyle says of himself :-

"I am a very unthankful, ill-conditioned, "bilious, wayward, and heartworn son of "Adam, I do suspect";

and it is said of him :-

"Carlyle's hatred of democracy was in a " great measure but the bigotry of bile."

The Lymphatic System and the Lymphatic Temperament.

The lymphatic system, after which the lymphatic temperament is named, consists of small vessels or tubes, everywhere throughout the body, which take up 
from, certain parts of the alimentary or digestive canal, a rich milky fluidchyle,-and from the rest of the body a clear, colourless fluid,-lymph,-and pour both into the blood, near the heart.

In composition and in appearance lymph resembles the serum of the blood, but it is more watery.

The lymphatic is called by some the serous temperament. It is so by Dr. Thomas Mayo, in his "Elements of "the Pathology of the Human Mind," I838. But as lymph and the serum of the blood are not exactly alike, and it is not serum but lymph that circulates in the lymphatics, the old name is more in harmony with the names of the other temperaments.

It may be accepted that in the lymphatic temperament there is a greater proportion of water in the tissues of the body. 
THE ORGANS OF THE TEMPERAMENTS. 245

Dr. Southey says:-

"The lymphatic are short-lived, and have "elements of inherent debility about them. "The constructive fault in them appears to "be a capacity and a proclivity to combine "and appropriate more water than is required "for the perfect nutrition of their tissues, "the error being an increase in the size of "parts rather than their solidity." - The Lancet, vol. i., 1876 .

Dr. Martin, previously quoted (p. 24I), says :-

"When the red globules were scarce in the "blood, and it was found thin and watery, "this was called a phlegmatic (lymphatic) " temperament."

Recent analysis of the blood in the different temperaments, by French chemists, confirms the old observation that it is more watery in the lymphatic than the other temperaments, and shows that the 
blood of women contains more water than that of men.

Dr. Jaeger, Professor of Zoology and Physiology at Stuttgart, found, by testing, that the body becomes specifically light through excess of water or fat, and that in the same proportion the nervous action is impeded or slow; that in one instance the water in the body having been lessened by a Turkish bath, the rapidity of nervous action increased to the extent of I 3 per cent.-The Times, Oct. 4th, I884: "Sanitary Clothing."

It is therefore a warrantable conclusion that the slowness, the inactivity, the love of ease, the colourless complexion, and the other characteristics assigned in the scheme to the lymphatic temperament, are the result of enfeebled organic action from diluted blood and watery nerves and tissues. 
The Nervous System and the Nervous Temperament.

The nervous system, after which the nervous temperament is named, consists of the nerves, and their centres,-the brain and spinal cord.

Issuing from their centres, the nerves are distributed to every part of the body, and not only bestow sensation everywhere, but convey messages to and from their centres, and call into action every movement of every part of the body.

In the nervous temperament-the face tapering from a high or broad forehead, small features, long neck, and slim buildthe action of the nervous system is accelerated, and in consequence, sensation is heightened, and perception, thought, and resulting speech are more rapid than in the other temperaments. See page I 37. 
There is abundant professional proof of the greater liability of every pure temperament to derangement of its special organ,- of the circulation in the sanguine; the bile in the bilious; the glandular or lymphatic system in the lymphatic; and the nervous system in the nervous,and were authors of works on the practice of medicine to name the organization specially susceptible to the causes of wellknown diseases, they might greatly promote the public health.

Practical acquaintance with the temperaments would then enable every one to guard himself and others against the diseases to which they are naturally liable.

It would be important to every one were the different relations of the four temperaments to food and climate carefully studied and made generally known, as the few following observations may show. 
Food and the Temperaments.

Every one knows that there are hearty eaters who can eat and digest every kind of food, and that there are small eaters who have found by experience that they must be very careful what they eat lest indigestion follow; that many can take a moderate quantity of wine and other stimulants daily, apparently with benefit; while not a few are unable to take even the smallest quantity without subsequent discomfort. And so with fat and rich dishes-that some trim every particle of fat off, and that others eat, enjoy, and digest it.

Observation would probably establish that the temperaments indicate these and other differences as regards food and digestion.

The nervous man, with tapering face 
250 OUR TEMPERAMENTS.

and slim frame, is a dainty eater, has a less capacity for food than the sanguine, the bilious, or the lymphatic, and if his engagements interfere with regularity of meals, is likely to become dyspeptic and sleepless, and obliged to live strictly by rule.

In contrast; the lymphatic man eats largely and indiscriminately; is the onemeal-a-day man we hear of; loves after dinner to linger over his port and smoke away the rest of the evening. He wakes in the morning to find that he has had a ten hours' sleep, and could enjoy an hour or two more.

The sanguine and bilious have a somewhat less capacity for food than the lymphatic, but, like them, can take wine and other stimulants freely - the bilious more so than the sanguine. They digest well and sleep well. 


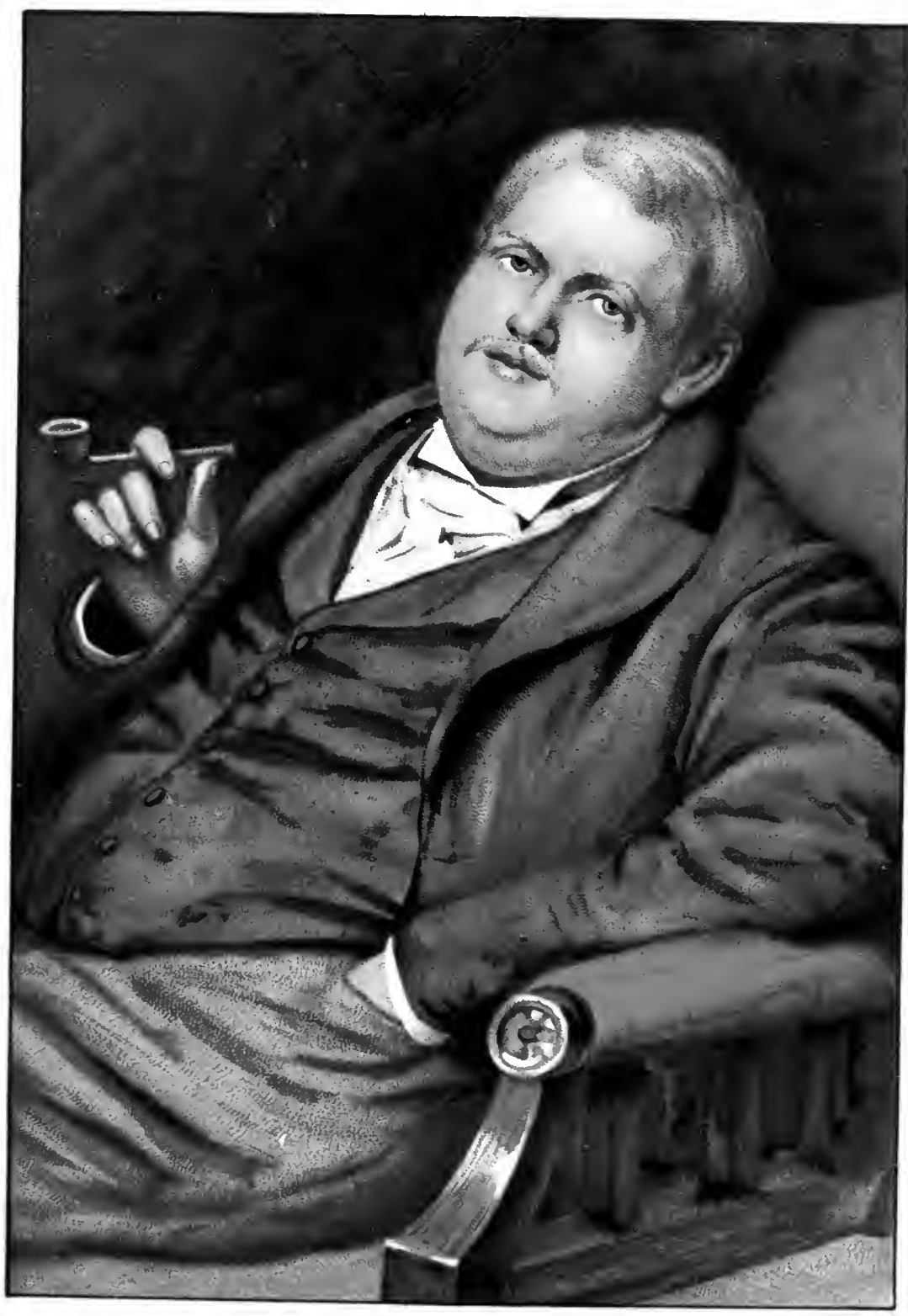

LYMPHATIC (CHIEFLY) 

THE ORGANS OF THE TEMPERAMENTS. 25 I

\section{Climate and the Temperaments.}

Although everyone knows that the same place suits some persons well and that others cannot live in it, the relation between climate, as between food and different individuals, has not been observed, and everyone has to find out by experience whether a place suits him.

Observation would, I think, establish the temperaments as guides, and were they so established, the mistake now made by many of visiting or settling where they cannot stay without loss of energy and strength, and, in some cases, serious derangement of the organs, would be avoided.

Dickens, whose temperament was probably a compound one-bilious, sanguine, and nervous-would have been saved a month of continuous misery had the 
unsuitability of certain climates to certain temperaments been studied and made known.

In a long letter to Mr. Forster, he describes, in his inimitable way, with a minuteness rivalling Hippocrates himself, how he was affected by a month's stay at Bonchurch, Isle of Wight.

Whoever experiences similar effects anywhere should not stay a month, but shake the dust from his feet without delay.

"The first effect is an almost constant "feeling of sickness, accompanied with great "prostration of strength, an extraordinary " disposition to sleep, except at night, and if "he have anything to do requiring thought " and attention, this overpowers him to such "a degree that he can only do it in "snatches, lying down on beds in the fitful " intervals. Extreme depression of mind, and " a disposition to shed tears from morning to " night, develops itself at the same period. 
THE ORGANS OF THE TEMPERAMENTS. 253

"If he happens ever to have possessed any " energy of any kind, he finds it quenched " in a dull, stupid languor. $\mathrm{He}$ has no " purpose, power, or object in existence what"ever. When he brushes his hair in the " morning he is so weak that he is obliged " to sit in a chair to do it. $\mathrm{He}$ is incap"able of reading at all times, and his bilious "system is so utterly overthrown, that a ball " of boiling fat appears to be always behind " the top of the bridge of his nose, simmer" ing between his haggard eyes." ...

"I am quite convinced that I should die " here in a year. When I leave at the end " of this September I must go down to some " cold place, as Ramsgate, for example, for a "week or two, or I seriously believe I shall "find the effects of it for a long time."

Mr. Forster adds :-

"These were grave imputations against one " of the prettiest places in England, but of "the generally depressing influence of that "Undercliff, on particular temperaments, I had 
" enough experience to abate some of the "surprise with which I read the letter."

There are many valuable works* on the good effects on invalids of many places at home and abroad; but all who suffer from the same complaint, even in the same stage, are not equally benefited by the same place; because, probably, the climate would have been injurious to some when in health.

The Undercliff is a winter resort for sufferers from chronic lung complaints, and had Dickens been so affected and sent there; would improvement have been likely in a climate which so depressed him when well ?

Dr. R. E. Scoresby-Jackson, in "Medical "Climatology," says:- " Like that of all

* Dr. Herman Weber's treatise, "Climate and Health"Resorts," in "The Book of Health" (Cassell \& Co.), is full of information, on both parts of the subject, valuable alike to the professional and the general reader. 
" methods of treating disease, the reputation of "change of climate has suffered on account of "its indiscriminate application."

Choice of a suitable place, in health and disease, would be more certain were the effects of different climates on the four temperaments and their common compounds, observed and made known.

Dr. Beddoe says :- “ Strangely enough, "blonds are said to stand the climate of West "Africa better than brunets."

That is the kind of information wanted by the thousands of our young men who every year leave home for our colonies and elsewhere abroad; but it is a solitary observation.

The influence of organic on mental action may be briefly noticed. When the circulation is checked, and the blood driven from the surface by cold, mental action is also checked. The effects of great heat on the 
organs, and through them on mental action, are thus noted by Dr. Wilks:-

"In the late hot summer (I 868)' gastric " and hepatic (stomach and liver) disturb" ances were rife, and as regarded physical " and mental energy we constantly heard the " remark that less work could be done, and "some even gained an insight into the plea" sures of sitting cross-legged all day long, "drinking coffee and smoking a hookah.".

The effects of altered action of the organs on mental characteristics are thus stated by Dr. Prichard:-

"Changes in the habitual state of the dis"position, and of the instincts and tendencies "to action, are induced by manifest causes "affecting the physical or organic functions."

"The states of the digestive organs influ"ence the temper in a very sensible manner. "Hunger or long fasting exasperates the fero" city of beasts of prey; the effect of a " full meal is well known to modify the "disposition in a reverse way; the inclina- 
THE ORGANS OF THE TEMPERAMENTS. 257

" tions are changed by the influence of wine " and stimulants; cowards become valiant, "and the timid and reserved loquacious."Cyclopedia of Practical Medicine.

In a recent address (Sept. I 882) by Sir Rutherford Alcock, the influence of the organs on mental action is fully recognized :- -

"As the bodily organs unquestionably did " influence the mind, and might enfeeble or " distort the judgment, whatever tended to " maintain a fair standard of health added " essentially to the sum of human happiness " and good judgment. A good digestion, "therefore, they might fairly conclude, was "quite as necessary as a good conscience."

The following extract from The Times also shows how essential good health is to natural mental action :-

"One of the most advanced thinkers and "men of science of our time has frankly 
" admitted that his theological views are " considerably modified by the state of his " health; and if one's ideas on futurity are " thus affected, it is no wonder that things " of this world wear a different aspect when "viewed from a sick bed."- " Invalid Litera"ture," August 3 1st, I $88 \mathrm{I}$.

The following, quoted from one of Robertson's sermons by Dr. Wilks, was probably influenced by nervousness:-

"We are fearfully and wonderfully made. "Of that constitution which we, in our "ignorance, call union of soul and body, "we know little, except of what is cause " and what effect. We would fain believe " that the mind has power over the body, "but it is just as true that the body rules " the mind. Causes apparently the most " trivial-a heated room, want of exercise, a "sunless day, a northern aspect-will make "all the difference between happiness and " unhappiness, between faith and doubt, be"tween courage and indecision. To our fancy 
THE ORGANS OF THE TEMPERAMENTS. 259

" there is something humiliating in being thus " at the mercy of our animal organism. "We would fain find nobler causes for our "emotions as well as our sublimest sorrows. "It is a duty, therefore, to keep the body " in temperance, soberness, and chastity; to "guard it from pernicious influence, and to " obey the laws of health, are just as. much "religious as moral duties."

Never more perhaps than when convalescent from an illness which overpowered all thought and interest, is it felt how dependent natural mental action is on the healthy action of the organs.

As day by day the temperature of the body becomes lower, and the pulse falls, and the appetite and sleep and muscular power return, it is felt that day by day the mind as well as the body is becoming able for, and returning with zest to, its former enjoyments. 
It remains to be noticed that competent thinkers believe that difference in minute structure accounts for the difference between men in everything that is expressed by temperament.

Sir James Paget says :-

"The inheritance of likeness in disease or " liability to disease is indeed clear evidence " of the transmission of likeness in the very "minutest structure and composition."-The Bradshaw Lecture, 1882.

Sir Dyce Duckworth, in an address given in 1883 , says :-

"One cannot doubt that these likenesses "of feature and character have also as " exactly reproduced counterparts in the several "bodily tissues, with the same potential "qualities as to evolution, and the same "tendencies to break down in similar lines " of decay." 
THE ORGANS OF THE TEMPERAMENTS. 26 I

If so, it follows that a son or daughter who greatly resembles one parent and is quite unlike the other, inherits the constitution and predisposition to disease of the former only.

Some proof of this may be found in the similar history of disease in twins who were alike (page 39), but it is a subject which seems to have a wide interest, and to call for the fullest inquiry.

The shadow of inherited insanity, with its social darkenings, would be removed from half of those it follows, were the probability made a certainty, that features altogether unlike carry freedom from inheritance.

Life Assurance Offices in refusing to insure a life if either parent has suffered from a disease that is hereditary, may 
be doing an injustice to a son or a daughter who inherits none of the parent's features.

I am hopeful that inquiry may confirm the inference drawn from Dr. Duckworth's argument, and that comparison of features may come to be considered essential when in Life Assurance there is a history of transmissible disease.

\section{An Assyrian Inscription.}

The following inscription, from Smith's "Assyrian Discoveries," is remarkable for the invocation of 'satisfaction'-whatever that meant-to the Liver; the organ of the Bilious temperament.

"May thy heart rejoice; may thy liver be " satisfied. 
THE ORGANS OF THE TEMPERAMENTS. 263

"O lord great Anu, may thy heart rejoice;

"O lord great mountain Bel, may thy liver " be satisfied.

" $O$ goddess lady of heaven, may thy heart " rejoice;

" $O$ mistress lady of heaven, may thy liver "be satisfied,

"O mistress lady of the temple of Anna, " may thy heart rejoice;

"O mistress lady of Erech, may thy liver " be satisfied.

" $O$ mistress lady of Zasuh-erech, may thy " heart rejoice;

" $O$ mistress lady of Harris-Kalama (mount of " the world), may thy liver be satisfied.

" $O$ mistress lady of Silim-Kalama, may thy " heart rejoice;

"O mistress lady of Babylon, may thy liver " be satisfied.

"O mistress lady named Nana, may thy " heart rejoice ;

"O lady of the temple, lady of the gods, " may thy liver be satisfied."

In another of the many inscriptions in 
264 OUR TEMPERAMENTS.

the same volume is the line:-

"The wide heaven is the expanse of thy "liver."

We, "a fair and reddish (sanguine) race" (page 105), attribute whatever is good or bad, in word or deed, to the Heart; the organ of the Sanguine temperament:-

"He hath a heart as sound as a bell and his "tongue is the clapper; for what his heart "thinks his tongue speaks."-Shakespeare.

"The heart aye's the part aye That makes us right or wrong."

-Burns. 
PART II.

\section{THE TEACHING OF THE} TEMPERAMENTS. 



\section{CHAPTER $\mathrm{X}$.}

THE TEMPERAMENTS AVAILABLE IN EDUCATION.

Gain to education by classing scholars according to the temperaments.-Dr. Carver, late of Dulwich College, on the importance of the careful study of the aptitudes of boys.Canon Farrar on indiscriminate education.Extracts from The Spectator, No. 307: 'Thoughts on Education."-Preparation for competitive examinations often injurious to health.-Sir J. Crichton Browne's views. -Mrs. Elizabeth Garrett Anderson, M.D., on "Examinations for Girls."-How injury to health may be avoided.-How parents may advantageously modify the mental action of their children's temperaments.Temperament classes in schools, from an American work.

A $\mathrm{S}$ the teacher, like the farmer, has to do with very different soils, education, it may safely be said, would 
produce a far greater number of prominent scholars, would far oftener influence success in professions and other pursuits, and be less often injurious to the health of those preparing for examinations, were advanced pupils classed according to their natural gifts, that these might be specially cultivated.

The physical characteristics of the four pure temperaments, as given in pages $79,80,8 \mathrm{I}$, and 82 , would render the classification easy; ${ }^{*}$ and as the mental characteristics, given with the physical ones, indicate the natural tendencies of the four temperaments, acquaintance with them would facilitate the selection of studies most likely to be successfully and safely pursued by the different classes.

* As the pure or fundamental temperaments are seldom seen, the classification by temperament would be formed of those chiefly sanguine, bilious, lymphatic, or nervous. (See page 289.) 
THE TEMPERAMENTS AND EDUCATION. 269

It is obviously wrong-unfair-to examine in the same subjects, and prepare for examination in the same way, those who differ so greatly in mental characteristics as the sanguine, the bilious, the lymphatic, and the nervous.

Having long insisted on the likings and aptitudes of children and youths being reliable guides to the studies they are most likely to pursue with ease, success, and distinction, I was pleased to read a report of what was said by Dr. Carver, the head-master of Dulwich College, on speech-day (July $\mathrm{r} 88 \mathrm{I}$ ), in reference to the practice of the College of harmonizing study and aptitude.

"His aim and that of the Governors had " been to make the basis of the College as "wide and comprehensive as possible. With" out neglecting classical learning, they took " care to provide each boy with the means of 
"preparing himself for the various occupations " of modern life. To some extent the method " was an experiment, but it had been justified "by success. There was too much danger in " the present day of making the curriculum " too comprehensive, and so frittering away the "pupil's energies in getting a smattering of " many subjects rather than soundness in a " few.

"This danger could only be counteracted "by careful study of the aptitudes of each "boy, and by directing his academical course " accordingly.

"In proof of the success of this plan the " master made reference to the long printed "list of honours and distinctions gained by "Dulwich boys at University and other public "competitive examinations."-The Times, Aug. Ist, I $88 \mathrm{I}$.

Of the usual system of education Canon Farrar, in an address at Baltimore (Oct. Ist, I 885 ), said :-

"The system in vogue neglected some of 
THE TEMPERAMENTS AND EDUCATION. 27 I

" the powers of all minds, and all of the "powers of some minds. By it some, like "Johnson, grew up as little prodigies; and " others, like Sir Walter Scott, as little dunces. "The same lustre was given to the snake as " to the diamond."

Were the temperaments generally known -every parent and every teacher being familiar with them-even the very early education of children would be influenced by them, and Dr. Carver and others in his position would receive scholars whose aptitudes are well known.

The common-sense plan pursued by Dr. Carver of harmonizing study and aptitude, of which the report says :-

"To some extent this method was an experi"ment, but it was justified by success,"

is, I fear, not yet pursued in many other colleges or schools. 
As, however, it is probably the practical outcome of a generally felt professional necessity, and has so far been successful, it may be hoped that it will ere long be widely adopted.

The plan which Dr. Carver was trying experimentally, in I88I, was forcibly insisted on in The Spectator in I7II-one hundred and eighty years since. Nos. 307,3 I $3,337,353$ are on education, and contain much that is as applicable now as it was then.

From No. 307, "Thoughts on Education," chiefly on the "importance of discovering the special aptitudes of youths and harmonizing their studies with them, I select the following pertinent parts:-

"I have seen a book written by Juan Huartes, "a Spanish physician, entitled Examen de Inge" nois, wherein he lays it down as one of his 
" first positions, that nothing but nature can "qualify a man for learning: and that without " a proper temperament for the particular art " or science which he studies, his utmost pains " and application, assisted by the ablest masters, " will be to no purpose.

"This author therefore proposes, that there "should be certain triers or examiners appointed "by the state, to inspect the genius of every "particular boy, and to allot him the part that " is most suitable to his natural talents.*

"The story of Clavius is very well known. "He was entered in a college of Jesuits, and "after having been tried at several parts of "learning, was upon the point of being dis" missed as an hopeless blockhead, until one "of the fathers took it into his head to make " an essay of his parts in geometry, which, it "seems, hit his genius so luckily, that he after"wards became one of the greatest mathema" ticians of the age. $\dagger$ It is commonly thought "that the sagacity of these fathers, in discovering

* The italics are not in the original.

+ "Clavius died at Rome in I6I2, aged seventy-five; "his works are comprised in five volumes in folio." 
" the talent of a young student, has not a "little contributed to the figure which their " order has made in the world.

"How different from this manner of educa"tion is that which prevails in our own " country! where nothing is more usual than " to see forty or fifty "boys of several ages, " tempers, and inclinations, ranged together in " the same class, employed upon the same " authors, and enjoined the same tasks!

"To be brief, instead of adapting studies to " the particular genius of a youth, we expect "from the young man, that he should adapt " his genius to his studies.

"If the present age is more laudable than " those which have gone before it in any single "particular, it is in that generous care which "several well-disposed persons have taken in " the education of poor children; and as in " these charity-schools there is no place left for "the overweening fondness of a parent, the " directors of them would make them beneficial " to the public, if they considered the precept "which I have been thus long inculcating. "They might easily, by well examining the 
"parts of those under their inspection, make a "just distribution of them into proper classes "and divisions, and allot to them this or that "particular study, as their genius qualifies them, "for professions, trades, handicrafts, or service "by sea or land.*

"The Spartans, though they acted with the " spirit which I am here speaking of, carried it "much farther than what I propose. Among "them it was not lawful for the father himself " to bring up his children after his own fancy. "As soon as they were seven years old, they "were all 'listed in several companies, and " disciplined by the public. The old men " were spectators of their performances, who " often raised quarrels among them, and set " them at strife with one another, that by those " early discoveries they might see how their "several talents lay, and, without any regard " to their quality, disposed of them accordingly "for the service of the commonwealth. By "this means Sparta soon became the mistress " of Greece, and famous through the whole "world for her civil and military discipline."

* The italics are not in the original. 
As The Spectator was eagerly read every morning by the educated classes it seems strange that the convincing views, so admirably expressed in the Nos. referred to, should have had no practical effect, and that boys of every rank are, it may be said, still allowed to leave school, no attempt having been made to make use of the opportunities given during their education to ascertain, from their natural gifts and aptitudes, the fields of work which they are likely to cultivate with success.

The papers appeared in I7II, and now in $1885 \mathrm{Mr}$. Chamberlain, in advocating free education in a speech at Trowbridge, used almost the same words as The Spectator:-

"Believe me, it is to the interest of the nation " as well as to the interests of the parents and " children that each child, according to its 
" natural gifts and aptitudes, should have the "opportunity of the best cultivation; that all " should be stimulated and encouraged to de"velop the faculties with which God has gifted " them to their advantage."

Our school-boards might do well to adopt some method as effective as the Spartan one of finding out and cultivating the natural gifts of the children, that they may be made the most of in the world.

A welcome result to ratepayers would be a system of registration of the fitness of girls and boys for particular pursuits; providing an unfailing and ready source from which they might supply themselves with those most likely to fill situations efficiently.

Competitive examinations have been accused of so overtaxing the brain that, by many, all studies have to be given up 
for a long time or altogether; a result that might be expected from a system of education which aims at preparing as many as possible for these examinations.

I give the opposite views of this important matter of two well-known authorities.

The following is from "Education and the Nervous System," by Sir J. Crichton Browne, M.D., LL.D., F.R.S., in The Book of Health, p. 269 :-

"The epidemic of examinations which has "overrun the country deserves a fuller exa" mination than can be granted here. It " threatens to defeat all the objects of those "who have been most zealous in advancing "education, for it must, if unchecked, blight "all true education, while at the same time " it cannot fail to make serious inroads on " the health of the people. 
"It is upon the most sensitive and refined " - the nervous and conscientious-that com"petitive examinations exert their worst effects.

"In the case of girls, in whom emulation " is generally intensively active, examinations " must be very jealously watched."

In a letter to The Times (Feb. I 7 th, I 88I) on "Examinations for Girls," Mrs. Elizabeth Garrett Anderson, M.D., writes:-

"I should be sorry to be supposed to think " that examinations, properly used and properly " prepared for, are necessarily dangerous. "This is certainly not my opinion in the "case of girls of fair average health, and "who inherit from their parents respectably "good nervous systems.

"When such a girl has been well and " regularly taught from the age of seven or " eight, she ought, I think, to be able to "pass the Junior Oxford or Cambridge Local "Examination before she is sixteen, and the "Senior before eighteen, quite easily, with "very little special preparation and without 
" any pernicious excitement; and if she is, "the examination cannot do her anything "but good. On the other hand, if a girl of "thirteen or fourteen, even of fair health, " begins then for the first time to be well " taught and is rapidly ground up into fitness, "first for the junior and then for the senior " examination, and is very conscious herself of " the effort required to keep her up to what " is wanted from her, the physical result will " in many cases be bad.

"Perhaps the most trustworthy rule in this "case is that that which is easy is safe.

"In youth long-continued strain is un" doubtedly more injurious than it is to persons "of mature age, and examinations are only "safe to those who are growing and developing "rapidly, when they can be gone through with " ease, i.e., without the mental and nervous "strain that belong to difficulty."

On all who are preparing themselves for these examinations I cannot urge too strongly the importance of selecting for special study and examination, when 
possible, physical geography, botany, geology, zoology, chemistry, or physics.

The study of any of these subjects, by occupying the senses, would temper the strain of studies that are sedentary, wholly intellectual, and therefore more difficult to be stored in the memory for instant recall.

The "fair average health" and "good nervous system" which Mrs. Garrett Anderson very wisely considers essential in girls are equally so in boys, and preparation for competitive examinations would less often injure the health of either, were a preliminary examination of physical fitness instituted in public schools; and many a break-down would, I am sure, be prevented by selecting for special study subjects in harmony with the temperament, the physical and mental characteristics of which should be well considered. 
As the more congenial the study the less will be the friction and wear, surely subjects that are learned with difficulty, and by many are no sooner learned than they begin to be forgotten, should, if possible, be avoided, and those in harmony with likings and aptitudes be chosen.

Those preparing for examinations should not grudge the time required for sufficient daily exercise to maintain the good health so essential for satisfactory work, without strain.

There are probably many more cases of break-down from ill-directed or over study among girls than boys; and that it should be so seems accounted for by the greater love and opportunities of out-door games that the latter have.

Fortunately, to excel physically is an innate desire of boys, most of whom have some coming match mixed up with 
THE TEMPERAMENTS AND EDUCATION. 283

their studies, and, as soon as released from classes, betake themselves to the field, where their chests are expanded, their limbs exercised, a new interest awakened, the mind toned, and the nervous system maintained.

Instead; studious girls betake themselves to their books. Some boys too. Of both, the body first, and then the mind succumbs.

This seems the most fitting place to observe that as the happiness of school and college life greatly depends on ability to make and keep friends, parents who have acquired a practical knowledge of the temperaments may, by modifying their natural action, when necessary, promote the happiness and welfare of their children through life.

A child, in whom the too ready manifestation of the leading mental 
characteristics of its temperament causes frequent regret, may have it tempered by the action of the modifying causes mentioned in chap. viii.

If, for example, of a sanguine temperament, excitable and thoughtlessly impetuous, the lymphatic temperament should be cultivated by diet that increases the watery portion of the blood, or thins it :-

"The temper of a gentleman of sanguine " temperament, who for some months lived on "vegetables, became much less excitable."-

Dr. Pereira.

Mr. George Combe, in his American Lectures on Phrenology, gives an instance of the children of an institution in New York being confined to vegetable diet to improve their morals; but this is a corrective that to be effective must be applied individually, by those acquainted with the temperaments, and how greatly those who 
THE TEMPERAMENTS AND EDUCATION. 285 differ in temperament differ in almost everything relating to food. See page 249, "Food and the Temperaments.".

As a too excitable child is not likely to become less so if there are brothers and sisters who are also excitable, it should be kept apart from them, with grown-up persons having control, and be sent away to school as early as possible.

Sanguine children, impulsive and without perseverance, may have these characteristics modified by suitable books-biographies of men who attained fame by steadily pursuing some great object, and by pastimes that employ the hands, and require thought, time, and quiet.

Most fathers see their former selves in the tendencies, impulses, and actions of their children, and remember with pain the troubles that resulted, and the long fight that went on between their reason 
and their nature ere the latter was sufficiently subdued:-

"I see another law in my members, warring "against the law of my mind."-Rom. vii. 23.

Hitherto the corrective means blindly used by parents, schoolmasters, and all in authority, have been persuasion, preaching, and punishment; but a rational treatment, less likely to fail, is supplied by an intimate and practical acquaintance with the temperaments, and how they may be modified, as I have outlined, by diet, companionship, and pastimes.

Soon after the issue of the first edition of this Essay, an American work,* partly devoted to Temperament, came into my hands, and greatly surprised me by con-

* "The Scientific Basis of Education demonstrated by an Analysis of the Temperaments, etc. In a series of letters to the Department of Public Instruction in the City of New York." By John Hecker (one of the Inspectors of the Public Schools of New York). 2nd edition, New York, 1868 . 
TEMPERAMENT CLASSES IN SCHOOLS. 287

taining a remarkably complete and wellinformed account of the subject, and very advanced views of its practical value in education.

Convincing reasons are given why scholars should be classed and taught according to their temperaments, and I give a few extracts from this interesting part of the volume, and from letters to the author from well-qualified judges, expressing appreciation of his views.

"The 'present system of classification makes " no allowance for differences of character, dis" position, etc. Now, I am convinced that it is " practicable to take notice of the distinctions " of temperaments at least, and in a way which "will increase the efficiency and success of the " teacher's efforts."

"The principals of our schools could easily " qualify themselves to divide a class into four "portions, according to the predominance of " the four temperaments, respectively, and such 
"a division would be thorough enough for "practical purposes."

"In initiating this method, my first effort " would be to obtain the concurrence of the " principal of some one of the primary schools " in the attempt. I should ascertain that she " had a general knowledge of the leading "temperaments, and the physical signs by which " they may be known; there are, of course, "many which, for want of space, are not "alluded to in this letter. I should then ask " her to arrange the pupils of each class into " four divisions, according to her own judgment " of their temperaments, and that they should "be so seated in the class-room that the "different temperaments would occupy separate "places. This being done, I should visit the " class from day to day, and confer with the "principal and teachers upon the different modes " by which these divisions might with advantage "be managed. Upon this head, explanations " cannot be given in detail upon paper; but " in the presence of any ordinary children I "should be able to make them at once." "As every person possesses, in some degree, 
TEMPERAMENT CLASSES IN SCHOOLS. 289

" all of the four primary temperaments,-the " nervous, the sanguine, the lymphatic, and the " bilious combined; in the classification in which "I advise that the pupils of a class be arranged " in four divisions according to these four " temperaments, I mean that those in whom a "given temperament predominates are to be placed " together."

"It is certainly within my hope and expec" tation that the time will come when the " ordinary combinations of the temperaments " will be well understood, and their physiological " indications familiarly known to observers; and "when methods of instruction and discipline "will be adapted to many different varieties " and shades of combination."

"The importance of the temperaments in "respect to the selection of studies consists " chiefly in their bearing on the choice of a " profession or vocation in life, in reference to "which some of the studies to be pursued in "the latter part of the course should be " chosen." 
The following extracts are from a few of the letters (pp. xiii.-xxxvii.) to the author, from leading School Superintendents and others, on his proposal to separate scholars into temperament classes:-

"Dear Sir,

"In accordance with your request, I "have carefully perused the full exposition of "your views on the subject of classification of "the pupils of our Public Schools, with " reference to the respective temperaments. "Those views are, in my judgment, of the " highest practical importance as well to teachers " as pupils-based upon the soundest principles "of physical, mental, and moral science, and "admitting of practical application by every " teacher who will take the pains of acquainting " himself or herself with the principles upon " which they are founded, and from whence " they are legitimately and clearly deduced. I "should be glad to see them placed in the "hands of all our teachers, in the assured "conviction that their general adoption would 
"essentially advance the best interests of "education.

\section{"S. S. RANDALL,} "City Superintendent."

From the Rev. Edward Ballard, D.D., State Superintendent of Schools, Brunswick, Maine.

"As to your proposals relative to an im"provement in the classification of scholars, by " temperament, I can say that it has much to "recommend it, and where the judicious teacher "can make the due selection and arrangement, " his work will be lightened, the tuition be " the more easily applied, the pupils the more " interested and the less fretted under the " restraints of the school-room and class exer"cises, and success the more certain to be "attained. Temperament classification is worthy " of a fair trial."

From Professor A. Parish, Superintendent of Schools, New Haven, Conn.

"If I know the temperament of a child I " know how to approach him to accomplish 
" a given object, to what motives to appeal, " what influences to bring to bear on him, etc. "In this view of the matter I am interested " to know more of your views and the whole "subject. If it can be brought to the compre" hension of the ordinary teacher, and can be " reduced to a practical application in the "schoolroom, it is obvious that the matter of " school discipline must be greatly modified if " not revolutionized, and all the processes of " instruction materially facilitated."

“Department of Public Instruction, Superintendent's Office, I46, Grand Street, New rork.

"I have read and re-read your 'Scientific " 'Basis of Education,' and feel bound to express " to you my sense of obligation. My work " as a teacher and as a reviewer of the work " of other teachers, presents itself to me in a " new light. Not a day passes that I do not " see many illustrations of the value of your sug"gestions. I am persuaded that when teachers "generally can be induced to study carefully " the subject, and to endeavour to put its 
" philosophy into practice, a new era in educa"tion will have dawned.

"I am convinced that your proposed plan of " classification by temperaments is itself founded " in unquestionable facts open to the observation " of all.

" My chief fear as to the success of experi" ments made to apply the system, is that the "application may be attempted by those who " have not given to the principles involved a "sufficient and careful study.

"I shall have great pleasure in commending " it to the attention of my fellow teachers.

$$
\text { "Thos. F. Harrison." }
$$

The expression of dissatisfaction with indiscriminate education by the many eminently competent judges whose opinions were asked by Mr. Hecker, and their welcome reception of his views, encourage the belief that the time may come when temperament classification and teaching will be adopted and become general; but there must first be preparation for so great a change 
by popular teaching of the temperaments and their associated mental characteristics.

Till the physical and mental characteristics of the temperaments become a part of school education, teachers being able to exemplify them in their scholars, any attempt to introduce temperament classification and teaching would be premature.

It would have been well had Mr. Hecker been able to support his views by the results of temperament classification and teaching, in a school under his own management. 


\section{CHAPTER XI.}

THE TEMPERAMENTS AVAILABLE IN THE CHOICE OF A PROFESSION.

Business openings difficult to find.-Fitness often overlooked.-Consequent continued regret. -A case in point.-Sons put into their father's business fit or unfit.-Their future often arranged before they are born.Mr. Ruskin's by his mother.-The temperaments a guide to parents in judging the fitness of their children.-Likings sometimes found without aptitude.

SONS having finished their education, $D$ business openings have to be found for them, but are so difficult to find, that all consideration of fitness is very often put aside, although it may govern their success and happiness through life. 
I have often heard it said, "Oh! Mr. —, a City man, is looking out for him,"-Mr. — never having seen the youth; knowing only his father.

It is one of the worst features of the age, that there is little or no choice; that parents are forced to place their sons, fit or unfit, in almost the first openings that present themselves; the result being, in many cases, chafing, fretting, failure.

Probably one half the number of men engaged in any profession or business have the conviction that they are naturally better fitted for some other pursuit than the one that occupies them, into which they may have been put without consideration of the scope it would give to their likings and aptitudes.

When change seems no longer possible, by far the greater number settle down to their work, and may pursue it successfully, 
but regret that their natural gifts are being wasted never altogether leaves them, and, if occasion arise, may be expressed to a sympathetic and trusted ear, even when they have grown old and had innumerable opportunities of comparing themselves with others.

Only yesterday I was more than usually impressed by such an expression of regret from one whose well-proportioned, welldeveloped, and powerful frame at once suggested fitness for out-door physical employment; whereas, for nearly twenty years he has been engaged in routine clerical work in a city office. Of a Sanguine and Nervous temperament-. energetic, intellectual, and inventive-he bitterly complained of the monotonous, uninteresting character of his work, which required no thought whatever. The nervous part of his temperament, however, has found an outlet during his leisure 
hours at home, in the successful construction and invention of mechanical arrangements; and his own conviction, which is shared by all who know him, is, that such was the field to have given scope to his natural gifts. How much might be gained by individuals and the public, were such as he-Sanguine and Nervous-to change places with plodding Lymphatics, who, also out of place, are in positions requiring energy and rapidity of action!

Albert Dürer (Life and Times, I882),

" explained the difference in the outward appear"ance of men simply by a reference to the "four complexions (temperaments), and he con"sidered it indispensable before choosing Art as " a profession for children that their tempera"ments should be well considered."

Although parents soon become aware of their children's likings and aptitudes, they are not, I think, sufficiently impressed by 
the important truth that success and happiness in after life are dependent on these having sufficient scope, or they would surely weigh them more carefully before accepting places for their sons in which their natural gifts must at best be wasted.

Fathers who have been successful in business very generally bring up one or more of their sons to succeed them, without thought of their ability, only that a good thing be kept in the family; and there are often cherished intentions with regard to the future of sons yet unborn; it being altogether ignored that nature may have different intentions.

In “Præterita," p. 22, Mr. Ruskin says :-

"My mother had, as she afterwards told "me, solemnly devoted me to God, before I "was born ; in imitation of Hannah. 
"Very good women are remarkably apt to " make away with their children prematurely " in this manner. ....

" 'Devoting me to God,' meant, as far as " my mother knew herself what she meant, " that she would try to send me to college, " and make a clergyman of me: and I was " accordingly bred for 'the Church.' Many " and many a year afterwards, my father said " with tears in his eyes-(true and tender " tears as ever father shed,) 'he would have " 'been a bishop." "

Fortunately he was allowed to follow his likings and aptitudes, for there have been many bishops in his time, but not yet another Ruskin; and it may be many a day ere England see his like again.

I do not doubt that the serious matter of entrance on the business of life would be less haphazard were the doctrine of the temperaments a part of general knowledge.

Were parents fully aware of the intimate 
THE CHOICE OF A PROFESSION. 3OI

relation between the physical and the mental parts of the temperaments, as in The Scheme, chap. iv., they would begin to read the features of their children from infancy, and would become so thoroughly familiar with the associated mental characteristics, that knowledge of the direction of their capabilities would grow with their growth, and become so confirmed that it would scarcely be possible to do such violence to matured conviction as to place a youth where his natural gifts would be buried.

They could not, for example, place brothers closely resembling each other in disposition, mind, tastes, features, and figure in positions which require for success physical and mental capabilities altogether different; or in the same profession or business two brothers as unlike each other as the twins, one of whom in his reply to Mr. Galton says :- 
" $\mathrm{He}$ was contemplative, poetical, and literary " to a remarkable degree, showing great power " in that line. I was practical, mathematical, "and linguistic" (page 46).

Youths, however, are often biassed by reading or otherwise, and have likings without aptitude; but parents who are familiar with the temperaments will see from the first that such likings are not in harmony with their physical characteristics, and will endeavour to substitute those that are. 


\section{CHAPTER XII.}

THE TEMPERAMENTS AVAILABLE IN THE PROMOTION OF HEALTH.

The teaching of the temperaments as regards health.-Only nervousness considered.Signs of nervousness.-Some of its causes.-Predisposition relative to the number of nervous characteristics.-Effects on business men and others.-Preventive and curative means.-Addison's modes of taking exercise.-The sleeplessness of nervousness.-Work and nervousness.-Work and sleep.-Expedients to procure sleep.The direction of the body in sleep.-The suburban homes of business men a cause of nervousness, especially in women. Appendix. "American Nervousness."

THE popular Teaching of the Tem1 peraments, as regards health, is that every one of the four temperaments 
is predisposed to derangement and disease of its own organ; the Heart in the Sanguine; the Liver in the Bilious; the Lymphatic or Glandular system in the Lymphatic; and the Nervous system in those of the Nervous temperament; and that every one should become acquainted with the action of the organs of the four temperaments that he may observe the causes that act injuriously on the organ that governs his own (chap. ix.).

As consideration of the causes of the diseases to which the organs of the four temperaments are susceptible would involve professional details, I shall confine this chapter to showing how the organ of the Nervous temperament-the Nervous system-may be fortified against Nervousness, the predisposing cause of many of the diseases of the three other organs. 
THE PROMOTION OF HEALTH. 305

Nervousness is very variously manifested, but apart from the special forms to which names have been given (see appendix to this chapter), sleeplessness, irritability, and exhaustion suffice to characterize it (see chap. vi., "The Nervous Temperament").

\section{A recent writer * says :-}

"Nervous diseases scarcely exist among "barbarians, half-civilised people, the lower " orders of cities, the peasantry, muscle-workers " as distinguished from brain-workers.

"The primary cause of nervousness is civili"sation with its recent accompaniments, the "telegraph, the railway, and the periodical press, "which continue to draw each year most "severely on the nerves of all classes, especially "those favoured with education."

* American Nervousness, its Causes and Consequences, by George M. Beard, A.M., M.D., etc. I88ז.

A summary of Dr. Beard's views, from The Times, is given as an appendix to this chapter. 
A similar cause which might, I think, have been added, is Cheap Postage, with its vast increase of letter-writing; impossible arrears which vex the conscience; interest in a greater number of people and affairs; and impatience should the post fail to bring the expected news of them.

It is undoubted that cases of breakdown among business men, necessitating " absolute rest," and also of fatal brain mischief, are increasing every year.

Here is a death-notice that appeared in The Times, and did not seem to startle as it would were such cases very uncommon :-

"On the 2 Ist, from an overtaxed "brain, George Chas. . . . of the "firm of . . . . . . . wool"brokers, London, aged 49." 
Two hundred years ago a death from "an over-taxed brain" was so remarkable that it was thought worthy of record in the Weston Papers, which form part of the latest report of the Historical Manuscript Commission: "There is "mourning for a wealthy man of " business,
"who has left clear $£ \mathrm{I} 60,000$ by a "pursuit keene and arduous, which "worked the capillaries of the brain " to a filament, and dissolved the "whole frame at $46 . "$

"Pursuit keene and arduous" has now become imperative in many a business, and many a robust frame "dissolves" at, or about forty-six, with, if any at all, a much smaller residuum than "a clear $f_{\mathrm{J}} \mathrm{6} 60,000$."

The following paragraphs from The Times-only one day intervening-are 
proofs of the too great mental strain from the preparation at short intervals of the original and brilliant discourses preached by eminent divines, probably already tired out by other work before their preparation could be commenced:-

"Mr. Spurgeon.-Yesterday morning the "Rev. C. H. Spurgeon announced to his " congregation that the state of his health "was such as to necessitate his leaving "London for some time. What with the " unceasing care of such a large church and "the numerous institutions connected therewith, "his brain had become weary, and some " repose, his medical adviser had told him, "was absolutely nećessary."-Nov. 23rd, 1885.

"DR. Liddon.-We are informed that "Canon Liddon has been ordered immediately "abroad by his physicians for a lengthened "period. $\mathrm{He}$ is ordered to abstain from "preaching and literary work, and to take " perfect rest."-Nov. 25th, I 885 . 
It will, I think, be found that those whose physical characteristics are Sanguine, Bilious, or Lymphatic, free from Nervous characteristics, seldom suffer from nervousness, and that the predisposition is greater or less as nervous characteristics are many or few.

Muscle-workers being comparatively free from nervousness, business men, and all, especially those of the nervous temperament, who lead anxious lives and have sedentary occupations, should begin early to divide the day between muscle-work and brainwork, by cultivating after business hours some kind of outdoor exercise which may rest their brains and strengthen their frames; and indoor evening pursuits which by expending muscular force may tire nature and secure sleep.

Fortunately outdoor games are now much enjoyed, but as they are impossible 
during at least six months of the year, it would surely be well were every neighbourhood provided with a coveredin and lighted gymnasium, tennis-court, bicycle course, and skating-rink, as rivals, in the winter months and unsuitable weather, to cards and other sedentary games, and billiards, when played, as they often are, in underground low-ceilinged rooms.

"In the days of the early Greeks, gymnasia "were the chief places where manly sports " of all kinds were indulged in. . .

"The Romans called their places of exercise " 'Thermæ,' where the bath and the gymnastic "area were under the same roof.

"Magnificent buildings, in many instances "enclosing enormous areas, provided ample "space for exercise, and no doubt did a vast "deal of good to the physique of these "nations."-The Book of Health, p. $45^{8}$. 
THE PROMOTION OF HEALTH. 3II

In the section- "The Influence of Exercise on Health"-in the same volume, will be found valuable information as regards muscular structure, the physiology of muscular action, training, etc., and details concerning every kind of exercise - walking, running, jumping, dancing, " riding, skating, rowing, cricket, foot"ball, swimming, lawn tennis, racquets, "bicycling and tricycling, other games, " gymnastics, calisthenics."

The kind of indoor muscular exercise at home that may promote health and ward off nervousness must be such as can be practised with regularity.

In The Spectator, No. I I 5, July I 2th, I7II, Addison fully acknowledges the daily necessity of bodily exercise, and gives his own modes of taking it:-

"There is no kind of exercise which I " would so recommend to my readers of both 
"sexes as this of riding, as there is none "which so much conduces to health, and is " every way accommodated to the body according "to the idea which I have given of it. Dr. "Sydenham is very lavish in its praises; and " if the English reader will see the mechanical " effects of it described at length, he may find "them in a book, published not many years " since, under the title Medicina Gymnastica." "For my own part when I am in town, for "want of these opportunities, I exercise myself " an hour every morning upon a dumb-bell that " is placed in a corner of my room, and it "pleases me the more because it does every"thing I require of it in the most profound " silence. My landlady and her daughters " are so well acquainted with my hours of " exercise, that they never come into my room " to disturb me whilst I am ringing.

"When I was some years younger than I " am at present I used to employ myself in " a more laborious diversion, which I learned "from a Latin treatise of exercises that is

* By Francis Fuller, M.A. 
THE PROMOTION OF HEALTH. 3 I 3

" written with a great deal of erudition : * it " is there called $\sigma \kappa \iota \mu \alpha \chi i a$, or the fighting "with a man's own shadow, and consists in " the brandishing of two short sticks grasped " in each hand, and loaded with plugs of lead " at either end. This opens the chest, exercises "the limbs, and gives a man all the pleasure " of boxing without the blows. I could wish " that several learned men would lay out that " time which they employ in controversies and "disputes about nothing, in this method of "fighting with their own shadows. It might "conduce very much to evaporate the spleen, "which makes them uneasy to the public as "well as to themselves.

"To conclude,-As I am a compound of "soul and body, I consider myself as obliged " to a double scheme of duties; and think I "have not fulfilled the business of the day "when I do not thus employ the one in labour " and exercise, as well as the other in study "and contemplation."

* Hieronymus Mercurialis's celebrated book, Artis Gymnastice apud Antiquos, etc. Libri sex. Venet. r569, 4to. 
As sleeplessness is often the first symptom of nervousness, and is soon followed by exhaustion, which paves the way for the rapid advance of every other symptom, it should not only cause alarm, but means should be promptly used to prevent its continuance, or the inevitable break-down may speedily ensue.

Sir Wm. Savory, F.R.S., on "Sleep and Work," in The Book of Health, p. 92, says :-

"Here, of course, the important question "of temperament comes in. An event which "will destroy the sleep and appetite of one " man for' a week will have no sensible effect " for a moment on another.

"Different temperaments are not so dif" ferently affected by hard work in the proper ": acceptation of the term, as by care, anxiety, "worry, and the like. In fact, for such people " hard work is often, in the long run, the best " remedy." 
I have somewhere seen it observed that the self-educated artizan, who studies by night, is saved from nervousness by being obliged to work at his handicraft by day; and the following extract shows that professional men whose work is more material, escape a calamity that overtakes some of those who draw continuously on the imagination:-

"A fact is mentioned by Dr. Conolly, which, "if it be confirmed by farther observation, "would lead to some important reflections.

"He states that it appears from the register "of the Bicètre that maniacs of the more "educated classes consist almost entirely of "Priests, Artists, Painters, Sculptors, Poets, and "Musicians ; while no instance, it is said, occurs "of the disease in Naturalists, Physicians, Geo"metricians, or Chemists."-Abercrombie on the Intellectual Powers.

The fact stated in the extract suggests that Poets, Painters, and Musicians, whose 
intellect, like Shelley's, "waits on their " temperament and works up warm emo" tions into exquisite abstractions" (p. 37I), and many others whose intellectual work is less in view, should remember, like Addison, that they are a compound of soul and body, and think it essential, as he did, to "employ the one. in labour " and exercise, as well as the other in "study and contemplation."

Poets and Painters are said by Sir J. Crichton Browne to die early compared with Mathematicians and Rational Philosophers.-The Book of Health, p. $3^{6} 3$.

All whose pursuits involve brain-work, and after-thought which may run into the night and spoil sleep, and who have sufficient exercise in the day, should, in the long winter evenings, practise some art, or acquire a practical knowledge of some science, which would fully 
occupy the mind and could be pursued at home. Such are wood-engraving, the turning-lathe, cabinet-work, chemistry, electricity, etc.-the last a study which is full of interest from its useful application in so many ways, and the hope which may be entertained by any one who devotes his evening leisure to its pursuit, of discovering other uses.

Lord Salisbury pours oil on troubled waters by chemical research, and is about, it is said, (The Atheneum, Dec. I 9 th, I 885), to publish some of the results.

Every one may find some way of employing the evenings so as to banish "care, anxiety, worry, and the like."

Banished these three enemies of sleep must be, or sleeplessness is certain to obtain the mastery.

Reading is a common resource. 
I have known a few problems of Euclid succeed.

I was told by a patient that, after many sleepless nights, he for the first time took the works of a clock to pieces, cleaned, and put them in place again before going to bed, and that the absorbing interest of the work, and the satisfaction he felt that he had completed it successfully, made him sleep soundly the whole night through.

Another sufferer got a lathe, bench, and tools, and persevered evening after evening for months, till at last he succeeded in constructing the model of a steam-engine, which was beautifully finished in every part, and worked smoothly.

"Whenever I cannot sleep I leave "town," said a well-known and hardworked member of Parliament to us.The Book of Health, p. 542. 
THE PROMOTION OF HEALTH. 3 I 9

Probably when Mr. Gladstone takes to tree-felling it is to ward off the sleeplessness for which his physician had to send him to the sunny South a few years ago.

Probably, also, we are indebted to sleeplessness for his welcome contributions to The Nineteenth Century, undertaken, it may be, to fill his mind with other thoughts than those that would banish sleep.

Mr. Gladstone's face is a tapering one, from a broad forehead,* and his temperament, judging from portraits, is probably Nervous and Sanguine, the former predisposing him to Nervousness, and the latter enabling him to overcome it.

Lord Beaconsfield's face was also tapering, from a high forehead,* and as his hair and eyes were black, his tempera-

* See photograph in Men of Mark; $A$ Gallery of Contemporary Portraits. London: Sampson Low, Marston, Searle, \& Rivington, I876-82. 
ment was probably Bilious and Nervous, in which, bilious characteristics being more numerous than nervous, nervousness is kept at bay.

Dr. Pollock, on "How to Induce "Sleep," in The Book of Health, p. 543, says :-

"Many plans have been recommended to "procure the blessing of repose for those who "cannot "lay them down in peace and sleep."

"Exercise late is good. "After supper run " 'a mile,' and it is certainly not advisable to "go direct from a hot sitting-room to a warm "bed-room for the night. A turn out into " the cool air is much more healthy, and often "succeeds in procuring a quiet night. The "bed should be firm and elastic-not feathers. "In India, Europeans use a pillow for their " knees to keep the bed cooler.

"To procure sleep we have been advised " to get up and walk about, to use the flesh"brush, and this will be found highly useful "where a dry state of skin gives that restless 
THE PROMOTION OF HEALTH. 32 I

"feeling called 'the fidgets.' We have found "total instantaneous immersion in a cold bath " highly useful. The Chinese advise to wash "the mouth with cold water; in India they "tickle the soles of the feet. Boerhaave re"commends to listen to dropping water, also "Spenser:-

"And more to lulle him in his slumber soft, "A trickling streame from high rock tumbling downe

"And ever drizling raine upon the loft,

"Mixed with a murmuring winde, much like the sowne

"Of swarming bees, did cast him in a swoyne."

"Others advise the Eolian harp, while Æs"clepiades used to be rocked asleep. Franklin "advised a cold-air bath, taken by walking "about the room in one's night-dress, and this " is very successful. Others put the feet in "very warm water. Electricity has been re"commended for this as for everything else."

In another section of the same valuable 
volume (p. 303) Sir J. Crichton Browne, M.D., LL.D., F.R.S., says :-

"Innumerable artifices and expedients for the " induction of sleep by means of mental opera"tions have been devised and recommended "by the victims of insomnia in all ages and " countries; but these, when critically examined, " resolve themselves into distractions from the "high roads of thought, and the monotonous " and wearying pursuit of some almost mechani"cal mental process. The harassed merchant " is urged to repeat poetry, the over-strung "artist to dive into logarithms, and all are "advised to count hundreds, to rehearse the " multiplication-table, to follow the ticking of " the clock, to think of the humming of bees, or " imagine that the bed whirls round with them.

"Only in mild cases can such expedients " avail, and only in them for a limited period."

\section{Dr. Pollock says :-}

"We are often consulted as to the best "posture in sleep. It is, perhaps, a matter of 
" indifference which side we select to lie on, "but all are agreed that sleeping on the back " is bad. "Sleep not on your back, or in the "“ " posture of a dead man,' says Confucius and "Hippocrates also."

\section{As the authors quoted in this chapter have} left unnoticed the influence of the direction of the body on sleep, I am induced to republish the following letter which gives the experience of a legal friend who is the most unlikely man I know to be misled:-

\section{SLEEPING NORTH AND SOUTH.}

TO THE EDITOR.

SIR,-I have read with much, interest your short article upon this question, and upon its bearing on longevity. It is a curious fact, bnt it is certainly true, that the position in which persons lie has a very important effect upon their sleeping. I discovered years ago that I could not sleep if I lay north and sorth; and, after many observations, I came to the conclusion that there was some influence of this kind which was little, if at all, understood. I found that I could sleep best lying east and west, particularly with the head to the west, and this practice I have adopted for many years. I always carry a small pocket compass, so that in sleeping at strange hotels I am enabled either to select a room in which the bed is so placed or to have the bed shifted. I feel convinced that in many instances where persons are suffering from insomnia they would find instant relief if the position in which they lay were changed. I trust that public attention will now be called to what I believe to be an exceedingly important subject.- I am, Sir, yours faithfully, A. G. D.

Mansion House-chambers, London, E.C., Sept. 6, 1883. 
The short article referred to in the letter is on the death of a foreign centenarian, who attributed his longevity and uninterrupted good health to sleeping north and south, the direction in which the writer of the letter cannot sleep.

As the direction of the head and feet has so great an influence on the sleep of some who are in health, as my friend is, and always has been, it may be found to influence the sleep of many who have become nervous and sleepless, and all such, even those who know that they could previously sleep well in any direction, should try the effect of every possible change.

In the last edition of "Hood on Gout," etc., I 885, there is a chapter on sleep, in which the direction of the head and feet is noticed:-

"Some persons have maintained, what, perhaps, 
THE PROMOTION OF HEALTH. 325

" is rather visionary, that a bedstead should "always be placed east and west, on the ground "that it is injurious to sleep in the line of the "currents of magnetism, which traverse the " earth from north to south. There is probably "no evidence in support of the belief that to "be either in the line of those currents or "transverse to them would exercise any appre"ciable effect" (page 396).

My friend's peculiarity, as given in his letter, was not the result of any visionary speculation, but was "discovered;" and the discovery having been confirmed by long experience, it must be regarded as a fact which ought to be generally known, that such peculiarity exists.

As, probably, many of those who tell us that they "never sleep well in strange beds," have the same peculiarity without knowing it, they should find out at home by changing the direction of the 
bedstead to the different points of the compass.

A somewhat similar peculiarity remains unaccounted for: the inability of some to ride in a carriage except facing the horses; and there are many others less generally known.

I conclude this chapter by calling attention to a widespread cause of the increase of nervousness, especially in women, which has, I think, escaped observation,- - the choice of suburban homes by young men about to marry, who leave them early in the morning for situations in offices or places of business in cities or towns, and return to them late in the evening, often so worn and exhausted that it is not in them to make the evenings cheerful to their wives, who, most days it may be, have spoken to no one except tradesmen or servants the whole of the day. 
THE PROMOTION OF HEALTH. 327

A dull evening is inevitable, for the neighbourhood provides no entertainment that would interest or amuse, and friends with whom they might spend a pleasant hour probably live in some other suburb, too far away.

A young wife from a home where relatives and friends within reach made her life interested and happy, is almost certain, sooner or later according to her temperament, to become nervous from the solitary and aimless life she is obliged to lead-alone all the day in a quiet suburban villa.

I am hopeful that in London the tide is about to turn from suburban hornes to the handsome, commodious, healthful, and comparatively inexpensive ones-the residential flats rising up so rapidly near the British Museum and farther west; the only homes which render happiness and 
328 OUR TEMPERAMENTS.

health possible to the greater number of the newly-married and others who have no young children.

They bring within reach the variety which is essential to keep the mind and nervous system in health. The husband may. be within walking distance of his place of business; the wife be able in the day to visit suburban friends wherever they are; and husband and wife, instead of being immured of an evening, can go as often as they wish where they may see or hear something new, at very little expense. 


\section{A P P E N D IX \\ To Chap. XII.}

\section{" AMERICAN NERVOUSNESS.'}

From The Times.

"American Nervousness.-In a recently"published paper on this subject by Dr. G. "M. Beard, of New York, the author adduces "some striking facts to prove the recent rapid "spread of nervous disease in the United States "-facts, we suspect, which apply with equal "force to the population of our own country. "Our fathers in medicine of the last century, "if they could be brought from their graves, "would have to be told what we mean by "the term nervousness. They would say, and "very truly, that the Greeks had no word for "nervousness as we now understand that term; "and that even down to the eighteenth century " nervousness was supposed to mean irritability 
" of temper, disposition to anger, excitability-a "mental quality, and not a physical disease. "In reply, we should be obliged to say that " in the nineteenth century nervousness means " nervelessness, nervous exhaustion, abnormal " susceptibility of the nervous system to ex"ternal or internal irritants. American nervous" ness during the past half-century has expressed " itself by a large variety of symptoms, a number " of which are so frequent, so positive in their "character, and so important, that they have "given names to disease, and are known as "such. Among these symptoms and expres"sions of modern nervousness are neuralgia, " sick headache, nervous dyspepsia, hay fever, " and, above all, neurasthenia, or nervous ex"haustion in all its various forms. These " conditions, with others that could be men" tioned, constitute a family of nervous diseases " that have developed chiefly during the last "half-century, and are most abundant, most "severe, and most varied in their manifestations " in the northern portion of the United States, "although they are found in, and are now "extending to, England and the Continent 
" of Europe. The scientific proofs of this " unprecedented nervousness of the Americans "during this generation are very numerous. "First of all, Dr. Beard tells us, there " is the increased sensitiveness to cold and "heat, which is observed among all the "brain-working classes. The fathers of this "generation were content with a temperature " of $60^{\circ}$ Fahr.; now a temperature of at "least $70^{\circ}$, and even higher in many cases, " is necessary for comfort. In other words, "the present generation of Americans are " $10^{\circ}$ more sensitive to cold than were "their fathers. The heat of the summers is "no greater than it was a century ago, but " the "cases of sunstroke and heat-prostration " are widely out of proportion to the increase " of the population. Dr. Beard also refers to "the sensitiveness to stimulants and narcotics, "as alcohol and tobacco, and even tea and " coffee: 'Not only our fathers, but our " ' mothers,' he says, 'could drink freely of " "wines and strong liquors, and even smoke " " as much as they wished, without developing " ' any of the nervousness of our time. At the 
" " present time, a very considerable proportion " " of the population of this country are unable "s " to smoke or chew or drink even mild wine, " " or tea or coffee-especially the latter-without "' making themselves perceptibly worse thereby.' "All this Dr. Beard believes to be modern " and pre-eminently American. Likewise the " idiosyncrasies of patients in regard to the " actions of medicines and the effects of drugs " and various external irritants, have, during " the last half-century, multiplied in variety " and phase, and greatly augmented in number. "There are thousands who cannot bear opium, "who are kept awake instead of being put " to sleep by it. One of the very best signs " of our civilization, Dr. Beard thinks, is found " in the premature decay of the teeth. None " of the usual explanations-the use of sweets, " the use of acids, neglect of cleanliness, and " the use of food that requires little mastica"tion-will account for the fact; witness the "fine teeth of most savages. The cause of " the decay of teeth is subjective far more than "objective, in the constitution of the modern "civilized man. Delicacy of digestion is one 
"of the best known and first observed effects "of civilization upon the nervous system. The "history of the rise and fall of pork as a " food is itself most instructive on this point. " Pork, like the Indian, flies before civilization; " the stomach of the brain-worker cannot digest " it. Yet former generations ate it almost daily "without ever asking themselves whether it "was easy or hard of digestion. This de"thronement of pork, Dr. Beard .states, is "having a disastrous effect upon the American "people; for, as yet, no article of food with "a sufficient amount of fat has been generally "substituted. Fat in our dietaries is one of "the most imperative hygienic needs of our "time, and which, on all hands, we are trying " to meet by the use of cream, cod-liver oil, "eggs, fish, and the fat of fresh meat. The " eyes are good barometers, of our nervous "civilisation; the increase of asthenopia and "shortsightedness, and, in general, of the func"tional disorders of the eye, are demonstrated "facts, and are most instructive. Dr. Beard "then shows the influence which the increase "of nervousness has had in the reproductive 
"system in a variety of ways. The acknow"ledged increase in the diseases of women, Dr. "Beard attributes to one great cause, to which " all others are subordinate-civilization. He " thinks there is no question but that diseases " have changed their type during the last half" century. The only question is, what are the "degrees of change, and what are the causes "which produce these results? Curiously " enough, statistics show that longevity has "increased almost pari passu with this increase " of nervousness. These two apparently oppo"site facts, according to Dr. Beard, are harmo" nized by a third factor-namely, nervousness " is not only consistent with longevity, but "actually favours it, by preserving the system "from attacks of acute inflammatory disease. "Nervous diseases scarcely exist among bar" barians, semi-civilized people, the lower orders " in cities, the peasantry, muscle-workers as "distinguished from brain-workers. The pri" mary cause of all this nervousness is civiliza"tion, with its recent accompaniments, the "telegraph, the railway, and the periodical " press, which continue to draw each year 
" most severely on the nerves of all classes, " especially those favoured with education. "They have intensified in ten thousand ways "cerebral activity and worry. This factor "applies to Europe as well as America. The " reason why Americans are more nervous than " any other people of this planet, Dr. Beard " finds first in the dryness of their atmosphere, " and second, the extremes of heat and cold. "Dr. Beard enters into interesting details on " these points, and also on the various methods "of treatment which ought to be adopted to "counteract or cure the various forms of "nervous disease."

A leading article of $\mathcal{T}$ he Times on the foregoing summary shows that some of the results attributed by Dr. Beard to nervousness are partly due to other causes, and the following is the conclusion arrived at on his views as a whole :-

"It may nevertheless be said that Dr. Beard's 
"opinions, like most of those which are ad"vanced from somewhat one-sided points of "view, by men of intelligence and capacity, " rest upon a not inconsiderable substratum of " truth." 


\section{CHAPTER XIII.}

THE USE OF THE WORD TEMPERAMENT.

In frequent use.-Should always indicate the physical characteristics of one of the four Temperaments, or a compound one.-Extracts showing that it seldom does.-Single mental or other traits wrongly called Temperaments.-List of twenty-nine so-called Temperaments.-Extracts containing some of them.-Temperament seldom used formerly.-Only once in Addison's Spectator.Not once in Johnson's Rambler, or Idler, or Goldsmith's Vicar of Wakefield.-Probable reason.-Additional extracts showing the misuse of the word.-Standard descriptions of the four Temperaments essential to the right use of the word in literature and conversation.

$\mathrm{T}$ is shown in chapter ii. that-

"The Temperaments are groupings of the " chief physical characteristics which distinguish 
"men from one another,-dark or fair; stout " or slim ; square, oval, or tapering face ; short "or long neck," etc.,

and the present chapter is intended to show that the word temperament is almost invariably used without reference to outward appearance, and therefore conveys no obvious meaning.

Few words of four syllables are in more frequent use. It comes readily to the tongue in conversation, and is so often met with in the ordinary course of reading that the gain would be great if it always named or clearly indicated one of the four temperaments or a compound one.

It so seldom does either, that Dr. Maudsley has probably not gone too far in saying, as already quoted (page xi.), that-

"Temperament and Idiosyncrasy are big "words, at present little better than cloaks of 
USE OF THE WORD TEMPERAMENT. 339

"ignorance; they are symbols representing un"known quantities rather than words denoting "definite conditions."

That the familiar phrases "my temperament," and "his temperament," are almost always used without thought of any of the temperaments, may be readily tested by asking any one who uses either of them to name the temperament.

This very day a well-informed friend with whom I was conversing accounted for the different ways of two brothers by saying, "Their temperaments however are " quite different," but was unable to name the temperament of either brother, having used the word in relation to mental traits only.

Were the meaning of the word questioned in the same way when met with in the ordinary course of reading, it would be found that as in conversation, so in 
literature, it scarcely ever refers to a particular temperament which can be named.

In proof, I give a few of many extracts, which I have taken from the daily press and recent publications.

\section{The Duke of Albany.}

"To a young man of the temperament and " tastes of the Duke of Albany, endowed with "all the opportunities which his position secures " him, there is clearly open a career of excep"tional usefulness and beneficence. Army and "Navy were alike closed to him, but there "still remained open the less active, but not "less useful, nor, to a youth of his temperament " and tastes, less attractive career of study and " intellectual pursuits."

Here, although his temperament is twice referred to as fitting the Duke for a particular career, we are left in the dark as to whether it was Sanguine, Bilious, Lymphatic, or Nervous. 
USE OF THE WORD TEMPERAMENT. 34 I

\section{Dean Stanley.}

In a short biography of the late Dean Stanley, which appeared in a daily paper the morning after his death, his temperament is introduced three times.

"To no one could the decay of mental and "physical vigour which comes too often with "advancing years have been a more painful " trial, than to a man of his temperament.*

"But the brilliant Dean of Westminster had "other, and for a man of his temperament and "genius, higher work to do than that of de"votion to the ordinary tasks of the Christian " ministry.

"In spite of his personal gentleness and his "abundant generosity of disposition, the Dean " never put forth his full powers of controversy "save in the face of almost crushing opposi"tion. A temperament of this kind..."

There could be no better examples of the unmeaning use of the word, as the

* This and the greater number of the following extracts may be read without the words in italics. 
reader does not learn from it what the late Dean's temperament was, and loses the temperament photograph of him-dark or fair; square, tapering, or oval face; stout or slim build, etc.,-which such knowledge gives.

The paragraphs seem to lose nothing by the omission of the references to temperament.

"To no one could the decay of mental and " physical vigour which comes too often with " advancing years, have been a more painful

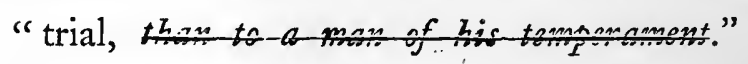

In the two other paragraphs the words in italics seem equally unnecessary.

\section{Carlyle.}

"In short, as was said of him by his own " mother, 'Thomas was gey ill to live wi'.' "And the shrewd old woman, fond parent as "she was, precisely hit off her favourite son's " temperament."

Which of the temperaments? 
USE OF THE WORD TEMPERAMENT. 343

\section{President Garfield.}

" $\mathrm{He}$ has met at the outset of his adminis" tration a series of troubles calculated to vex " the spirit of any man, especially one of his "temperament, who takes to his couch at night "the cares of the day."

In this extract temperament conveys no definite meaning, and the words in italics may be omitted and not missed.

\section{Mr. Fawcett.}

In the following extract from a review of Stephen's Life of Fawcett, the reference to temperament may for the same reason be similarly passed over without loss.

"Here, as in all other phases of his life, "Mr. Stephen rightly insists on the thorough "kindliness and generosity which in Fawcett's "temperament were combined with remarkable "shrewdness and unswerving independence."

In several of the newspaper obituary 
memoirs of Fawcett his temperament is referred to, but in none does the word name or indicate his real temperament-his physical characteristics.

\section{Lord Hartington.}

"Lord Hartington's Bury audience received " this curious hint (his retirement from political " life) with laughter. But it is not perhaps " altogether a joke. Statesmen of Lord Har"tington's temperament and position do not jest "over such subjects in public."

As Lord Hartington's temperament is not generally known, the writer would have done well to name it.

In the Home Rule debate (May IIth, I886) Mr. O'Brien attributes "anxieties and apprehensions" to Lord Hartington's temperament, which is referred to as if it were well known, although probably the speaker himself could not have named it if asked:- 
USE OF THE WORD TEMPERAMENT. 345

" Mr. W. O'Brien said ... To a politician " of the noble marquis's temperament it seemed " natural that apprehensions such as he appears " to entertain should occur; but they could not "forget that very much the same sort of anxieties " and apprehensions had weighed on the noble " marquis's mind in reference to other Irish "reforms."

\section{Mr. Irving on Players.}

Mr. Henry Irving, at the dinner of the Royal General Theatrical Fund I 884, said :-

"I doubt whether the poor player is much "indebted to those who linger in tedious "detail on the dangers of his temperament " and the slenderness of his purse."

Had it been usual in literature and conversation to name and so make known the temperament, Mr. Irving would probably have used some other word; for among players there is apparently as great a variety of temperament as among Englishmen in general (page 353). 
There seems no limit to the naming of temperaments from mental and other traits which have no dependence on, or association with, outward appearance; in ignorance, apparently, of the very limited influence of the temperaments on mental action and character (page 28).

The following so-called temperaments, and others which give little or no clue to physical characteristics, caught my eye in the ordinary course of reading :-

An Artistic Temperament.

The Musical Temperament.

The Poetic Temperament.

The Scientific Temperament.

The Sensational Temperament.

A Moral Temperament.

A Positive Temperament.

An Ascetic Temperament.

A Convivial Temperament.

A Dreamy Temperament. 
USE OF THE WORD TEMPERAMENT. 347

An Erratic Temperament.

A Suspicious Temperament.

A Combative Temperament.

A Religious Temperament.

His Political Temperament.

$A$ Conservative Temperament.

A Middle-Class Temperament.

$A$ Peculiar Temperament.

$A$ Versatile Temperament.

$A$ Dry and Languid Temperament.

$A$ Feeble Temperament.

An Unsound Temperament.

An Insane Temperament.

The Female Temperament.

The Masculine Temperament.

The Roman Temperament.

The French Temperament.

The American Temperament.

The English Temperament.

Several of the pseudo-temperaments of the list will be found in the following extracts :- 


\section{Charles James Fox.}

"Charles James Fox, a good example of the "emotional temperament. Both the virtues and " defects of his character, as a statesman and " as a man, are explicable from the same pro" minent temperament."

Although by its repetition temperament is brought conspicuously to notice in this extract, neither emotional, nor any single trait, can constitute a temperament. Emotional is one of the mental characteristics of the Sanguine temperament of the Scheme, and has no more right than any of the others to be called a temperament.

Had the writer been familiar with the temperaments, he would probably, instead of temperament, have used some word which has an unlimited range of application. 
USE OF THE WORD TEMPERAMENT. 349

NAture was at his service. "An emotional nature" is in common use, and would have expressed his meaning without challenge.

\section{Lord Salisbury.}

"Lord Salisbury's temperament is supposed "to be combative, but it does not follow that "in the maturity of his powers and with the " responsibility of leadership he will not be "able to pursue steadily a policy of moderation."

As it would be useful to know which of the temperaments is combative, it is to be regretted that the writer did not name Lord Salisbury's temperament. But probably he had no thought of any of the temperaments; and if so, Nature, or Disposition, which, like Nature, is free from the tie of physical characteristics, would have expressed his meaning and led to no questioning. 
io. Prince Bismarck.

"The Chancellor is, it seems, a man of a "profoundly religious temperament."

\section{i i. Carlyle and Macaulay.}

"But when two men of positive temperament " hold views diametrically opposite, and neither "can entertain even the suspicion that the "other may accidentally be right . . . ."

These two extracts show the prevailing custom of calling any mental, moral, or other trait, a temperament, seemingly without thought of associated physical characteristics; for a man, surely, is not more positive, or more or less religious, because dark or fair, stout or slim.

The author who in the preceding extract says that Carlyle and Macaulay were of the same temperament-positiveshows that the term did not include outward appearance; for in the same work 
USE OF THE WORD TEMPERAMENT. $35 \mathrm{I}$

he describes Carlyle as " 5 feet I I inches and thin, at fifty-four," and Macaulay as " a squat, thick-set, low-browed, short, grizzled little man, at fifty."

The use of the word temperament in the extract was quite unnecessary, for two positive men would have given readers as much information as "two men of positive temperament," and led to no question of outward appearance.

I2. A Versatile Temperament.

"Sir Stafford Northcote had to undergo a "trial of versatility of temperament in his "installation on Wednesday as Lord Rector of "the University of Edinburgh."

Sir Stafford had elsewhere, on the same or the previous day, given a political address, and having given one of a very different kind so soon after, is called versatility of temperament. Versatility it may 
have been, but not versatility of temperament, which means, if anything, dark at one time, fair at another.

The extract may be read without the words in italics and suffer no loss.

\section{i3. A Middle-Class Temperament.}

In a recent "literary portrait" of the Rev. C. H. Spurgeon it is said :-

"But he has the true middle-class tempera"ment-the temperament whose best expression " is Mr. Gladstone."

$A$ middle-class temperament! I cannot gather from the context what characteristics the writer supposes middle-class, but as Mr. Gladstone and Mr. Spurgeon are remarkably unlike in feature and build, the temperament of both is certainly not the same, whether middle, upper, or lower class. 
14. A Peculiar Temperament.

"If we are a nation of shopkeepers we "have at all events inherited the peculiar "temperament of the mediæval shopkeeper, "who was as fond of a tough fight in a "good cause as the most turbulent baron."

Readiness to fight in a good cause can scarcely be attributed to the temperament of Englishmen, among whom, except in some out-of-the-way places, variety of temperament from intermixture of races is so great that probably no one temperament prevails more than another.

There can be no doubt that the word temperament is much more frequently used now than formerly. It appears twice in extract 1 . Three times in the obituary biography of Dean Stanleysee extracts, page 34I. Twice in extract 8 , and as often in other extracts which 
I have withheld; but in the 635 papers in Addison's Spectator, although personal description abounds in the greater number, it appears only once, and then it is taken from a Spanish author (see page 273 of this volume).

Neither in Dr. Johnson's Rambler, nor his Idler; the former containing 208, and the latter I03 papers, most of them, like those in the Spectator, on men, manners, and morals, does it occur even once. It is not in "The Vicar of Wakefield." *

The reason why it is avoided by these old masters is at hand.

Johnson, in praising Addison's style in Lives of the Poets, says:- " He seeks no

*. I have confidence in this statement being correct, as the volumes have been purposely gone through by careful readers. 
USE OF THE WORD TEMPERAMENT. 355

"ambitious ornaments and tries no hazardous "innovations."

To express the habit of mind that prompts to individual action, Addison, Johnson, and Goldsmith, instead of temperament, used temper, disposition, nature, or some other word which is not tied, as temperament is, to physical characteristics.

I give a few additional extracts which farther show the unlimited use of the word at the present day:-

15. Miss Terry and Mr. Irving.

"Temperament and charm are gifts bestowed "on Miss Terry, but withholden from Mr. "Irving. His acting lacks both, and is un"sympathetic." New York Times, Oct. 21, I883.

Temperament is strangely used here. 
Seemingly, instead of expression, and the source of the extract shows that the unlimited and random use of the word is probably as general in America as at home.

\section{I6. Miss Anderson.}

In a notice of Miss Anderson at the Lyceum as Parthenia in Ingomar, it is said :-

"The beautiful Parthenia like a soulless "statue pleased the eye, but left the heart " untouched. It became evident that faults of "temperament were to be set off against the "actress's unquestionable merit."

Like "lack of temperament" in the preceding extract, "faults of temperament" in this, seems "an ambitious ornament," used instead of the familiar phrase want of feeling. 


\section{i7. Temperament and Political}

\section{ACtion.}

"The Conservative party, unlike their oppo"nents, are not divided in opinion as to the "danger of erecting a rival Legislature in Dublin, "and unlike them, we must also add, they are " actuated by no very strong inducement, either " of temperament or political aims, to strive for "the recovery of office."

\section{The Temperament of Con- STITUENCIES.}

"Some constituencies have, like Wigan, " according to Mr. Cross, a vivacity of tem"perament which, in conjunction with an excess "of zeal in agents, conduces to sudden alterations "in the representation."

i 9 The Temperament of Wesleyans.

"The selection just made by the Wesleyans "for the office of President, illustrates the "practical wisdom and even temperament which "have enabled that body to prosper in spite " of inherent weaknesses." 
In these three extracts temperament is used quite in a random way, unless it is meant that the majority of Conservatives, Wesleyans, and of the constituency of Wigan, are Sanguine, Bilious, Lymphatic, or Nervous-fair or dark; stout or slim.

As with the greater number of the extracts in this chapter, so with the last two, there seems no loss of meaning by passing over the reference to temperament, in italics.

There is every reason why temperament should continue to be used as frequently as now; but. with the difference, that it make known the physical characteristics of one of the four temperaments, or a compound one.

That it do so, standard descriptions of the four temperaments are essential; for till such have been supplied and accepted, temperament must continue to imply an 
USE OF THE WORD TEMPERAMENT. 359 indefinite force which impels to individual action, instead of naming or indicating a definite one-physical characteristics.

Precise. knowledge of the physical characteristics of the four temperaments would soon be followed by precise observation of their naturally associated mental qualities and traits of character, and by a particular temperament-pure or compound -being invariably named or indicated. "My temperament," and "his temperament," would become my or his sanguine, bilious, lymphatic, or nervous temperament. Including, as it then would, both physical and mental characteristics, temperament would be one of the most comprehensive words in the language.

The gain to literature and conversation by thus naming the temperament would be, that " to be told that any one " is of a sanguine temperament should 
" bring before the mind's eye a man with " red or reddish hair, blue eyes, a more " or less florid complexion, and the other "physical characteristics of the temperament. "And so of the other pure temperaments" (page I5I). The names of compound temperaments, however, require to be supplemented by those of the replacing characteristics (see page I 52).

Still more extraordinary than any of the preceding examples of the random use of the word is the following (intended to be given with them):-

20. French Newspapers have TemperaMENTS!

"The French newspapers for some days, "according to their respective habits and tem"peraments, have been indulging in denun"ciation, irony, or regret, with regard to the "Governments . . ." 


\section{CHAPTER XIV.}

WORD, BIOGRAPHIC, OR TEMPERAMENT PORTRAITURE.

Word portraiture seldom effective. - Method necessary.-The form and colour characteristics of the temperaments recommended.-Sir Walter Scott on the value of portraits in biography.-Engravings only partly effective.-Descriptions of Dickens from Mr. Forster's Life.-Of Sir Thomas More and Shelley.-Of Southey, Dickens, Tennyson, and others, by Carlyle.-Biographic portrait of Mr. Fawcett.Temperament portraiture valuable in conversation, cases of identity, and heredity.Likeness of Her Majesty Queen Victoria, and Anne Clifford, Countess of Dorset, Pembroke, and Montgomery, to both their parents.

Conclusion.-Fields in which observation of the temperaments may yield useful results.

WORD portraiture, or, as Carlyle calls it, " biographic portraiture," now greatly neglected by authors, would 
probably become as general and as effective as canvas portraiture were some system or method uniformly applied to it ; and none I think could be more serviceable than the physical characteristics of the four temperaments as arranged in the Scheme, chapter iv.:-

\section{Colour Characteristics.}

I. Colour of the hair.

2. Colour of the eyes.

3. Colour of the complexion.

Form Characteristics.

I. Form of the face.

2. Outspread or narrow nose.

3. Short or long neck.

4. Build of the body.

Very rarely does a biography contain a personal description of its subject that brings him before us as in life. Yet such a description should be easy enough 
TEMPERAMENT PORTRAITURE. 363

to a biographer who had personal acquaintance with him whose life he writes, and would probably be always given were some acceptable method introduced. Nothing could add so much to the gratification of readers as such a description.

"If the desire to look upon the face of living "men denotes a pardonable and even healthy "curiosity, it is not less commendable to wish " to know what was the outward form of " those who have made their mark in history." -Notice of the National Portrait Gallery in The Times.

Addison began the first number of The Spectator by asserting that, to know the appearance of the writer of a book, increases our interest in it:-

"I have observed that a reader seldom "peruses a book with pleasure till he knows "whether the writer of it be a black or a 
"fair man, of a mild or a choleric disposi" tion, married or a bachelor, with other " particulars of a like nature, that may conduce "very much to the understanding of an "author."

If anyone hesitates to accept Addison's argument as applicable to the writer of every kind of book, no one can doubt its application to the subject of a biography, if he remembers the heightened interest with which he read the life of some one he knew and recollected: how his personal appearance, his voice, his manner of speech, his expression and gesture, were present to him from the first page to the last.

The value of portraiture in biography is well expressed in a letter from Sir Walter Scott to the publishers of Lodge's Portraits :-

"It is impossible for me to conceive a 
TEMPERAMENT PORTRAITURE. 365

"work which ought to be more interesting "to the present age than that which exhibits "before our eyes our fathers as they lived, " accompanied with such memorials of their " lives and characters as enable us to compare "their persons and countenances with their "sentiments and actions."

Such comparison is obviously imperfect unless colour be given to make countenances wholly life-like-the colour of the hair, eyes, and complexion,-and as personal description is conspicuously ausent from Lodge's memoirs, Sir Walter's idea was only partly realized by the colourless engravings.

Wanting colour, the usual vignette engraving facing the title-page of a biography, is a useful addition to a good description, but an imperfect substitute, giving only the form of the face and of its features. 
As the physical characteristics of the temperaments include the form of the face, the colour of the hair, eyes, and complexion, and the build of the body, temperament portraiture, as this might be called, would enable readers to see with the mind's eye the subject of a biography as he was seen by his contemporaries, and familiarize them with the connection between the physical and mental characteristics of the temperaments.

The newspaper biography of Dean Stanley, already noticed as referring to his temperament no less than three times, was no doubt written by one who had often seen the Dean, yet of his personal appearance there is not the slightest mention. Readers remain ignorant of what he was to look at, and, in consequence, all about his mind, heart, and work, although admirably given, 
TEMPERAMENT PORTRAITURE. 367

is not only less interesting, but less vividly remembered. Had temperament portraiture ruled in literature it would have been the breath of life, and the late Dean would have been before us almost as plainly as if we had known him.

Even in the three large volumes of Forster's Life of Dickens, so full of personal traits and records by one who knew him most intimately, there is no description of the man that supplements, by colour especially, the several engravings of portraits by artist friends.

Forster's description of him at thirtyfive years of age (vol. i., page 79) is most general.

I give the greater part; the indefinite terms in italics:-

"The features were very good. He had a 
" capital forehead. Eyes wonderfully beaming. " A firm nose, with full, wide nostrils. A " rather prominent mouth, well-formed, and "symmetrical. The hair was then of a rich "brown and most luxuriant abundance."

No mention of the colour of the eyes, or of the complexion, or the build of the man! His temperament, therefore, can only be guessed.

A young American lady's description (vol. i., page 364) is even more general than Mr. Forster's:-

" $\mathrm{He}$ is young and handsome, has a mellow, " beautiful eye, fine brow, and abundant hair."

No colour given here! Reserved for his dress seemingly!

" $\mathrm{He}$ had a dark coat, with lighter "pantaloons, a black waistcoat, embroidered 
"with coloured flowers, and about his neck, "covering his white shirt-front, was a black " neckcloth, also embroidered in colours, in "which were placed two large diamond pins, " connected by a chain. A gold watch-chain "and a large red rose in his button-hole "completed his toilet."

Here, colour everywhere! Strange that one so observant of colour should have overlooked the colour of the hair, the eyes, and the complexion! Impossible, had she known anything of the temperaments!

In contrast; here is a biographic portrait of 140 years ago, when the temperaments still impressed their stamp on literature :-

Sir Thomas More, Lord Chancellor.

" $\mathrm{He}$ was of middle stature, well pro"portioned; his complexion pale; his hair " neither black nor yellow, but between both: 
" his eyes grey; his countenance amiable and "cheerful; his voice clear and distinct; and " his body healthful."

Colour is not forgotten here, and as the engraved portrait which accompanies the description shows the face to taper from a broad forehead, and a nose outspread; a compound temperament, in which Nervous characteristics prevail, is indicated.

\section{SheLley.}

Here is a biographic, almost a temperament portrait of Shelley:-

"In person he was tall and slight (Nervous); " his eyes were large, and animated with a "dash of wildness in them (colour wanting); " his face small, but well-shaped, particularly " the mouth and chin, the turn of which was "sensitive and graceful (Nervous); his com"plexion fair and delicate, with a colour in 
"the cheek (Sanguine). He had brown hair "(Bilious, if dark brown; Nervous, if light "brown), which, though tinged with grey, "surmounted his face well, being considerable " in quantity, and tending to curl. Like the "Stagyrite, his voice was high and weak. "Though well turned, his shoulders were "bent a little, owing to premature thought " and trouble (he perished in his twenty-ninth "year). The same causes (Nervous) had "touched his hair with grey."-Leigh Hunt's "Lord Byron," page 174.

Also of Shelley, Professor Shairp writes :-

"His intellect waited on his temperament, "and, so to speak, did its will, caught up "one by one the warm emotions as they "were thrown off, and worked them up into "the most exquisite abstractions."

In Mr. Froude's volumes on Carlyle are many striking examples of word portraiture, in sorne of which colour and form are minutely given, and I reproduce 
a few that have much in them that may be called temperament portraiture :-

\section{The Irving Family.}

"All these Irvings were of blond, or even " red complexion-red hair a prevailing or "sole colour in several of their families. Gavin " himself (Edward's father) was reddish, or at "least sandy-blond, but all his children had "beautifully coal-black hair, except one girl, " the youngest of the set but two, who was "carroty, like her cousins. The brunette "mother, with her swift black eyes, had pre"vailed so far."

\section{Frank Dillon.}

\section{(Nervous.)}

"A slightly-built man, nimble-looking, and " yet lazy-looking; thin, neatly-expressive, " aquiline face; grey, genially-laughing eyes; "something sternly-serious and resolute in "the squarish, fine brow; nose specially "aquiline, thin, and rather small." Form, not colour, here! 


\section{Mr. BadHams.}

" A tight, middle-sized, handsome kind of "man; eyes blue (Sanguine), sparkling, soft; "nose and other features inclining to the "pointed (Nervous); complexion, which was the "weak part of him, tending rather to bluish; "face always shaven bare, and no whiskers "left. A man full of hope, full of natural " intellect, ingenuity, invention (Sanguine and "Nervous) . . . . true he was, but not sternly "enough, and would listen to imagination and "delusive hopes when Fact said No" (Sanguine and Nervous).

\section{Southey.}

"A lean, grey, white-headed man, of dusky "complexion; unexpectedly tall when he rises, "and still leaner then; the shallowest chin; "prominent snubbed Roman nose; small, "care-lined brow; huge bush of white-grey "hair on high crown, and projecting on all "sides; the most vehement pair of faint, "hazel eyes I have ever seen; a well-read, "honest, limited (strait-laced even), kindly“ hearted, most irritable man." 


\section{Dickens.}

" $\mathrm{He}$ is a fine little fellow-Boz-I think. "Clear, blue, intelligent eyes; eyebrows that " he arches amazingly; large, protrusive, rather "loose mouth; a face of most extreme " mobility, which he shuttles about, eyebrows, "eyes, mouth and all, in a very singular " manner while speaking. Surmount this with "a loose coil of common-coloured hair, and "set it on a small compact figure, very "small, and dressed à la D'Orsay, rather than "well-this is Pickwick. For the rest, a "quiet, shrewd-looking little fellow, who seems " to guess pretty well what he is, and what "others are."

\section{TenNyson.}

"A fine, large-featured, dim-eyed, bronze" coloured, shaggy-headed man is Alfred; "dusty, smoky, free-and-easy, who swims "outwardly and inwardly with great com" posure in an inarticulate element of tranquil 
"chaos and tobacco smoke, great now and "then when he does emerge-a most restful, "brotherly, solid-hearted man."

Admirable as these descriptions are, I cannot doubt that had the hand of the old master been guided by the method of the temperaments, they would have been still more Rembrandt-like, and more lastingly engraven on the memory.

In the following striking description of the late Mr. Fawcett's appearance, by the most practised hand of the day, two nearly full-length engraved portraits are fully supplemented as to form; but colour, which engravings do not give, is almost overlooked; and readers may judge for themselves whether, had the author used the methodical arrangement of the temperaments (page 362), he would have given, as I think he would, a more lifelike and intellectual portrait:- 
"I noticed a very tall, gaunt figure "swinging along with huge strides upon the "towing-path. He was over six feet three " inches in height. His chest, I should say, "was not very large in proportion to his "height, but he was remarkably large of "bone and massive of limb. The face was "impressive, though not handsome. The "skull was very large; my own head vanished, " as into a cavern, if I accidentally put on his "hat. The forehead was lofty, though rather "retreating, and the brow finely arched. "The complexion was rather dull, but more "than one of his early acquaintances speak " of the brightness of his eye and the "keenness of his glance. The eyes were "full, and capable of vivid expression, though " not, I think, brilliant in colour. The "features were strong, and, though not " delicately carved, were far from heavy, " and gave a general impression of remark"able energy. The mouth, long, thin-lipped, "and very flexible, had a characteristic "nervous tremor, as of one eager to speak " and voluble of discourse. . . . A 
"certain wistfulness was a frequent shade "of expression. But a singularly hearty and "cordial laugh constantly lighted up the "whole face with an expression of most "genial and infectious good humour."

In conversation, as in biography, personal description so generally fails to convey a definite likeness, that a uniform method would undoubtedly be a great gain; and the physical characteristics of the temperaments-four of form and three of colour-being readily remembered, and giving, as they do, a portrait that could not fail to be recognized, might well be adopted.

Its adoption would probably lead to the desirable use of temperament phraseology in reference to single features; as, a sanguine, bilious, lymphatic, or nervous eye; a sanguine, bilious, lymphatic, or nervous complexion, etc.-phrases which indicate associated mental traits. 
An accepted method of personal description, - as the few physical characteristics of the temperaments,- - by insuring clearness of recollection and more conclusive comparison, would be found of value in many important matters.

In cases of identity the evidence of witnesses would be more convincing were they to give the colour and form characteristics-page 362-instead of different methodless descriptions, which cannot be compared.

Heredity - including physical characteristics, mental qualities, health, and disease-is an important and interesting subject, not yet sufficiently observed to warrant definite conclusions; nor likely to be, till some method of observing and recording physical characteristics become prevalent; some observers seeing likeness between people, and between portraits and their subjects, where others see none. 
TEMPERAMENT PORTRAITURE. 379 (In Heredity.)

Mr. Galton, in a lecture on Personal Identification and Description, at the Royal Institution, May I 888 , said :-

"It is strange that we should not have "acquired more power of describing form and "personal features than we actually possess. "For my own part I have frequently chafed " under the sense of inability to verbally "explain hereditary. resemblance and types of "feature."

The colour and form characteristics of the temperaments supply the want felt by Mr. Galton and others; and were they generally adopted to describe personal appearance and compare likeness, the study of heredity would, I doubt not, soon begin to progress towards trustworthy laws.

The following extracts show the unsatisfactory state of this important subject:- 
"We are completely in the dark as to the "circumstances which regulate the hereditary " transmission of character, temperament, and "other peculiarities. . . . None of the "laws of hereditary descent connected with "the formation of character have yet been "generalized, nor is our knowledge much "more advanced respecting the theory of "temperaments."-Mr. Buckle.

"Few subjects can be more attractive to "all who desire the welfare of the human "race than an investigation of the principles "which underlie heredity, and which, up to "this time, have baffled all inquiry. The "elements of the problem are so complex, "the tendency to revert to ancestral types " is sometimes so strongly marked, and the "difficulties of the inquiry are so formidable, "that no one has hitherto arrived at any "intelligible basis for predicting the probable "physical or mental characters of the children "of any given parents." - The Times on Mr. Galton's address on Heredity at the 1885 meeting of the British Association. 
TEMPERAMEN'T PORTRAITURE. 38 I (In Heredity.)

After the above testimony readers may not be inclined to accept without proof that :-

"Sons, according to an observed law of "inheritance, usually inherit the temperament "of their mother's father, and daughters that "of their father's mother, the same types "re-appearing with all their correlated qualities "of form and feature and mental temper "very little neutralised or altered."-T'he Lancet, I 876, vol. i., page 236.

A law this that startles by its simplicity. Did it hold good, all the brothers of a family would usually be of one temperament, and all the sisters of another.

Mr. Starkweather thinks that observation warrants his belief in a very simple law of transmission of sex and temperament :- 
"At the seaside one often sees whole "families together - father, mother, children. " $\mathrm{He}$ will see a portly father, dull and "lymphatic, coupled with a nervous, sprightly "wife; and with them he will find a troop "of boys, inheriting probably much more of "the mother's temperament than the father's. "On the other hand, when he meets a thin " and active father, perhaps resting from the "exertions of his profession, with a stout "and pleasant, but indolent or lymphatic " mother, he will as surely find a family of "daughters who have evidently inherited the "father's activity. The cases of this sort "that I have met with in my travels, every "one confirming my theory, are innumerable, "and I doubt not that others will have a "similar experience."-T The Law of Sex (page 263).

I doubt not that others will find, as I do, that such cases are, comparatively, very seldom seen.

Whoever may formulate a law of physical heredity should not overlook 
TEMPERAMENT PORTRAITURE. 383 (In Heredity.)

that there may be a likeness to more than one relation, near or distant.

Of Her Majesty Queen Victoria, when an infant, her father, the Duke of Kent, wrote (August I7th, I8I9):-

"As to her resemblance to both of her "parents, I may tell you that her mouth and "her hair, which last promises to be dark "brown, are like her mother's. Everybody "says that her eyes and nose are mine."

In the memoir by Lodge, which accompanies the engraved portrait * of Anne Clifford, Countess of Dorset, Pembroke, and Montgomery, is the following personal description by herself:-

"I was very happy in my first constitu"tion, both in mind and body; both for "internal and external endowments; for never "was there a child more equally resembling

* Portrait No. xi., end of this vol. 
"father and mother than myself. The colour " of mine eyes was black, like my father's; and " the form and aspect of them was quick and "lively, like my mother's. The hair of my " head was brown, and very thick, and so "long that it reached to the calf of my "legs when I stood upright; with a peak "of hair on my forehead, and a dimple " on my chin: like my father, full cheeks; and "round face, like my mother; and an exquisite "shape of body, resembling my father."

Mr. Galton, in the Record of Family Faculties, issued "to further the science of heredity," says :-

"Nearly every individual is notable for " some peculiarity of mind or disposition, " and in some few persons the sanguine, "melancholic, nervous, or lymphatic tempera" ment is well marked. All such peculiarities "should be noted, as they are strongly "hereditary, and may throw much light on "the faculties of the family. "Moreover, the "study of them is peculiarly attractive." 
TEMPERAMENT PORTRAITURE. 385 (In Heredity.)

In his valuable, interesting, and wellknown work, Hereditary Genius, Mr. Galton has, by method and extensive research, traced inheritance of mental superiority in a very great number of eminent men and women; but should acquaintance with the temperaments become general, readers may wish that he had extended his research to inheritance of temperament characteristics. 


\section{CONCLUSION.}

As advocacy of the practical value of any subject can have no great weight unless supported by proof, I hope that some readers who have become familiar with the temperaments, and have the required field, may observe the association between physical characteristics and the mental qualities and aptitudes that lead to success in studies and pursuits, and make known the results of their observations.

Teachers might make valuable use of their great opportunities of observing the temperaments of youths and establishing conclusions that could not be gainsaid.

"The conditions in schools are obviously "favourable for all kinds of statistical inquiries. "Boys of similar antecedents, age, and occupa" tions are grouped together, and are under 
" inspection for long periods. "What excellent " 'psychological work might be accomplished,' "says an author who has given a notable " example of the sort of inquiries that might " be carried out in schools; "what excellent " "psychological work might be accomplished " " if a schoolmaster were now and then found " " capable and willing to codify, in a scientific " "manner, his large experience of boys-to " " compare their various moral and intellectual " "qualities, to classify their natural tempera" " ments, and generally to describe them as " " a naturalist would describe the fauna of " some new land. The masters, however, " "come and go, their experiences are lost, " " or almost so, and the incidents on which " " they are founded are forgotten, instead " " of being stored and rendered accessible " " to their successors." "-Sir J. Crichton Browne, M.D., L.L.D., F.R.S., in "The Book "of Health," pages 27I, 272.

Examiners have a more concentrated field than teachers, and by making use of it would no doubt 
arrive at valuable conclusions. What could be more valuable than tables giving the temperaments of candidates, the subjects they selected, those they passed in, and those they failed to pass?

The secretaries of our. learned and other societies might, by the method of the Scheme, make us acquainted with the temperaments of their eminent members, and thereby establish a connection between physical characteristics and success in science, art, literature, professions, and other occupations, that should influence the choice of a calling.

The medical profession would do good service by observing, for general guidance, the relation which I have suggested (chap. $i x$.) between food, climate, the ordinary causes of disease, or derangement of health, and the temperaments. 
The medical officers of our large and ever-increasing asylums for the insane might tabulate observations that would establish a connection between the temperaments of patients, the character of their delusions, and the causes that induced them,- -knowledge that might be available in counteracting the tendency to attack, by showing the probable direction of its approach.

The medical advisers of Life Assurance Societies, by carefully noting the tem-. peraments of the assured, and making known the causes of death, might evolve a difference in the death-rate, and would enable every one familiar with the temperaments to guard against the diseases to which they are naturally predisposed.

Many others might lend a helping hand to give precision to the subject, and I am hopeful that some may have become sufficiently interested in it to do so. 
Acquaintance with the mental qualities and traits of character that are associated with the physical characteristics of the temperaments, as in the scheme of the four pure temperaments, pages 79,80 , $8 \mathrm{I}, 82$, is very soon gained, the streets affording unlimited practice, and home, sufficient proof; and as it will be found useful in many of the ordinary affairs of life,-obviously, in the selection from candidates of the one naturally best qualified for the work,-I hope such acquaintance may become general.

The following extract shows that they have begun in America to consider phy-. sical characteristics in estimating fitness :-

"A very bitter sentiment of rivalry has "sprung up between fair-haired women and "brunettes in Washington. The feeling has " arisen amongst lady applicants for situations as " clerks in the Civil Service, in which department 
"women as well as men can be appointed. As " a rule, and this was the original grievance of "blondes and brunettes alike, favouritism was, "alleged the ladies, shown to male applicants; " and now another accusation is brought "by fair-haired applicants, who are com"plaining that, when vacancies have to be " filled, and women are accepted, it is invari"ably the dark-haired sisterhood upon whom "the appointment is bestowed. The officials " charged with making this distinction to the "prejudice of the blondes, excuse themselves "by saying that the latter are apt to be "quick-tempered, that they are less steady at "work, and, in short, do not make such "good clerks as the brunettes."-The Evening Standard, February I 7 th, I 885.

Many readers may be as glad as I am to learn that Dr. Richardson, who has so successfully rendered many medical subjects familiar to the general reader, may be expected to add a volume on The Temperaments to his well-known works. 
In a lecture on "Felicity as a Sanitary Research," he says:-

"There are some constitutional differences de" termined by temperaments, which are of first "importance. Of the four primary tempera"ments, the sanguine, the nervous, the bilious, "the lymphatic, and of their relation to felicity, " a volume might be written, and I have col"lected the facts relating to the temperaments "of over a thousand persons towards such a "work."

It may be accepted with confidence that all who become familiar with the temperaments and their associated mental qualities, will not only find it easy to select whoever is naturally gifted for the work required, but make themselves and others happier, by greater tolerance of the different ways of those who differ from them in temperament. 


\section{CLASSIFICATION OF FACES.}

The following selection from Lodge's well-known collection of engraved portraits * is given to familiarize observers with four forms of the face; the square; the tapering; the oval; and the semi-oval: their long and broad varieties; and the melancholic form $\rightarrow$ an easily remembered classification which may help them to recognize and read every form of face.

I am sanguine that general familiarity with the colour and form characteristics of the temperaments may lead to the indefinite phrase "I see it in his face" being always supplemented, as follows:-

$$
\begin{aligned}
& \text { I see it in his square face. } \\
& \text { I see it in his tapering face. } \\
& \text { I see it in his oval face. }
\end{aligned}
$$

* Reproduced by the Typographic Etching Company. 
I see it in his outspread nose.

I see it in his short neck.

I see it in his build.

I see it in his blue eyes.

I see it in his black eyes.

I see it in his lustreless eyes. or

I see it in his expression.

So of the colours of the complexion and hair.

Only by such, or some other accepted method, can readers of faces compare their readings with those of others. 
ARRANGEMENT OF THE PORTRAITS.

Nos.

I, 2 - . . . Square.

$3,4,5,6$. . . Tapering.

7 . . . . . Oval.

8 . . . . . , , (long).

9, I0 . . . . . , , (broad).

I I, I 2, I 3 . . . Semi-oval.

I 4, I 5 - . . . , , (long).

I6, I7 . . . . , , (broad).

18, 19, 20, 2 I . . Oblong.

22, 23 . . . Tapering (long).

24, 25 . . • . ， ， (broad).

26, 27 . . . . The Melancholic.

There are other forms of faces besides those seen in the portraits, but, like the semi-oval (No. XI.), they are obviously compounds of two of the three chief forms-the 'square, the tapering, and the oval. 
396 OUR TEMPERAMENTS.

Observation of the forms of a hundred faces gave the following results:-

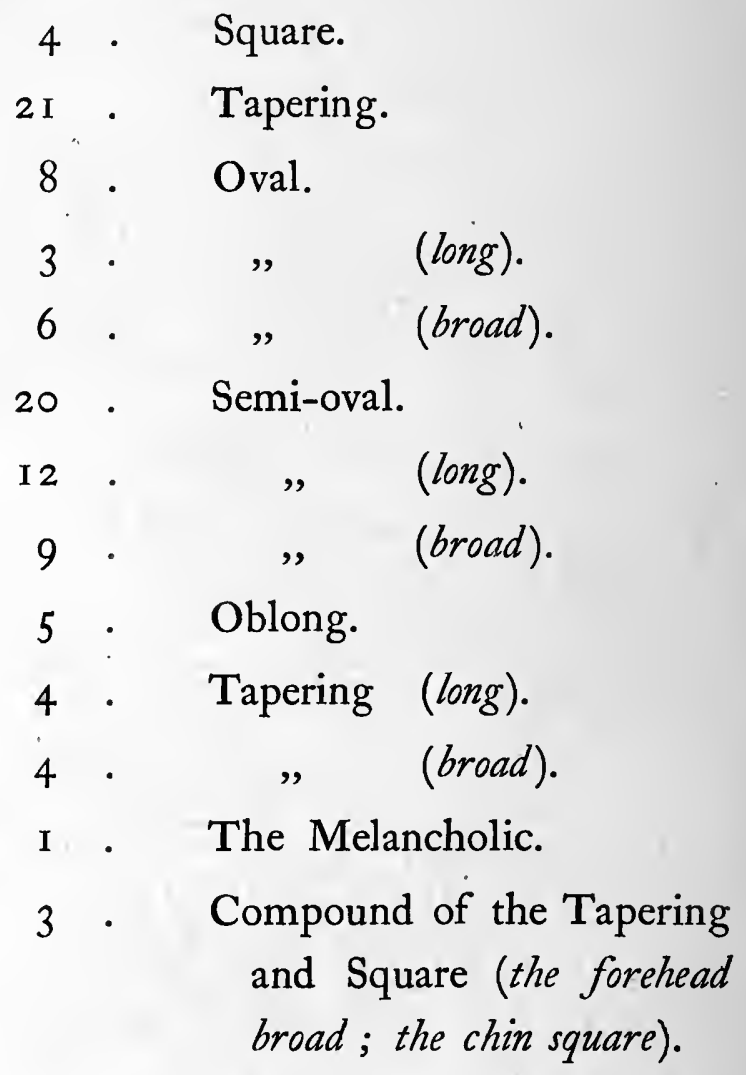
and Square (the forehead broad; the chin square). 


\section{NOTE.}

The Scheme of the pure temperaments, chap. iv., may be referred to for the mental traits of the square and tapering faces. Those of the oval face are given in chap. vii. All other forms of the face being compounds or varieties of these three, the assignment of their mental traits should be relative to the proportion of square, tapering, or oval features. 

A SELECTION

FROM

\section{LODGE'S HISTORICAL PORTRAITS,}

SHOWING THE CHIEF FORMS OF FACES. 



\section{SQUARE FACES.}

Sre Scheme, Chan. ir.

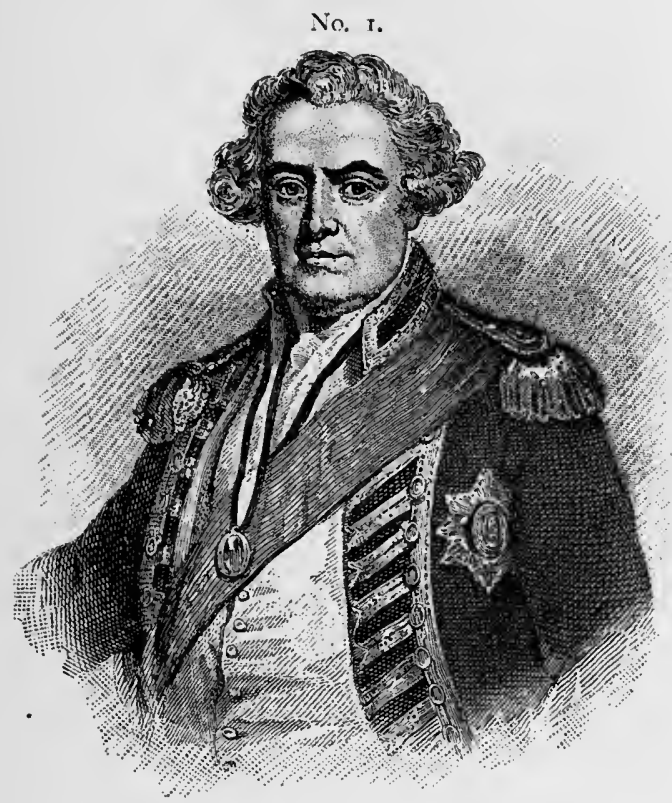

ADAM, FIRST VISCOUNT DUNCAN.

Ob. 1804 .

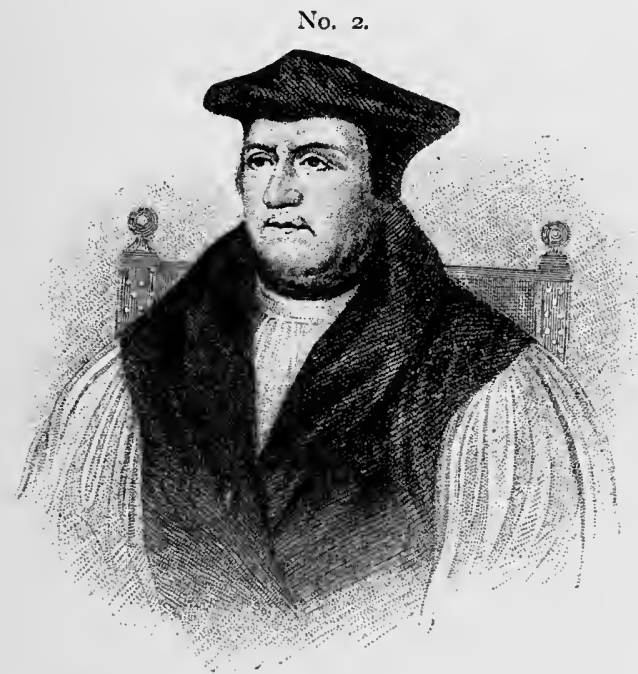

MATTHEW PARKLR, ARCHBISHOP OF CANTERBURY.

Ob. 1575 

. 
TAPERING FACES.

See Scheme, Chap. iv.

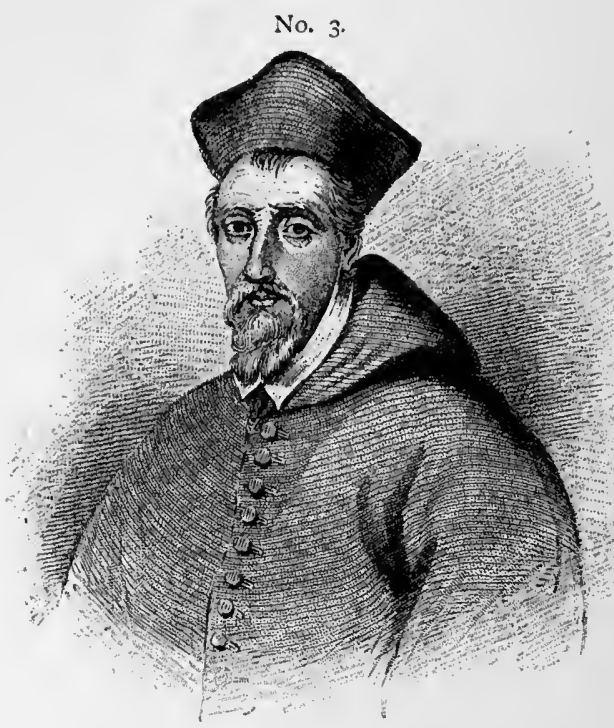

CARDINAL ALLEN.

Ob. 1594 .

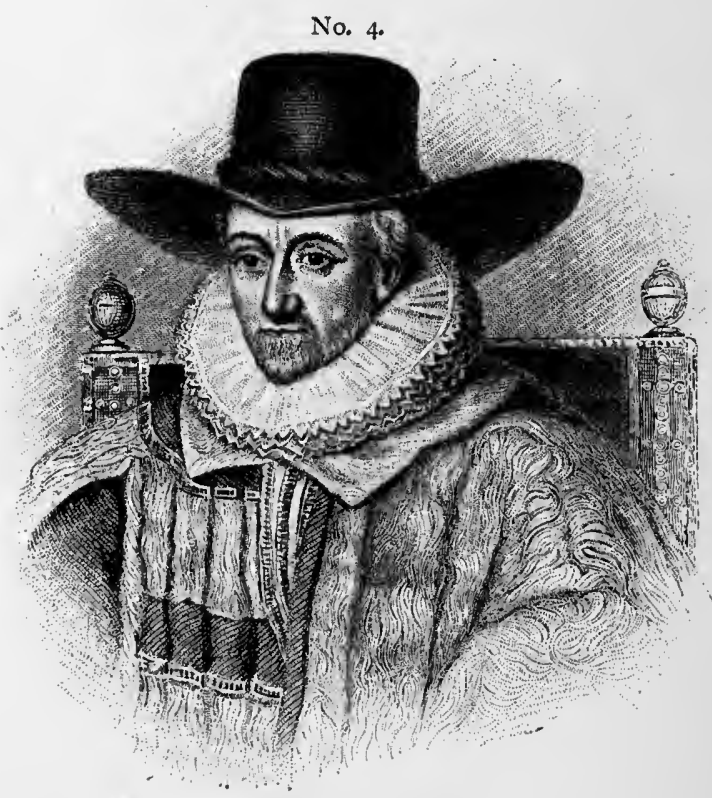

THOMAS EGERTON, VISCOUNT BRACKIEY. Lord High Chancellor.

Ob. $161 \%$. 


\section{TAPERING FACES.}

No. 5 .

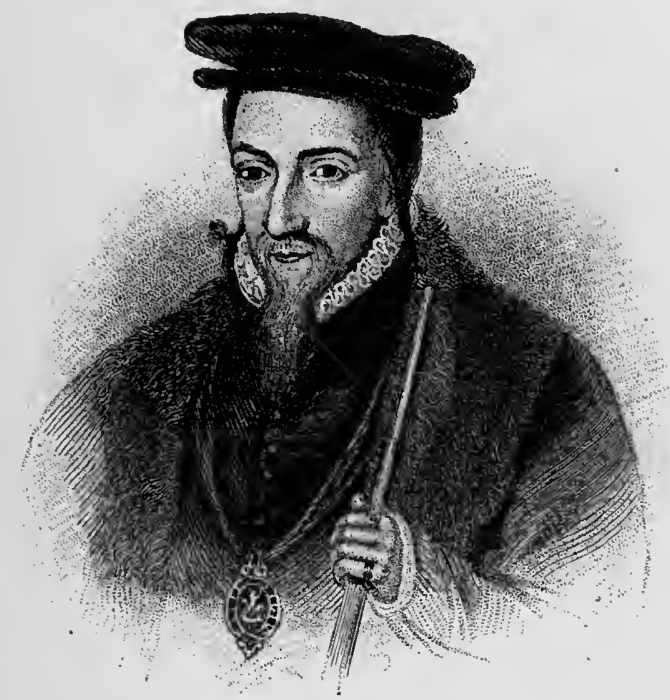

WILLIAM POWLETT, MARQUIS OF WINCHESTER. Ob. 1572 .

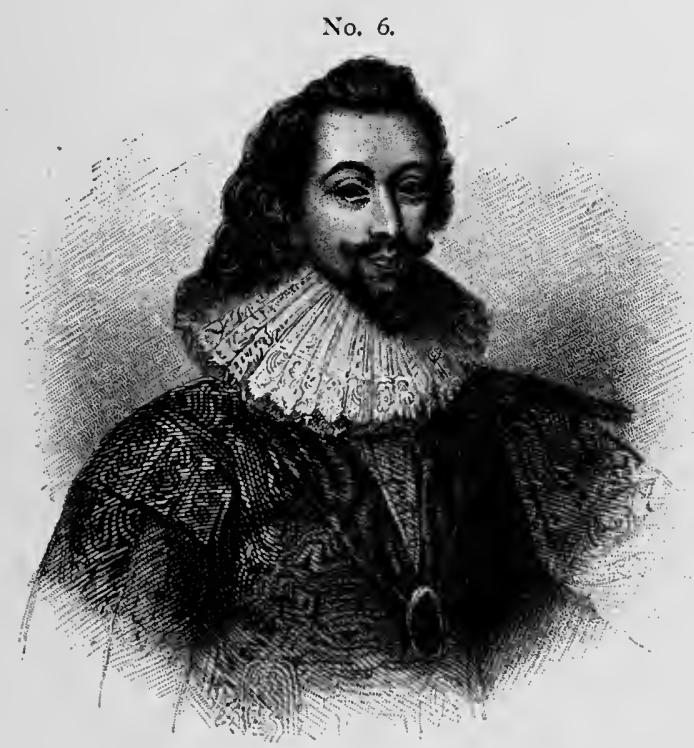

GEORGE VILLIERS, DUKE OF BUCKINGHAM. Ob. 1628 . 



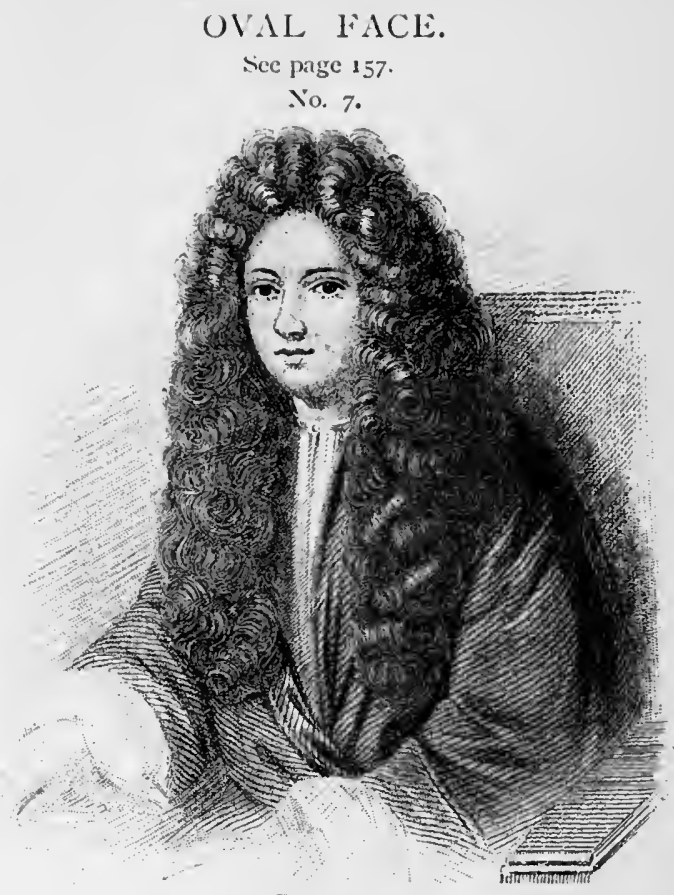

Page $7 \mathrm{r}$.

THE HON. ROBERT-BOYLE. Ob. 1691.

LQNG OVAL FACE. No. 8.

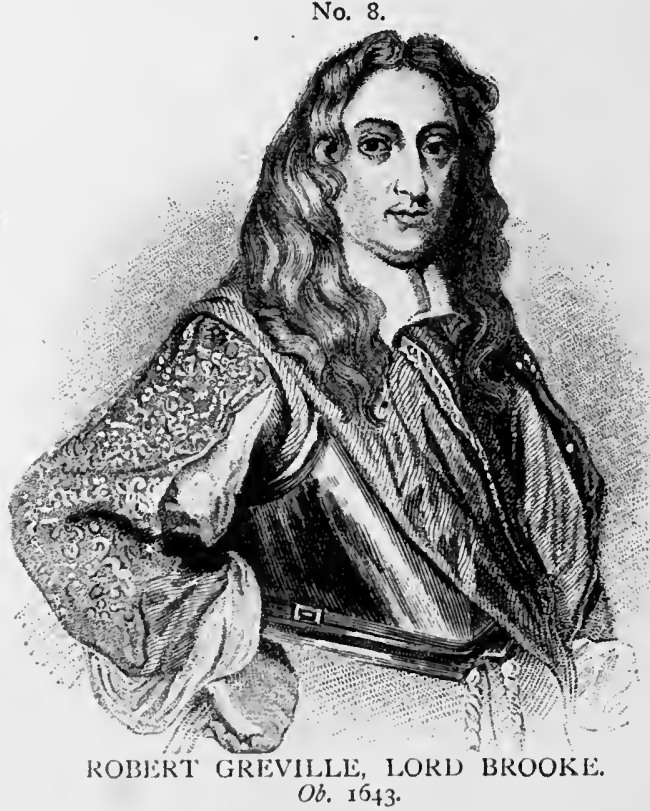




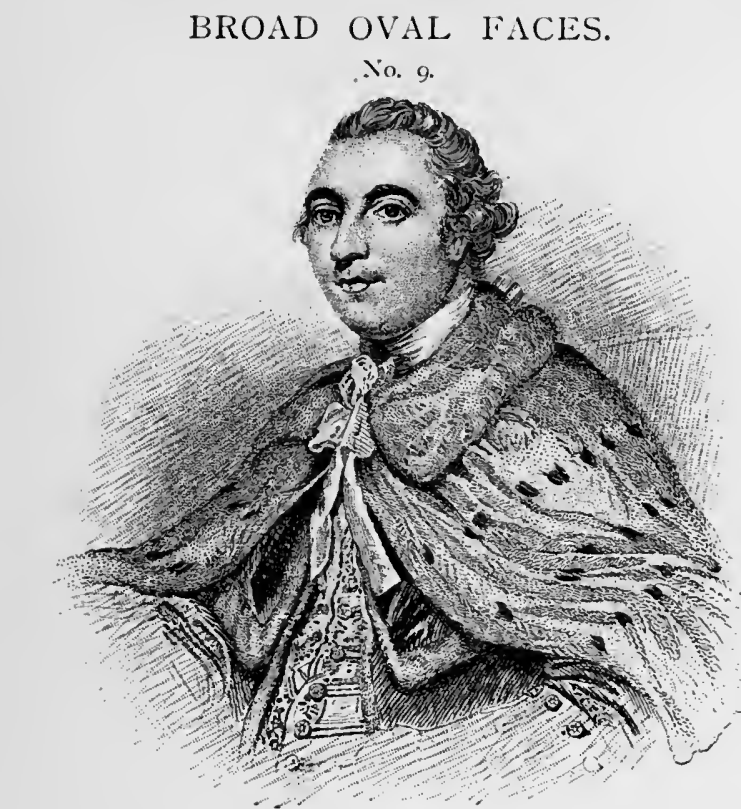

WILLIAM FITZ-MAURICE PETTY, FIRST MARQUIS OF LANSDOWNE.

Ob. 1605 .

No. ro.

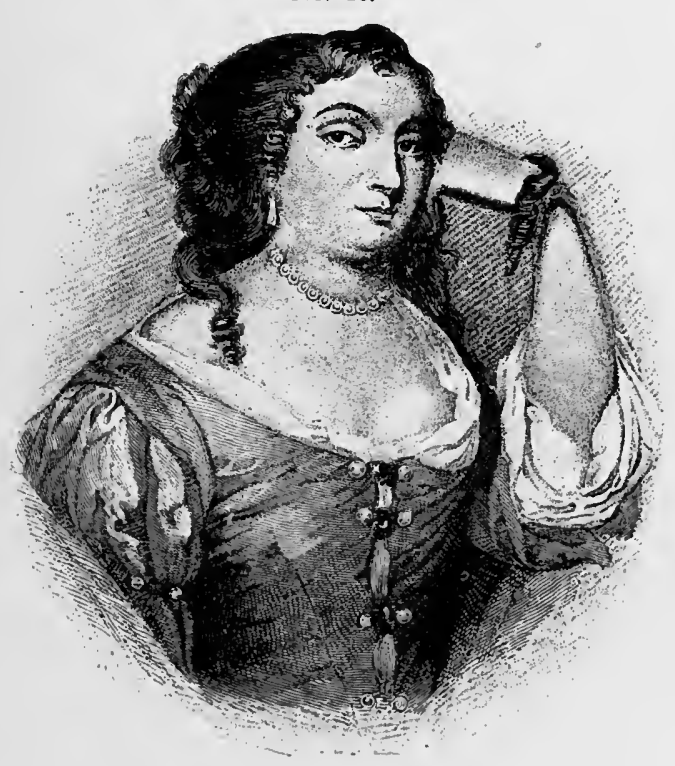

ANNE HYDE, DUCHESS OF YORK.

Ob. 167 r. 




\section{SEMI.OVAL FACE.}

(The broad forehead of the tapering form).

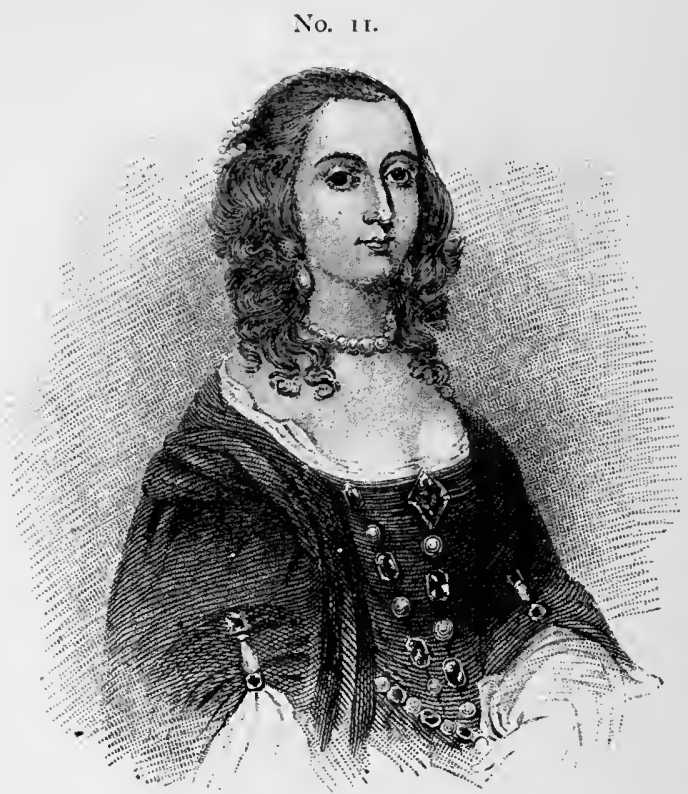

LIKENESS TO BOTH PARENTS.

See page 382 .

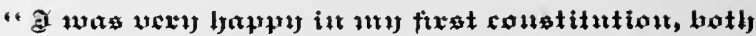

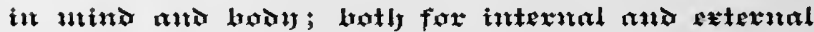
emanuments; for menex uras tljeve a chjld maxe

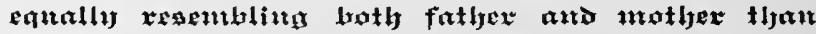

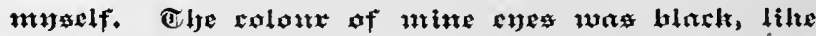

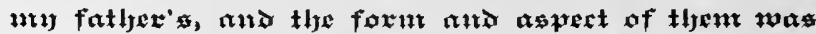

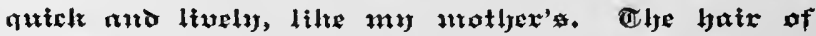

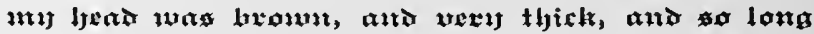

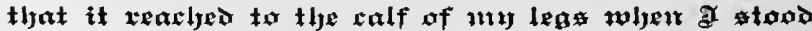

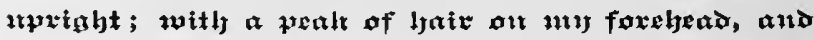

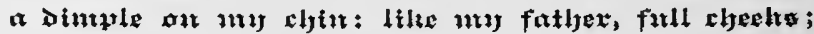
atro xound faxe, lilke maj mothex; and an examisite

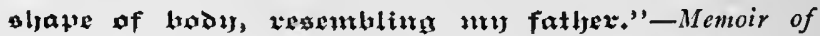
Anne Clifford, Countess of Dorset, Pembroke and Montgomery, in Lodge's Historical Portraits. 
SEMI-OVAL FACES.

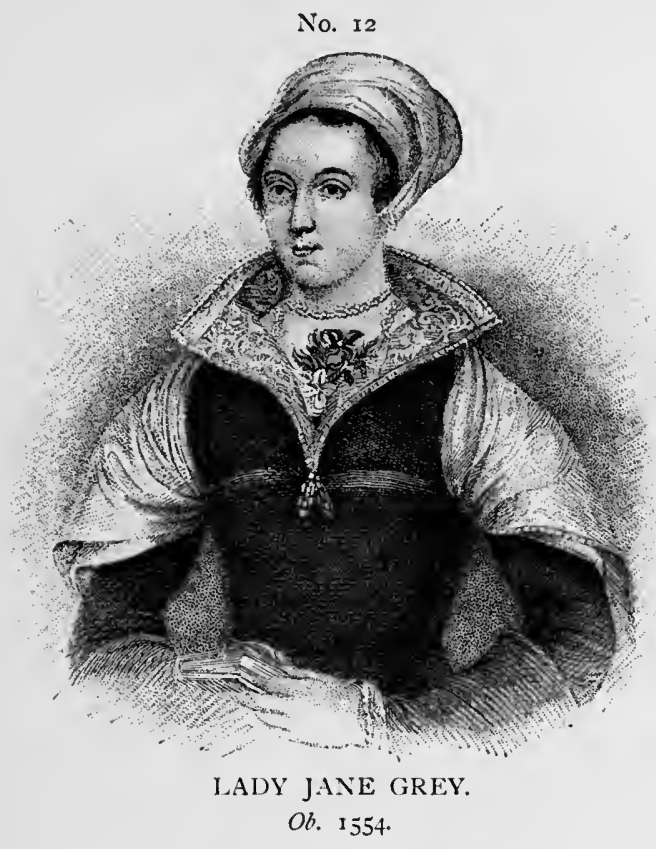

No. 13.

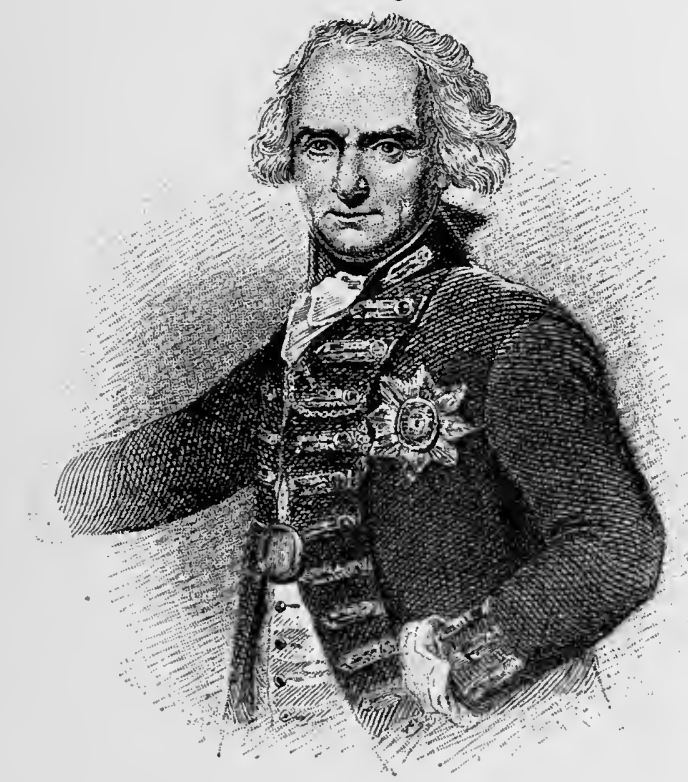

ALEXANDER HOOD, VISCOUNT BRIDPORT, $O b$. $18 \mathrm{I}_{4}$. 


LONG SEMI-OVAL FACES.

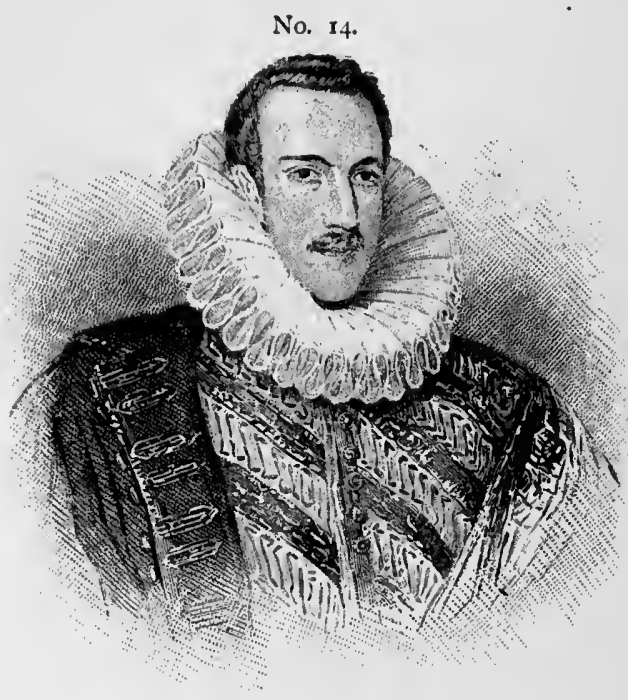

PHILIP HOWARD, EARL OF ARUNDEL. Ob. 1595 .

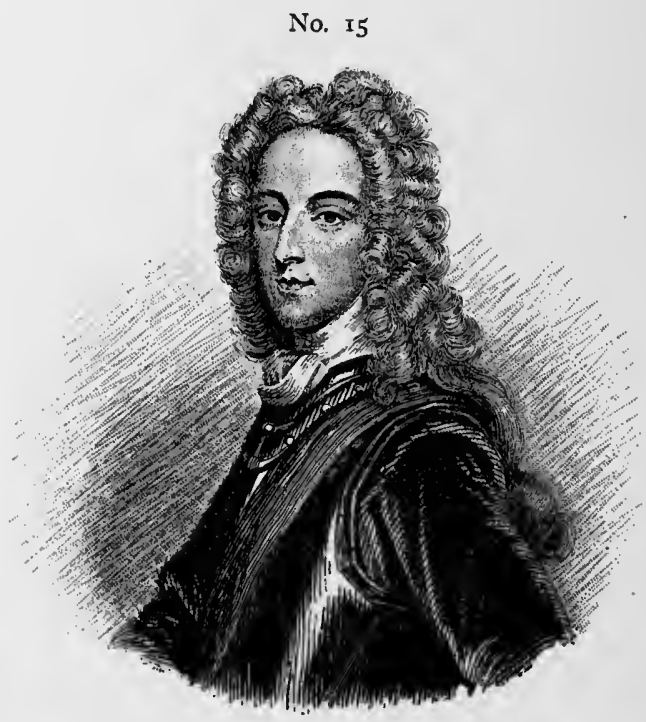

JOHN, DUKE OF MONTAGU. Ob. r749. 
BROAD SEMI-OVAL FACES.

No. 16.

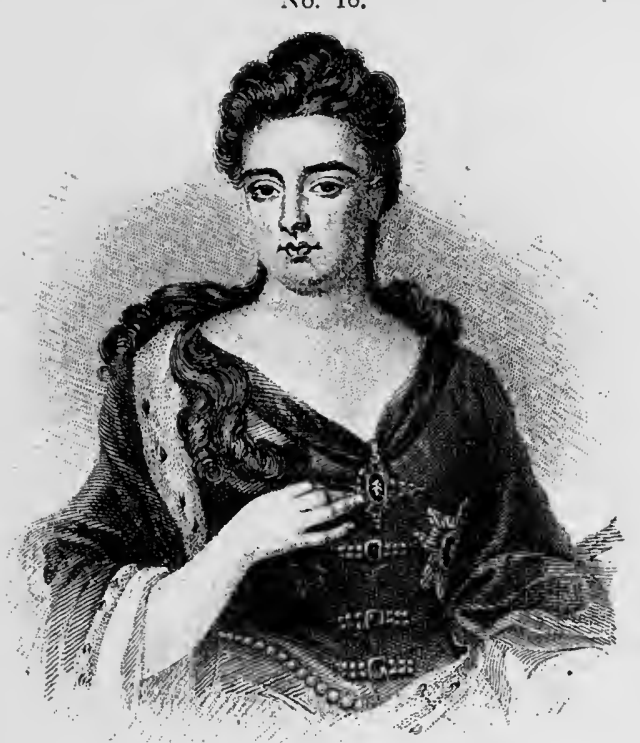

QUELN ANNE:

Ob. I7I4.

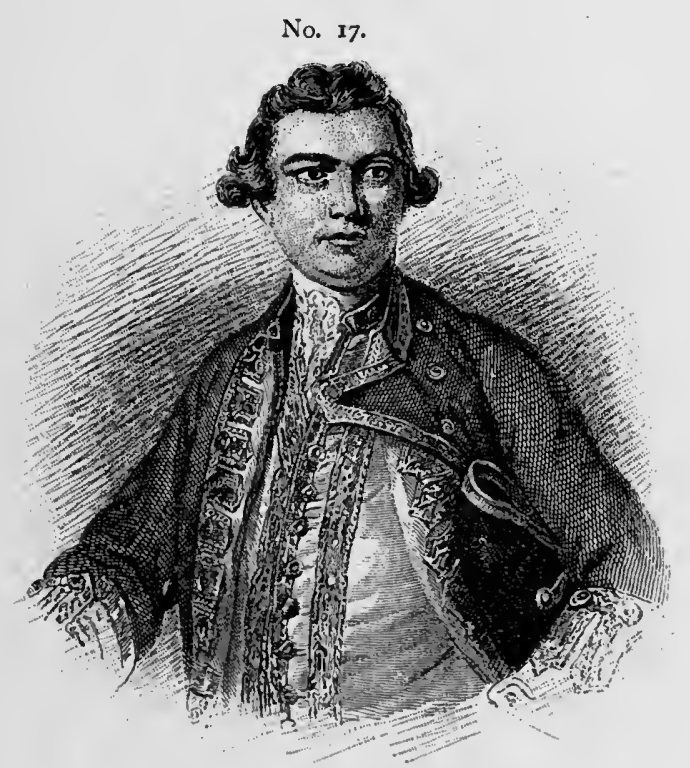

AUGUSTUS, VISCOUNT KEPPEL.

Ob. 1786 . 




\section{OBLONG FACES.}

No. 18.

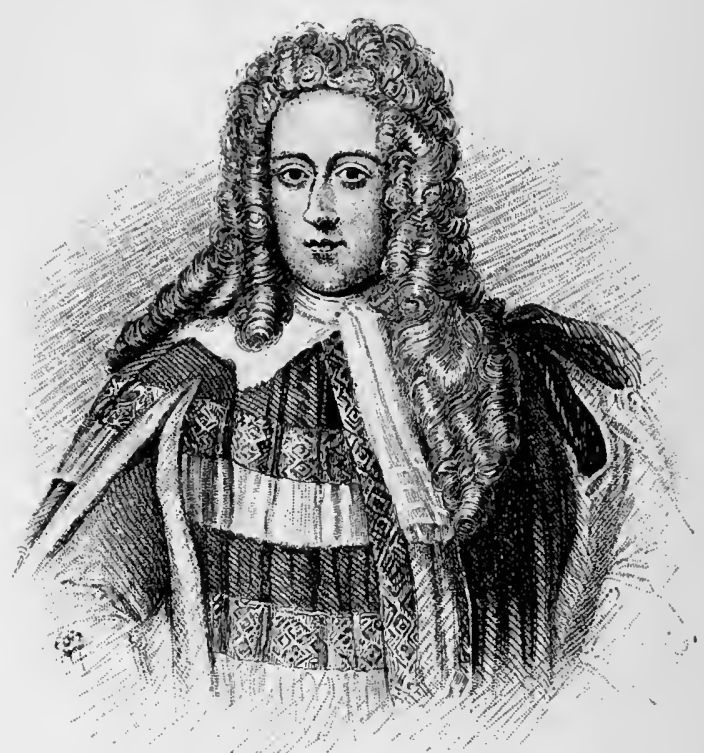

HLNRY ST. JOHN, VISCOUNT BOLINGBROKE $\mathrm{Ob}$. $\mathbf{1 7 5}$.

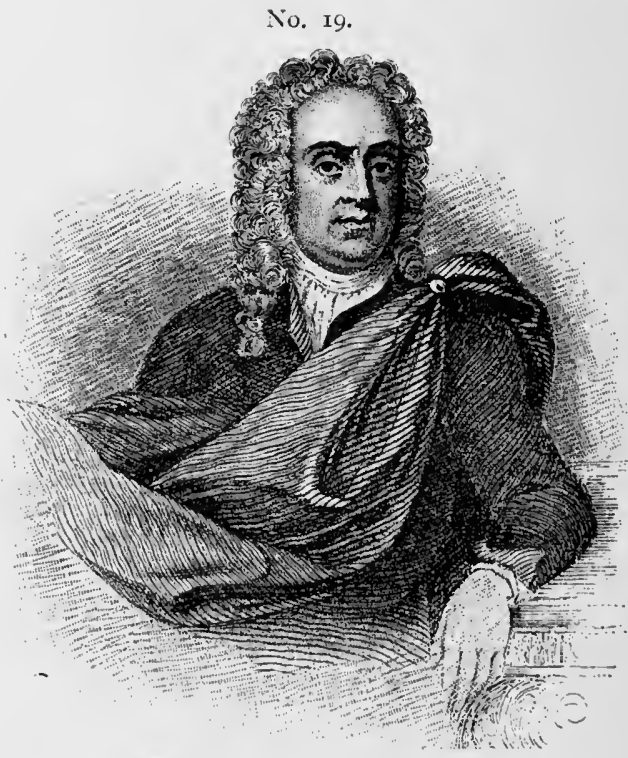

WILLIAM PULTNEY, EARL, OF BATH. Ob. 1764 . 


\section{OBLONG FACES.}

No. 20.

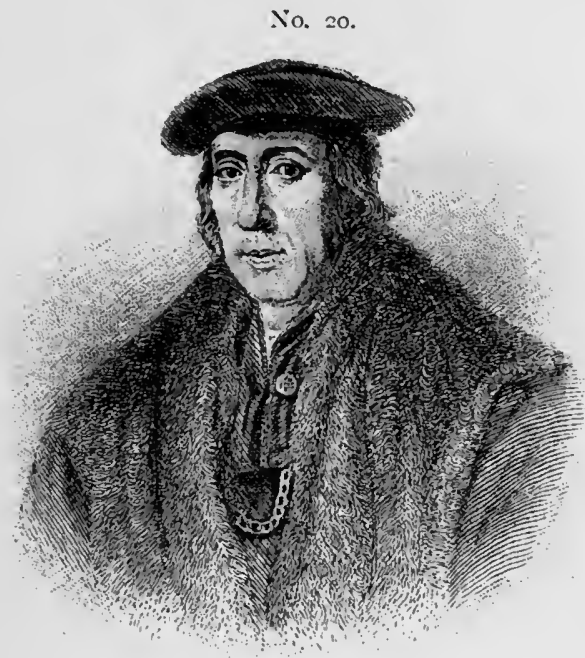

SIR JOHN MORE.

Ob. I 533 .

No. 2 r.

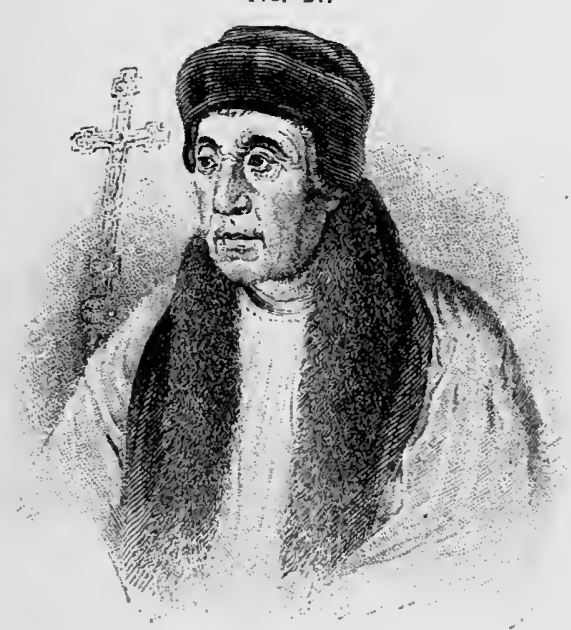

WILLIAM WARHAM, ARCHBISHOP OF CANTERBURY. Ob. 1532. 




\section{LONG TAPERING FACES.}

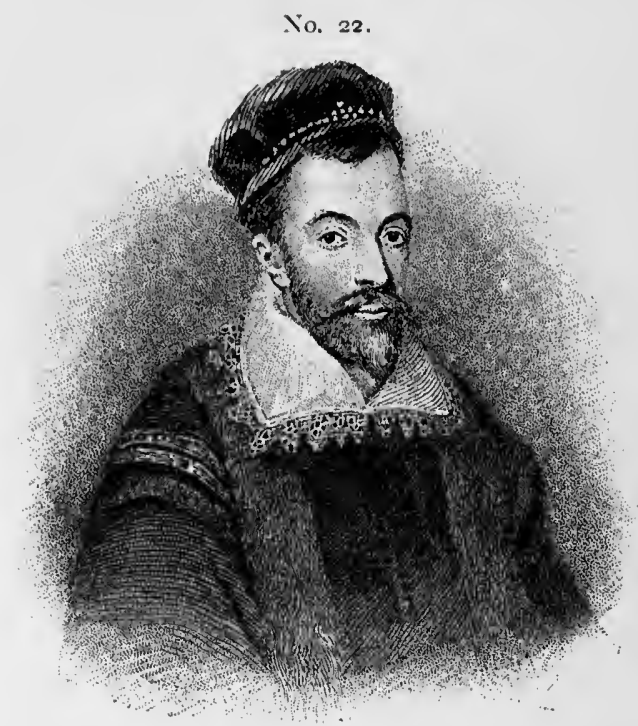

SIR WILLIAM MAITLAND, OF LETHINGTON.

Ob. 1573 .

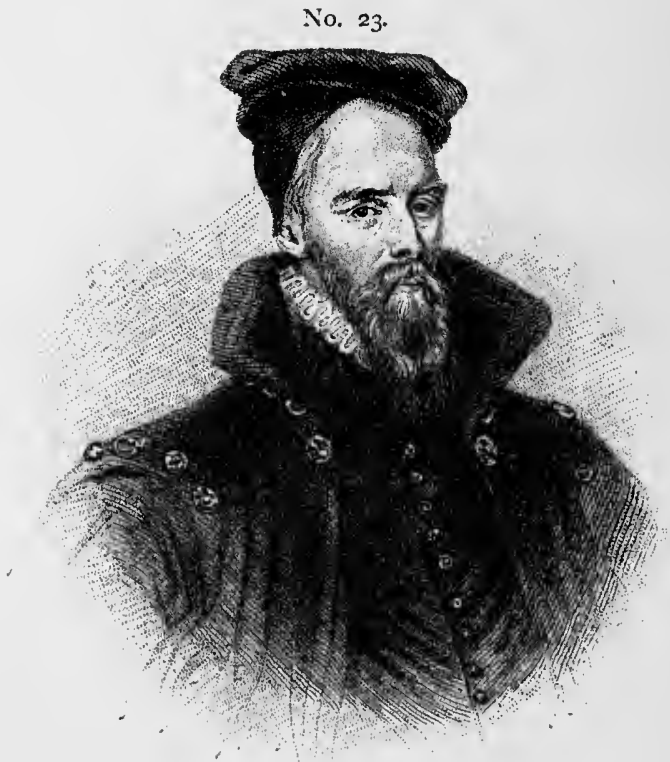

AMBROSE DUDIEY EARI, OF WARWICK, Ob. 1590 . 


\section{BROAD TAPERING FACES.}

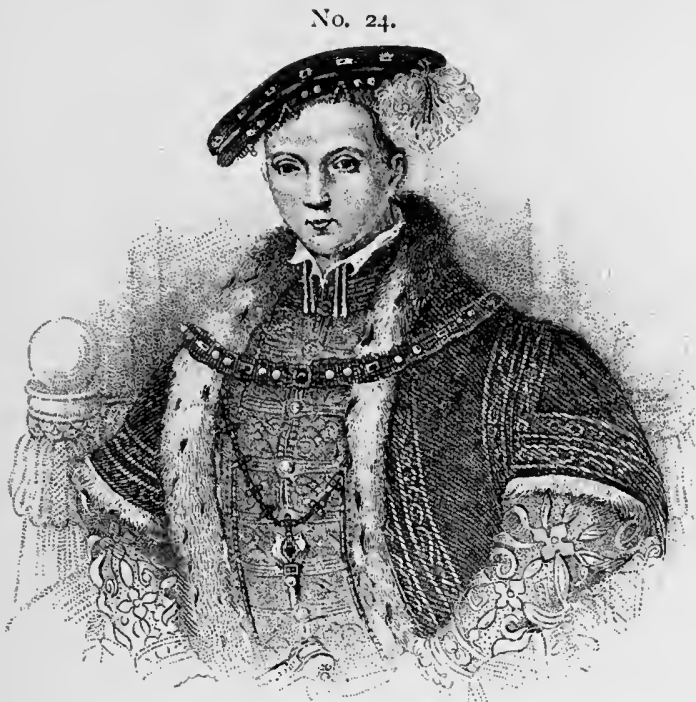

KING EDWARD THE SIXTH.

Ob. 1553 .

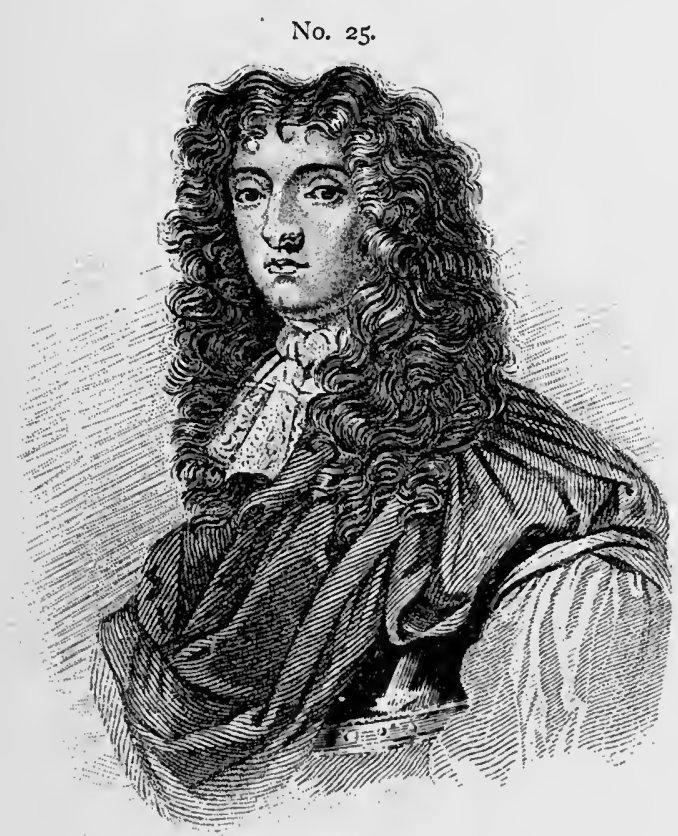

JOHN GRAHAM, VISCOUNT OF DUNDEE, $O b, \mathbf{1} 689$. 

THE MELANCHOLIC FACE.

No. 26.

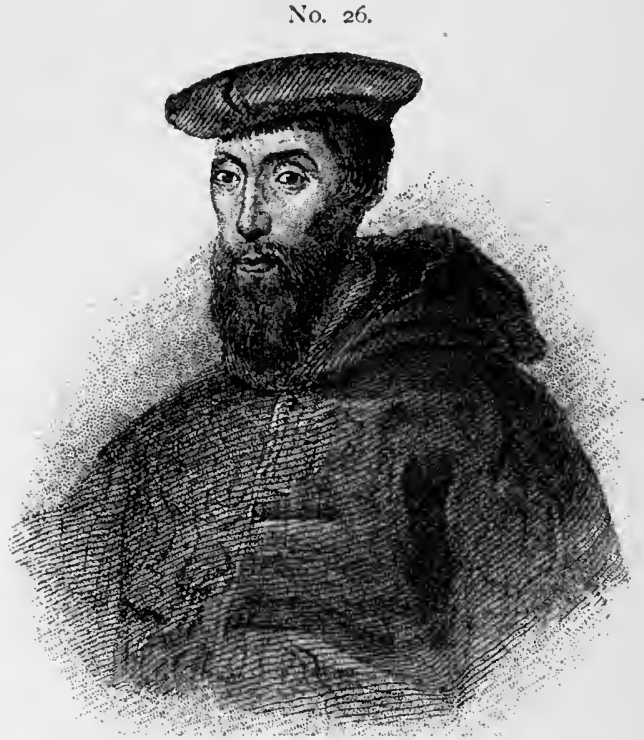

CARDINAL POI.E.

Ob. $\times 557$

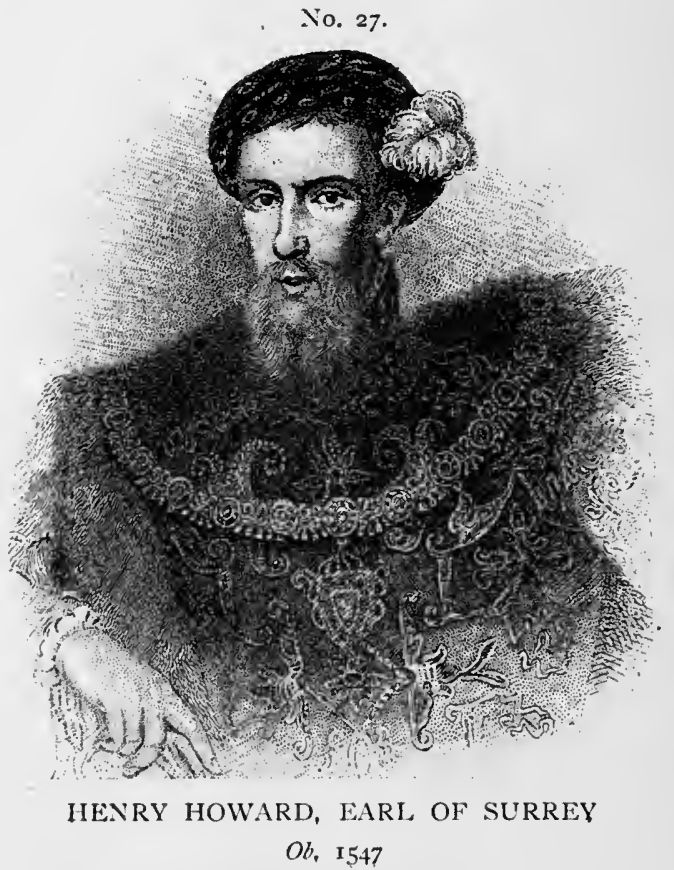


I N D E X E S. 



\section{IN DEXES.}

1. To Authors and Quotations.

2. To Personal Notices.

\section{INDEX.}

I. TO AUTHORS AND QUOTATIONS.

ABercrombie, DR.

Insanity more frequent in some professions . . 315

ADDISON.

Habit of reading faces in the streets . . . $3^{2}$

His modes of taking exercise. . . . . . 311

Pleasure from reading a book increased by know-

ing the author's appearance . . . . 363

A. G. D.

Letter on sleeping north and south . . . . 323

ALCOCK, SiR RUTHERFoRD.

Influence of the organs on mental action . ${ }^{257}$

Anderson, Mrs. Gs.rRett.

Letter on Examinations for girls . $\quad . \quad 279$ 


\section{INDEX TO AUTHORS AND QUOTATIONS.}

ANONYMous MEdical Work.

PAGE

Physical characteristics of the nervous temperament 70

Appleton's NeW American Cyclopedia

Account of Dr. Powell's work: Human temperaments .

Ballakd, Rev. Dr.

Temperament classification in schools. . 291 BEARD, DR.

American nervousness . . . 305 and 329 to 336

BeDdoe, DR.

The Races of Britain. 1885 • . . . . 231

The importance of the work . . . 231 to 233

Prolonged darkening. of the hair . . . . 108

Physical superiority of blonds . . . . 122

The colour of the hair and marriage . . . 124

Colour of the eyes in districts . . . . 125

Colour of the complexion in districts . . . 126

Change from fair to dark in England . . . 127

Holbein's portraits of women . . . . . 128

Method of observing colour characteristics . . 233

Head measurements obtained by stratagem . $\quad \therefore 235$

Climate of West Africa on blonds and brunets . 255

BRitish ANd Foreign Medical Review.

Physical characteristics of the nervous temperament 70

Brown, Dr. J. Graham.

Physical characteristics of the nervous temperament 70 


\section{INDEX TO AUTHORS AND QUOTATIONS. 397}

Browne, SiR J. CRICIHTON.

Rate of nerve action and mental processes highest in the nervous temperament . . . . 136

Education induces the nervous temperament. I4I

Effects of competitive examinations . . $\quad 278$

Comparatively early death of poets and painters. 316

Expedients to induce sleep . . . . . 322

Schools not sufficiently used to study and compare temperament and character . . 386

BUCKLE, Mr.

Nothing known about the transmission of character and temperament . . . . . I3

Influence of physical laws over the organization of society and the character of individuals. 201

BURNS.

Right and wrong attributed to the heart . . 264

BURTON, SIR RICHARD.

Facial characteristics in Iceland . . . . I13

The Icelander's temperament . . . . . 152

Cardinal Manning.

Oxford and Cambridge oratory . . . . IgI

\section{CARLyle.}

Kneaded out of the same clay . . . . I6

The sanguine diffusive, the bilious intense. . 73

Morbidly nervous . . . . . . . 134

We are strangely shapeable . . . . . 185 
398 INDEX TO AUTHORS AND QUOTATIONS.

CARLYLE-continued. PAGE

Influenced by biliousness. . . . . . 243

His temperament . . . . . . . $34^{2}$

Examples of word portraiture: Dickens, Southey,

Tennyson, and others . . . 372,3,4

CARVer, Dr.

Aptitudes should influence education . . . 269

Chamberlain, Mr.

Cultivation of natural gifts in schools . . 276

Clark, Rev. W.

The four temperaments (sermons) . . . . 5

Combe, George.

Descriptions of the four temperaments . 87,8

Phrenology dependent on the temperaments. . 89

School children kept on vegetable diet to improve their morals . . . . . . ${ }^{284}$

Cullen, Dr.

Undetermined state of the doctrine of the temperaments . . . . . . . . $\quad .7,9$

Found it difficult to distinguish the temperaments 48 Sanguine physical characteristics . . . . 65

Cyclopedia, Penny.

The organization makes the temperament . ${ }^{238}$ Dickens.

Nervous energy-"keeping it up" . . . . I39 His temperament . . . . . . . 251 
INDEX TO AUTHORS AND QUOTATIONS. 399

\section{DICKENS-continued.}

PAGE

Effects of Bonchurch climate on him . . $\quad 252$

Description of him by Forster . . . . 367

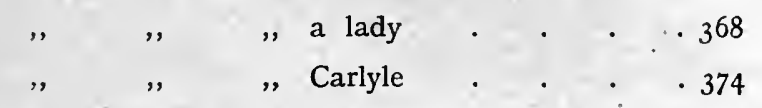

Douglas, Mr. Fred.

President Lincoln slow-moving . . . . 68

DUCKWORTH, SiR DYCE.

When features alike, the tissues alike. . . 260

Dürer, Albert.

The temperaments by measurement . . . 19

A firm believer in the then well-known doctrine of the temperaments . . . . . . . 94

Considered it indispensable that before choosing

art as a profession for children their tempera-

ments should be studied . . . . . 94

Studied the four temperaments closely • • 95

His greatest works inspired by the subject. 95

Account of some of these works . • • 95

The four temperaments, the four complexions . . 298

Edinburgh Medical and Surgical Journal.

Scope and value of the subject . . . . 10

FARRAR, ARchdeacon.

Indiscriminate education ..$\quad$. $\quad .270$

Forster, Mr.

Bonchurch climate and temperament $\quad . \quad 253$ 
400 INDEX TO AUTHORS AND QUOTATIONS.

FRENCH NEWSPAPERS. PAGE

Their temperaments . $\cdot 360$

French Play.

Blondes and Brunettes . . . . . 74 Froude, Mr.

Change in colour of Carlyle's eyes . . . 108 Professional mannerism . . . . . . 187

GAIRDNER, PROFESSOR.

The organization indicated by the features. . 6I GaLton, Mr.

History of twins 35 to 46

Sanguine physical characteristics . . . . 66

The Puritan features . . . . . . 72

Puritan joylessness . . . . . . . 76

Englishmen a fair and reddish race . . . 105

Change in colour of the hair. . . . . 108

Sources of happiness . . . . . . . I2I

Holbein's portraits . . . . . . 128, 204

Looking for a typical John Bull in Kensington Gardens I4I

Change in type of face. . . . . . 203

Personal identity and description . . . . 379

Heredity and temperament . . . . . 384

Garrod, Sir Alfred.

Ancient doctrine of the temperaments . . 20

GLadstone, Mr.

Observation of features and personal appearance. 33 His temperament . . . . . . 319, 352 
INDEX TO AUTHORS AND QUOTATIONS. 40I

GOOD, DR. J. MASON.

BAGE

Change of temperament . . . . . 193

GuildFord, HaNdBook to.

The four temperaments on old chimney-piece $97,8,9$

Harrison, Thomas F., Schools' Superintendent.

Letter on temperament classification in schools . 292

HECKeR, Mr.

The Scientific Basis of Education demonstrated

by an Analysis of the Temperaments . $\quad .286$

Physical characteristics of the sanguine temperament 66

" " , bilious ", 67

", , ", lymphatic ,

" " , nervous " , 71

Temperament classification in schools . . $28_{7}, 8,9$

Letters on same subject from leading super-

intendents of schools $\quad . \quad . \quad$. 290, I, 2

HOOD, DR.

The direction of the body in sleep . . . . $3^{2}+$

HOUGHTON, LORD.

Shelley or Byron the greater poet? debate on . 190

Hutchinson, Jonathan, Mr.

The Pedigree of Disease: Being Six Lectures

on Temperament, etc. 1884 . . Preface ix

Recognition of the temperaments . . . . 49

Cannot be recognised by complexion . . . 50

Their recognition important . . . $\quad 5^{2}$ 
402 INDEX TO AUTHORS AND QUOTATIONS.

Hutchinson, Jonathan, Mr.-continued.

PA

Temperament in surgery. $. \quad . \quad . \quad$. 55

Prescribers of medicine should consider the natural

differences between patients . . . 55

Some of the names given to complexion-colours. I Io

Complexion, what it includes . . . . . III

Something more than complexion required to discriminate the temperaments . . . . III

Historical MANUSCRIPT REPORT.

The brain worked to death for $\notin \mathrm{I} 60,000 \quad$. 307

IRVING, MR. HENRY.

The temperament of players . . . . 345

JACkson, Dr. Scorseby.

Reputation of change of climate in disease injured by want of discrimination . . 254

JACQUES, DR.

A new classification of the temperaments : . 9I JAEGER, DR.

Nerve transmission less rapid when water or fat in excess. . . . . . . . . 246

JOHN INGILSANT.

Creeds the result of temperament . . . $\quad 25$ JOHNSON, DR.

Addison's style . $\quad . \quad$. $\quad . \quad$. $\quad . \quad$. 354

LAMB, ChARLES.

Haunted by nervousness . . . . . . 134 
INDEX TO AUTHORS AND QUOTATIONS. 403

LAVATER.

PAGE

Three form characteristics of bodily strength and three of weakness contrasted . . . . 119

LAYCOCK, PROFESSOR.

Medical-Times and Gazette. 1862. Vol. i.

The doctrine of the temperaments is from the experience of early observers . . . . 8

Temperament from tempero, to mix or temper . 20

The mixing different in the four temperaments . 20

Results Professor Laycock expected from his classification . . . . . . . . 49

Observation, and the formation of standards for comparison, urged . . . . . . . $5^{1}$

Physical characteristics of the sanguine temperament . . . . . . . . . 64

Sir John Forbes' sanguine characteristics . . 65

Slowness, and other lymphatic characteristics . 68

Physical characteristics of the nervous temperament 69

Finer susceptibilities, greater rapidity of thought, action, speech, and greater imagination, in the nervous temperament . . . . 70,75

Fair hair, blue eyes, and florid complexion in early life, the hair becoming dark in later years . I09

William Hunter a well-marked example of the nervous temperament $\cdot$. $. \quad . \quad .138$

Opportunities of study at hand, as the temperaments may be observed wherever faces and forms are seen . . . . . . . 146 


\section{INDEX TO AUTHORS AND QUOTATIONS.}

LEIGH HUNT.

PAGE

Biographic portrait of Shelley. . . . : 370

LEIGHTON, SiR F.

Organization in place of temperament. . $\quad 239$

Life History Album.

Colours of the hair . . . . . . . . 103

" " eyes . . . . . . . . 106

Change in colour of the eyes of infants . . 108

Martin, Dr. George.

The blood in the sanguine and lymphatic temperaments . . . . . . . . 24I, 245

Maudsley, Dr.

Temperament and idiosyncrasy are big indefinite words . . . . . . . . . II

Scientific classification of character from the features,

a desideratum . . . . . . . II

Belief very much a matter of temperament . . 25

Mayo, Dr. Thomas.

The lymphatic called the serous temperament . 244 MILL, J. S.

Mental character modified by bodily structure . 12

The nervous temperament capable of sustained excitement - spirit. The material of great orators and preachers . . . . ${ }_{1}{ }_{13}^{8}$

Murray, Dr. J. C.

The temperaments and Smokers . . II5, 6 
INDEX TO AUTHORS AND QUOTATIONS. 405

Newnham, W.

PAGE -

Physical characteristics of the sanguine tempera-

ment . . . . . . . $\quad 64$

Old and Modern Phrenology.

Phrenology requires the help of temperament to form positive conclusions as to character . 90

Paget, Sir James.

Transmission of likeness to minute structure . 260

PARISH, PROFESSOR A.

Temperament in education . . . . . $29 \mathrm{I}$

Pereira, Dr.

Temperament modified by the kind of food. . 196 .

POLLOCK, DR.

How to induce sleep . . . . . . 320

The best posture in sleep . . . . $\cdot 3^{22}$

POPE.

Character influenced by the profession, sect, etc. I $8 \varepsilon$

A jaundiced eye . . . . . . . ${ }_{243}^{243}$

PRICHARD, DR.

Cyclopadia of Practical Medicine, article "Temperament."

The connexion of mental with physical qualities an essential part of the theory of tempera-

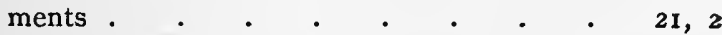

The relation of mental peculiarities to corporeal

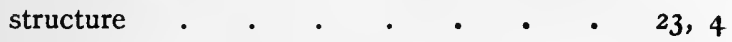




\section{INDEX TO AUTHORS AND QUOTATIONS.}

PRICHARD, DR.-continued.

PAGE

Physical characteristics of the bilious temperament 66 " " " lymphatic " . 67

Ancient idea of the elements of the temperaments 100

The nervous temperament not sufficiently characterized physically . . . . . . I 30

Origin of 'temperaments . . . . . . . 199

Effects of altered action of the organs on mental action . . . . . . . . . 256

RANDALL, S. S., Superintendent of Schools.

Letter on temperament classes in schools . . 290 RICHARDSON, DR.

The relation of the four temperaments to felicity $39^{2}$

Richerand, Professor.

Elements of Physiology, translated from the

French. Revised by Dr. Copland. 1829 . 83

Influence of physical organization on the intel-

lectual faculties. . . . . . . 26

The characteristics given to distinguish the four temperaments not generally available $.84,5,6$

ROBERTSON'S SERMONS.

Dependence of mind on body . . . . ${ }^{258}$

RUSKIN, Mr.

Bred for the Church . . . . . . 299

SAVORY, Sir William.

Sleep and work . . . . . . $\cdot 314$ 
INDEX TO AUTHORS AND QUOTATIONS. 407

Scott, Sir Walter.

PACES

Portraiture in biography . . . . . . 364

SHAIRP, PROFESSOR.

Shelley and temperament. . . . . . $37^{1}$

SHAKESPEARE.

The heart thinks and speaks. . . . . 264

SмITH, G.

An Assyrian inscription blessing the liver . ${ }^{262}$

SOUTHEY, M.D.

Character of lymphatics . . . . . . 74

The lymphatic constitution . . . . 245

Starkweather, Mr.

Difference of opinion as to what temperament is, and the class to which any one belongs . 48

Rapidity of the nervous contrasted with the slow-

ness of the lymphatic temperament $\quad 68,9$

The musical temperament . . . . ${ }^{1} 53$

Transmission of sex and temperament . $38 \mathrm{I}, 2$

STERne.

The different influence of the same circumstances on different temperaments. . . . 28

Temperature instead of temperament . • • 99

THACKERAY.

Steele's face and build . . . . . . II3

THE Book OF Health.

Greek and Roman Gymnasia . . . . . 310 


\section{INDEX TO AUTHORS AND QUOTATIONS.}

The Cornhill Magazine.

PAGE

Nervous and lymphatic compound, the temperament

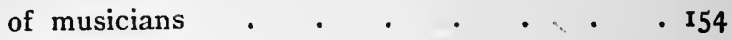

The Evening Standard.

Blondes preferred to brunettes as clerks . 390

The FAIRIE QueEN.

Three brothers from one mould . . . . 16

THE LANCET.

Simple law of heredity $\cdot$. $\quad . \quad \cdot \quad \cdot \quad \cdot 38 \mathbf{I}$

The National Review.

The temperaments and character . . . . 27

The Spectator, No. 307.

Thoughts on Education.

The importance of discovering the aptitudes of youth and harmonizing studies with them . $\quad 272$ to 276

The TIMes.

Two sides to Mrs. Carlyle's character; bustling, frugal, practical; at the same time intensely emotional and susceptible. . . . . . 187

British Calibre :

An account of the work done by the Anthropometric

Committee of the British Association 205 to 230 Theological views modified by the state of health 257

Death at forty-nine from an overtaxed brain . 306 American nervousness . . . . 329 to 336

Desire to know the appearance of men of mark 363 
INDEX TO AUTHORS AND QUOTATIONS. 409

WEBER, DR. HERMAN.

Climate and Health Resorts. . . . . 254

WILKS, Dr.

The doctrine of the temperaments neglected by

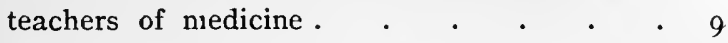

Many men seem taken from the same mould . 16

The temperaments of Englishmen studied by few; authors giving those of the Greeks as described by Hippocrates . . . . . . . . . . 84

Diversity of temperament attributed to climate and food . $.6 . \quad . \quad . \quad . \quad .199,200$

The effects of great heat on the organs and mental action . . . . . . . . $255^{5}$

\section{IN DEX.}

2. TO PERSONAL NOTICES.

Her Majesty, The Queen.

Likeness to both parents. . . . . . $3^{83}$

The Duke of Albany.

His temperament . . . . . . 340

ANDERSON, Miss.

Has faults of temperament . . . $35^{6}$ 
410 INDEX TO PERSONAL NOTICES.

BADHAMS, MR.

Description and character of, by Carlyle $\cdot \quad 373$

BeACONSFIELD, LORD.

His temperament . . . . . . . 319

Canon Liddon.

Perfect rest ordered. . . . . . . 308

Cardinal Manning, Ind. 1, p. 397.

Carlyle, Ind. 1, pp. 397, 8, and 400.

" Mrs., Ind. 1, p. 408.

Clifford, Anne, Countess of DoRset.

Likeness to both parents. . . . . . 383

Dickens, Ind. 1, pp. 398, 9.

Dillon, Frank.

Description of, by Carlyle . . . . 372

FAWCETT, MR.

His temperament . . . . . . 343

Biographic portrait of . . . . 375,6

Forbes, Sir Fohn, Ind. 1, p. 403.

Fox, Charles James.

His temperament . . . . . . . $34^{8}$

Galton, Mr., Ind. 1, p. 400.

Gladstone, Mr., Ind. 1, p. 400. 
INDEX TO PERSONAL NOTICES. 4II

HALLAM, Mr. ARTHUR.

PAGE

His style of oratory.

HARTINGTON, LORD.

His temperament . . . . . . 344,5

HENRY THE EIGHTH.

Form of his face . . . . . . . . . I12

Houghton, Lord, Ind. 1, p. 401.

Hunter, William, Ind. 1, p. 403.

Lamb, Charles, Ind. 1, p. 402.

Macaulay.

His temperament . . . . . . $35^{\circ}$

MORE, SIR ThOMAS.

Biographic portrait of . . . . . . 369

NorthCote, Sir Stafford.

His temperament . . . . . . 351

President Garfield.

His temperament . . . . . . 343

President Lincoln, Ind. 1, p. 399.

Prince Bismarck.

His temperament . . . . . . 350

Prince Napoleon.

Resemblance to President Gerlach. . . . I7

Ruskin, Mr., Ind. 1, p. 406 . 
4I2 INDEX TO PERSONAL NOTICES.

SAlisburY, LORD.

Pursues chemical research . . . . 317

His temperament . . . . . . . 349

Shelley, Ind. 1, pp. 404, 7.

SOUTHEY.

Description of, by Carlyle . . . . . 373

SPURGEON, Mr.

Rest required for brain weariness . . . . 308

His temperament . . . . . . $35^{2}$

Steele, Ind. 1, p. $40 \%$.

Sunderland, Mr.

His style of oratory. . . . . . . . 192

Tennyson.

Description of, by Carlyle $\quad . \quad$. $\quad . \quad$. 374

TERry, Miss, ANd Mr. IRving.

Temperament bestowed on Miss Terry; not on Mr. Irving . • • • • • • 355

The Irving Family.

Colour characteristics of, by Carlyle . . $37^{2}$ 


\section{POPULAR WORKS}

PUBLISHED BY

\section{CROSBY LOCKWOOD \& SON,}

\section{7, Stationers' Hall Court, Ludgate Hill, E.C.}

CHOOLDAYS OF EMINENT MEN. Containing School and College $\checkmark$ Lives of the most celebrated British Authors, Poets, and Philosophers; nventors and Discoverers; Divines, Heroes, Statesmen, \&c. By JoHN TimBs. With Thirteen Views of Public Schools, and Twenty Portraits by HARVEY. Fcap., 3s. 6d. cloth.

"A book to interest all boys, but more especially those of Westminster, Eton, Harrow, Rugby, and Winchester ; for of these the accounts are full and interesting."NOTES AND QUERIES.

\section{"THE LAWGIVER OF THE PLAYGROUND."}

THE BOY'S OWN BOOK: a Complete Encyclopædia of Sports and Pastimes, Athletic, Scientific, and Recreative. A New Edition, revised, with many Additions and Improvements, including the Newest Games and Amusements; with more than 600 Illustrations (many of them quite new), Io Vignette Titles printed in gold, and over 700 pages. 8s. 6d. handsomely bound in cloth.

'. The Boy's Own Book' has had many imitators, but they have been but puny counterfeits, and the new edition just issued may bid defiance to them all. Brought up to the present day, it is itself alone the book for boys."-BAILY's MAGAZINE of SPORTS.

'.'The Boy's Own Book' is still the book which English lads take most delight in and read with the greatest interest."-CIVIL SERviCE GAZETTE.

"Mr. Lockwood's 'Boy's Own Book' is the real original work which we knew in days long gone by, but in a new and much enlarged form. To name it is to praise it." SATURDAY REVIEW.

"Time and thought have rendered it perfect."-ART JOURNAL.

TRUTHS ILLUSTRATED BY GREAT AUTHORS: a Dictionary of nearly Four Thousand Aids to Reflection, Quotations of Maxims, Metaphors, Counsels, Cautions, Proverbs, Aphorisms, \&c., \&c. In Prose and Verse. Compiled from the Great Writers of all Ages and Countries. New and Cheaper Edition, small crown 8vo, 568 pp. cloth, bevelled edges, 3s. 6d.

"The quotations are perfect gems; their selection evinces sound judgment and an excellent taste."-DisPATCH.

"We know of no better book of its kind."-EXAMINER.

THE TWIN RECORDS OF CREATION; or, Geology and Genesis, their Perfect Harmony and Wonderful Concord. By George W' VICT LE VAUX. Numerous Illustrations. Fcap. 8vo, 5s. cloth.

"A valuable contribution to the evidences of Revelation, and disposes very conclusively of the arguments of those who would set God's works against God's word. No real difficulty is shirked, and no sophistry is left unexposed."-THE ROCK. 
TALES FROM SHAKESPEARE. Designed for the Use of Young 1 Persons. By Charles and Mary Lamb. Sixteenth Edition, with Steel Portrait and Twenty full-page Engravings by HARvEY. Fcap. 8vo, 3s. 6d. extra cloth gilt.

TALES FROM CHAUCER, IN PROSE. With a Memorial of the 1 Poet. Designed chiefly for the Use of Young Persons. By Chas. Cowden Clarke, Author of "The Riches of Chaucer," \&c. New and revised Edition, with Twelve full-page Engravings. Fcap. 8vo, 3s. 6d. extra cloth gilt.

"Mr. Clarke's worthy purpose is worthily carried out, and the tales will be read with pleasure by those who are acquainted with the originals, and with eager delight by the young who are unable as yet to comprehend Chaucer's terse and noble verse."-NEws OF THE WORLD.

"Mr. Clarke has done that for Chaucer which Charles and Mary Lamb did for Shakespeare."-City PREss.

THE RICHES OF CHAUCER: In which his Impurities have been 1 Expunged; his Spelling Modernised; his Rhythm Accentuated; and his Obsolete Terms Explained; with Explanatory Notes and a Memoir of the Poet. By Charles Cowden Clarke, Author of "Tales in Prose from Chaucer," \&c. . Third Edition, carefully Revised. With fine Steel Portrait of Chaucer, and Woodcuts. Crown 8vo, elegantly printed (642 pages), 7s. 6d. Roxburgh binding.

"Mr. Clarke has modernised Chaucer's spelling, but without impairing the antique beauty of his verse; and his system of accentuation removes the last stumbling-block from the feet of the general reader."-TIMES.

"Innumerable readers, who would have turned away alarmed at the antique orthography of the genuine texts, have been tempted by the facility with which they have mastered the 'Canterbury Tales,' and other poems in Mr. Clarke's modernised form, to study Chaucer, and appreciate the pathos, imagery, and humour which abound in his writings."-NOTES AND QUERIES.

CONE BEFORE: A Manual of Consolation for the Bereaved and a $U$ Well of Sympathy for the Sorrowing, filled from Many Sources. Being a Collection of Great Thoughts on Bereavement, Consolation, and Resignation; from the Works of Celebrated Poets, Authors, and Divines of all ages, and from the inspired pages of Holy Writ. By HeNry SouthGATE, Author of "Many Thoughts of Many Minds," \&c. Fourth Edition, revised. Crown 8ro, 400 pp., 3s. 6d. cloth.

" This exquisite selection of prose and verse-made with the judgment which might be cxpected from Mr. Southgate's experienced taste-will be welcome to many a sorrowing hcart."-PUBLIC OPINION.

"In the present compilation Mr. Southgate has exceeded his former efforts, and has produced a book full of the best, the most devout, and most carnest outpourings of our greatest wrilers upon subjects which are most deeply rooted in human nature."-ENGLISH CHURCHMAN.

Crosby Lockwood \& Son, 7, Stationers' Hall Court, Ludgate Hill, E.C. 
"A WORLD OF THINGS TOGETHER BROUGHT."

Now Ready, in Six Double Volumes, 3os., handsomely half-bound.

THE COMPLETE SET OF

\section{THINGS NOT GENERALLY KNOWN.}

By Joнn Timbs, F.S.A.

** The Athendeum says :- "Anyone who reads and remembers $M r$. Timbs Encyclopadic varieties should ever after be a good tea-table talker, an excellent companion for children, a 'well-read perscn,' and a proficient lecturer."

Contents of the Double Volumes (sold separately, price 5s. each, half-bound) :Vol. I. GENERAL INFORMATION. ("Things Not Generally Known.") 5 s.

II. CURIOSITIES OF SCIENCE. 5s.

III. CURIOSITIES OF HISTORY; POPULAR ERRORS. $5 \mathrm{~s}$.

IV. NOTABLE THINGS; THINGS TO BE REMEMBERED IN DAILY LIFE. $5 \mathrm{~s}$.

" V. A GARLAND FOR THE YEAR; SOMETHING FOR EVERYBODY; AND KNOWLEDGE FOR THE TIME. 5s.

" VI. MYSTERIES OF LIFE, DEATH, AND FUTURITY; PREDICTIONS REALISED IN MODERN TIMES. $5 \mathrm{~s}$.

\section{** Sold also in Twelve Single Volumes as follows :-}

I. Things Not Generally Known Familiarly Explained. ist Series, 2s. 6 d. cloth.

2. Things Not Generally Known Familiarly Explained. 2nd Series, 2s. 6d. cloth.

3. Curiosities of Science, Past and Present. Ist Series. Fcap., 2s. 6d. cloth.

4. Curiosities of Science, Past and Present. 2nd Series. 2s. 6d. cloth.

5. Curiosities of History. 2s. 6d. cloth.

6. Popular Errors Explained and Illustrated. 2s. 6 d. cloth.

7. Notable Things of Our Own Trme. 2s. 6 d. cloth.

8. Things to be Remembered in Daily Life. With Personal Experiences and Recollections. 2s. 6d. cloth.

9. A Garland for the Year, and Something for Everybody. 2s. 6d. cloth.

10. KNOWLEDGE FOR THE TIME. 2S. 6d. cloth.

II. Mysteries of Life, Death, and Futurity. 2s. 6d. cloth.

12. Predictions Realised in Modern Times. 2s.6 6d. cloth.

Crosby Lockwood \& Son, 7, Stationers' Hall Court, Ludgate Hill, E.C. 


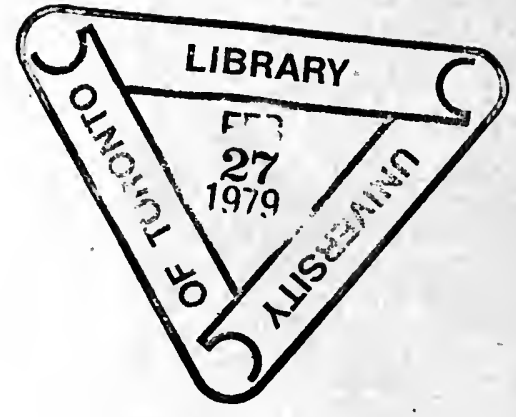





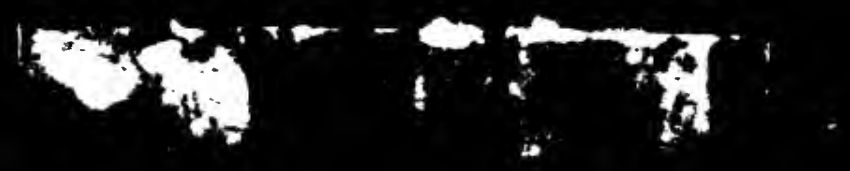




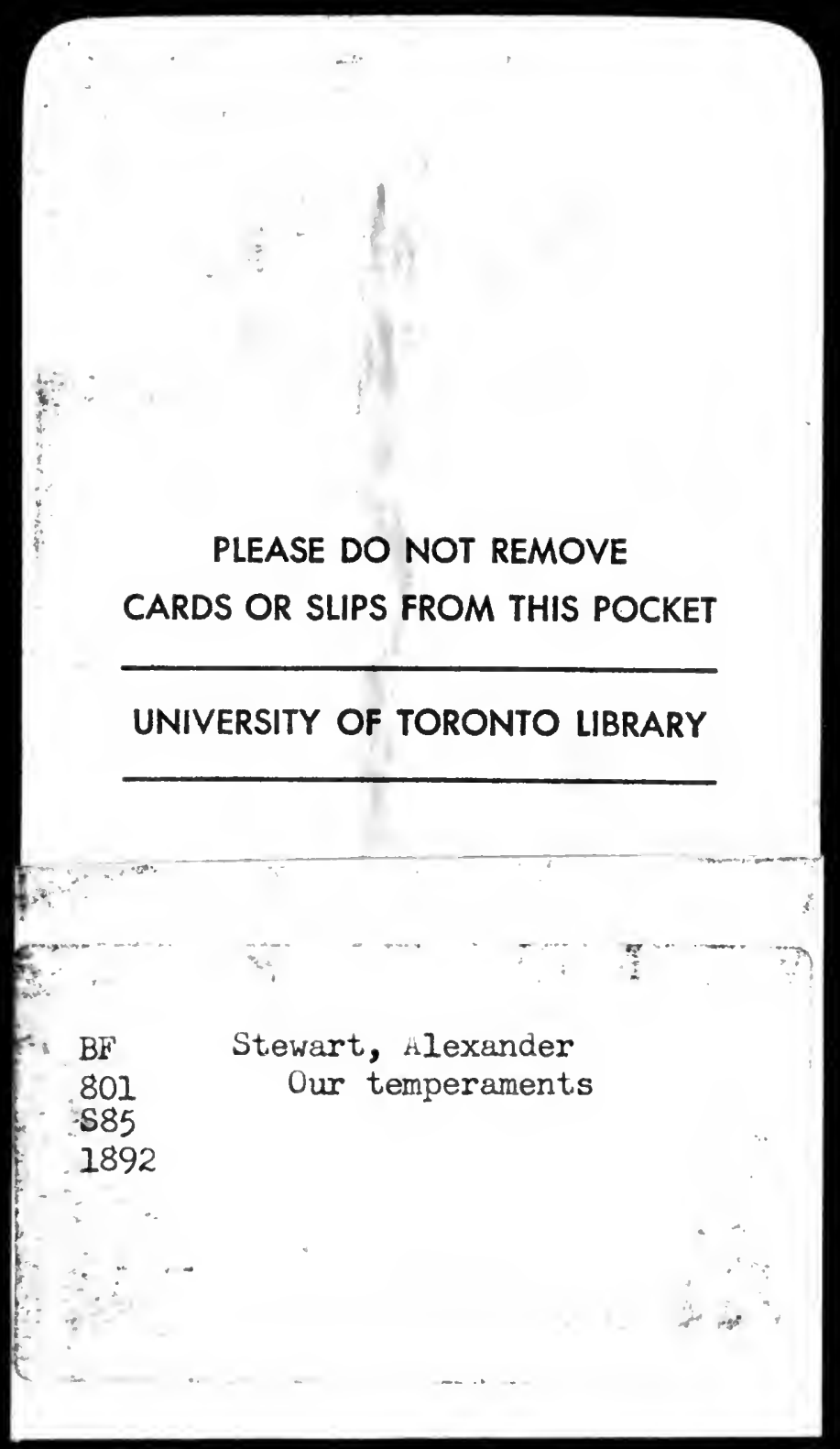




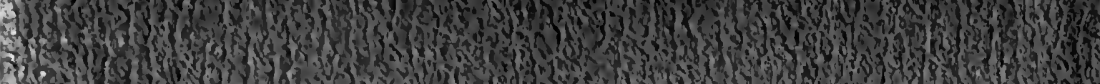

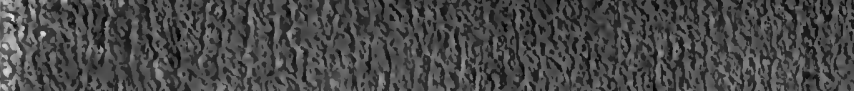

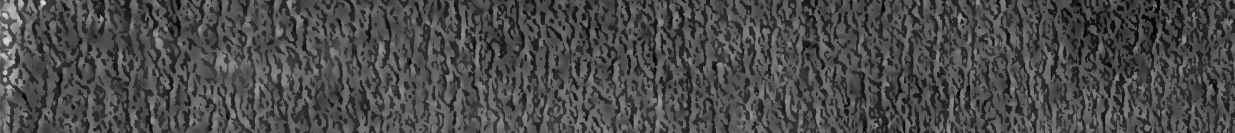

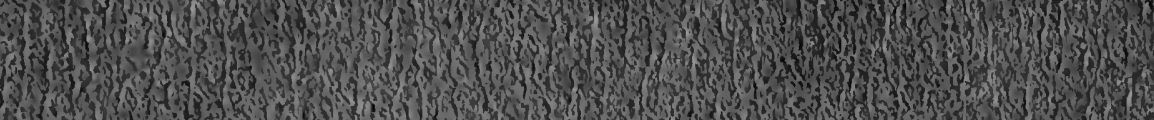

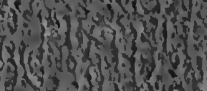

mist

ing 3 his

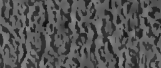

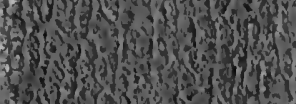

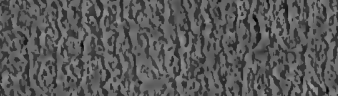

8) 1 i)

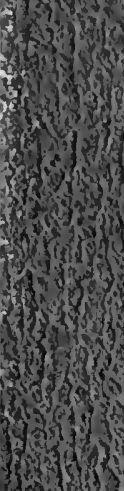

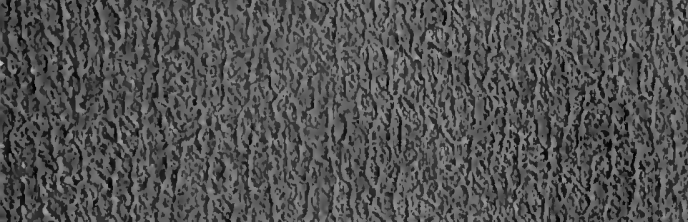

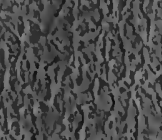

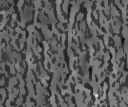

sid

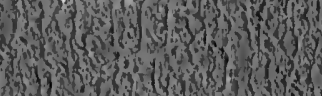

5.9.

ming

(3)

I

(3)

4 in

ing

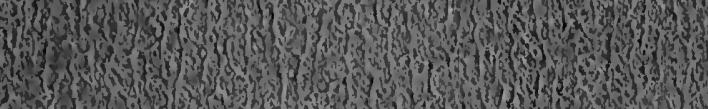

som

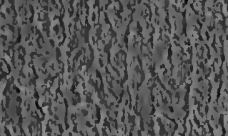

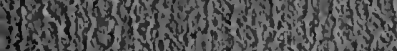

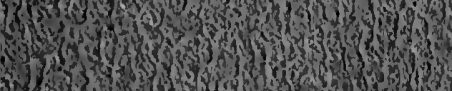

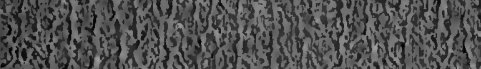

3. 31 .

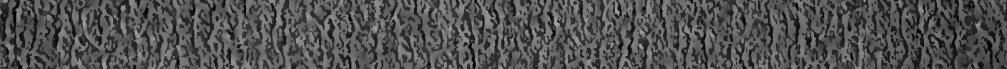

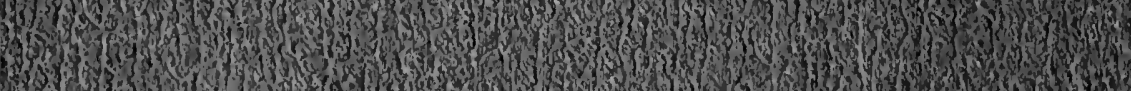

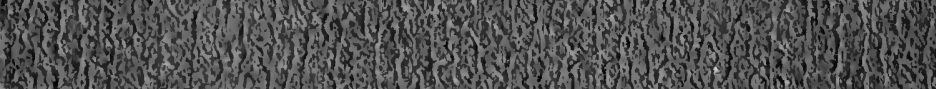
3.7. 136. 1.4.

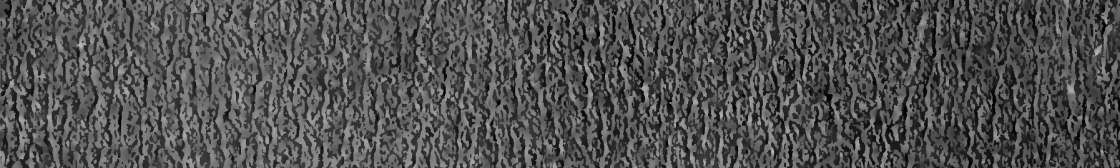
3.5
3

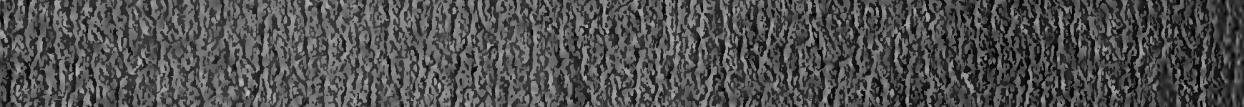

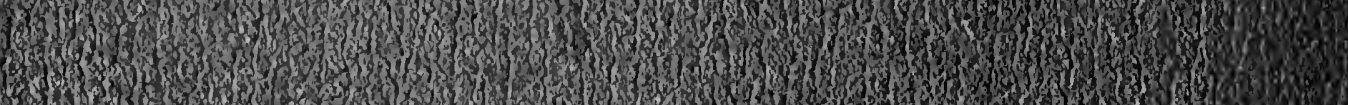
3)

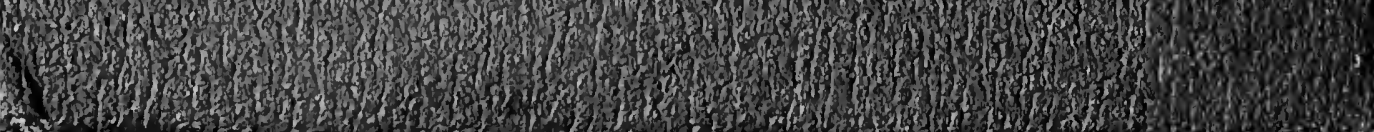

